\title{
CONSTRUÇÃO DE MAPAS GENÉTICOS EM ESPÉCIES DE POLINIZAÇÃO ABERTA: UMA ABORDAGEM BAYESIANA COM O USO DE UMA PRIORI INFORMATIVA
}

\author{
FRANCINE RAGONHA
}

\begin{abstract}
Dissertação apresentada à Escola Superior de Agricultura "Luiz de Queiroz", Universidade de São Paulo, para a obtenção do título de Mestre em Agronomia, Área de Concentração: Estatística e Experimentação Agronômica.
\end{abstract}

P I R A C I C A B A

Estado de São Paulo - Brasil

Janeiro - 2005 


\title{
CONSTRUÇÃO DE MAPAS GENÉTICOS EM ESPÉCIES DE POLINIZAÇÃO ABERTA: UMA ABORDAGEM BAYESIANA COM \\ O USO DE UMA PRIORI INFORMATIVA
}

\section{FRANCINE RAGONHA}

Licenciada em Matemática

Orientadora: Prof. Dr. ROSELI APARECIDA LEANDRO

\begin{abstract}
Dissertação apresentada à Escola Superior de Agricultura "Luiz de Queiroz", Universidade de São Paulo, para a obtenção do título de Mestre em Agronomia, Área de Concentração: Estatística e Experimentação Agronômica.
\end{abstract}

P I R A C I C A B A

Estado de São Paulo - Brasil

Janeiro - 2005 
Dados I nt ernacionai s de Cat al ogação na Publi cação ( CI P) DI VI SÃO DE BI BLI OTECA E DOCUMENTAÇÃO - ESALQI USP

Ragonha, Francine

Construção de mapas genéticos em espécies de polinização aberta: uma abordagem bayesiana com o uso de uma priori informativa / Francine Ragonha. - - Piracicaba, 2005. $149 \mathrm{p}$.

Dissertação (Mestrado) - - Escola Superior de Agricultura Luiz de Queiroz, 2004. Bibliografia.

1. Inferência bayesiana (inferência estatística) 2. Genética estatística 3. Verossilhança I. Título

CDD 519.54 


\section{DEDICATÓRIA}

A

DEUS e a Nossa Senhora

Nosso Pai e Nossa Mãe.

As pessoas que dão significado à minha vida tornando possível este trabalho: aos meus pais,

Luiz Fernado Ragonha e

Dinorá Dionízio Ragonha,

aos meus irmãos

Junior, Fernanda e Jéssica

e ao meu namorado

Marcelo

Aos meus avós Zinha, Avelino, Dora e Dorival (in memorian). 


\section{AGRADECIMENTOS}

À Deus pela vida, pela oportunidade de estudar e pela constante Presença.

À Maria, Mãe de Deus e Nossa Mãe, por todas as graças recebidas.

À Prof $\underline{\underline{a}}$ Dr $\underline{\underline{a}}$ Roseli Aparecida Leandro pela orientação, apoio, confiança e carinho que foram fundamentais para a realização deste trabalho.

Ao Prof. Dr. Antônio Augusto Franco Garcia pela participação contínua neste trabalho, por todo o incentivo, pelas idéias e amizade.

Aos meus pais Luiz Fernando Ragonha e Dinorá Dionízio Ragonha, o amor, a compreensão, o apoio e por se manterem sempre forte e zelarem pelo bem-estar e amor de nossa família.

Aos meus irmãos Luíz Fernando Ragonha Junior, Fernanda Cristina Ragonha e Jéssica Ragonha pela força, amizade e amor que sempre me propuseram.

Ao meu namorado Marcelo Moura dos Santos pelo amor, paciência e incentivo durante toda a realização deste trabalho.

Aos meus cunhados Maria Laura e Rodrigo pela forte amizade.

Aos meus tios, primos e avós por todo o carinho e pelas orações que fizeram.

Ao meu amigo Júlio César Pereira, com o qual estudei durante todo o período de graduação e de mestrado, pela ajuda nos programas computacionais, pelas sugestões dadas, pelas discussões produtivas que nortearam todo este trabalho e, principalmente, pela amizade.

Aos amigos do mestrado e doutorado, em especial ao Willian, Alfredo, Hélio, David, Marcela, Angela, Telde, Maurício, Denise e Melissa pelos conselhos, 
pela amizade e por todo o carinho.

As minhas amigas de república e de pós-graduação Beth e Luciana, pela convivência agradável, pelas boas risadas e por toda compreensão, amizade e força que me deram.

Aos professores do Departamento de Ciências Exatas e que me deram aulas Décio Barbin, Clarice Garcia Borges Demétrio, Édwin Moisés Marcos Ortega e Sílvio Sandoval Zocchi, pelos bons ensinamentos e amizade.

Aos funcionários do Departamento de Ciências Exatas da ESALQ/USP, em especial à Luciane, Solange, Expedita, Fátima e Jorge, pelos seus profissionalismos, pela amizade e por um simples sorriso capaz de dar força e incentivo nos momentos mais difíceis.

Ao Éder, pela revisão da dissertação na parte de Genética.

Aos alunos Marta, pelos ensinamentos de genética, e Gabriel, pela ajuda na programação computacional.

À todo o grupo de Genética e Estatística Bayesiana pelos conhecimentos adquiridos e carinho.

Aos meus amigos de graduação, em especial à Bibi por se manter sempre tão presente.

Aos meus professores de graduação da Unesp-Rio Claro por todos os ensinamentos e carinhos que me propuseram.

Aos meus orientadores de graduação Profo $\stackrel{o}{\text { Dro }}$ Geraldo Garcia Duarte Filho e Prof ${ }^{o}$ Dro $\underline{o}$ Antônio Carlos Simões Pião pela torcida, carinho e confiança que sempre depositaram em mim.

Ao CNPQ pelo apoio financeiro para a realização desta pesquisa. 


\section{SUMÁRIO}

Página

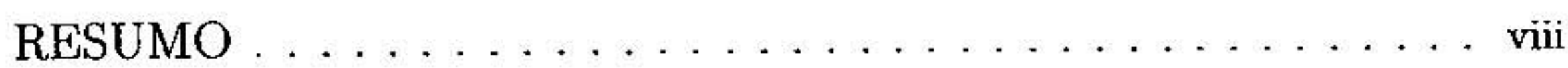

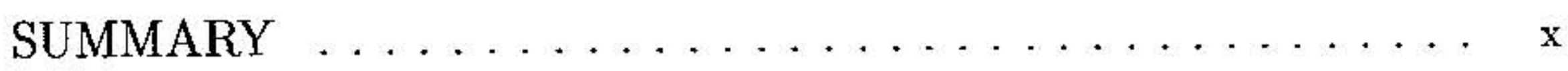

1 INTRODUÇÃO . . . . . . . . . . . . . . . . 1

2 REVISÃO DE LITERATURA . . . . . . . . . . . . . 4

2.1 O que é Inferência Bayesiana . . . . . . . . . . . . . 4

2.2 Teorema de Bayes . . . . . . . . . . . . . . . . . . 4

2.3 Função de Verossimilhança . . . . . . . . . . . . . . 5 5

2.4 Distribuição a priori . . . . . . . . . . . . . 6

2.4.1 Distribuição a priori própria e imprópria . . . . . . . . 7

2.4 .2 Distribuição a priori Conjugada . . . . . . . . . . . . 8

2.4 .3 Distribuição $a$ priori não informativa . . . . . . . . . . . 9

2.5 Distribuição a posteriori . . . . . . . . . . . . 10

2.6 Intervalo de Confiança clássico . . . . . . . . . . . . 10

2.7 Intervalo de Credibilidade . . . . . . . . . . . . . 11

2.7.1 Intervalo de Máxima Densidade a Posteriori (HPD) $\ldots \ldots \ldots 11$

2.8 Teste de Hipóteses Bayesiano . . . . . . . . . . . . . 11

2.9 Algoritmo EM - Esperança e Maximização . . . . . . . . . . . . . 12

2.10 Algoritmo EM - Esperança e Maximização . . . . . . . . . . . 13

2.11 Meiose e Crossing-over . . . . . . . . . . . . . . . 14

2.12 Análise de Ligação e Fases de Ligação . . . . . . . . . . . . 15

2.13 Distâncias entre genes num mesmo cromossomo . . . . . . . . . 19

2.14 Estimação da freqüência de recombinação com fase de ligação desconhecida 20 
2.15 Estimação simultânea da freqüência de recombinação e da fase de ligação 22

3 MATERIAL E MÉTODOS . . . . . . . . . . . . . . 27

3.1 Material ............................ 27

3.2 Métodos . . . . . . . . . . . . . . . . . . . . 28

4 RESULTADOS E DISCUSSÃO . . . . . . . . . . . . . . . . . . 38

4.1 Freqüência de recombinação . . . . . . . . . . . . . . . . . . 39

4.2 Fases de Ligação . . . . . . . . . . . . . . . . . . . . . . . . 68

4.3 Considerações Finais . . . . . . . . . . . . . . . . . . . . 84

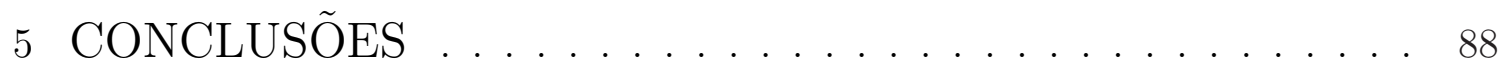

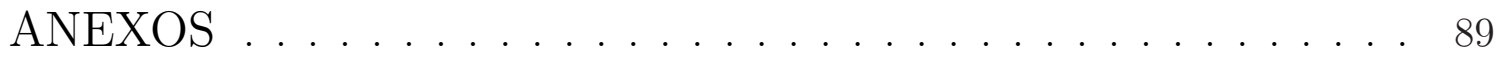

REFERÊNCIAS BIBLIOGRÁFICAS . . . . . . . . . . . . . 148 


\title{
CONSTRUÇÃO DE MAPAS GENÉTICOS EM ESPÉCIES DE POLINIZAÇÃO ABERTA: UMA ABORDAGEM BAYESIANA COM O USO DE UMA PRIORI INFORMATIVA
}

\author{
Autor: FRANCINE RAGONHA
}

Orientadora: Prof. Dr. ROSELI APARECIDA LEANDRO

\section{RESUMO}

A construção dos mapas Genéticos é importante para o melhoramento genético de plantas, pois são através desses mapas que pode se determinar em que pontos dos cromossomos as unidades hereditárias podem estar. Com o objetivo de verificar se o método Bayesiano incluindo a informação a priori pode ou não ser empregado nos estudos de construção de mapas Genéticos, estimativas Bayesianas e de máxima verossimilhança para a freqüência de recombinação foram obtidas, envolvendo espécies de polinização aberta. Para isso, foram considerados diferentes tipos de marcadores: marcadores completamente informativos e marcadores parcialmente informativos. Através de simulações de conjuntos de dados combinando dois marcadores de cada vez, as estimativas da freqüência de recombinação foram obtidas através de um algoritmo baseado na função de verossimilhança para os dois 
métodos de estimação usados. A caracterização das fases de ligação foi baseada na distribuição da probabilidade a posteriori dos arranjos de alelos alternativos em dados marcadores para dois cromossomos homólogos de cada genitor, condicional aos fenótipos observados dos marcadores. Os resultados obtidos permitem concluir que o método Bayesiano pode ser usado em estudos de ligação Genética com o uso da informação a priori. Quanto a estimação das fases de ligação, os dois métodos levam sempre à mesma conclusão. 


\section{CONSTRUCTION OF GENETICS MAPS IN OUTBREEDING SPECIES: A BAYESIAN APPROACH WITH THE USE OF A PRIOR INFORMATIVE}

Author: FRANCINE RAGONHA

Adviser: Prof. Dr. ROSELI APARECIDA LEANDRO

\section{SUMMARY}

The construction of the Genetic maps are essential for the genetic improvement of plants, because through this maps that it can be determined in which spots within the chromosomes the hereditary unities could be. With the aim of checking whether the Bayesian method including the prior information can or not to be used in the studies of Genetic maps construction, Bayesians estimates and of maximum likelihood for the recombination frequency were obtained, outbreeding species. For that, different types of markers were considered containing fully informative markers and partially informative markers. Through simulations of groups of data combining two markers one at a time, the estimates of the recombination frequency were obtained through a general maximum-likelihood based algorithm for the two used estimate methods. The characterization of linkage phases 
was based in the posterior probable distribution of the assignment of alternative alleles at given markers to two homologous chromosomes of each parent, conditional on the observed phenotypes of the markers. The results obtained allows to conclude that the Bayesian method can be used in studies of Genetic linkage with the use of the priori information. As the estimate of the linkage phases, the two methods always get to the same conclusion. 


\section{INTRODUÇÃO}

A Genética tem grande interesse na construção de mapas genéticos. É através deles que se pode determinar em que pontos dos cromossomos as unidades hereditárias podem estar. Esse mapa pode ser construído a partir de informações de um teste que considera como hipótese nula a segregação independente, isto é, considera que os pares de alelos, células germinativas, não se encontram sobre o mesmo par de cromossomos homólogos. Por par de cromossomos homólogos, entende-se o par de cromossomos que têm a mesma forma, o mesmo tamanho e possuem os alelos correspondentes na mesma posição. Se a segregação não for independente, formamse grupos dos alelos que estão ligados, isto é, associam-se os alelos localizados num mesmo cromossomo. Além disso, ordenam-se esses alelos ao longo dos cromossomos e mede-se a distância entre eles.

Há um grande número de estudos voltados para a detecção da ligação considerando espécies em que é possível a obtenção de linhagens endogâmicas por meio de autofecundações sucessivas. Para essas espécies a análise de ligação é simples, pois é possível distingüir os indivíduos recombinantes dos não recombinantes na progênie e, assim, a fase de ligação dos diferentes locos de marcadores é conhecida.

Para os casos em que é possível obter linhagens endogâmicas, a fase de ligação é conhecida e, portanto, não há grande dificuldade na construção do mapa em questão. Embora pareça ideal realizar experimentos com cruzamento controlado a fim de obter linhagens, em muitos casos tais experimentos são impraticáveis devido ao elevado custo e/ou ao elevado tempo que se leva para obter a progênie (Nordheim et al., 1983). Dessa maneira, em muitos casos, o estudo para a construção do mapa genético se torna mais complexo. Tais casos envolvem espécies de polinização aberta 
em que a fase de ligação não é conhecida. Assim, além de testar a ligação, é necessário estimar a fase de ligação, isto é, estimar como os alelos estão ligados caso a segregação não seja independente. Essas espécies não recebiam muita atenção nas pesquisas devido à complexidade com que apresentam sua estrutura genotípica. Com o uso dos marcadores moleculares, os estudos de ligação genética em espécies de polinização aberta ampliam seus espaços nas pesquisas genéticas.

Os marcadores moleculares constituem uma ferramenta rápida e eficaz para a construção do mapa genético. Tais marcadores são genotipados e servem como referência para a construção do mapa, possibilitando a obtenção de informações básicas sobre a estrutura e organização do genoma de uma espécie (Pastina, 2002). $\mathrm{Na}$ construção do mapa, esses marcadores são comparados dois a dois e, a partir daí, são formados os grupos de locos ligados (aqueles que se localizam num mesmo cromossomo). A partir disso, estima-se a fase de ligação para casos em que estas fases são desconhecidas e calcula-se a distância entre os marcadores ligados. Essa distância é obtida através da estimação da freqüência de recombinação. Estimar a freqüência de recombinação consiste em estimar a freqüência da troca de material genético durante um processo de divisão celular conhecido como meiose.

Nordhein et al. (1983) realizaram um estudo sobre a ligação considerando a fase de ligação desconhecida num cruzamento entre um indivíduo heterozigótico em ambos os locos com um homozigótico em ambos os locos. Para isso foram estimadas as freqüências de recombinação através do método da Máxima Verossimilhança, do método Bayesiano (com o uso de distribuições a priori não informativa e informativa) e do método Natural "ad hoc". Desses métodos, foi concluído que o método Bayesiano com o uso de uma distribuição a priori não informativa apresentou o menor erro quadrático médio. Contudo, há necessidade de se fazer um estudo para outros tipos de cruzamentos em que a fase de ligação é desconhecida aplicando o método clássico e Bayesiano na obtenção das estimativas da freqüência de recombinação.

Mais recentemente, Maliepaard et al. (1997) e Wu et al. (2002) apre- 
sentam um estudo de ligação genética de cruzamentos abertos com o uso de marcadores moleculares. Nesse estudo, são apresentados todos os possíveis tipos de cruzamentos (28 tipos) que se dão a partir da combinação dois a dois dos marcadores codificados. A generalização de um algoritmo baseado na função de verossimilhança para todos os possíveis tipos de cruzamentos é apresentada por Wu et al. (2002) a fim de simultaneamente estimar a ligação e as fases de ligação para uma mistura de diferentes tipos de marcadores. No entanto, um enfoque Bayesiano não é avaliado.

As limitações encontradas no estudo da construção do mapa são dadas para alguns tipos de cruzamentos em que não é possível distingüir os recombinantes (alelos obtidos através da troca do material genético durante a meiose) dos não recombinantes. Dessa maneira, é impossível construir o mapa para cruzamentos deste tipo.

Considerando as fases de ligação desconhecidas, a caracterização das fases de ligação estudadas neste trabalho é baseada na distribuição a posteriori do arranjo (tipo de cruzamento) de alelos alternativos dados os marcadores de dois cromossomos homólogos para cada pai, condicionados aos fenótipos observados dos marcadores. Assim, este trabalho tem como objetivo determinar as distribuições de probabilidade a posteriori para a freqüência de recombinação, considerando diversos tipos de cruzamentos, através da função de verossimilhança, apresentada por Wu et al. (2002), combinada com uma distribuição de probabilidade a priori informativa. Além das estimativas da freqüência de recombinação foram obtidas as estimativas das fases de ligação entre os marcadores ligados. Também, foram calculadas as estimativas das freqüências de recombinação e das fases de ligação através do método da Máxima Verossimilhança. Para estes dois métodos, estatísticas foram avaliadas tais como os intervalos de confiança clássico e de credibilidade e as somas dos quadrados dos resíduos. 


\section{REVISÃO DE LITERATURA}

\subsection{O que é Inferência Bayesiana}

A informação prévia que se tem sobre a quantidade de interesse $\boldsymbol{\theta}$ é fundamental na abordagem Bayesina. O verdadeiro valor de $\boldsymbol{\theta}$ é desconhecido e a idéia é tentar reduzir este desconhecimento. Além disso, a intensidade da incerteza a respeito de $\boldsymbol{\theta}$ pode assumir diferentes graus.

Na abordagem Bayesiana, de acordo com a Teoria da Probabilidade, os diferentes graus de incerteza são representados através de modelos probabilísticos para $\boldsymbol{\theta}$. Neste contexto, é natural que diferentes pesquisadores possam ter diferentes graus de incerteza sobre $\boldsymbol{\theta}$, já que os modelos especificados podem ser distintos.

A inferência Bayesiana requer um modelo amostral (verossimilhança) combinado com uma distribuição a priori para os parâmetros, $\boldsymbol{\theta}$, que resultará numa distribuição conhecida como distribuição a posteriori, que resume o resultado sobre os parâmetros do modelo e sobre quantidades não observadas tais como predição para novas observações (Gelman et al., 2003).

\subsection{Teorema de Bayes}

Suponha o vetor das quantidades de interesse $\boldsymbol{\theta}^{\prime}=\left(\theta_{1}, \theta_{2}, \ldots, \theta_{k}\right)$ não observável. A informação de que se dispõe sobre $\boldsymbol{\theta}$, resumida probabilisticamente através de $\pi(\boldsymbol{\theta})$, pode ser modificada observando-se uma quantidade aleatória $\mathbf{y}^{\prime}$ $=\left(\mathrm{y}_{1}, \mathrm{y}_{2}, \ldots, \mathrm{y}_{n}\right)$ relacionada com $\boldsymbol{\theta}$. A distribuição amostral $L(\boldsymbol{\theta} \mid \boldsymbol{y})$ que define essa relação é conhecida como verossimilhança. A idéia de que após observar $\boldsymbol{y}$, a informação sobre $\boldsymbol{\theta}$ é modificada é bastante intuitiva e o teorema de Bayes é a 
regra de atualização utilizada para quantificar esta mudança de informação, a qual é conhecida como distribuição a posteriori.

A função de densidade de probabilidade conjunta pode ser escrita como o produto de duas densidades (Gelman et al., 2003):

$$
\pi(\boldsymbol{\theta}, \boldsymbol{y})=\pi(\boldsymbol{\theta}) L(\boldsymbol{\theta} \mid \boldsymbol{y})
$$

em que $\pi(\boldsymbol{\theta})$ é a distribuição a priori e $L(\boldsymbol{\theta} \mid \boldsymbol{y})$ é a distribuição amostral. Usando propriedades da probabilidade condicional obtém-se a distribuição a posteriori:

$$
\pi(\boldsymbol{\theta} \mid \boldsymbol{y})=\frac{\pi(\boldsymbol{\theta}) L(\boldsymbol{\theta} \mid \boldsymbol{y})}{\pi(\boldsymbol{y})}
$$

em que $\pi(\boldsymbol{y})=\sum_{\boldsymbol{\theta}} \pi(\boldsymbol{\theta}) L(\boldsymbol{\theta} \mid \boldsymbol{y})$ é a soma de todos os possíveis valores de $\boldsymbol{\theta}$, quando $\boldsymbol{\theta}$ é discreto e $\pi(\boldsymbol{y})=\int_{\boldsymbol{\theta}} \pi(\boldsymbol{\theta}) L(\boldsymbol{\theta} \mid \boldsymbol{y})$ é a integral de todos os possíveis valores de $\boldsymbol{\theta}$, no caso em que $\boldsymbol{\theta}$ é contínuo.

Uma forma equivalente da eq.(1), omite o denominador $\pi(\boldsymbol{y})$, que independe de $\boldsymbol{\theta}$ e, sendo $\boldsymbol{y}$ fixo, pode-se considerá-lo como sendo uma constante, o que resulta na distribuição a posteriori não normalizada:

$$
\pi(\boldsymbol{\theta} \mid \boldsymbol{y}) \propto \pi(\boldsymbol{\theta}) L(\boldsymbol{\theta} \mid \boldsymbol{y})
$$

Essa expressão implica em dizer que a distribuição para $\boldsymbol{\theta}$ posterior aos dados é proporcional ao produto da distribuição a priori para $\boldsymbol{\theta}$ e a verossimilhança de $\boldsymbol{\theta}$ dado $\boldsymbol{y}$ (Box \& Tiao, 1992). Deve ser ressaltado que, quando se multiplica a função de verossimilhança por uma constante, a inferência relativa ao parâmetro $\boldsymbol{\theta}$ não se altera. Dessa maneira, a distribuição a posteriori não será alterada o que justifica o símbolo de proporcionalidade na eq. (2) (Leandro, 2001).

\subsection{Função de Verossimilhança}

É conhecida como função de verossimilhança a função $L(\boldsymbol{\theta} \mid \boldsymbol{y})$, que é uma função de $\boldsymbol{\theta}$, para $\boldsymbol{y}$ fixo. Em Inferência Bayesiana, a partir do teorema de 
Bayes, combina-se a função de verossimilhança com a distribuição de probabilidade a priori para se obter a distribuição de probabilidade a posteriori que é utilizada para fazer inferências sobre o vetor de parâmetros de interesse.

Em outras palavras, através do teorema de Bayes, obtém-se a distribuição de probabilidade do vetor de parâmetros de interesse $\boldsymbol{\theta}$ posterior aos dados que é proporcional ao produto da distribuição de $\boldsymbol{\theta}$ anterior aos dados com a verossimilhança para $\boldsymbol{\theta}$ dado $\boldsymbol{y}$.

É através da função de verossimilhança que os dados podem modificar o conhecimento que se tem a priori sobre $\boldsymbol{\theta}$. Dessa forma, $L(\boldsymbol{\theta} \mid \boldsymbol{y})$ pode ser considerada como a representação da informação de $\boldsymbol{\theta}$ obtida dos dados (Box \& Tiao, 1992).

Vale ser ressaltado que o Princípio da Verossimilhança postula que para fazer inferência sobre uma quantidade de interesse $\boldsymbol{\theta}$ só importa aquilo que for realmente observado e não aquilo que poderia ter ocorrido mas efetivamente não ocorreu.

\subsection{Distribuição a priori}

Nota-se que a fórmula de Bayes requer a especificação de $\pi(\boldsymbol{\theta})$ que é conhecida como distribuição a priori de $\boldsymbol{\theta}$. É através da especificação de uma distribuição a priori, para a quantidade de interesse $\boldsymbol{\theta}$, que se faz uso do conhecimento prévio em inferência Bayesiana. Tal distribuição deve representar probabilisticamente o conhecimento que se tem sobre $\boldsymbol{\theta}$ antes de os dados serem obtidos, ou até mesmo representar a ignorância relativa (Leandro, 2001).

A crença a priori sobre $\boldsymbol{\theta}$ pode diferir de pesquisador para pesquisador (Lee, 1997). Há casos em que a priori dada é informativa, refletindo algum conhecimento prévio sobre o parâmetro desconhecido. Outras vezes, a priori é não informativa, deixando que os dados mostrem todas as informações sobre $\boldsymbol{\theta}$.

É através das experiências e/ou crenças do indivíduo que a densidade a priori é especificada. Nesse caso, então, o problema é como converter essas experiências e/ou crenças na forma de uma distribuição de probabilidade $\pi(\boldsymbol{\theta})$ (Smith, 
1991).

Há casos em que a distribuição a priori é ajustada às freqüências relativas, isto é, através da disponibilidade de experiências extensivas pode-se assumir uma distribuição de freqüência sólida sobre os valores assumidos por $\boldsymbol{\theta}$ no passado (Box \& Tiao, 1992).

Já na ausência dos dados históricos, a escolha da distribuição a priori está baseada simplesmente na expectativa subjetiva do pesquisador, em que o ajuste dessa distribuição é feito através da transmissão do "sentimento" à distribuição $a$ priori. Daí, percebe-se a importância da interação pesquisador-estatístico, cabendo ao segundo sugerir ao pesquisador medidas que resumam a sua subjetividade. Mesmo depositando sua crença na priori, os resultados refletidos pela distribuição a posteriori podem trazer insatisfações ao pesquisador e, nesse caso, a interação pesquisador estatístico é fundamental (Leandro, 2001).

\subsubsection{Distribuição a priori própria e imprópria}

Sabe se, por definição, que a distribuição de probabilidade é uma função $f(x)$, positiva, cuja integral ou soma apresenta resultado 1. Contudo, no caso da distribuição a priori o conceito de distribuição de probabilidade deve ser estendido (Lee, 1997) para casos em que

$$
\begin{aligned}
& \sum_{\Theta} \pi(\theta)=\infty, \text { para dados discretos, } \\
& \int_{\Theta} \pi(\theta) d \theta=\infty, \text { para dados contínuos. }
\end{aligned}
$$

Tal densidade recebe o nome de densidade imprópria. Geralmente, isto acontece quando $\pi(\theta)$ é uniforme sobre toda a reta. Funções desse tipo são geralmente empregadas para representar um comportamento local da distribuição $a$ priori na região onde a verossimilhança é avaliada, mas não sobre toda sua possível variação (Box \& Tiao, 1992).

Nos casos em que a densidade a priori não viola a verdadeira definição de distribuição de probabilidade, tal densidade é conhecida como densidade a priori 
própria.

Deve ser ressaltado, novamente, que o caso descrito só é possível para a distribuição a priori e, portanto, não deve ser empregado para a posteriori, a qual necessariamente tem que satisfazer a definição de distribuição de probabilidade.

\subsubsection{Distribuição a priori Conjugada}

A idéia de distribuição a priori conjugada é que as distribuições $a$ priori e a posteriori pertençam à mesma classe de distribuições e, assim, a atualização do conhecimento que se tem de $\theta$ envolve apenas uma mudança nos hiperparâmetros. Por hiperparâmetros, entendem-se parâmetros indexadores da família de distribuições a priori que difere dos parâmetros de interesse $\theta$. Do conhecimento que se tem sobre $\theta$, pode-se definir uma família paramétrica de densidades. Assim, nesse caso, a distribuição a priori é representada por uma forma funcional cujos parâmetros, isto é, os hiperparâmetros devem ser especificados de acordo com este conhecimento.

Assim, sendo $L(\boldsymbol{\theta} \mid \boldsymbol{y})$ a função de verossimilhança, a classe $\Psi$ de distribuições a priori é dita formar uma família conjugada se a densidade a posteriori

$$
\pi(\boldsymbol{\theta} \mid \boldsymbol{y}) \propto \pi(\boldsymbol{\theta}) L(\boldsymbol{\theta} \mid \boldsymbol{y})
$$

é também da classe $\Psi$ para todo $\boldsymbol{y}$ sempre que a densidade a priori está em $\Psi$ (Lee, 1997).

Nota-se que é muito importante na estatística Bayesiana o uso de prioris conjugadas pois o aspecto seqüencial do método Bayesiano pode ser explorado definindo-se apenas a regra de atualização dos hiperparâmetros, já que as distribuições permanecem as mesmas. Contudo, deve-se ter cuidado ao trabalhar com prioris conjugadas já que estas nem sempre são consideradas uma representação adequada da incerteza a priori. 


\subsubsection{Distribuição a priori não informativa}

O uso de uma distribuição a priori não informativa implica em permitir que os "dados falem por si só" (Gelman, 2003), isto é, quando se espera que a informação dos dados seja dominante, no sentido de que a informação a priori seja vaga. Nesse caso, a primeira idéia de não informação é considerar todos os possíveis valores de $\theta$ como igualmente prováveis. Assim, tomando $\pi(\theta) \propto \mathrm{k}$, distribuição $a$ priori uniforme, para $\theta$ variando em um subconjunto da reta significa que nenhum valor particular de $\theta$ tem preferência. No entanto, deve-se considerar que os dados nos dêem todas as informações possíveis sobre $\theta$ e, portanto, acrescentar a priori significaria apenas na mudança de locação da função de verossimilhança.

Jeffreys (1961) propôs a classe de prioris não informativas que é invariante a transformações 1 a 1 . Entretanto, antes de apresentá-la, é preciso definir o conceito de medida de informação de Fisher, que para um parâmetro unidimensional é:

$$
\mathrm{I}_{n}(\theta)=\mathrm{E}_{\theta \mid y}\left[-\frac{\partial^{2} l(\theta \mid y)}{\partial \theta^{2}}\right]
$$

sendo $\mathrm{I}_{n}(\theta)$ baseado em n observações e $l(\theta \mid y)$ o logaritmo da função de verossimilhança. A priori não informativa de Jeffreys em função da densidade é dada por (Leandro, 2001):

$$
\pi(\theta) \propto\left[\mathrm{I}_{n}(\theta)\right]^{\frac{1}{2}}
$$

Sendo $\boldsymbol{\theta}$ um vetor paramétrico, define-se a matriz de informação esperada de Fisher, de $\boldsymbol{\theta}$, como:

$$
\boldsymbol{I}(\boldsymbol{\theta})=E\left[-\frac{\partial^{2} l(\boldsymbol{\theta} \mid \boldsymbol{y})}{\partial \boldsymbol{\theta} \partial \boldsymbol{\theta}^{\prime}}\right] .
$$

Neste caso, a priori não informativa de Jeffreys é dada por:

$$
\pi(\boldsymbol{\theta}) \propto|\operatorname{det} I(\boldsymbol{\theta})|^{\frac{1}{2}} .
$$




\subsection{Distribuição a posteriori}

O teorema de Bayes pode ser usado para combinar a informação dos dados com a distribuição a priori. Assim, obtém-se a distribuição a posteriori $\pi(\boldsymbol{\theta} \mid \boldsymbol{y})$ que contém toda informação sobre o parâmetro $\boldsymbol{\theta}$.

A fim de resumir as informações obtidas pela distribuição a posteriori, alguns valores numéricos podem ser calculados, tais como: média, mediana, moda, intervalos de credibilidade e HPD (highest posterior density interval) de interesse. Além disso, através do gráfico dessa distribuição as informações contidas na posteriori podem ser resumidas, implicando em uma melhor descrição do processo inferencial. Contudo, a construção de gráficos torna-se difícil em casos onde $\boldsymbol{\theta}$ é multidimensional.

\subsection{Intervalo de Confiança clássico}

Um intervalo $[a, b]$ é conhecido como um intervalo de confiança (IC) clássico para o parâmetro $\theta$ se a probabilidade de cobertura

$$
P\left(\theta_{0}\right)=P\left(a \leq \theta_{0} \leq b \mid \theta=\theta_{0}\right)
$$

é a mesma para todos os valores $\theta_{0}$ do parâmetro. Assim, $[a, b]$ é um intervalo de $95 \%$ para $\theta$ se

$$
P\left(a \leq \theta_{0} \leq b \mid \theta=\theta_{0}\right)=0,95
$$

para todos os possíveis valores $\theta_{0}$ do parâmetro. Essa probabilidade é chamada de coeficiente de confiança.

Um intervalo de confiança $95 \%$ é interpretado através de uma seqüência imaginária de repetições de um experimento, ou seja, esse intervalo deverá incluir o verdadeiro valor do parâmetro $\theta_{0}$, em $95 \%$ das repetições dos experimentos com o $\theta$ fixado. Portanto, não é correto afirmar que um intervalo de $95 \%$ de confiança $[a, b]$ tem $95 \%$ de probabilidade de incluir o verdadeiro valor para $\theta$. 


\subsection{Intervalo de Credibilidade}

Sabe-se que toda informação que se tem sobre $\boldsymbol{\theta}$ é expressa pela distribuição a posteriori. Como já mencionado, essa informação pode ser resumida através de um valor numérico. É importante, também, associar alguma informação sobre o quão precisa é a especificação desse número.

O intervalo $(a, b)$ é um intervalo de credibilidade de 100(1- $\alpha) \%$, ou nível de credibilidade (1- $\alpha)$, para $\theta$ (Smith, 1991) se:

$$
\int_{a}^{b} \pi(\theta \mid \mathrm{y}) d \theta=1-\alpha(0 \leq \alpha \leq 1)
$$

Quanto menor for a amplitude do intervalo mais concentrada é a distribuição do parâmetro, ou seja, a amplitude do intervalo informa sobre a dispersão de $\theta$.

\subsubsection{Intervalo de Máxima Densidade a Posteriori (HPD)}

Um intervalo de credibilidade é um intervalo de máxima densidade $a$ posteriori ("highest posterior density interval", HPD) quando a densidade para todo ponto pertencente ao intervalo é maior do que para qualquer ponto não pertencente ao intervalo. Além disso, deve-se considerar o menor intervalo possível (Box \& Tiao, 1992). Geralmente, esses intervalos são associados a 90, 95 ou $99 \%$ de probabilidade total.

\subsection{Teste de Hipóteses Bayesiano}

Supondo que deseja-se saber se um dado parâmetro $r$, pertencente ao espaço paramétrico $\Theta$, pertence ao subconjunto paramétrico $\Theta_{0}$ ou ao subconjunto $\Theta_{1}$, em que $\Theta_{0} \cup \Theta_{1}=\Theta$ e $\Theta_{0} \cap \Theta_{1}=\varnothing$. Equivalentemente:

$$
\begin{aligned}
& H_{0}: r \in \Theta_{0} \\
& H_{1}: r \in \Theta_{1}
\end{aligned}
$$


o fator de Bayes em que $\Theta_{0} \cup \Theta_{1}=\Theta$ e $\Theta_{0} \cap \Theta_{1}=\varnothing$ utiliza-se definido por:

$$
\boldsymbol{B}=\frac{p_{0} / p_{1}}{\pi_{0} / \pi_{1}}
$$

em que $\pi_{0}$ e $\pi_{1}$ são as probabilidades a priori, $\pi_{0}+\pi_{1}=1$, e $p_{0}$ e $p_{1}$ as probabilidades a posteriori, $p_{0}+p_{1}=1$.

Se $\Theta_{0}=\left\{r_{0}\right\}$ e $\Theta_{1}=\left\{r_{1}\right\}$ para algum $r_{0}$ e para algum $r_{1}$, tem-se $p_{0} \propto \pi_{0} p\left(\boldsymbol{y} \mid r_{0}\right)$ e $p_{1} \propto \pi_{1} p\left(\boldsymbol{y} \mid r_{1}\right)$. Dessa maneira e de acordo com a eq. (3), o fator de Bayes a favor de $H_{0}$ e contra $H_{1}$ é:

$$
\boldsymbol{B}=\frac{p\left(\boldsymbol{y} \mid r_{0}\right)}{p\left(\boldsymbol{y} \mid r_{1}\right)}
$$

, isto é, o fator de Bayes é a razão da verossimilhança de $H_{0}$ contra $H_{1}$, que pode ser interpretada como a vantegem de $H_{0}$ contra $H_{1}$ que é dada pelos dados.

Para o caso em que $H_{0}$ e $H_{1}$ são compostas por mais de um elemento, define-se:

$$
\begin{gathered}
\rho_{0}=\frac{p(r)}{\pi(r)}, \text { para } r \in \Theta_{0} \mathrm{e} \\
\rho_{1}=\frac{p(r)}{\pi(r)}, \text { para } r \in \Theta_{1}
\end{gathered}
$$

em que $p(r)$ é a densidade a posteriori de $r ; \rho_{0}$ é a restrição de $p(r)$ para $\Theta_{0}$ e $\rho_{1}$ a restrição para $\Theta_{1}$. Então, tem-se:

$$
p_{0}=\int_{r \in \Theta_{0}} p(r) p(\boldsymbol{y}) d r \propto \pi_{0} \int_{r \in \Theta_{0}} p(\boldsymbol{y} \mid r) \rho_{0}(r) d r
$$

De modo análogo, obtém-se $p_{1}$. Logo, o fator de Bayes é definido por:

$$
\boldsymbol{B}=\frac{\int_{r \in \Theta_{0}} p(\boldsymbol{y} \mid r) \rho_{0}(r) d r}{\int_{r \in \Theta_{1}} p(\boldsymbol{y} \mid r) \rho_{1}(r) d r} .
$$

\subsection{Algoritmo EM - Esperança e Maximização}

Em muitos casos, é necessário o uso de métodos numéricos a fim de maximizar uma determinada função. O algoritmo EM (Esperança e Maximização) 
é um método numérico que tem se mostrado muito poderoso para a obtenção de estimativas de máxima verossimilhança quando as observações consistem de dados incompletos (dados observados $Y$ ).

O passo E desse algoritmo se dá a partir do cálculo da esperança condicional:

$$
Q\left(\theta \mid \theta_{n}\right)=E\left[\log f(X \mid \boldsymbol{\theta}) \mid Y, \boldsymbol{\theta}_{\boldsymbol{n}}\right]
$$

em que $\boldsymbol{\theta}_{\boldsymbol{n}}$ é o vetor estimado atual de $\theta$ e $f(X \mid \theta)$ a densidade de probabilidade que é uma função de um vetor de parâmetro $\theta$ bem como de $X$. No passo M, maximiza-se $Q\left(\boldsymbol{\theta} \mid \boldsymbol{\theta}_{\boldsymbol{n}}\right)$ em relação à $\boldsymbol{\theta}$ (Lange, 1997).

Esse procedimento fornece uma nova estimativa para $\boldsymbol{\theta}_{\boldsymbol{n}}$, denominado $\boldsymbol{\theta}_{\boldsymbol{n}+\mathbf{1}}$. Os dois passos são repetidos até haver convergência.

\subsection{Algoritmo EM - Esperança e Maximização}

Em muitos casos, é necessário o uso de métodos numéricos a fim de maximizar uma determinada função. Por exemplo, considerando um loco que é heterozigótico em ambos os genitores, que segregam na razão 1:2:1, sendo que tais genitores têm o mesmo genótipo de dois alelos codominantes, isto é, $a b \times a b$, e o outro loco com as mesmas características, não é possível obter um estimador para a freqüência de recombinação analiticamente. O algoritmo EM (Esperança e Maximização) é um método numérico que tem se mostrado muito poderoso para a obtenção de estimativas de máxima verossimilhança quando as observações consistem de dados incompletos (dados observados $Y$ ).

O passo E desse algoritmo se dá a partir do cálculo da esperança condicional:

$$
Q\left(\theta \mid \theta_{n}\right)=E\left[\log f(X \mid \boldsymbol{\theta}) \mid Y, \boldsymbol{\theta}_{\boldsymbol{n}}\right]
$$

em que $\boldsymbol{\theta}_{\boldsymbol{n}}$ é o vetor estimado atual de $\theta$ e $f(X \mid \theta)$ a densidade de probabilidade que é 
uma função de um vetor de parâmetro $\theta$ bem como de $X$. No passo M, maximiza-se $Q\left(\boldsymbol{\theta} \mid \boldsymbol{\theta}_{\boldsymbol{n}}\right)$ em relação à $\boldsymbol{\theta}$ (Lange, 1997).

Esse procedimento fornece uma nova estimativa para $\boldsymbol{\theta}_{\boldsymbol{n}}$, denominado $\boldsymbol{\theta}_{\boldsymbol{n}+\mathbf{1}}$. Os dois passos são repetidos até haver convergência.

\subsection{Meiose e Crossing-over}

Os cientistas verificaram que todas as células provêm da divisão de uma célula pré-existente. Antes dessa divisão, tudo o que está na célula é dividido. O gameta masculino e o gameta feminino carregam, cada um, metade do conjunto de cromossomos. No momento da fertilização, seus núcleos unem-se formando o zigoto, que reúne o conjunto de todos os cromossomos paternos e maternos. Portanto, já existem realmente duas cópias de cada cromossomo da célula, chamados pares de homólogos. Do zigoto, por mitose, originam-se todas as outras células. Esse último processo garante que cada célula filha receba um conjunto de cromossomos perfeito e completo (Griffits, 2002).

A meiose é um processo de divisão celular que origina um grupo de quatro células, chamadas de produtos da meiose, através de duas divisões sucessivas. Em animais e plantas, esses produtos tornam-se os gametas haplóides. Através da meiose, os cromossomos homólogos pareiam-se fisicamente e segregam-se na primeira divisão. Já as cromátides irmãs segregam na segunda divisão. Tal processo de divisão celular ocorre da seguinte maneira:

i ) Enquanto ainda invisíveis, os cromossomos duplicam-se e tornam-se espessos;

ii ) Os cromossomos homólogos ajustam-se em pares;

iii ) A membrana que envolve o núcleo dissolve-se; forma-se a seguir uma teia de fibras sobre a qual os quartetos cromossômicos se alinham;

iv ) Em seguida, separam-se os pares que seguem para pólos opostos; 
v ) Quando atingem os pólos, a teia de fibras desaparece e novas fibras surgem em sentido contrário;

vi ) Os cromossomos, então separam-se da mesma forma, como na mitose, resultando num total de quatro células.

Logo após os cromossomos se ajustarem em pares, durante a meiose, pode ocorrer troca de material genético entre os pares de cromossomos homólogos, recombinando, assim, os cromossomos. Essa troca é chamada de crossing-over (Griffits, 2002).

A recombinação definida em relação à meiose é qualquer processo que gere um produto haplóide com um genótipo que o diferencie de ambos os genótipos haplóides que constituem a célula meiótica diplóide (Griffits, 2002). Então, o produto da meiose gera o que se chama de recombinantes.

Espera-se que o número máximo de recombinantes existente seja a metade do número de gametas possíveis, isto é, considerando que durante a meiose ocorreu $100 \%$ de crossing-over, $50 \%$ dos gametas formados serão parentais e os outros $50 \%$ serão recombinantes. Isso deve-se ao fato de que, sendo um cromossomo formado por duas cromátides irmãs, durante a meiose ocorre troca material genético somente entre cromátides não-irmãs. Logo, as outras duas cromátides que não trocaram material genético resultam nos gametas parentais.

\subsection{Análise de Ligação e Fases de Ligação}

Mendel propôs o princípio da segregação independente que ficou conhecido como segunda lei de Mendel (Griffits, 2002). Essa lei indica que os genes segregantes distribuem-se independentemente na meiose. Dessa maneira, os genes que se segregam independentemente na meiose são ditos não ligados (Figura 1). Nesse caso, a freqüência dos gametas recombinantes e dos gametas não recombinantes encontram-se na mesma proporção. 


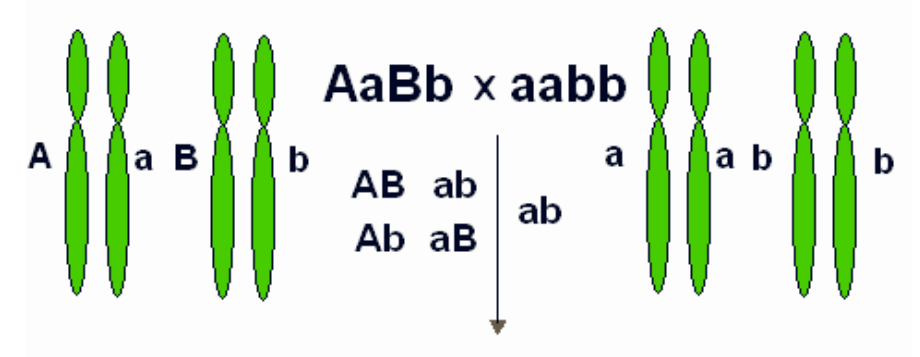

Aabb aaBb AaBb aabb

Figura 1 - Retrocruzamento em que os alelos não estão ligados

Após três anos da redescoberta do trabalho pioneiro de Mendel, Sutton sugeriu que cada cromossomo deveria ter mais de um alelo e que os alelos deveriam ser herdados juntos (Griffits, 2002). No entanto, Sutton foi incapaz de sustentar experimentalmente sua hipótese. Apenas poucos anos depois, William Bateson e R.C. Punnett (1905-1908) chegaram a ter dados para fazê-lo, mas não reconheceram que estavam lidando com pares de alelos localizados no mesmo cromossomo e, ao realizarem uma experiência com ervilhas, não foram capazes de explicar por que ou como se formou uma certa proporção de gametas, já que não a relacionaram com o comportamento dos cromossomos na meiose.

Como explicação para os resultados obtidos em suas experiências, Bateson e Punnett propuseram um acoplamento entre os alelos dominantes e entre os alelos recessivos. Em tal trabalho sobre acoplamento, Bateson e Punnett introduziram, também, o termo repulsão para descrever a situação em que os alelos dominantes "repeliam-se", o oposto da situação de acoplamento em que os alelos dominantes pareciam "estar juntos". A explicação destes dois fenômenos (acoplamento e repulsão) foi dada por Thomas Hunt Morgan em 1910. Ele sugeriu que os genes que controlam ambos os fenótipos estão situados no mesmo par de cromossomos homólogos (Griffits, 2002). 
A confirmação da hipótese de Bateson e Punnett surgiu do estudo da Drosophila realizado por Morgan. Morgan sugeriu que, quando os cromossomos homólogos se pareiam na meiose, os cromossomos ocasionalmente trocam partes em um processo chamado crossing-over, o que explica a formação da certa proporção de gametas encontrada no trabalho de Bateson e Punnett.

Todos os genes localizados no mesmo par cromossômico constituem um grupo de ligação, isto é, os genes que se encontram num mesmo par de cromossomos são ditos ligados, e devia-se esperar que fossem herdados em bloco, se não fosse o crossing-over. Deve ser ressaltado, que é apropriado, também, referir-se a ligação de alelos específicos: por exemplo, em um indivíduo $\frac{A B}{a b}$, A está ligado a $\mathrm{B}$ e, necessariamente, $a$ está ligado a $b$.

Atualmente, acoplamento indica um certo tipo de ligação que é conhecida como ligação em associação e refere-se à ligação de dois alelos dominantes ou dois recessivos (Figura 2).

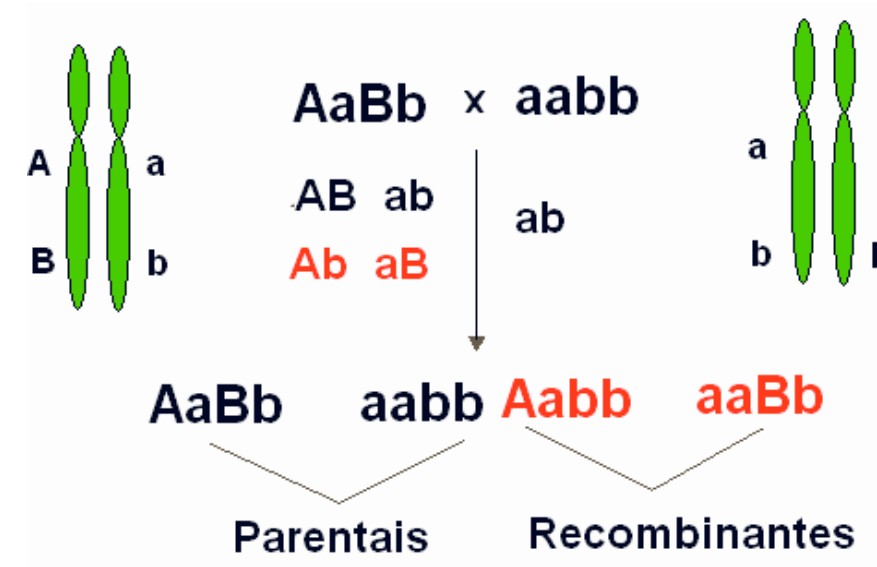

Figura 2 - Ligação em Associação num retrocruzamento

Nesse caso, sem o crossing-over, a geração F1 produziria apenas dois tipos de gametas, AB e ab. Contudo, o crossing-over produz mais dois gametas Ab e aB. Como já citado, esses quatro gametas não são produzidos na mesma freqüência. Já, a repulsão indica que os alelos dominantes estão ligados a alelos 
recessivos. Em tal ligação, os gametas parentais são Ab e aB, enquanto os recombinantes são AB e ab, como mostra a Figura 3.

É interessante observar que os parentais da ligação em associação correspondem aos recombinantes da repulsão, enquanto seus recombinantes correspondem aos parentais desse último tipo de ligação. Assim, o teste para determinar se dois genes estão ligados é baseado no conceito de recombinação e a hipótese nula considerada é:

$$
H_{0}: \theta=0,5
$$

em que $\theta$ é a freqüência de recombinação.

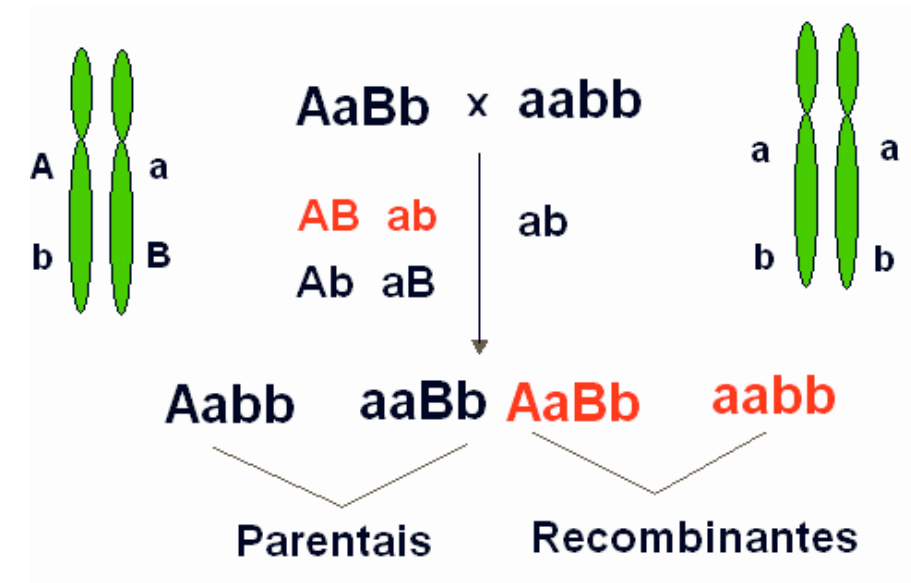

Figura 3 - Ligação em Repulsão num retrocruzamento

Testar essa hipótese implica em testar a ocorrência de não ligação entre os genes, já que neste caso a freqüência de gametas recombinantes é igual à freqüência de gametas não recombinantes. Para isso, devem-se comparar as marcas e usar métodos estatísticos para daí concluir se se deve, ou não, rejeitar tal hipótese. Além disso, quando tal teste for significativo, é preciso conhecer as fases de ligação entre os genes que estão sendo estudados, ou seja, conhecer se tais genes estão ligados em associação ou em repulsão. Assim, é preciso determinar as estimativas para as fases de ligação quando tais fases são desconhecidas.

Como já notado, após a descoberta de Mendel, a Genética teve um 
grande avanço na ciência o que contribuiu para muitos esclarecimentos em inquietações que perduraram durante séculos e séculos. Mas as inquietações e as descobertas não pararam por aí. Também em 1910, Morgan forneceu evidências para a localização de um gene no cromossomo, concluindo também que existe uma relação definida entre freqüência de recombinação e distância linear separando genes que estão ligados. Assim, deu-se início à construção de mapas cromossômicos que mostram grupos de ligação e distâncias relativas entre genes sucessivos.

\subsection{Distâncias entre genes num mesmo cromossomo}

O Mapa Genético serve para mostrar em que ponto dos cromossomos as unidades hereditárias podem estar. Até mesmo nos dias de hoje, muitas são as pesquisas que envolvem sua construção. Sabe-se que é necessário um grande número de genes para controlar um organismo e que o número de cromossomos é relativamente pequeno. Logo, é fácil concluir que, em cada cromossomo existem muitos genes e que, portanto, não é uma tarefa simples mapear um cromossomo. A fim de mapear um cromossomo, é necessário conhecer as distâncias que separam os alelos que se encontram sobre este cromossomo.

De fato, como previu Morgan, tendo percebido que a proporção da prole recombinante varia consideravelmente, dependendo de que genes ligados estavam sendo estudados, as variações da freqüência de crossing podem indicar as distâncias reais que separam genes nos cromossomos. Assim, Alfred Sturtevant, aluno da graduação de Morgan, desenvolveu um método para descrever as relações entre genes que ainda é usado hoje em dia. Sturtevant postulou que quanto maior for a distância entre os alelos ligados, maior é a chance de ocorrer crossing-over entre as cromátides não irmãs. Tal relação não é "diretamente proporcional" no sentido matemático. Há casos em que os alelos se encontram à uma distância tão grande em um mesmo cromossomo que se comportam como se não estivessem ligados. Dessa maneira, pode-se definir a distância entre alelos num mesmo cromossomo como sendo uma função da freqüência de recombinação. 
O método desenvolvido por Sturtevant sugere que se pode usar a porcentagem de recombinantes como um indicador quantitativo da distância linear entre dois alelos em um mapa genético, ou mapa de ligação, como é as vezes chamado (Griffits, 2002). De fato, pode-se usar uma unidade arbitrária para descrever as distâncias entre os alelos ligados: a unidade de mapa. Tal unidade é equivalente a $1 \%$ dos crossings (recombinantes), isto é, representa a distância linear ao longo do cromossomo para o qual se observa uma freqüência de $1 \%$ de recombinação. Essas distâncias também podem ser expressas em unidades Morgan; uma dessas unidades representa $100 \%$ de crossing. Portanto, $1 \%$ de crossing-over também pode ser expresso como um centimorgan (um cM), 10\% de crossing-over como um decimorgan, e assim por diante.

Existem vários tipos de funções as quais relacionam a distância $d$ que separam os alelos num mesmo cromossomo com a freqüência de recombinação $(r)$. Uma delas é conhecida como função de Haldane e é definida como sendo

$$
d=-0,5 \log (1-2 r)
$$

Esta função apresenta uma vantagem em relação as outras funções, pois possui a propriedade da aditividade, isto é, por exemplo, dada a distância entre o primeiro e o segundo loco e a distância entre o segundo e terceiro loco, a distância entre o primeiro e terceiro loco é dada pela soma das duas distâncias conhecidas.

\subsection{Estimação da freqüência de recombinação com fase de ligação desconhecida}

Muitas vezes, estudos de ligação genética em plantas e animais são feitos por meio de delineamentos genéticos controlados em que a fase de ligação é conhecida. Entretanto, existem situações para as quais esse trabalho é inviável devido ao longo tempo para a obtenção de gerações e / ou devido ao elevado custo (Nordheim et al., 1983). Dessa maneira, estimativas da freqüência de recombinação são obtidas de estudos em que a fase de ligação é desconhecida. 
Nordheim et al. (1983) apresentam um modelo que pode ser usado em estudos de ligação genética quando os dados são gerados por um retrocruzamento em que a fase de ligação é desconhecida. Tal modelo considera dois locos, onde um dos genitores é heterozigótico em ambos os locos $(\mathrm{AaBb})$ e o outro genitor é homozigótico em ambos os locos (aabb ou AABB). Nesse caso, a progênie fornece informação sobre a fase de ligação. No entanto, em casos em que um dos genitores é heterozigótico para um loco e o outro genitor é heterozigótico para o outro loco (Aabb x aaBb), a progênie não fornece informações sobre as fases de ligação (Liu, 1998). O modelo apresentado por Nordhein et al. (1983) é dado por:

$$
P(k \mid n, r)=\left\{\begin{array}{cc}
\left(\begin{array}{c}
n \\
k
\end{array}\right)\left[r^{k}(1-r)^{n-k}+r^{n-k}(1-r)^{k}\right], & 0 \leq k<\frac{n}{2} \\
\frac{1}{2}\left(\begin{array}{c}
n \\
k
\end{array}\right)\left[r^{k}(1-r)^{n-k}+r^{n-k}(1-r)^{k}\right], & k=\frac{n}{2}
\end{array}\right.
$$

em que $n$ é o tamanho amostral (número de gametas), $k$ é o número de observações na menor classe (associação ou repulsão), $r$ é a freqüência de recombinação restrita ao intervalo $0 \leq r \leq 0,5$.

A idéia de usar o modelo da eq. (6) para esse tipo de cruzamento se dá pelo fato de que ao olhar para o conjunto de dados, considera-se como sucesso o número de recombinantes que, geralmente, corresponde ao número da classe de menor freqüência. Neste modelo, o termo $r^{k}(1-r)^{n-k}$ vem da distribuição binomial e o termo $r^{n-k}(1-r)^{k}$ é devido à restrição $0 \leq k \leq \frac{1}{2}$. A soma dos termos na eq. (6) deve-se ao fato de que a probabilidade da união de dois eventos é a soma das probabilidades dos eventos em questão, subtraindo a probabilidade da intersecção destes dois eventos. Como a intersecção é vazia, já que se $k$ representa o número de recombinantes, então $(n-k)$, representa o número de parentais e vice-versa, a probabilidade resulta apenas na soma das probabilidades dos dois possíveis eventos. No caso em que $k=\frac{n}{2}$, o número de recombinantes coincide com o número de parentais. 
Nesse estudo de ligação, Nordhein et al. (1983) apresentam três métodos de estimação para a freqüência de recombinação: método da máxima verossimilhança, método Bayesiano (com o uso de uma distribuição a priori não informativa e com o uso de uma distribuição a priori informativa) e o método "ad hoc". e concluem que o estimador Bayesiano com o uso de uma distribuição a priori não informativa apresenta o menor erro quadrático em relação aos outros estimadores.

A partir de dois genitores homozigóticos em ambos os locos (AABB $\times$ aabb), cruzando o indivíduo da geração F1 (AaBb) com um de seus genitores ou com ele mesmo, isto é, o retrocruzamento ou a autofecundação, respectivamente, é necessário testar apenas se os marcadores considerados estão ou não ligados, pois, se estiverem ligados, de imediato, é conhecida a maneira como eles estão ligados, isto é, é conhecida a fase de ligação. Para cruzamentos desses tipos, mas sem conhecer os genitores que foram cruzados para a obtenção da geração F1 (AaBb), a fase de ligação é desconhecida. Dessa maneira, no caso da autofecundação, a estimação da freqüência de recombinação se torna mais complexa, já que não será possível distinguir os recombinantes dos não recombinantes.

Um estudo mais detalhado sobre a estimação da freqüência de recombinação abordando vários tipos de cruzamentos é realizado por Maliepaard et al. (1997) que consideram cruzamentos de espécies de polinização aberta e, portanto, a fase de ligação não é conhecida. Dessa maneira, também, são estimadas as fases de ligação entre dois marcadores que estejam ligados.

\subsection{Estimação simultânea da freqüência de recombinação e da fase de ligação}

No contexto deste trabalho, por família de irmãos germanos, entende-se como sendo a progênie resultante do cruzamento entre dois indivíduos de uma espécie diplóide de polinização aberta. Análise de ligação e construção de mapas genéticos usando marcadores moleculares é mais complexa em famílias de irmãos germanos do 
que em progênies derivada de genitores homozigóticos. As diferenças para a análise de ligação entre esses dois casos são devido ao número de alelos segregantes por locos dos genitores e a fase de ligação dos locos. Nas espécies de polinização aberta em que não é possível a obtenção de linhagens endogâmicas, pode-se ter até quatro alelos segregando em um único loco e isso pode variar entre locos. Por isso, a análise de ligação se torna mais complexa neste tipo de cruzamento. É importante ressaltar que, nesse caso, um ou ambos os genitores podem ser heterozigóticos. Além disso, os pares de marcadores fornecem informações diferentes para a estimação da freqüência de recombinação e das fases de ligação nos dois genitores e, usualmente, esses têm sido estimados simultâneamente.

Um método para a estimação da freqüência de recombinação e das fases de ligação são apresentados por Maliepaard et al. (1997) que dão uma completa classificação de todos os possíveis marcadores genotipados ou fenotipados em termos dos números e tipos de marcadores alélicos, além de todas as possíveis configurações entre dois pares de marcadores alélicos. Considerando uma família de irmãos germanos de dois genitores de espécies de polinização aberta, são assumidos quatro alelos, simbolizados por $a, b, c$ e $d$ codominantes uns aos outros e dominantes sobre um quinto alelo chamado de alelo nulo, o, o que caracteriza a classificação de todos os possíveis marcadores. É também apresentada a função LOD score a fim de testar se dois marcadores estão ligados sob a hipótese nula de não ligação. Tal função é expressa como o logaritmo de base 10 da razão de verossimilhança sobre a fração de recombinação estimada aplicada na função de verossimilhança. Dessa maneira, um LOD score significativo implica em ligação entre dois marcadores analisados.

Maliepaard et al. (1997) fazem um estudo de propriedades estatísticas sobre os estimadores da freqüência de recombinação analíticamente e por simulação. Eles estudam o viés graficamente apenas para casos em que o teste (o LOD score) deu significativo. Para isso, foram obtidas as médias das estimativas das freqüências de recombinação com aqueles que apresentavam um LOD significativo $(>3,0)$ sobre 1.000 simulações para cada valor da verdadeira freqüência de recombinação para uma 
população de 50 indivíduos. A variância dos estimadores de máxima verossimilhança também são mostradas graficamente. Tal variância é aproximadamente igual ao inverso da informação de Fisher.

A variância também foi investigada por simulação, assumindo que a combinação da fase de ligação era conhecida. Nesse estudo, Maliepaard et al. (1997) concluem que a discrepância entre o cálculo da variância como uma aproximação da informação de Fisher e por simulação não é bem entendida. Além disso, foram obtidos os intervalos de confiança para uma das configurações estudadas e a função de informação relativa de todas as possíveis configurações em relação a configuração que tem como marcador o mais informativo.

Mais recentemente, Wu et al. (2002) apresentam técnicas mais elaboradas para estimar a freqüência de recombinação e a fase de ligação simultâneamente através de um algoritmo baseado na função de verossimilhança. Também apresentam todos os possíveis cruzamentos organizados em uma tabela através dos cinco alelos considerados por Maliepaard et al.(1997). Dependendo de como os cinco alelos são combinados nos dois genitores usados para o cruzamento, existe um total de 18 tipos de cruzamentos em um loco (marcador), como mostra a Tabela 1.

Tabela 1. Marcadores, banda paterna observada e banda da progênie observada

\begin{tabular}{|c|c|c|c|c|c|c|c|}
\hline Grupos & Marcadores & $\mathrm{N}^{\mathrm{O}}$ de ordem & Cruzamentos & Bandas observadas & Simetria & Progênie & Segregação \\
\hline \multirow[t]{4}{*}{ A } & & 1 & $\mathrm{ab} \times \mathrm{cd}$ & $\mathrm{ab} \times \mathrm{cd}$ & Assimétrico & $\mathrm{ac}, \mathrm{ad}, \mathrm{bc}, \mathrm{bd}$ & $1: 1: 1: 1$ \\
\hline & & 2 & $\mathrm{ab} \times \mathrm{ac}$ & $\mathrm{ab} \times \mathrm{ac}$ & Assimétrico & $\mathrm{a}, \mathrm{ac}, \mathrm{ba}, \mathrm{bc}$ & $1: 1: 1: 1$ \\
\hline & & 3 & $\mathrm{ab} \times \mathrm{co}$ & $\mathrm{ab} \times \mathrm{c}$ & Assimétrico & $\mathrm{ac}, \mathrm{a}, \mathrm{bc}, \mathrm{b}$ & $1: 1: 1: 1$ \\
\hline & & 4 & ao $\mathrm{x}$ bo & $\mathrm{a} \times \mathrm{b}$ & Assimétrico & $\mathrm{ab}, \mathrm{a}, \mathrm{b}, \mathrm{o}$ & $1: 1: 1: 1$ \\
\hline \multirow[t]{3}{*}{ B } & $B_{1}$ & 5 & $\mathrm{ab} \times$ ao & $\mathrm{ab} \times \mathrm{a}$ & Assimétrico & $\mathrm{ab}, 2 \mathrm{a}, \mathrm{b}$ & $1: 2: 1$ \\
\hline & $B_{2}$ & 6 & ao $\mathrm{x} \mathrm{ab}$ & $\mathrm{a} \times \mathrm{ab}$ & Assimétrico & $\mathrm{ab}, 2 \mathrm{a}, \mathrm{b}$ & $1: 2: 1$ \\
\hline & $B_{3}$ & 7 & $\mathrm{ab} \times \mathrm{ab}$ & $a b \times a b$ & Simétrico & $\mathrm{a}, 2 \mathrm{ab}, \mathrm{b}$ & $1: 2: 1$ \\
\hline $\mathrm{C}$ & & 8 & ao $\mathrm{x}$ ao & $\mathrm{a} \times \mathrm{a}$ & Simétrico & $3 \mathrm{a}, \mathrm{o}$ & $3: 1$ \\
\hline \multirow[t]{10}{*}{$\mathrm{D}$} & $D_{1}$ & 9 & $\mathrm{ab} \times \mathrm{cc}$ & $\mathrm{ab} \times \mathrm{c}$ & Assimétrico & $\mathrm{ac}, \mathrm{bc}$ & $1: 1$ \\
\hline & & 10 & $\mathrm{ab} \times \mathrm{aa}$ & $\mathrm{ab} \times \mathrm{a}$ & Assimétrico & $\mathrm{a}, \mathrm{ab}$ & $1: 1$ \\
\hline & & 11 & $\mathrm{ab} \times$ oo & $\mathrm{ab} \times \mathrm{o}$ & Assimétrico & $\mathrm{a}, \mathrm{b}$ & $1: 1$ \\
\hline & & 12 & bo $\mathrm{x}$ aa & $\mathrm{b} \times \mathrm{a}$ & Assimétrico & $a b, a$ & $1: 1$ \\
\hline & & 13 & ao $\mathrm{x}$ oo & $\mathrm{a} \times 0$ & Assimétrico & $\mathrm{a}, \mathrm{o}$ & $1: 1$ \\
\hline & $D_{2}$ & 14 & $\mathrm{cc} \times \mathrm{ab}$ & $\mathrm{c} \mathrm{x} \mathrm{ab}$ & Assimétrico & $\mathrm{ac}, \mathrm{bc}$ & $1: 1$ \\
\hline & & 15 & aa $\times a b$ & $\mathrm{a} \times \mathrm{ab}$ & Assimétrico & $\mathrm{a}, \mathrm{ab}$ & $1: 1$ \\
\hline & & 16 & oo $\mathrm{x} \mathrm{ab}$ & $\mathrm{ox} a \mathrm{ab}$ & Assimétrico & $\mathrm{a}, \mathrm{b}$ & $1: 1$ \\
\hline & & 17 & aa $\mathrm{x}$ bo & $\mathrm{a} \times \mathrm{b}$ & Assimétrico & $\mathrm{ab}, \mathrm{a}$ & $1: 1$ \\
\hline & & 18 & oo $\mathrm{x}$ ao & $\mathrm{o} \times \mathrm{a}$ & Assimétrico & $\mathrm{a}, \mathrm{o}$ & $1: 1$ \\
\hline
\end{tabular}


Na Tabela 1, no grupo A os locos são heterozigóticos em ambos os genitores e segregam na razão 1:1:1:1. No grupo $\mathrm{B}$, formado pelos marcadores $\mathrm{B}_{1}$, $\mathrm{B}_{2}$ e $\mathrm{B}_{3}$, os locos também são heterozigóticos em ambos os genitores mas, neste caso, a segregação é 1:2:1. Já no grupo C a segregação é 3:1 com locos heterozigóticos em ambos os genitores. O grupo $\mathrm{D}$, formado pelos marcadores $\mathrm{D}_{1}$ e $\mathrm{D}_{2}$, os locos apresentados são de um cruzamento-teste entre os genitores e segregam na razão 1:1.

O cruzamento dado através da combinação dos marcadores $D_{1}$ e $D_{2}$ não fornece nenhuma informação para distinguir os recombinantes dos não recombinantes na progênie, portanto, a análise de ligação não pode ser realizada entre esses dois grupos. No entanto, a ligação entre eles pode ser indiretamente estabelecida através dos marcadores dos outros grupos (Wu et al., 2002).

Baseado em ambos os genitores e na progênie, esses tipos de cruzamentos podem ser classificados em 7 grupos, em que cada um deles será um marcador. Através da combinação dois a dois destes marcadores moleculares, teoricamente, resultando num total de 28 combinações (cruzamentos), pode-se realizar a análise de ligação entre marcadores arbitrários.

A fase de ligação entre quaisquer dois marcadores pode ser determinada se é conhecido quais dos alelos alternativos de um par de cromossomos homólogos carrega para cada marcador em um genitor. Portanto, a questão de determinar a fase de ligação torna-se uma questão de rotular os cromossomos dos genitores usando os alelos em dados marcadores. A associação dos marcadores alélicos e dos cromossomos homólogos pode ser obtida através dos cálculos da probabilidades dos pares de cromossomos dos genitores (PCGs) de um marcador condicional no estado em marcadores ligados em uma família de irmãos germanos.

Wu et al. (2002) apresentam a probabilidade condicional dos PCG genotipado do marcador $2\left(M^{2}\right)$ na progênie dados os PCG's genotipado do marcador $1\left(M^{1}\right)$ como sendo a probabilidade de transição dos eventos recombinantes entre os dois marcadores. Para cada arranjo possível, é apresentado uma matriz que têm como elementos tais probabilidades de transição. Também, é apresentado 
matrizes que têm como elementos o número de eventos recombinantes ocorrido entre dois marcadores em relação a um particular arranjo. A partir desses dois tipos de matrizes e das matrizes de incidência, matrizes que relacionam os genótipos dos PCG's com os fenótipos, Wu et al. (2002) constroem o algoritmo baseado na função de verossimilhança para estimar a freqüência de recombinação e a fase de ligação para uma mistura de diferentes tipos de marcadores, contendo marcadores completamente informativos (segregação $1: 1: 1: 1$ ) e marcadores parcialmente informativos (segregações $1: 2: 1,3: 1$ e $1: 1$ ) em uma família de irmão germanos. A fim de obterem as estimativas de máxima verossimilhanaça, Wu et al. (2002) fazem uso do processo iterativo EM (Esperança e Maximização), em termos das matrizes construídas. 


\section{MATERIAL E MÉTODOS}

\section{$3.1 \quad$ Material}

De acordo com a Tabela 1 (ver seção 2.14), há sete essenciais tipos de segregações disntintas: A, B1, B2, B3, C, D1 e D2. Estes sete tipos de segregações conduzem a um total de 17 diferentes combinações duas a duas entre os locos que resultam nas diferentes configurações: $D 1-D 1 B 3-D 1, A-D 1, C-D 1, B 1-D 1$, $B 2-D 1, B 3-B 3, B 3-C, C-C, B 1-C, B 1-B 1, A-B 3, B 1-B 3, A-A, A-C$, $A-B 1$ e $B 1-B 2$. Assim, os conjuntos de dados foram simulados para estas configurações referentes à progênie $F_{1}$ de uma família de irmãos germanos considerando os cruzamentos de espécies de polinização aberta. Para isso, foram considerados cinco alelos, sendo quatro deles codominantes uns aos outros e dominantes em relação ao quinto alelo chamado de alelo nulo, como apresentam Maliepaard et al. (1997). Os cruzamentos considerados se deram a partir de algumas das combinações de quatro desses alelos, ou seja, de algumas das possíveis combinações entre os sete grupos de marcadores considerados por Maliepaard et al. (1997).

Tais conjuntos de dados foram gerados a partir da discretização do intervalo $(0 ; 0,5)$ (espaço paramétrico) em 51 valores da freqüência de recombinação $(r)$ igualmente espaçados, isto é, para tais simulações foram considerados valores da freqüência de recombinação iguais à $0 ; 0,01 ; 0,02 ; 0,03 ; 0,04 ; 0,05 ; \ldots ; 0,45 ; 0,46 ; 0,46 ; 0,48 ; 0,49 ; 0,50$. Para cada tipo de cruzamento e, consequentemente, para cada possível arranjo e para cada $r$ discretizado foram simulados conjuntos de dados com tamanhos 100 (um tamanho usual na prática) e 50, considerando que possa existir uma perda de $50 \%$ dos 
dados, referentes às classes fenotípicas esperadas, as quais foram dadas a partir da associação do vetor de probabilidades esperadas de cada elemento da classe fenotípica com o vetor da classe fenotípica, correspondente à um determinado tipo de configuração. Dessa maneira, foram simulados 6.936 conjuntos de dados. Tais simulações foram feitas no pacote R.1.9.0 (Anexo A). Além disso, fazendo o uso desse mesmo pacote, a partir das simulações, foram obtidas as estimativas da freqüência de recombinação através dos métodos de máxima verossimilhança e Bayesiano bem como os intervalos de confiança e de credibilidade, respectivamente (Anexo B).

Tanto para as estimativas de Máxima Verossimilhança como para as estimativas Bayesianas fez-se o uso da função de verossimilhança associada a um particular cruzamento, fixado um dos quatro possíveis arranjos. As funções de verossimilhança foram obtidas através do pacote Maple 6 (Anexo $\mathrm{C}$ ).

\subsection{Métodos}

Como sugerido por Wu et al. (2002), considera-se um grupo de $m$ marcadores ligados, $M^{1}, M^{2}, \ldots, M^{m}$, com uma ordem conhecida. Para o primeiro marcador $M^{1}$ (considerado no topo vertical do arranjo), os cromossomos dos genitores podem ser, arbitrariamente, rotulados usando seus alelos. Assume-se que os cromossomos dos genitores para o primeiro marcador são rotulados como $P_{1} \| P_{2}$ e $Q_{1} \| Q_{2}$, em que $\|$ entende-se como sendo dois cromossomos homólogos um estando a esquerda e o outro a direita, respectivamente. A fase de ligação entre os alelos do primeiro marcador e do segundo marcador pode ser determinada atribuindo alelos alternativos do segundo marcador em diferentes cromossomos do par de cromossomos homólogos, fixado nos cromossomos homólogos os alelos referentes ao primeiro marcador. Dessa maneira, existe um total de quatro possíveis arranjos $\left(A_{w}, w=\right.$ 1, 2, 3 e 4) considerando os dois genitores simultâneamente, isto é, existem quatro possíveis fases de ligação considerando ambos os genitores, como mostra a Figura 4. 


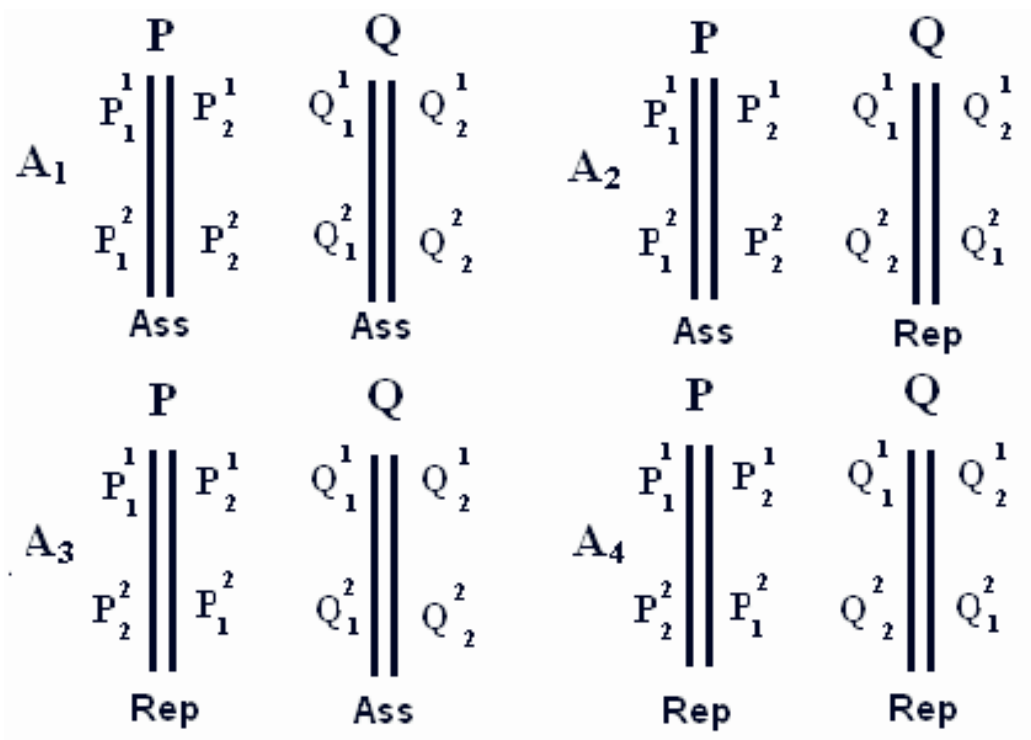

Figura 4 - Pares de Cromossmos Parentais

A probabilidade condicional dos genótipos do par de cromossomos dos genitores (PCG) de $M^{2}$ na progênie dado o genótipo do PCG de $M^{1}$ é a probabilidade de transição dos eventos recombinantes $\left(h_{w}^{12}\right)$ entre os dois marcadores no PCG genotipado. A probabilidade de transição entre os dois marcadores $\left(M^{1}\right.$ e $\left.M^{2}\right)$ sobre $w$-ésimo arranjo $A_{w}$ pode ser expressa na forma matricial. Sendo $r^{12}$ a freqüência de recombinação entre os marcadores 1 e 2, para os arranjos $A_{1}$ (marcadores ligados em associação nos dois genitores), $A_{2}$ (marcadores ligados em associação no primeiro genitor e em repulsão no segundo genitor), $A_{3}$ (marcadores ligados em repulsão no primeiro genitor e em associação no segundo genitor) e $A_{4}$ (marcadores ligados em repulsão nos dois genitores) estas matrizes de probabilidade de transição são, respectivamente:

$$
H_{1}^{12}=\left[\begin{array}{cccc}
\left(1-r^{12}\right)^{2} & r^{12}\left(1-r^{12}\right) & r^{12}\left(1-r^{12}\right) & \left(r^{12}\right)^{2} \\
r^{12}\left(1-r^{12}\right) & \left(1-r^{12}\right)^{2} & \left(r^{12}\right)^{2} & r^{12}\left(1-r^{12}\right) \\
r^{12}\left(1-r^{12}\right) & \left(r^{12}\right)^{2} & \left(1-r^{12}\right)^{2} & r^{12}\left(1-r^{12}\right) \\
\left(r^{12}\right)^{2} & r^{12}\left(1-r^{12}\right) & r^{12}\left(1-r^{12}\right) & \left(1-r^{12}\right)^{2}
\end{array}\right] ;
$$




$$
\begin{aligned}
& H_{2}^{12}=\left[\begin{array}{cccc}
r^{12}\left(1-r^{12}\right) & \left(1-r^{12}\right)^{2} & \left(r^{12}\right)^{2} & r^{12}\left(1-r^{12}\right) \\
\left(1-r^{12}\right)^{2} & r^{12}\left(1-r^{12}\right) & r^{12}\left(1-r^{12}\right) & \left(r^{1} 2\right)^{2} \\
\left(r^{12}\right)^{2} & r^{12}\left(1-r^{12}\right) & r^{12}\left(1-r^{12}\right) & \left(1-r^{12}\right)^{2} \\
r^{12}\left(1-r^{12}\right) & \left(r^{12}\right)^{2} & \left(1-r^{12}\right)^{2} & r^{12}\left(1-r^{12}\right)
\end{array}\right] \text {; } \\
& H_{3}^{12}=\left[\begin{array}{cccc}
r^{12}\left(1-r^{12}\right) & \left(r^{12}\right)^{2} & \left(1-r^{12}\right)^{2} & r^{12}\left(1-r^{12}\right) \\
\left(r^{1} 2\right)^{2} & r^{12}\left(1-r^{12}\right) & r^{12}\left(1-r^{12}\right) & \left(1-r^{12}\right)^{2} \\
\left(1-r^{12}\right)^{2} & r^{12}\left(1-r^{12}\right) & r^{12}\left(1-r^{12}\right) & \left(r^{12}\right)^{2} \\
\left(1-r^{12}\right)^{2} & r^{12}\left(1-r^{12}\right) & \left(r^{12}\right)^{2} & r^{12}\left(1-r^{12}\right)
\end{array}\right] \text {; } \\
& H_{4}^{12}=\left[\begin{array}{cccc}
\left(r^{12}\right)^{2} & r^{12}\left(1-r^{12}\right) & r^{12}\left(1-r^{12}\right) & \left(1-r^{12}\right)^{2} \\
r^{12}\left(1-r^{12}\right) & \left(r^{1} 2\right)^{2} & \left(1-r^{12}\right)^{2} & r^{12}\left(1-r^{12}\right) \\
r^{12}\left(1-r^{12}\right) & \left(1-r^{12}\right)^{2} & \left(r^{12}\right)^{2} & r^{12}\left(1-r^{12}\right) \\
\left(1-r^{12}\right)^{2} & r^{12}\left(1-r^{12}\right) & r^{12}\left(1-r^{12}\right) & \left(r^{12}\right)^{2}
\end{array}\right] \text {. }
\end{aligned}
$$

Cada linha destas matrizes representa um dos alelos do primeiro genitor e um dos alelos do segundo genitor, referentes ao primeiro marcador que está fixado. Já as colunas representam os alelos também dos dois genitores, mas referentes ao segundo marcador. Dessa maneira, fixado um certo tipo de arranjo e o marcador $M^{1}$, calcula-se qual a probabilidade de eventos recombinates que são os elementos da matriz.

O número de eventos recombinantes $\left(d_{w}^{12}\right)$ entre os dois marcadores $\left(M^{1}\right.$ e $\left.M^{2}\right)$ sobre $w$-ésimo arranjo $A_{w}$ pode também ser expresso na forma matricial associando cada um desses aos elementos da matriz de probabilidade de transição.

$$
\mathrm{D}_{1}^{12}=\left[\begin{array}{llll}
0 & 1 & 1 & 2 \\
1 & 0 & 2 & 1 \\
1 & 2 & 0 & 1 \\
2 & 1 & 1 & 0
\end{array}\right], \text { para o } A_{1}
$$




$$
\begin{aligned}
\mathrm{D}_{2}^{12}= & {\left[\begin{array}{llll}
1 & 0 & 2 & 1 \\
0 & 1 & 1 & 2 \\
2 & 1 & 1 & 0 \\
1 & 2 & 0 & 1
\end{array}\right], \text { para o } A_{2} ; } \\
\mathrm{D}_{3}^{12}= & {\left[\begin{array}{llll}
1 & 2 & 0 & 1 \\
2 & 1 & 1 & 0 \\
0 & 1 & 1 & 2 \\
1 & 0 & 2 & 1
\end{array}\right], \text { para o } A_{3} ; } \\
\mathrm{D}_{4}^{12}= & {\left[\begin{array}{llll}
2 & 1 & 1 & 0 \\
1 & 2 & 0 & 1 \\
1 & 0 & 2 & 1 \\
0 & 1 & 1 & 2
\end{array}\right], \text { para o } A_{4} . }
\end{aligned}
$$

Considera-se $A_{w}^{2}$ como sendo o $w$-ésimo arranjo dos alelos do segundo marcador $M^{2}$ dado o cromossomo fixado do primeiro marcador $M^{1}$ e $\boldsymbol{M}=$ $\left(M^{1}, M^{2}\right)^{T}$ os dados para os dois marcadores. Assumindo que os dados dos marcadores são independentes sobre as $N$ progênies, tem-se a função de verossimilhança de $\boldsymbol{M}$ dado $A_{w}^{2}$ :

$$
P\left(\boldsymbol{M} \mid A_{w}^{2}\right)=\prod_{j=1}^{n} \boldsymbol{m}_{i_{1} j}^{T} \boldsymbol{I}_{p_{1}}^{T} \boldsymbol{H}_{w}^{12} \boldsymbol{I}_{p_{2}} \boldsymbol{m}_{i_{2} j}=\prod_{j=1}^{n} \boldsymbol{m}_{i_{1} j}^{T} \boldsymbol{P}_{\boldsymbol{w}}^{\mathbf{1 2}} \boldsymbol{m}_{i_{2} j}
$$

em que $\boldsymbol{m}_{i_{k} j}$ é um vetor de dimensão $p_{k}$ (número de fenótipos na progênie do marcador $\left.M^{k}\right)$ da variável indicadora $P\left(M_{k j} \mid(P Q)_{i_{k}}\right)$ para o marcador $M^{k} ; \boldsymbol{I}_{p k}$ é uma matriz de incidência de dimensão $4 \times p_{k}$ que relata os genótipos dos PCGs para os fenótipos, os quais podem ser identificados para cada um dos quatro arranjos alélicos como: 


$$
\boldsymbol{I}_{p_{A}}=\left[\begin{array}{llll}
1 & 0 & 0 & 0 \\
0 & 1 & 0 & 0 \\
0 & 0 & 1 & 0 \\
0 & 0 & 0 & 1
\end{array}\right]
$$

para cruzamento com marcador do tipo $A$,

$$
\boldsymbol{I}_{p_{B_{1}}}^{T}=\left[\begin{array}{llll}
1 & 1 & 0 & 0 \\
0 & 0 & 1 & 0 \\
0 & 0 & 0 & 1
\end{array}\right]
$$

para cruzamento com marcador do tipo $B_{1}$,

$$
\boldsymbol{I}_{p_{B_{2}}}^{T}=\left[\begin{array}{llll}
1 & 0 & 1 & 0 \\
0 & 1 & 0 & 0 \\
0 & 0 & 0 & 1
\end{array}\right]
$$

para cruzamento com marcador do tipo $B_{2}$,

$$
\boldsymbol{I}_{p_{B_{3}}}^{T}=\left[\begin{array}{cccc}
1 & 0 & 0 & 0 \\
0 & 1 & 1 & 0 \\
0 & 0 & 0 & 1
\end{array}\right]
$$

para cruzamento com marcador do tipo $B_{3}$,

$$
\boldsymbol{I}_{p_{C}}^{T}=\left[\begin{array}{llll}
1 & 1 & 1 & 0 \\
0 & 0 & 0 & 1
\end{array}\right]
$$

para cruzamento com marcador do tipo $C$,

$$
\boldsymbol{I}_{p_{D_{1}}}^{T}=\left[\begin{array}{llll}
1 & 1 & 0 & 0 \\
0 & 0 & 1 & 1
\end{array}\right]
$$

para cruzamento com marcador do tipo $D_{1}$, e

$$
\boldsymbol{I}_{p_{D_{2}}}^{T}=\left[\begin{array}{cccc}
1 & 0 & 1 & 0 \\
0 & 1 & 0 & 1
\end{array}\right]
$$


para cruzamento com marcador do tipo $D_{2}$.

Considerando dois particulares marcadores, as estimativas de máxima verossimilhança são obtidas a partir do algoritmo EM, visto que não é possível determinar um estimador de forma analítica. Implementado no pacote R (Anexo B), tal algoritmo foi construído através dos passos E e M.

PassoE : No passo atual $\tau$, usando a matriz $\boldsymbol{H}_{w}^{12\{\tau\}}$ baseada na atual estimativa $r_{w}^{12\{\tau\}}$, calcula-se o valor esperado de eventos recombinantes entre dois marcadores $M^{1}$ e $M^{2}$ através da eq. (8) para a progênie $j$ sobre o arranjo $A_{w}^{2}$

$$
c_{i_{1} i_{2} j}^{w\{\tau+1\}}=\frac{\boldsymbol{m}_{i_{1} j}^{T}\left[\boldsymbol{I}_{p_{1}}^{T}\left(\boldsymbol{D}_{w}^{12} \circ \boldsymbol{H}_{w}^{12\{\tau\}}\right) \boldsymbol{I}_{p_{2}}\right] \boldsymbol{m}_{i_{2} j}}{\boldsymbol{m}_{i_{1} j}^{T} \boldsymbol{P}_{w}^{12\{\tau\}} \boldsymbol{m}_{i_{2} j}}
$$

em que $\boldsymbol{D}_{w}^{12}$ é uma matriz $4 \times 4$ e o denota o produto elemento a elemento de duas matrizes de mesma dimensão.

Passo $M$ : Calcula-se $r_{w}^{12\{\tau+1\}}$ sobre o arranjo $A_{w}^{2}$ usando a eq. (9).

$$
r_{w}^{12\{\tau+1\}}=\frac{1}{2 N} \sum_{j=1}^{N} \sum_{i_{1}=1}^{p_{1}} \sum_{i_{2}=1}^{p_{2}} c_{i_{1} i_{2} j}^{w\{\tau+1\}} .
$$

Este processo iterativo é repetido entre as equações até que $r_{w}^{12}$ convirja para um valor estável. Esse valor estável representará a estimativa de Máxima Verossimilhança da freqüência de recombinação entre os marcadores $M^{1}$ e $M^{2}$ para o arranjo $A_{w}^{2}$.

No caso Bayesiano, as estimativas da freqüência de recombinação foram obtidas através da esperança da distribuição a posteriori, como mostra a eq.10.

$$
\widehat{r}=E[r \mid \boldsymbol{M}]=\int_{0}^{0,5} r \pi(r \mid \boldsymbol{M}) d r
$$

em que $\pi(r \mid \boldsymbol{M})$ é a distribuição a posteriori da freqüência de recombinação. Tal distribuição é dada como se segue:

$$
\pi(r \mid \boldsymbol{M})=\frac{\pi(r) L(r \mid \boldsymbol{M})}{\int_{0}^{0,5} \pi(r) L(r \mid \boldsymbol{M}) d r}
$$


em que $\pi(r)$ é a distribuição a priori e $L(r \mid \boldsymbol{M})$ a função de verossimilhança. Combinada com a verossimilhança, a distribuição a priori foi obtida a partir das suposições e informações baseadas no trabalho de Maliepaard et al. (1997). Supondo que existem mapas já feitos por outros autores na literatura, em que os marcadores $A, B$ e $D$ estão ligados, bem como, $B, C$ e $D$, em que se deseja estimar a freqüência de recombinação entre $A$ e $C$. Supondo, ainda, que o marcador $B$ se encontra entre os marcadores $A$ e $D$ e o marcador $C$ se encontra entre $B$ e $D$. Com base nesses dados da literatura, a informação incorporada na priori é de que $A$ e $C$ estão ligados, usando a propriedade da transitividade. Dessa maneira, a probabilidade se torna bem pequena para valores de $r$ próximos de 0,5 . Tal probabilidade é assumida, também, para valores de $r$ no intervalo $(0,0,05)$. Tal intervalo não apresenta alta probabilidade pois, com base no trabalho de Maliepaard et al. (1997), nota-se que as estimativas da freqüência de recombinação sub estimam os verdadeiros valores de $r$ (freqüência de recombinação), principalmente, quando os marcadores considerados apresentam pouca informação. Dessa maneira, para mapas genéticos já publicados em que as distâncias entre locos são muito pequenas, acredita-se que tal distância é resultado do viés. Assim, a distribuição a priori foi construída com a intenção de diminuir esse viés. Tal distribuição considera uma maior probabilidade para valores de $r$ que se encontram no intervalo $(0,05 ; 0,45)$. A distribuição a priori aqui estudada é própria e é dada como se segue:

$$
\pi(r)=\left\{\begin{array}{ccc}
0,01 & \text { se } & 0<r<0,05 \\
2,5 & \text { se } & 0,05 \leq r \leq 0,45 \\
0,01 & \text { se } & 0,45<r<0,5
\end{array}\right.
$$

O gráfico correspondente a esta distribuição é dado pela Figura 5. 


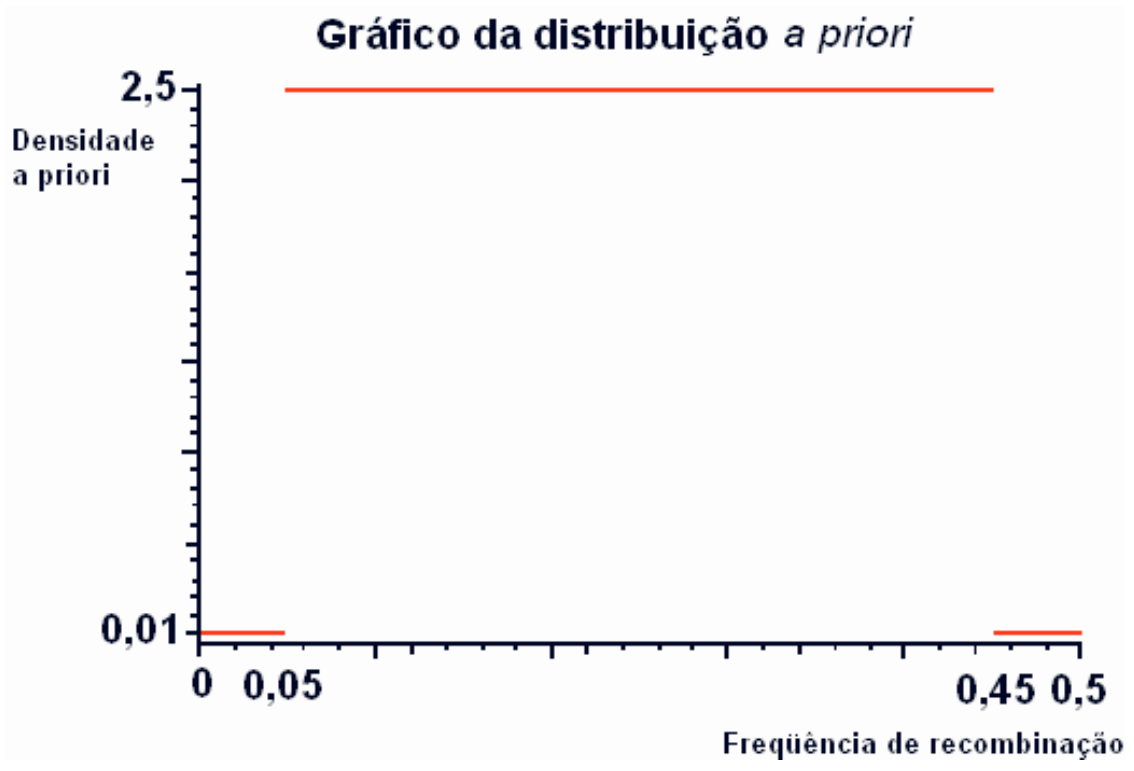

Figura 5 - Gráfico da priori

Deve ser ressaltado que, além da priori dada pela eq. (5), outras prioris podem ser construídas a partir de informações presentes nos dados da literatura.

Os testes LRT e fator de Bayes (Anexo B) foram usados para avaliar se as marcas estudadas em relação aos dados que foram simulados estavam ligadas ou não. Tais testes foram realizados com base nas estimativas das freqüências de recombinação obtidas pelo método de máxima verossimilhança e pelo método Bayesiano, respectivamente.

O teste LRT é menos duas vezes o logaritmo da razão entre a função de verossimilhança para $r=0,5$ e a função de verossimilhança para $\widehat{r}$, sendo este último a estimativa de máxima verossimilhança encontrada.

$$
L R T=-2 \ln \left(\frac{L(r)}{L(\widehat{r})}\right)
$$

Através deste teste, foram obtidos quais dos valores das estimativas de máxima verossimilhança são significativos. Para as estimativas Bayesianas, os valores significativos das estimativas obtidas foram identificados utilizando o fator de Bayes, $\boldsymbol{B}$. 
No caso Bayesiano, para se testar a ligação entre dois locos, as hipóteses nula e alternativa foram definidas, respectivamente:

$$
\begin{aligned}
& H_{0}: r \in[0,45 ; 0,5] \\
& H_{1}: r \in[0 ; 0,45]
\end{aligned}
$$

em que a hipótese nula considerada implica em não ligação. Assim, calcula-se o fator de Bayes. Se $\boldsymbol{B}<1$, rejeita-se $H_{0}$ e aceita-se a hipótese de que os locos estão ligados.

A fim de avaliar as estimativas de Máxima Verossimilhança e Bayesiana, foram obtidas as somas de quadrado dos resíduos e os intervalos de confiança clássico e Bayesiano (intervalo de credibilidade). A soma de quadrado do resíduo se deu através do cálculo da eq. (12).

$$
\text { SQRes }=\sum_{i=1}^{51}\left(\widehat{r}_{i}-r_{i}\right)^{2}
$$

em que $\widehat{r_{i}}$ é a estimativa da freqüência de recombinação do conjunto de dados simulado a partir do valor $r_{i}$.

Como já citado, determinar a fase de ligação se torna uma questão de rotular os cromossomos dos genitores com os alelos dos dados marcadores. A partir das estimativas das freqüências de recombinação encontradas para cada uma das fases de ligação, considerando os métodos clássico e Bayesiano, a fase de ligação entre dois marcadores considerados foi estimada.

A estimativa da fase de ligação considerando um dado cruzamento se deu através dos cálculos das probabilidades a posteriori, eq. (13), para os quatro arranjos.

$$
P\left(A_{w}^{2} \mid \boldsymbol{M}\right)=\frac{P\left(A_{w}^{2}\right) P\left(\boldsymbol{M} \mid A_{w}^{2}\right)}{\sum_{w=1}^{4} P\left(A_{w}^{2}\right) P\left(\boldsymbol{M} \mid A_{w}^{2}\right)}=\frac{P\left(\boldsymbol{M} \mid A_{w}^{2}\right)}{\sum_{w=1}^{4} P\left(\boldsymbol{M} \mid A_{w}^{2}\right)}
$$

em que $P\left(\boldsymbol{M} \mid A_{w}^{2}\right)$ é definida da eq. (7) e $P\left(A_{w}^{2}\right)$ é a distribuição a priori uniforme, já que se considera todas as fases equiprováveis.

$$
P\left(A_{w}^{2}\right)=\frac{1}{4}
$$


A maior probabilidade a posteriori corresponde a fase mais provável, isto é, a estimativa da fase de ligação é o arranjo que apresenta a maior probabilidade a posteriori e foram obtidas no pacote R 1.9.0 (Anexo D). 


\section{RESULTADOS E DisCUSSÃO}

Como já citado, os 7 tipos de segregação (D1, B3, A, C, B1, B2 e D2) conduzem a um total de 17 diferentes tipos de combinações entre os locos: D1-D1, B3-D1, A-D1, C-D1, B1-D1, B1-D2, B3-B3, B3-C, C-C, B1-C, B1-B1, A-B3, B1-B3, A-A, A-C, A-B1 e B1-B2. Maliepaard et al. (1997) apresentam os números das configurações de todos os pares de combinações destes 7 tipos de segregação, como mostra a Tabela 2 .

Tabela 2. Números das configurações dadas a partir das combinações duas a duas dos marcadores

\begin{tabular}{|c|c|c|c|c|c|c|c|}
\hline & $a b \times a a(\mathrm{D} 1)$ & $a a \times a b(\mathrm{D} 2)$ & $a b \times a b(\mathrm{~B} 3)$ & $a b \times c d(\mathrm{~A})$ & $a o \times a o(\mathrm{C})$ & $a b \times a o(\mathrm{~B} 1)$ & $a o \times a b(\mathrm{~B} 2)$ \\
\hline$a b \times a a(\mathrm{D} 1)$ & 1 & - & 2 & 3 & 4 & 5 & 6 \\
\hline$a a \times a b(\mathrm{D} 2)$ & & (1) & $(2)$ & (3) & (4) & (6) & (5) \\
\hline$a b \times a b(\mathrm{~B} 3)$ & & & 7 & 8 & 9 & 10 & (10) \\
\hline$a b \times c d(\mathrm{~A})$ & & & & 11 & 12 & 13 & (13) \\
\hline$a o \times a o(\mathrm{C})$ & & & & & 14 & 15 & (15) \\
\hline$a b \times a o(\mathrm{~B} 1)$ & & & & & & 16 & 17 \\
\hline$a o \times a b(\mathrm{~B} 2)$ & & & & & & & (16) \\
\hline
\end{tabular}

Na Tabela 2, as combinações que não apresentam número são equivalentes às combinações enumeradas com os locos trocados. Quando o número é dado entre parênteses, a configuração é equivalente à combinação que apresenta o mesmo número. A combinação D1-D2 representada na tabela por - não é considerada já que não há informação na recombinação avaliada.

Como já citado, o marcador A é conhecido como totalmente informativo, já que segrega na razão 1:1:1:1. Os demais marcadores são conhecidos como parcialmente informativos, já que segregam nas razões 1:2:1 (B1, B2 e B3), 3:1 (C) e 1:1 (D1 e D2). Considerando apenas um único loco, a segregação 1:2:1 significa 
que de quatro genótipos dois deles apresentam o mesmo fenótipo. Na segregação 3:1, dos quatro possíveis genótipos, três deles têm o mesmo fenótipo sendo, então, identificados apenas dois diferentes fenótipos.

Se 4 diferentes fenótipos são identificados na progênie, os haplóides que formam estes fenótipos podem ser reconstruídos completamente, isto é, pode-se identificar com qual haplóide cada genitor contribuiu na formação de cada indivíduo da progênie. O tipo de segregação com 3 alelos não nulos e heterozigótico em ambos os genitores $(a b \times a c)$, ou dois alelos nulos e heterozigóticos em ambos os genitores $(a o \times b o)$ também permitem uma repleta reconstrução. Portanto, estes tipos de segregação são equivalentes à segregação com 4 distintos alelos e, assim, são totalmente informativos.

Para loco heterozigótico em somente um genitor (marcador D1: $a b \times$ $c c, a b \times a a, a b \times o o, b o \times a a, a o \times o o ;$ marcador D2: recíproco de D1) a reconstrução pode ser feita para apenas um dos genitores, já que o outro genitor é homozigótico. A segregação $a o \times o o$ não segrega fenotípicamente e, portanto, não é considerada.

Locos com dois alelos e heterozigóticos em ambos os genitores (marcador B3: $a b \times a b$ ) o alelo $a$ do fenótipo $a b$ pode ter sido derivado de um ou do outro genitor e o alelo $b$ do genitor alternativo. Para o fenótipo $a$ do tipo de segregação $a o \times a o$ (marcador $\mathrm{C})$, o genótipo pode ser aa ou ao. Além disso, como no caso do marcador B3, para este último tipo de genótipo $(a o)$, não se sabe de quais dos genitores foi derivado o alelo $a$.

Finalmente, a situação com 3 alelos, entre os quais um deles é um alelo nulo e heterozigótico em ambos os genitores (marcador B1: $a b \times a o$; marcador B2: $a o \times a b)$. Tal situação permite duas possíveis reconstruções para o fenótipo a na progênie: $a a$ ou $a o$. No entanto, para o fenótipo $a b$ a reconstrução é completa.

\subsection{Freqüência de recombinação}

Para determinar a freqüência de recombinação é preciso conhecer o número de eventos recombinantes em ambos os genitores produzidos durante a 
meiose. Se é conhecido os genótipos dos gametas, então, tais recombinantes podem ser contados facilmente. Dessa maneira, as estimativas da freqüência de recombinação são mais precisas para os casos em que os genótipos podem ser distingüidos a partir dos seus fenótipos.

A fim de construir um mapa genético, a ligação entre as marcas consideradas devem ser testadas e, dessa maneira, somente as estimativas da freqüência de recombinação com teste estatístico significativo devem ser consideradas.

Na Figura 6 são apresentadas as estimativas da freqüência de recombinação $(r)$ obtidas pelos métodos de máxima verossimilhança e Bayesiano para a configuração $\mathrm{D} 1(a b \times a a)$-D1 $(a b \times a a)$, arranjo $A 1$ (marcadores ligados em associação nos dois genitores). Nota-se que, na maioria do intervalo paramétrico, principalmente quando aumenta-se o tamanho amostral, as estimativas de $r$ obtidas pelos dois métodos estão próximas da reta identidade, a qual representa os verdadeiros valores de $r$ usados na simulação dos conjuntos de dados. Tal comportamento já era esperado pois, na combinação D1-D1 um dos genitores é heterozigótico em ambos os locos e o outro genitor é homozigótico em ambos os locos. Dessa maneira, o genitor homozigótico contribui para a progênie apenas com um único tipo de gameta $(a a)$ e, portanto, os genótipos podem ser identificados a partir dos fenótipos, para qualquer tipo de arranjo considerado. 

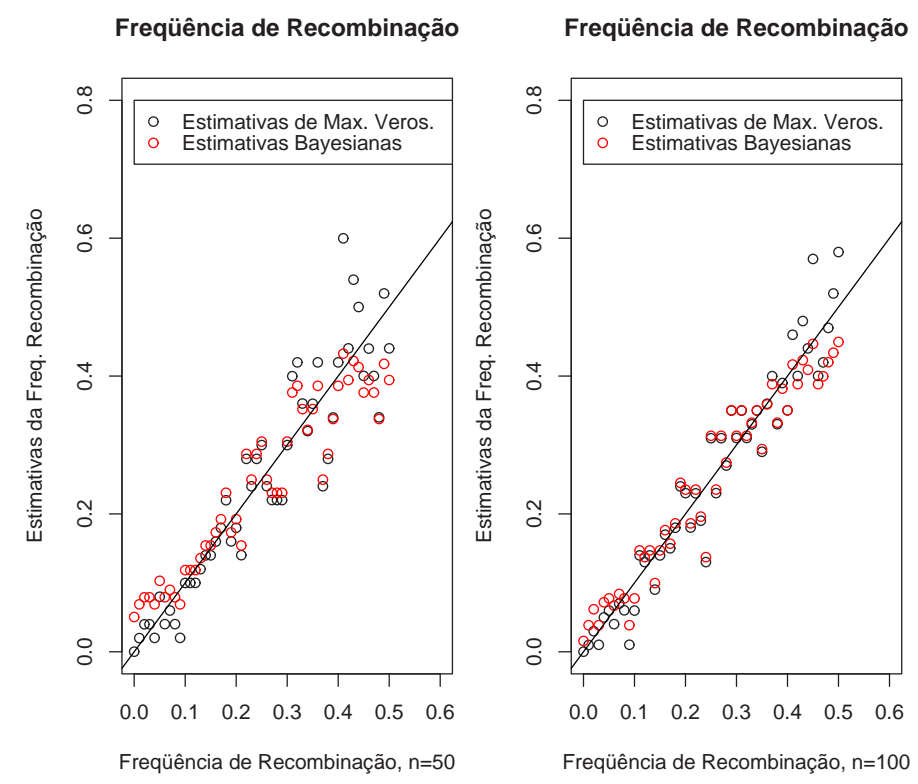

Figura 6 - Gráficos das estimativas Bayesianas e de Máxima Verossimilhança, configuração $D 1-D 1$ e arranjo A1, com tamanhos amostrais n=50 e n=100, respectivamente

Nota-se, graficamente, que as estimativas determinadas pelos dois métodos não diferem muito. Na região do espaço paramétrico próxima ao seu extremo inferior, mais precisamente na região $(0 ; 0,05)$, as estimativas Bayesianas tendem a super-estimar os verdadeiros valores freqüência de recombinação $(r)$. Já na região próxima ao extremo superior do espaço paramétrico, $(0,45 ; 0,5)$, as estimativas de $r$ obtidas pelo método de máxima verossimilhança tendem a super-estimar alguns dos verdadeiros valores de $r$ e as estimativas Bayesianas de $r$ tendem a sub-estimar os verdadeiros valores. Foi verificado que as estimativas encontradas pelos dois métodos apresentam o mesmo comportamento para os quatro tipos diferentes de arranjos.

Como mostra a Tabela 3, considerando a combinação D1-D1, com exceção dos arranjos A2 (marcadores ligados em associação no primeiro genitor e em repulsão no segundo genitor) e A3 (marcadores ligados em repulsão no primeiro genitor e em associação no segundo genitor) com tamanho amostral n=100, as somas de quadrado dos resíduos das estimativas de $r$ obtidas pelo método Bayesiano 
$\left(S Q \operatorname{Res}_{b}\right)$ são menores que as correspondentes somas de quadrado dos resíduos das estimativas de $r$ obtidas pelo método de máxima verossimilhança $\left(S Q R e s_{v}\right)$. Restringindo o espaço paramétrico em $I_{r}=(0,05 ; 0,45)$, todas as somas de quadrado dos resíduos para as estimativas Bayesianas $\left(S Q R e s_{b I_{r}}\right)$ são menores que as correspondentes somas de quadrado dos resíduos para as estimativas de máxima verossimilhança $\left(S Q R e s_{v I_{r}}\right)$. Na Tabela 3 também são apresentadas as diferenças entre $\left(S Q R e s_{v}\right)$ e $\left(S Q R e s_{b}\right)$ e as diferenças entre $\left(S Q R e s_{v I_{r}}\right)$ e $\left(S Q R e s_{b I_{r}}\right)$.

Tabela 3. Somas do quadrado dos resíduos para $D 1-D 1$

\begin{tabular}{cccccccc}
\hline $\mathrm{n}$ & Arranjos & SQRes $_{b}$ & SQRes $_{v}$ & SQRes $_{v}-$ SQRes $_{b}$ & SQRes $_{\text {bI }}$ & SQRes $_{v I_{r}}$ & SQRes $_{v I_{r}}-$ SQRes $_{b I_{r}}$ \\
\hline \multirow{2}{*}{$n=50$} & Arranjo A1 & 0,1353 & 0,1732 & 0,0379 & 0,0728 & 0,1429 & 0,0702 \\
& Arranjo A2 & 0,1347 & 0,1460 & 0,0112 & 0,0969 & 0,1273 & 0,0303 \\
& Arranjo A3 & 0,1322 & 0,1508 & 0,0185 & 0,0894 & 0,1369 & 0,0475 \\
& Arranjo A4 & 0,1202 & 0,1757 & 0,0555 & 0,0894 & 0,1462 & 0,0567 \\
\multirow{5}{*}{$n=100$} & Arranjo A1 & 0,0708 & 0,0859 & 0,0151 & 0,0475 & 0,0719 & 0,0244 \\
& Arranjo A2 & 0,1014 & 0,1013 & $-0,0131$ & 0,0797 & 0,0838 & 0,0040 \\
& Arranjo A3 & 0,0855 & 0,0679 & $-0,0176$ & 0,0582 & 0,0621 & 0,0038 \\
& Arranjo A4 & 0,0730 & 0,0844 & 0,0114 & 0,0524 & 0,0700 & 0,0145 \\
\hline
\end{tabular}

Para as combinações B3-D1, A-D1, C-D1, B1-D1 e B1-D2, um dos genitores é heterozigótico em ambos os locos, enquanto que, o outro genitor é heterozigótico em apenas um loco. No entanto, estes 5 tipos de combinações podem apresentar comportamentos distintos quanto a estimação da freqüência de recombinação. Na combinação B3 $(a b \times a b)-\mathrm{D} 1(a b \times a a)$, um dos locos apresenta apenas dois diferentes alelos e, dessa maneira, considerando qualquer um dos tipos de arranjos, nem sempre será possível reconhecer o indivíduo na progênie que é formado pelo gameta recombinante enviado pelo genitor heterozigótico em ambos os locos.

As estimativas de $r$ determinadas pelos métodos de máxima verossimilhança e Bayesiano abordando a combinação B3-D1 e arranjo A3 (marcadores ligados em repulsão no primeiro genitor e em associação no segundo genitor) são apresentadas graficamente na Figura 7.

Também, neste caso, nota-se que as estimativas Bayesianas superestimam os valores verdadeiros de $r$ na região $(0 ; 0,05)$ e sub-estimam tais valores verdadeiros na região $(0,45 ; 0,5)$. Na Tabela 4 , estão apresentadas as $S Q R e s_{b}$, 
$S Q R e s_{v}, S Q R e s_{v}-S Q R e s_{b}, S Q R e s_{b I_{r}}, S Q R e s_{v I_{r}}$ e $S Q R e s_{v I_{r}}-S Q R e s_{b I_{r}}$ para a combinação B3-D1. Considerando cada um dos possíveis arranjos e cada um dos tamanhos amostrais usados nas simulações dos conjuntos de dados, a $S Q R e s_{b}$ e $S Q R e s_{b I_{r}}$ apresentaram valores menores que $S Q R e s_{v}$ e $S Q R e s_{v I_{r}}$, respectivamente.
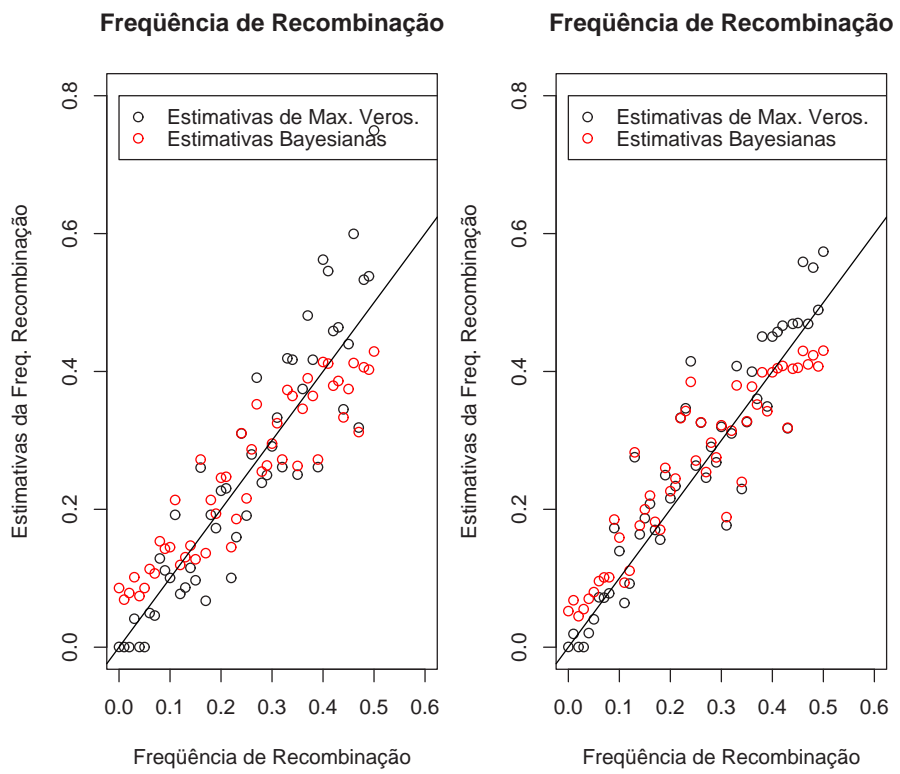

Figura 7 - Gráficos das estimativas Bayesianas e de Máxima Verossimilhança para a configuração $B 3-D 1$, considerando o arranjo $A 3$, com tamanhos amostrais $n=50$ e $n=100$, respectivamente

Tabela 4. Somas do quadrado dos resíduos para $B 3-D 1$

\begin{tabular}{cccccccc}
\hline $\mathrm{n}$ & Arranjos & SQRes $_{b}$ & SQRes $_{v}$ & SQRes $_{v}-S Q \operatorname{Res}_{b}$ & SQRes $_{b I_{r}}$ & SQRes $_{v I_{r}}$ & SQRes $_{v I_{r}}-$ SQRes $_{b I_{r}}$ \\
\hline \multirow{2}{*}{$n=50$} & Arranjo A1 & 0,22514 & 0,24637 & 0,02123 & 0,13463 & 0,20727 & 0,07164 \\
& Arranjo A2 & 0,23674 & 0,45410 & 0,21736 & 0,16736 & 0,37273 & 0,20537 \\
& Arranjo A3 & 0,18196 & 0,31496 & 0,13300 & 0,11602 & 0,20292 & 0,08690 \\
& Arranjo A4 & 0,19123 & 0,43872 & 0,24749 & 0,13316 & 0,38530 & 0,25214 \\
\multirow{5}{*}{$n=100$} & Arranjo A1 & 0,16273 & 0,19279 & 0,03006 & 0,12277 & 0,18549 & 0,06272 \\
& Arranjo A2 & 0,12790 & 0,15812 & 0,03022 & 0,08904 & 0,13350 & 0,04446 \\
& Arranjo A3 & 0,18125 & 0,19265 & 0,01140 & 0,15357 & 0,17068 & 0,01711 \\
& Arranjo A4 & 0,10825 & 0,18918 & 0,08093 & 0,08362 & 0,13281 & 0,04919 \\
\hline
\end{tabular}

Para a combinação A-D1, as estimativas de máxima verossimilhança e Bayesiana para a freqüência de recombinação se encontram graficamente na Figura 8, que considera apenas o arranjo $A 1$ (marcadores ligados em associação nos dois 
genitores). Para qualquer arranjo usado na simulação dos conjuntos de dados, as estimativas da freqüência de recombinação apresentam um bom comportamento em relação à reta identidade, a qual representa os verdadeiros valores de $r$. De fato pois, em tal combinação, um dos locos apresenta quatro diferentes alelos. Dessa maneira, é possível distinguir os genótipos a partir dos fenótipos da progênie.
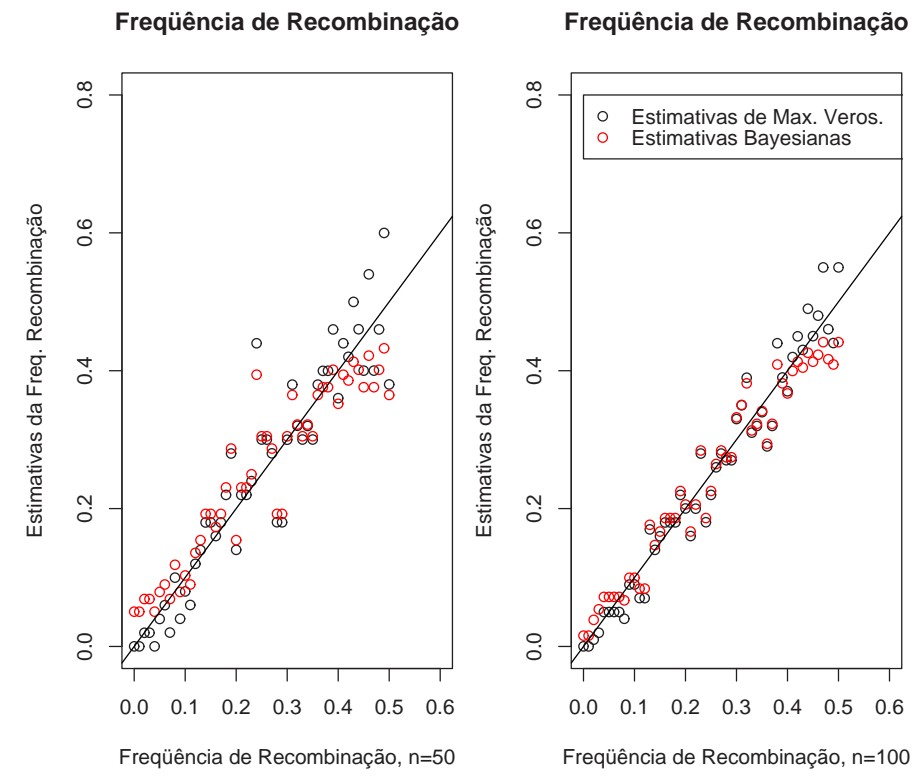

Figura 8 - Gráficos das estimativas Bayesianas e de Máxima Verossimilhança para a configuração A - D1, considerando o arranjo A1, com tamanhos amostrais com $n=50$ e $n=100$, respectivamente

Na Tabela 5, estão apresentadas as SQRes ${ }_{b}, S Q R e s_{v}, S Q R e s_{v}-$ $S Q R e s_{b}, S Q R e s_{b I_{r}}, S Q R e s_{v I_{r}}$ e $S Q R e s_{v I_{r}}-S Q R e s_{b I_{r}}$ para a combinação A-D1. Considerando cada um dos possíveis arranjos e cada um dos tamanhos amostrais usados nas simulações dos conjuntos de dados, a e $S Q R e s_{b I_{r}}$ apresentara valor menor que e $S Q R e s_{v I_{r}}$. Considerando todo o intervalo paramétrico, com exceção aos arranjos $A 2(\mathrm{n}=100)$ e $A 4(\mathrm{n}=50)$, e $S Q R e s_{b}<S Q R e s_{v}$. 
Tabela 5. Somas do quadrado dos resíduos para A-D1

\begin{tabular}{cccccccc}
\hline $\mathrm{n}$ & Arranjos & SQRes $_{b}$ & SQRes $_{v}$ & SQRes $_{v}-$ SQRes $_{b}$ & SQRes $_{b I_{r}}$ & SQRes $_{v I_{r}}$ & SQRes $_{v I_{r}}-$ SQRes $_{b I_{r}}$ \\
\hline \multirow{2}{*}{$n=50$} & Arranjo A1 & 0,13453 & 0,15603 & 0,02150 & 0,08833 & 0,11614 & 0,02781 \\
& Arranjo A2 & 0,14027 & 0,18534 & 0,04507 & 0,09456 & 0,16861 & 0,07405 \\
& Arranjo A3 & 0,10945 & 0,15758 & 0,04813 & 0,06502 & 0,13609 & 0,07107 \\
& Arranjo A4 & 0,13788 & 0,13364 & $-0,00424$ & 0,09050 & 0,10575 & 0,01525 \\
\multirow{5}{*}{$n=100$} & Arranjo A1 & 0,05310 & 0,05593 & 0,00283 & 0,03471 & 0,04339 & 0,00868 \\
& Arranjo A2 & 0,07179 & 0,05655 & $-0,01524$ & 0,04185 & 0,04903 & 0,00718 \\
& Arranjo A3 & 0,07264 & 0,08405 & 0,01141 & 0,05399 & 0,07301 & 0,01902 \\
& Arranjo A4 & 0,05463 & 0,08033 & 0,02570 & 0,03552 & 0,06307 & 0,02755 \\
\hline
\end{tabular}

Como mostra a Figura 9, as estimativas da freqüência de recombinação encontram-se mais dispersas em relação à reta identidade na combinação $\mathrm{C}(a o \times a o)$ - D1 $(a b \times a b)$ que as outras vistas até agora, considerando o arranjo $A 3$, sendo que, o mesmo acontece para os demais arranjos. De fato, pois, para esta combinação, além de não ser possível distinguir os recombinantes dos não recombinantes, nem sempre será possível reconhecer qual dos genitores enviou para a progênie um certo tipo de gameta. Em C-D1, apenas dois genótipos podem ser reconhecidos a partir do seu respectivo fenótipo, os demais geram dúvidas. Também,deve ser notado que, para esse tipo de configuração, os valores das estimativas de máxima verossimilhança de $r$ sub-estimam os verdadeiros valores de $r$ para a maioria dos valores no intervalo $(0 ; 0,5)$ do espaço paramétrico. Tais estimativas são aproximadamente nulas com uma aproximação de três casas decimais. Considerando os 4 tipos de arranjos e os tamanhos amostrais $\mathrm{n}=50$ e $\mathrm{n}=100$, foram calculadas as $S Q R e s$ para as estimativas obtidas pelos dois métodos considerando todo o intervalo do espaço paramétrico e a restrição desse intervalo, $I_{r}=(0,05 ; 0,45)$. Em todas as situações, as $S Q R e s_{b}$ e $S Q R e s_{b I}$ foram menores que $S Q R e s_{v}$ e $S Q R e s_{v I}$, respectivamente, como mostra a Tabela 6 . 
Freqüência de Recombinação
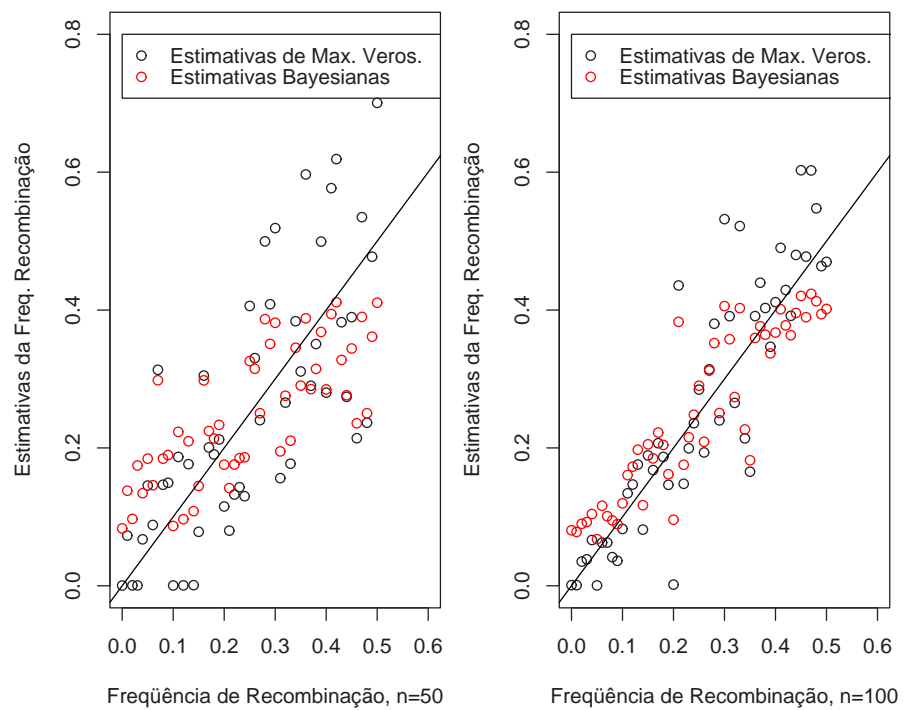

Figura 9 - Gráficos das estimativas Bayesianas e de Máxima Verossimilhança para a configuração $C-D 1$, considerando o arranjo $A 3$, com tamanhos amostrais com $n=50$ e $n=100$, respectivamente

Tabela 6. Somas dos quadrado dos resíduos para C-D1

\begin{tabular}{cccccccc}
\hline $\mathrm{n}$ & Arranjos & SQRes $_{b}$ & SQRes $_{v}$ & SQRes $_{v}-$ SQRes $_{b}$ & SQRes $_{b I_{r}}$ & SQRes $_{v I_{r}}$ & SQRes $_{v I_{r}}-$ SQRes $_{b I_{r}}$ \\
\hline \multirow{2}{*}{$n=50$} & Arranjo A1 & 0,3174 & 0,4157 & 0,0983 & 0,1769 & 0,3656 & 0,1887 \\
& Arranjo A2 & 0,3136 & 0,4650 & 0,1514 & 0,1987 & 0,4436 & 0,2449 \\
& Arranjo A3 & 0,4880 & 0,7622 & 0,2742 & 0,2951 & 0,5920 & 0,2969 \\
& Arranjo A4 & 0,3150 & 0,4733 & 0,1583 & 0,1915 & 0,3864 & 0,1949 \\
\multirow{2}{*}{100} & Arranjo A1 & 0,2049 & 0,2392 & 0,0343 & 0,1510 & 0,2004 & 0,0494 \\
& Arranjo A2 & 0,2014 & 0,2549 & 0,0535 & 0,1491 & 0,2280 & 0,0789 \\
& Arranjo A3 & 0,2087 & 0,3518 & 0,1432 & 0,1541 & 0,3267 & 0,1726 \\
& Arranjo A4 & 0,1928 & 0,2333 & 0,0405 & 0,1403 & 0,2110 & 0,0707 \\
\hline
\end{tabular}

Nas combinações B1-D1 $(a b \times a b)$ e B1-D2, os locos representado por B1 $(a b \times a o)$ apresenta um alelo nulo. Nestes casos, é possível reconhecer quatro genótipos a partir dos seus respectivos fenótipos. As estimativas de $r$ encontradas pelos dois métodos aqui abordados referentes às configurações B1-D1 e B1-D2 com arranjo $A 1$ se encontram nas Figuras 10 e 11. 

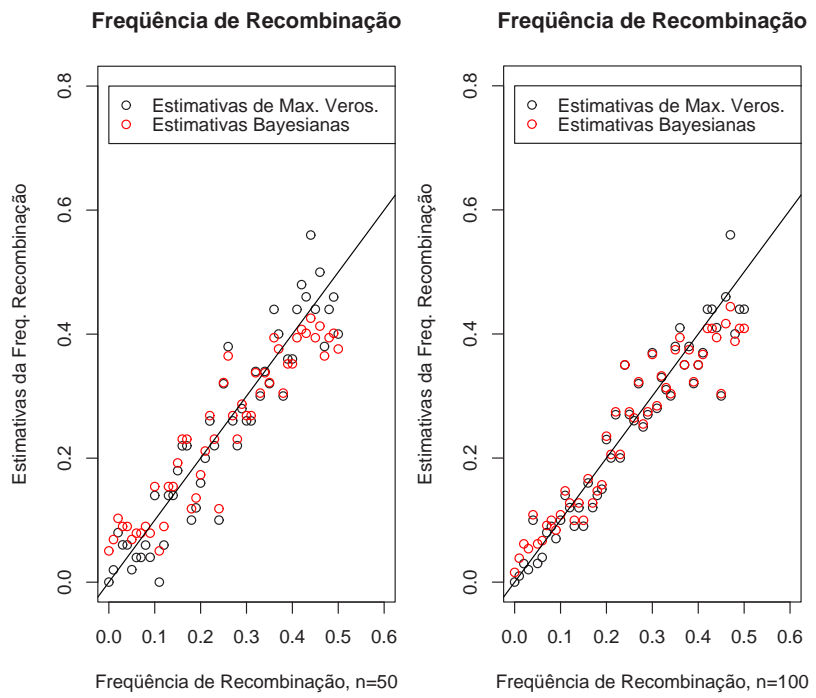

Figura 10 - Gráficos das estimativas Bayesianas e de Máxima Verossimilhança para a configuração $B 1-D 1$, considerando o arranjo $A 1$, com tamanhos amostrais com $n=50$ e $n=100$, respectivamente

Nota-se em ambas as figuras, que as estimativas Bayesianas estão próximas das estimativas de máxima verossimilhança na região $(0,05 ; 0,45)$ do espaço paramétrico, principalmente quando aumenta-se o tamanho amostral.

As somas de quadrado dos resíduos para esses dois tipos de configurações se encontram nas Tabelas 7 e 8. Para B1-D1, com exceção do arranjo A2 (n=50), SQRes $s_{b}<S Q R e s_{v}$ e, sem nenhuma exceção, SQRes II $_{r}<S Q R e s_{v I_{r}}$. Já na combinação B1-D2, SQRes $b>S Q R e s_{v}$ apenas para os arranjos $A 1(\mathrm{n}=50)$, $A 2(\mathrm{n}=50$ e $\mathrm{n}=100)$ e $A 4(\mathrm{n}=100)$ e, $S Q R e s_{b I_{r}}<S Q R e s_{v I_{r}}$ para todos os arranjos e tamanhos amostrais considerados. 
Freqüência de Recombinação

Freqüência de Recombinação
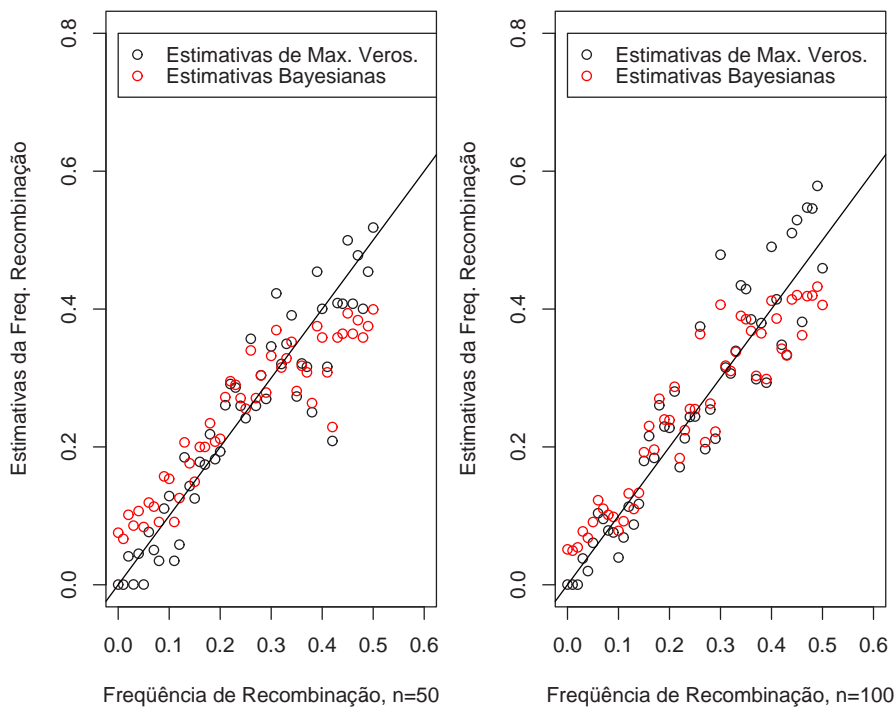

Figura 11 - Gráficos das estimativas Bayesianas e de Máxima Verossimilhança para a configuração $B 1-D 2$, considerando o arranjo $A 1$, com tamanhos amostrais com $n=50$ e $n=100$, respectivamente

Tabela 7. Somas dos quadrado dos resíduos para B1-D1

\begin{tabular}{cccccccc}
\hline $\mathrm{n}$ & Arranjos $_{\mathrm{N}}$ & SQRes $_{b}$ & SQRes $_{v}$ & SQRes $_{v}-$ SQRes $_{b}$ & SQRes $_{b I_{r}}$ & SQRes $_{v I_{r}}$ & SQRes $_{v I_{r}}-$ SQRes $_{b I_{r}}$ \\
\hline \multirow{2}{*}{$n=50$} & Arranjo A1 & 0,14520 & 0,15615 & 0,01095 & 0,08242 & 0,12899 & 0,04657 \\
& Arranjo A2 & 0,11269 & 0,11047 & $-0,00222$ & 0,06982 & 0,07735 & 0,007553 \\
& Arranjo A3 & 0,13625 & 0,15006 & 0,01381 & 0,10043 & 0,11695 & 0,01652 \\
& Arranjo A4 & 0,63483 & 1,53911 & 0,90428 & 0,48009 & 1,10195 & 0,62186 \\
\multirow{5}{*}{100} & Arranjo A1 & 0,10733 & 0,10301 & $-0,00432$ & 0,07344 & 0,07867 & 0,00523 \\
& Arranjo A2 & 0,08489 & 0,09493 & 0,10004 & 0,06389 & 0,08639 & 0,0225 \\
& Arranjo A3 & 0,09289 & 0,07688 & $-0,07688$ & 0,06463 & 0,06900 & 0,00437 \\
& Arranjo A4 & 0,62581 & 1,49130 & 0,86549 & 0,54027 & 1,14105 & 0,60078 \\
\hline
\end{tabular}


Tabela 8. Somas dos quadrado dos resíduos para B1-D2

\begin{tabular}{cccccccc}
\hline $\mathrm{n}$ & Arranjos & SQRes $_{b}$ & SQRes $_{v}$ & SQRes $_{v}-$ SQRes $_{b}$ & SQRes $_{b I_{r}}$ & SQRes $_{v I_{r}}$ & SQRes $_{v I_{r}}-$ SQRes $_{b I_{r}}$ \\
\hline \multirow{2}{*}{$n=50$} & Arranjo A1 & 0,21802 & 0,16182 & $-0,05620$ & 0,14025 & 0,14961 & 0,00936 \\
& Arranjo A2 & 0,21285 & 0,20645 & $-0,00640$ & 0,13606 & 0,18049 & 0,04443 \\
& Arranjo A3 & 0,24089 & 0,25547 & 0,01458 & 0,15308 & 0,17923 & 0,02615 \\
& Arranjo A4 & 0,22882 & 0,32513 & 0,09631 & 0,15435 & 0,25382 & 0,09947 \\
& Arranjo A1 & 0,13848 & 0,17995 & 0,04147 & 0,10203 & 0,15300 & 0,05097 \\
& Arranjo A2 & 0,13121 & 0,10746 & $-0,02375$ & 0,06948 & 0,07284 & 0,00336 \\
& Arranjo A3 & 0,12446 & 0,13529 & 0,01083 & 0,08218 & 0,11079 & 0,02861 \\
& Arranjo A4 & 0,16406 & 0,15739 & $-0,00667$ & 0,11508 & 0,13722 & 0,02214 \\
\hline
\end{tabular}

Para as combinações B3-B3, B3-C, C-C, B1-C e B1-B1, o comportamento das estimativas de $r$ encontradas pelos métodos de máxima verossimilhança e Bayesiano não são os mesmos para todos os tipos de arranjos, como vistos até agora. Considerando os arranjos $A 1$ (marcadores ligados em associação nos dois genitores) e $A 4$ (marcadores ligados em repulsão nos dois genitores) (marcadores ligados em repulsão nos dois genitores), as estimativas de $r$ obtidas pelos dois métodos apresentam a mesma tendência em relação à reta identidade quando a combinação for B3-B3 ou B3-C, assim como, as estimativas da freqüência de recombinação obtidas pelos dois métodos considerando os arranjos $A 2$ (marcadores ligados em associação no primeiro genitor e em repulsão no segundo genitor) e $A 3$ (marcadores ligados em repulsão no primeiro genitor e em associação no segundo genitor) apresentam o mesmo comportamento entre si. No caso C-C o arranjo $A 1$ se diferencia do comportamento dos outros arranjos. Em B1-C e B1-B1, os arranjos que têm suas estimativas seguindo a mesma tendência em relação à reta identidade são: $A 1$ e $A 2 ; A 3$ e $A 4$.

Na combinação B3 $(a b \times a b)$-B3 nem sempre será possível distinguir qual gameta que cada genitor enviou para a progênie, já que B3 é um marcador do tipo simétrico. Só será possível distinguir os genótipos a partir dos fenótipos para os casos em que os genitores enviam alelos iguais referentes aos dois locos, por exemplo: um dos genitores envia o alelo $a$ referente ao primeiro loco e o alelo $b$ referente ao segundo loco e, o outro genitor envia esses mesmos alelos referentes aos mesmos locos, respectivamente. Dessa maneira, apenas 4 genótipos podem ser distingüidos a partir de seus fenótipos. 
Como já citado, as estimativas de $r$ obtidas pelos dois métodos apresentam o mesmo comportamento para os arranjos $A 1$ e $A 4$. Tais estimativas apresentam uma boa aproximação em relação à reta identidade, como mostra a Figura 12 que considera apenas o arranjo $A 1$.

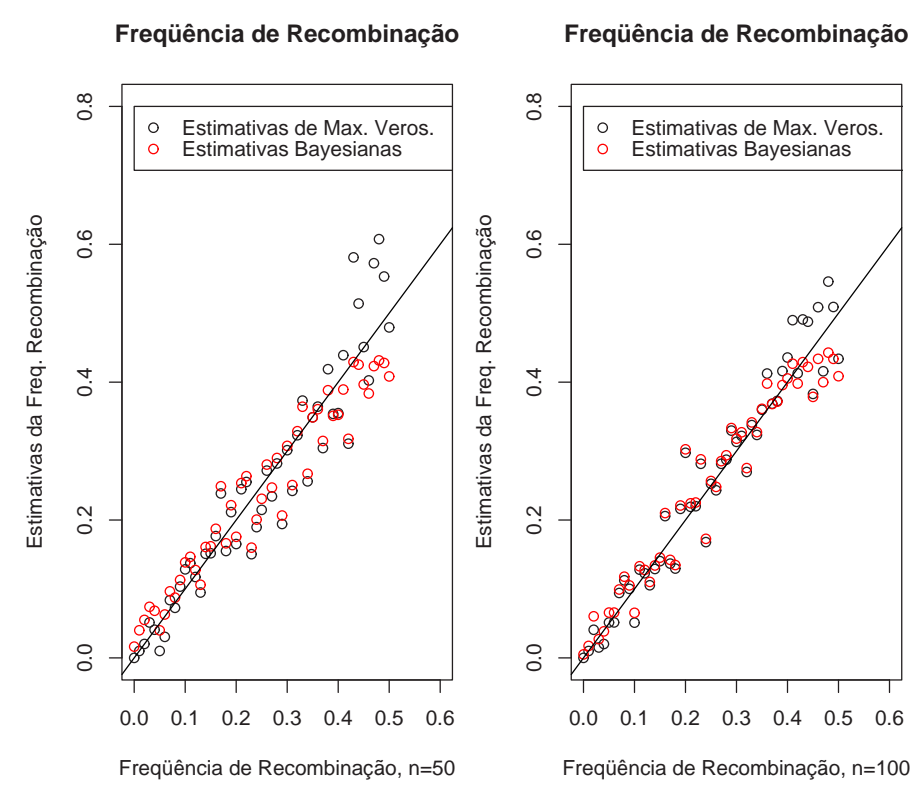

Figura 12 - Gráficos das estimativas Bayesianas e de Máxima Verossimilhança para a configuração $B 3-B 3$, considerando o arranjo $A 1$, com tamanhos amostrais com $n=50$ e $n=100$, respectivamente

Para estes dois últimos tipos de arranjos, as somas de quadrado dos resíduos para as estimativas Bayesianas são menores que as somas de quadrado dos resíduos para as estimativas de máxima verossimilhança considerando todo o intervalo paramétrico e o intervalo $I_{r}$. O mesmo acontece para as estimativas encontradas considerando os arranjos $A 2$ e $A 3$, como mostra a Tabela 9. 
Tabela 9. Somas dos quadrado dos resíduos para B3-B3

\begin{tabular}{cccccccc}
\hline $\mathrm{n}$ & Arranjos & SQRes $_{b}$ & SQRes $_{v}$ & SQRes $_{v}-S Q \operatorname{Res}_{b}$ & SQRes $_{b I_{r}}$ & SQRes $_{v I_{r}}$ & SQRes $_{v I_{r}}-$ SQRes $_{b I_{r}}$ \\
\hline \multirow{2}{*}{$n=50$} & Arranjo A1 & 0,09158 & 0,13489 & 0,04331 & 0,06379 & 0,09995 & 0,03616 \\
& Arranjo A2 & 0,25091 & 0,26940 & 0,01849 & 0,12763 & 0,16026 & 0,03263 \\
& Arranjo A3 & 0,27923 & 0,44562 & 0,16639 & 0,20143 & 0,41413 & 0,21270 \\
& Arranjo A4 & 0,16048 & 0,11744 & $-0,04304$ & 0,07118 & 0,10470 & 0,03352 \\
\multirow{5}{*}{$n=100$} & Arranjo A1 & 0,06346 & 0,07170 & 0,00824 & 0,04326 & 0,05626 & 0,01300 \\
& Arranjo A2 & 0,19140 & 0,22901 & 0,03761 & 0,10665 & 0,15083 & 0,04418 \\
& Arranjo A3 & 0,14552 & 0,14817 & 0,00265 & 0,08197 & 0,10936 & 0,02739 \\
& Arranjo A4 & 0,05218 & 0,05950 & 0,00732 & 0,03223 & 0,03873 & 0,00650 \\
\hline
\end{tabular}

Com relação aos arranjos $A 2$ e $A 3$, considerando ainda a combinação B3-B3, as estimativas de $r$ se encontram mais dispersas em relação à reta identidade que as estimativas de $r$ encontradas considerando os outros dois arranjos, como mostra a Figura 13 que considera apenas o arranjo $A 2$.
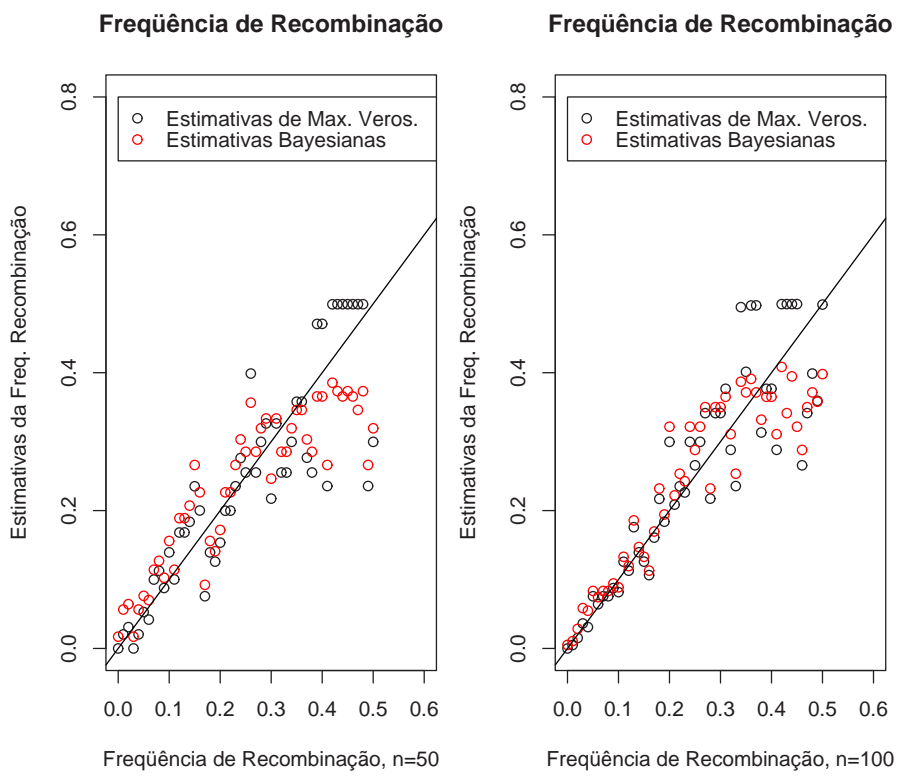

Figura 13 - Gráficos das estimativas Bayesianas e de Máxima Verossimilhança para a configuração $B 3-B 3$, considerando o arranjo $A 2$, com tamanhos amostrais com $n=50$ e $n=100$, respectivamente

A maioria das estimativas Bayesianas em $(0 ; 0,05)$ super-estimam os verdadeiros valores de $r$ quando $\mathrm{n}=50$. Para o caso em que o tamanho amostral é 100, em $(0 ; 0,5)$, para os dois métodos de estimação, as estimativas de $r$ se encontram 
praticamente sobre a reta identidade.

A combinação B3-C também é formada por dois marcadores que apresentam segregação do tipo simétrico: B3 $(a b \times a b)$ e C $(a o \times a o)$. Com exceção de apenas dois fenótipos, não é possível detectar quando aconteceu recombinação ou não nos gametas produzidos pelos dois genitores e, sendo um cruzamento do tipo simétrico, não é possível identificar com qual gameta que cada genitor contribuiu para a formação de um determinado indivíduo na progênie.

Considerando os arranjos $A 2$ e $A 3$ para B3-C, as estimativas de $r$ se encontram mais dispersas em relação à reta identidade que as estimativas considerando os arranjos $A 1$ e $A 4$, como mostram as Figuras 14 e 15 em que consideram apenas os arranjos $A 1$ e $A 2$, respectivamente.

A Tabela 10 mostra as SQRes, SQRes $v, S Q R e s_{b}-S Q R e s_{v}$, $S Q R e s_{b I_{r}}, S Q R e s_{v I_{r}}$ e $S Q R e s_{b I_{r}}-S Q R e s_{v I_{r}}$ para a combinação B3-C. Nota-se que as $S Q R e s_{b}$ são maiores que as $S Q R e s_{v}$ apenas para o arranjo $A 2(\mathrm{n}=50$ e $\mathrm{n}=100)$. Já as $S Q R e s_{b I_{r}}$ são menores que as $S Q R e s_{v I_{r}}$ para todos os possíveis arranjos.
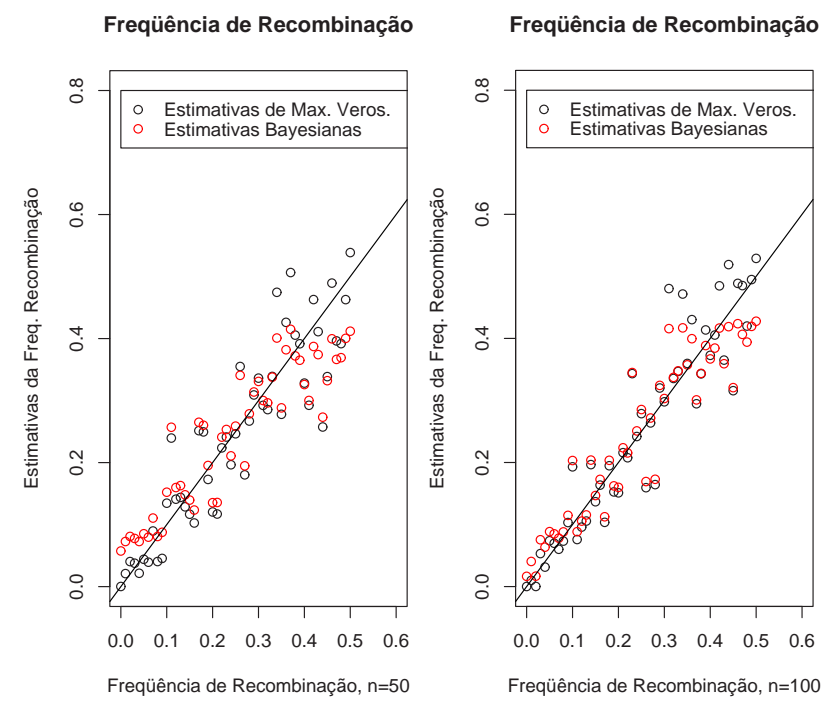

Figura 14 - Gráficos das estimativas Bayesianas e de Máxima Verossimilhança, configuração $B 3-C$ e arranjo $A 1$, com tamanhos amostrais com n=50 e $\mathrm{n}=100$, respectivamente 
Freqüência de Recombinação
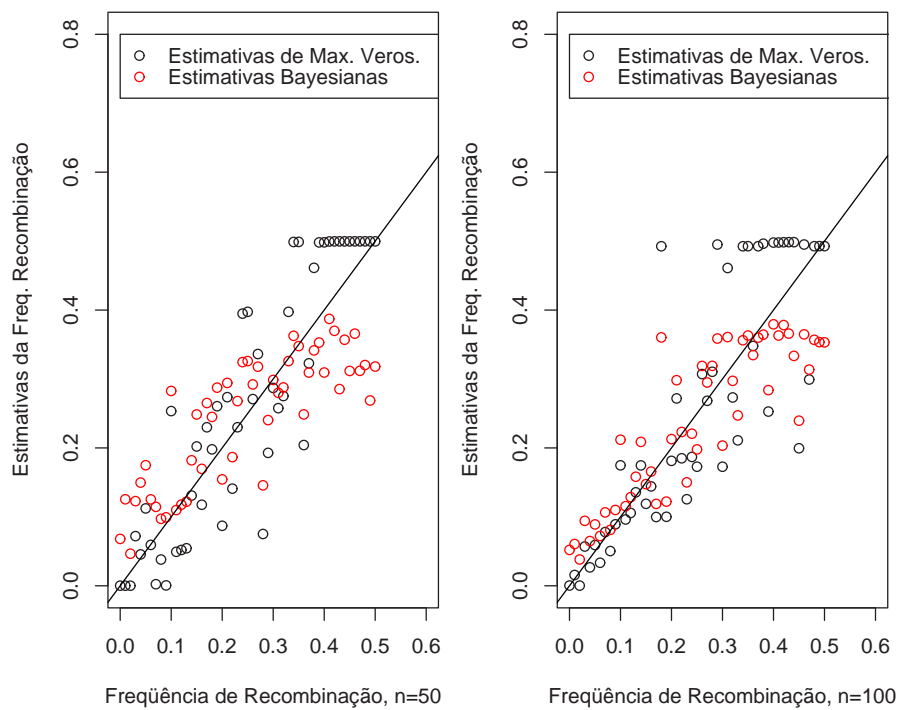

Figura 15 - Gráficos das estimativas Bayesianas e de Máxima Verossimilhança, configuração $B 3-C$ e arranjo $A 2$, com tamanhos amostrais com n=50 e $\mathrm{n}=100$, respectivamente

Tabela 10. Somas dos quadrado dos resíduos para $B 3-C$

\begin{tabular}{|c|c|c|c|c|c|c|c|}
\hline $\mathrm{n}$ & Arranjos & $S Q \operatorname{Res}_{b}$ & $\operatorname{SQRes}_{v}$ & $S Q \operatorname{Res}_{v}-S Q \operatorname{Res}_{b}$ & $S Q \operatorname{Res}_{b I_{r}}$ & $S Q \operatorname{Res}_{v I_{r}}$ & $S Q \operatorname{Res}_{v I_{r}}-S Q \operatorname{Res}_{b I_{r}}$ \\
\hline \multirow[t]{4}{*}{$n=50$} & Arranjo A1 & 0,2042 & 0,2080 & 0,0037 & 0,1475 & 0,1907 & 0,0432 \\
\hline & Arranjo A2 & 0,3989 & 0,3356 & $-0,0632$ & 0,2181 & 0,3304 & 0,1123 \\
\hline & Arranjo A3 & 0,3987 & 0,6759 & 0,2772 & 0,2617 & 0,6643 & 0,4026 \\
\hline & Arranjo A4 & 0,1525 & 0,2127 & 0,0602 & 0,1019 & 0,1923 & 0,0904 \\
\hline \multirow[t]{4}{*}{$n=100$} & Arranjo A1 & 0,1367 & 0,1615 & 0,0248 & 0,1099 & 0,1550 & 0,0450 \\
\hline & Arranjo A2 & 0,2845 & 0,4639 & 0,1794 & 0,1852 & 0,4319 & 0,2467 \\
\hline & Arranjo A3 & 0,3394 & 0,3824 & 0,0429 & 0,2022 & 0,3772 & 0,1750 \\
\hline & Arranjo A4 & 0,0878 & 0,0878 & $-0,00003$ & 0,0516 & 0,0768 & 0,0252 \\
\hline
\end{tabular}

Em C-C $(a \circ \times a o)$, apenas um único genótipo pode ser identificado a partir de seu fenótipo. De fato, pois, além de ser um cruzamento do tipo simétrico, ambos os locos têm um alelo nulo em ambos os genitores. Para este tipo de combinação, o genitor 1 correspondente ao arranjo $A 2$ é o mesmo do genitor 2 correspondente ao arranjo $A 3$ e vice-versa. Dessa maneira, é de se esperar que as estimativas de $r$ apresentem o mesmo comportamento em relação à reta identidade para estes dois tipos de arranjos. O comportamento das estimativas em relação a tal reta diferem 
entre os arranjos $A 1$ e $A 4$. Para estes dois últimos tipos de arranjos, os fenótipos são os mesmos e se encontram na mesma proporção. Entretanto, existem indivíduos na progênie que, se for considerado a arranjo $A 1$ sabe-se, com certeza, que ocorreu pelo menos em um genitor a recombinação. Para esses mesmos indivíduos, considerando o arranjo A4, nada se sabe sobre a ocorrência ou não da recombinação. Dessa maneira, é de se esperar que os comportamentos das estimativas de $r$ em relação à reta identidade não sejam iguais para estes dois tipos de arranjos e, que além disso, as estimativas de $r$ obtidas considerando $A 1$ apresentem um comportamento melhor em relação à reta identidade que as estimativas considerando $A 4$.

A Figura 16 mostra as estimativas da freqüência de recombinação obtidas pelos dois métodos aqui abordados, considerando o arranjo $A 1$ e os tamanhos amostrais 50 e 100 .
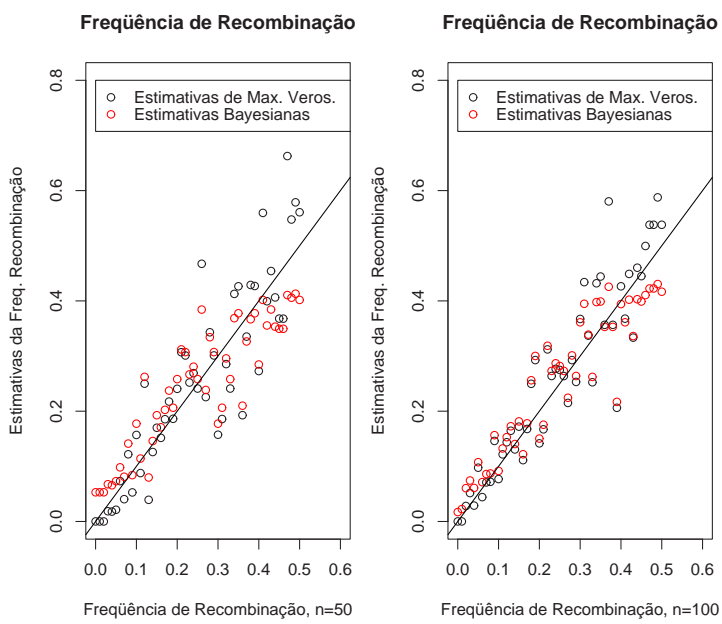

Figura 16 - Gráficos das estimativas Bayesianas e de Máxima Verossimilhança para a configuração $C-C$, considerando o arranjo $A 1$, com tamanhos amostrais com $n=50$ e $n=100$, respectivamente

A Figura 17 mostra as estimativas da freqüência de recombinação obtidas pelos dois métodos considerando o arranjo $A 3$ para os dois primeiros gráficos desta figura, e o arranjo $A 4$ para os outros dois gráficos. Para esses dois tipos de arranjos e, conseqüentemente para o arranjo $A 2$, nota-se que as estimativas da 
freqüência de recombinação se encontram mais dispersas em relação à reta identidade que as estimativas da Figura 16.
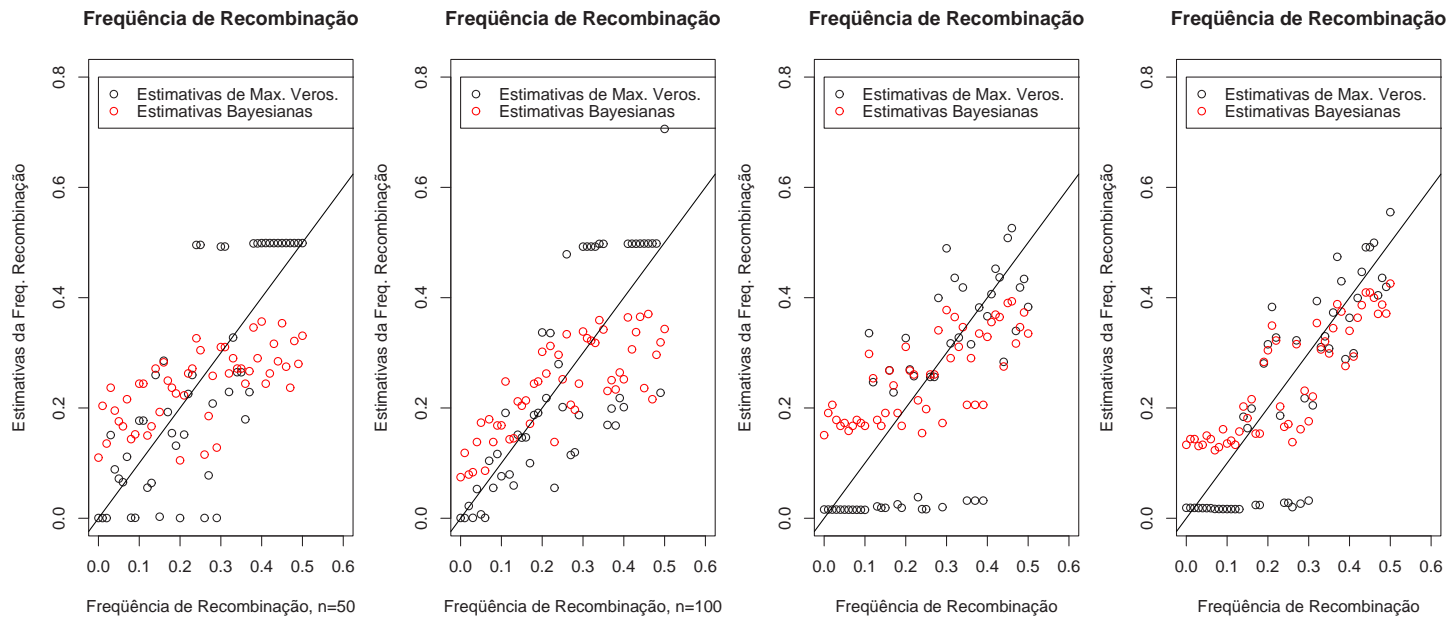

Figura 17 - Gráficos das estimativas Bayesianas e de Máxima Verossimilhança para a configuração $C-C$, considerando: o arranjo $A 3$, com tamanhos amostrais com $\mathrm{n}=50$ e com $\mathrm{n}=100$, o arranjo $A 4$, com tamanhos amostrais com $\mathrm{n}=50$ e $\mathrm{n}=100$, respectivamente

Como mostra a Tabela 11, as $S Q R e s_{b}$ são menores que as $S Q R e s_{v}$, com exceção dos arranjos $A 2(\mathrm{n}=100)$ e A3 $(\mathrm{n}=50)$. Restringindo o intervalo ao subintervalo $I_{r}$, todas as somas de quadrado dos resíduos das estimativas de $r$ Bayesianas foram menores que as de máxima verossimilhança.

Tabela 11. Somas do quadrado dos resíduos para $C-C$

\begin{tabular}{cccccccc}
\hline $\mathrm{n}$ & Arranjos & SQRes $_{b}$ & SQRes $_{v}$ & SQRes $_{v}-$ SQRes $_{b}$ & SQRes $_{b I_{r}}$ & SQRes $_{v I_{r}}$ & SQRes $_{v I_{r}}-$ SQRes $_{b I_{r}}$ \\
\hline \multirow{2}{*}{$n=50$} & Arranjo A1 & 0,2251 & 0,3035 & 0,0783 & 0,1805 & 0,2406 & 0,0601 \\
& Arranjo A2 & 0,6849 & 0,8996 & 0,2147 & 0,3903 & 0,7291 & 0,3388 \\
& Arranjo A3 & 0,6882 & 0,6796 & $-0,0086$ & 0,3719 & 0,6594 & 0,2875 \\
& Arranjo A4 & 0,5336 & 0,9258 & 0,3922 & 0,3188 & 0,8828 & 0,5639 \\
\multirow{5}{*}{$n=100$} & Arranjo A1 & 0,1478 & 0,2044 & 0,0566 & 0,1250 & 0,1831 & 0,0581 \\
& Arranjo A2 & 0,6988 & 0,6679 & $-0,0309$ & 0,3647 & 0,6609 & 0,2962 \\
& Arranjo A3 & 0,4963 & 0,5825 & 0,0862 & 0,2996 & 0,5787 & 0,2791 \\
& Arranjo A4 & 0,3140 & 0,5424 & 0,2284 & 0,2026 & 0,5256 & 0,3230 \\
\hline
\end{tabular}

Para a combinação $\mathrm{B} 1(a b \times a o)-\mathrm{C}(a o \times a o)$, fixado o arranjo $A 3$ ou 
$A 4$, apenas um único genótipo pode ser identificado diretamente a partir de seu fenótipo. Considerando os arranjos $A 1$ e $A 2$, dois genótipos podem ser identificados diretamente a partir de seus fenótipos. Dessa maneira, é de se esperar que as estimativas de $r$ para $A 1$ e $A 2$ apresentem um melhor comportamento que as de $A 3$ e $A 4$ em relação à reta identidade. De fato isso acontece, como mostra a Figura 18.
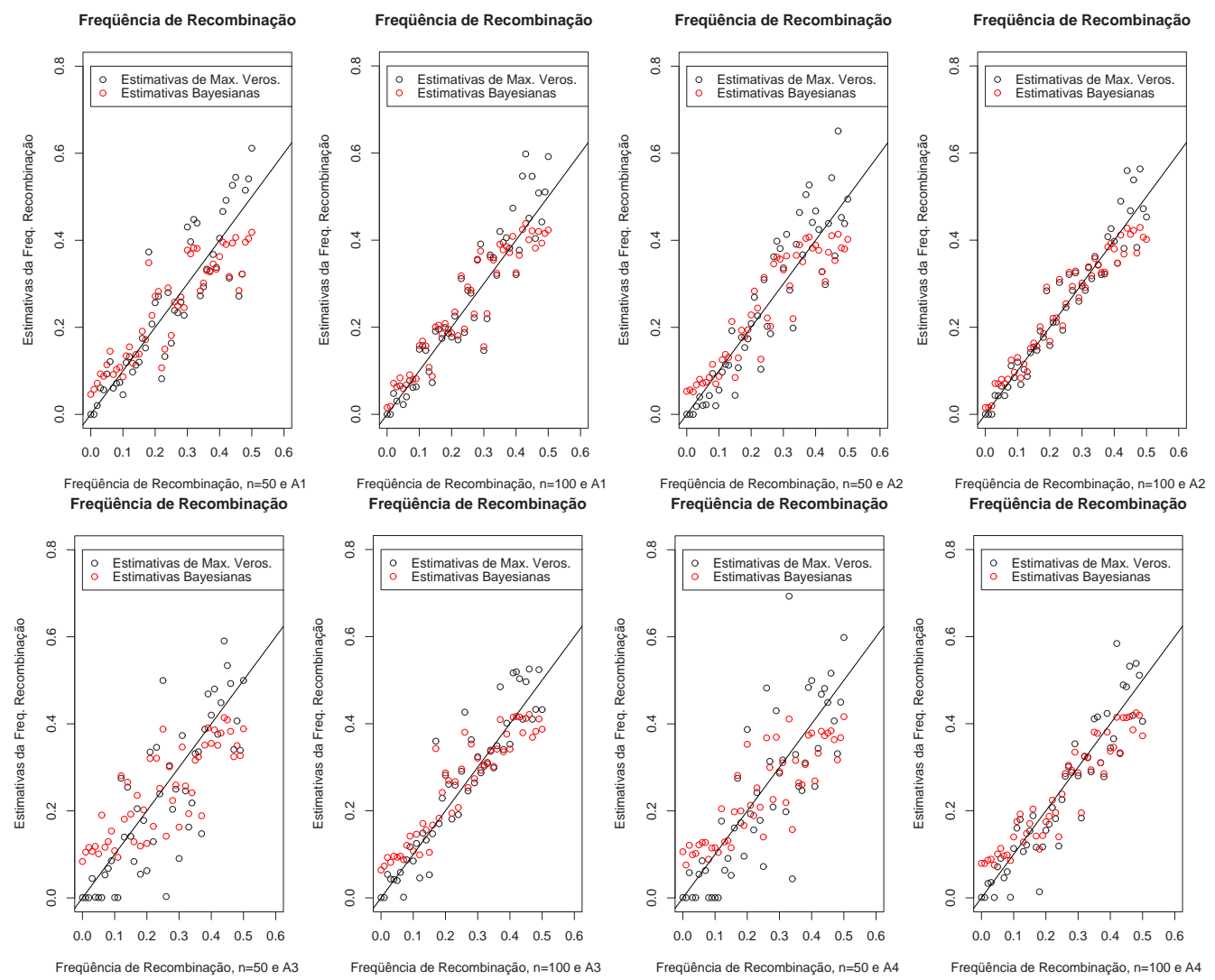

Figura 18 - Gráficos das estimativas Bayesianas e de Máxima Verossimilhança, configuração $B 1-C$ considerando: arranjo $A 1$ com tamanhos amostrais $\mathrm{n}=50$ e $\mathrm{n}=100 ;$ arranjo $A 2$ com tamanhos amostrais $\mathrm{n}=50$ e $\mathrm{n}=100$; arranjo $A 3$ com tamanhos amostrais $\mathrm{n}=50$ e $\mathrm{n}=100$; arranjo $A 4$ com tamanhos amostrais $n=50$ e $n=100$;

Considerando todo o intervalo paramétrico e o intervalo $I_{r}$, as somas de quadrado dos resíduos das estimativas Bayesianas são todas menores que as somas de quadrados dos resíduos para as estimativas de máxima verossimilhança, como 
mostra a Tabela 12.

Tabela 12. Somas do quadrado dos resíduos para B1-C

\begin{tabular}{cccccccc}
\hline $\mathrm{n}$ & Arranjos & SQRes $_{b}$ & SQRes $_{v}$ & SQResv $_{v}-$ SQRes $_{b}$ & SQRes $_{b}$ & SQRes $_{v I_{r}}$ & SQRes $_{v I_{r}}-$ SQRes $_{b I_{r}}$ \\
\hline \multirow{2}{*}{$n=50$} & Arranjo A1 & 0,21994 & 0,27993 & 0,05999 & 0,13290 & 0,20511 & 0,07221 \\
& Arranjo A2 & 0,16536 & 0,26541 & 0,10005 & 0,11068 & 0,21931 & 0,10863 \\
& Arranjo A3 & 0,37243 & 0,51973 & 0,14730 & 0,25213 & 0,47173 & 0,21960 \\
& Arranjo A4 & 0,31491 & 0,58939 & 0,27448 & 0,21504 & 0,54486 & 0,32982 \\
\multirow{5}{*}{$n=100$} & Arranjo A1 & 0,12215 & 0,17610 & 0,05395 & 0,08868 & 0,15961 & 0,07093 \\
& Arranjo A2 & 0,08193 & 0,08893 & 0,00700 & 0,04850 & 0,06507 & 0,01657 \\
& Arranjo A3 & 0,15878 & 0,17932 & 0,02054 & 0,09937 & 0,16208 & 0,06271 \\
& Arranjo A4 & 0,14699 & 0,18924 & 0,04225 & 0,09344 & 0,16681 & 0,07337 \\
\hline
\end{tabular}

Para a combinação B1-B1 $(a b \times a o)$, considerando qualquer um dos tipos de arranjos, é possivel reconhecer quatro genótipos a partir dos seus fenótipos. Entretanto, para os arranjos $A 3$ e $A 4$, dos nove possíveis fenótipos, em três deles não é possível saber se aconteceu recombinação em um dos genitores ou em nenhum deles. Já nos casos em que os arranjos são $A 1$ e $A 2$, desses nove fenótipos, em apenas um deles isso acontece. Graficamente, é notado que as estimativas de $r$ obtidas pelos dois métodos aqui abordados apresentam um melhor comportamento em relação à reta identidade para os arranjos $A 1$ e $A 2$, como mostra a Figura 19.

Considerando esse último tipo de configuração citado, como mostra a Tabela 13, SQRes II $_{r}<S Q R e s_{v I_{r}}$ sendo $\mathrm{n}=50$ e $\mathrm{n}=100$ para qualquer um dos tipos de arranjos e, $S Q \operatorname{Res}_{b}>S Q \operatorname{Res}_{v}$ apenas para o $A 3(\mathrm{n}=50$ e $\mathrm{n}=100)$.

Tabela 13. Somas do quadrado dos resíduos para B1-B1

\begin{tabular}{cccccccc}
\hline $\mathrm{n}$ & Arranjos & SQRes $_{b}$ & SQRes $_{v}$ & SQRes $_{v}-$ SQRes $_{b}$ & SQRes $_{b I_{r}}$ & SQRes $_{v I_{r}}$ & SQRes $_{v I_{r}}-$ SQRes $_{b I_{r}}$ \\
\hline \multirow{2}{*}{$n=50$} & Arranjo A1 & 0,1499 & 0,2168 & 0,0678 & 0,1176 & 0,1858 & 0,0682 \\
& Arranjo A2 & 0,3239 & 0,3404 & 0,0165 & 0,1741 & 0,2019 & 0,0278 \\
& Arranjo A3 & 0,1724 & 0,1528 & $-0,0195$ & 0,1170 & 0,1231 & 0,0060 \\
& Arranjo A4 & 0,1580 & 0,1883 & 0,0300 & 0,1255 & 0,1812 & 0,0557 \\
\multirow{2}{*}{$n=100$} & Arranjo A1 & 0,0507 & 0,0358 & $-0,0148$ & 0,0306 & 0,0311 & 0,0004 \\
& Arranjo A2 & 0,1858 & 0,1930 & 0,0072 & 0,1122 & 0,1247 & 0,00124 \\
& Arranjo A3 & 0,1256 & 0,1217 & $-0,0039$ & 0,0817 & 0,0893 & 0,0076 \\
& Arranjo A4 & 0,0869 & 0,0762 & $-0,0107$ & 0,0622 & 0,0700 & 0,0078 \\
\hline
\end{tabular}



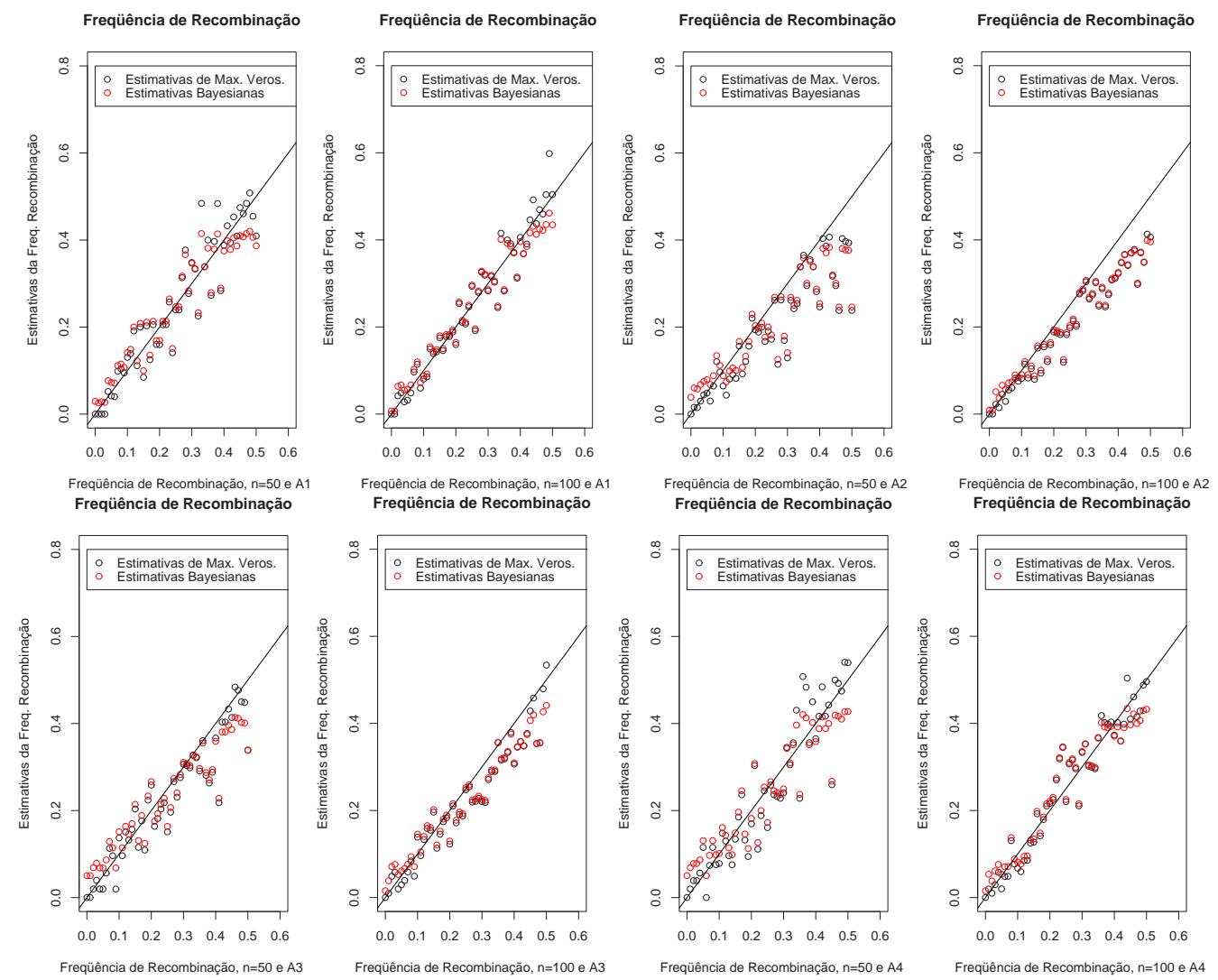

Figura 19 - Gráficos das estimativas Bayesianas e de Máxima Verossimilhança, configuração $B 1-B 1$ e arranjo $A 2$, com tamanhos amostrais $\mathrm{n}=50$ e $\mathrm{n}=100$, respectivamente

Para as outras restantes combinações, A-B3, B1-B3, A-A, A-C, A-B1 e B1-B2, o comportamento de suas estimativas em relação à reta identidade são os mesmos para qualquer tipo de arranjo.

Das combinações A-B3 e B1-B3, a primeira apresenta suas estimativas com um melhor comportamento em relação à reta identidade, já que o marcador A é mais informativo que o marcador B1. Considerando a combinação A-A, não foi possível estimar a freqüência de recombinação através do método de máxima verossimilhança pois, no algoritmo EM, para valores de $r$ próximos de zero, o denominador no passo E será nulo. Entretanto, as estimativas Bayesianas foram obtidas, como mostra a Figura 20. Tal combinação é dada pelo marcador A que é completamente 
informativo.

Freqüência de Recombinação

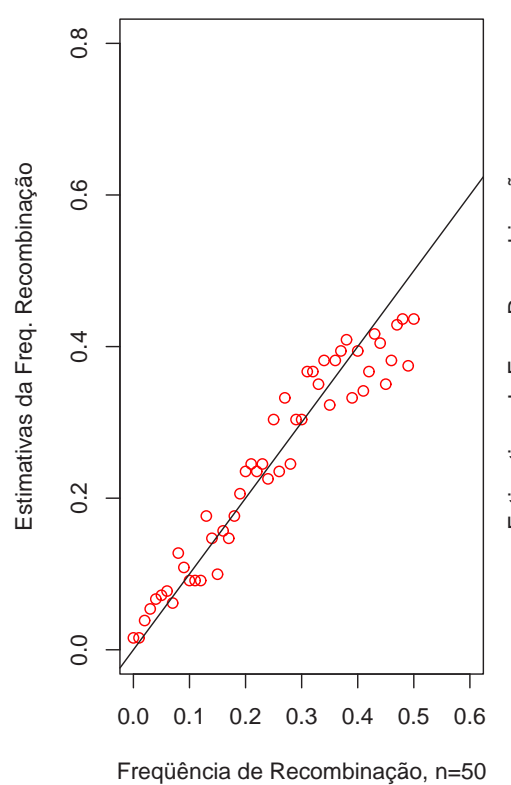

Freqüência de Recombinação

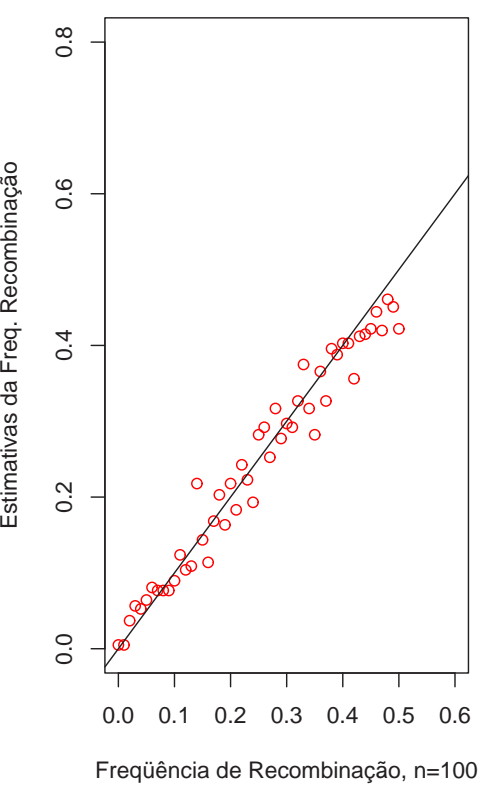

Figura 20 - Gráficos das estimativas Bayesianas e de Máxima Verossimilhança, configuração A-A e arranjo A3, com tamanhos amostrais $\mathrm{n}=50$ e $\mathrm{n}=100$, respectivamente

As Figuras 21, 22, 23, 24 e 25 apresentam gráficos com as estimativas de $r$ obtidas pelos dois métodos para as combinações A-B3 ( $\mathrm{n}=50$ e $\mathrm{n}=100)$, B1$\mathrm{B} 3(\mathrm{n}=50$ e $\mathrm{n}=100), \mathrm{A}-\mathrm{C}(\mathrm{n}=50$ e $\mathrm{n}=100), \mathrm{A}-\mathrm{B} 1(\mathrm{n}=50$ e $\mathrm{n}=100)$ e $\mathrm{B} 1-\mathrm{B} 2(\mathrm{n}=50$ e $\mathrm{n}=100$ ), respectivamente, considerando em todas elas o arranjo A1. Nas Tabelas 14, 15, 16, 17 e 18, são mostradas as respectivas $S Q R e s_{b}, S Q R e s_{v}, S Q R e s_{b}-S Q R e s_{v}$, $S Q R e s_{b I_{r}}, S Q \operatorname{Res}_{v I_{r}}$ e $S Q \operatorname{Res}_{b I_{r}}-S Q \operatorname{Res}_{v I_{r}}$. Os valores negativos mostrados nessas tabelas correspondem aos casos em que $S Q R e s_{v}<S Q R e s_{b}$. 
Freqüência de Recombinação

Freqüência de Recombinação
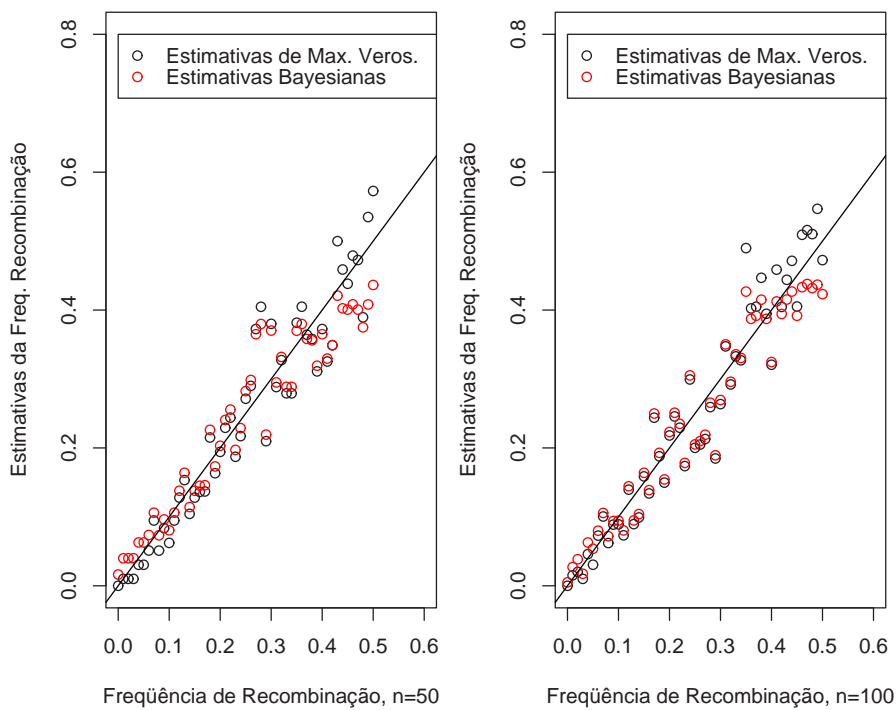

Figura 21 - Gráficos das estimativas Bayesianas e de Máxima Verossimilhança, configuração A-B3 e arranjo A1, com tamanhos amostrais n=50 e n=100, respectivamente

Tabela 14. Somas do quadrado dos resíduos para A-B3

\begin{tabular}{cccccccc}
\hline $\mathrm{n}$ & Arranjos & SQRes $_{b}$ & SQRes $_{v}$ & SQRes $_{v}-$ SQRes $_{b}$ & SQRes $_{b I_{r}}$ & SQRes $_{v I_{r}}$ & SQRes $_{v I_{r}}-$ SQRes $_{b I_{r}}$ \\
\hline \multirow{2}{*}{$n=50$} & Arranjo A1 & 0,10185 & 0,10456 & 0,00271 & 0,07039 & 0,08810 & 0,01771 \\
& Arranjo A2 & 0,11295 & 0,11724 & 0,00429 & 0,07580 & 0,10739 & 0,03159 \\
& Arranjo A3 & 0,11161 & 0,13177 & 0,02016 & 0,08156 & 0,12650 & 0,04494 \\
& Arranjo A4 & 0,12008 & 0,11300 & $-0,00708$ & 0,08533 & 0,10243 & 0,01710 \\
& Arranjo A1 & 0,07699 & 0,09627 & 0,01928 & 0,06282 & 0,08638 & 0,02356 \\
& Arranjo A2 & 0,05320 & 0,05780 & 0,00460 & 0,03780 & 0,05459 & 0,01679 \\
& Arranjo A3 & 0,05182 & 0,06770 & 0,01588 & 0,03357 & 0,04439 & 0,01082 \\
& Arranjo A4 & 0,07132 & 0,06805 & $-0,00327$ & 0,04506 & 0,04623 & 0,00117 \\
\hline
\end{tabular}


Freqüência de Recombinação
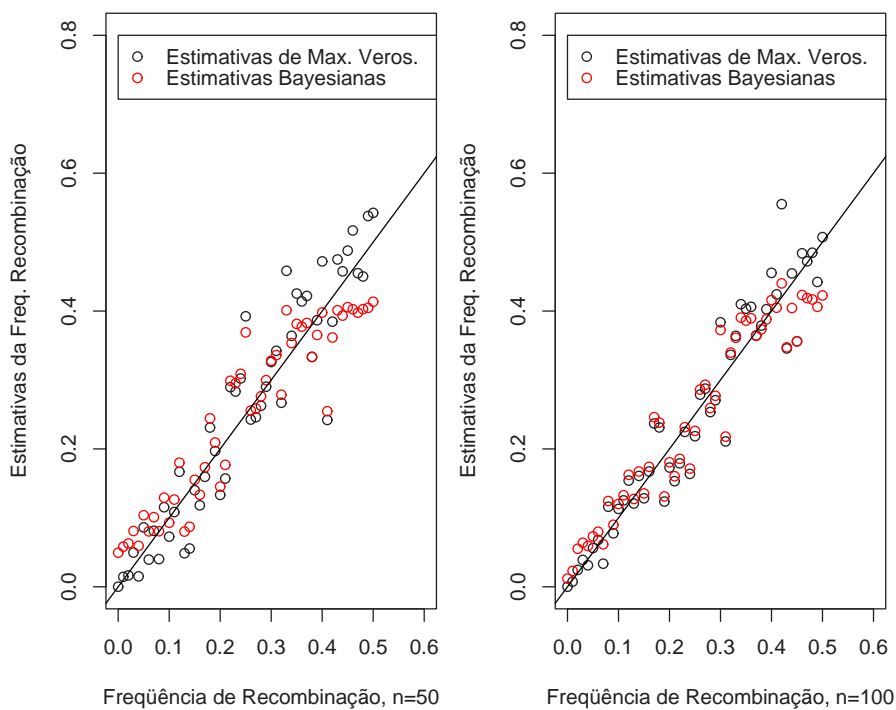

Figura 22 - Gráficos das estimativas Bayesianas e de Máxima Verossimilhança, configuração B1-B3 e arranjo A1, com tamanhos amostrais $\mathrm{n}=50$ e $\mathrm{n}=100$, respectivamente

Tabela 15. Somas do quadrado dos resíduos para B1-B3

\begin{tabular}{cccccccc}
\hline $\mathrm{n}$ & Arranjos & SQRes $_{b}$ & SQRes $_{v}$ & SQRes $_{v}-$ SQRes $_{b}$ & SQRes $_{b I_{r}}$ & SQRes $_{v I_{r}}$ & SQRes $_{v I_{r}}-$ SQRes $_{b I_{r}}$ \\
\hline \multirow{2}{*}{$n=50$} & Arranjo A1 & 0,13804 & 0,14859 & 0,01055 & 0,09920 & 0,13911 & 0,03991 \\
& Arranjo A2 & 0,11846 & 0,24376 & 0,12530 & 0,08065 & 0,21091 & 0,13026 \\
& Arranjo A3 & 0,16419 & 0,19282 & 0,02863 & 0,10172 & 0,15379 & 0,05207 \\
& Arranjo A4 & 0,15883 & 0,20154 & 0,04271 & 0,11433 & 0,18463 & 0,07030 \\
\multirow{5}{*}{$n=100$} & Arranjo A1 & 0,09218 & 0,10029 & 0,00811 & 0,06812 & 0,09718 & 0,02906 \\
& Arranjo A2 & 0,07036 & 0,06352 & $-0,00684$ & 0,04631 & 0,05518 & 0,00887 \\
& Arranjo A3 & 0,10333 & 0,11829 & 0,01496 & 0,08199 & 0,10876 & 0,02677 \\
& Arranjo A4 & 0,07785 & 0,12463 & 0,04678 & 0,05913 & 0,08383 & 0,02470 \\
\hline
\end{tabular}


Freqüência de Recombinação
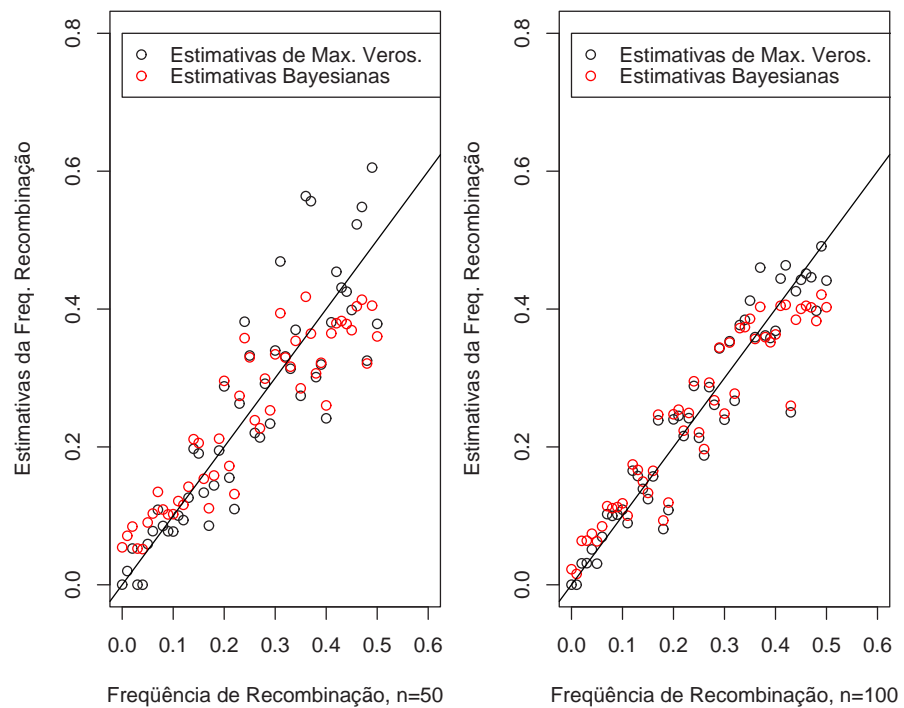

Figura 23 - Gráficos das estimativas Bayesianas e de Máxima Verossimilhança, configuração A-C e arranjo A1, com tamanhos amostrais $\mathrm{n}=50$ e $\mathrm{n}=100$, respectivamente

Tabela 16. Somas do quadrado dos resíduos para A-C

\begin{tabular}{cccccccc}
\hline $\mathrm{n}$ & Arranjos & SQRes $_{b}$ & SQRes $_{v}$ & SQRes $_{v}-$ SQRes $_{b}$ & SQRes $_{b I_{r}}$ & SQRes $_{v I_{r}}$ & SQRes $_{v I_{r}}-$ SQRes $_{b I_{r}}$ \\
\hline \multirow{2}{*}{$n=50$} & Arranjo A1 & 0,19818 & 0,29341 & 0,09523 & 0,12835 & 0,22769 & 0,09934 \\
& Arranjo A2 & 0,13392 & 0,20569 & 0,07177 & 0,09267 & 0,18874 & 0,09607 \\
& Arranjo A3 & 0,15854 & 0,18846 & 0,02992 & 0,10668 & 0,16319 & 0,05651 \\
& Arranjo A4 & 0,25995 & 0,43066 & 0,17071 & 0,15811 & 0,31093 & 0,15282 \\
\multirow{5}{*}{$n=100$} & Arranjo A1 & 0,12952 & 0,11639 & $-0,01313$ & 0,09340 & 0,10515 & 0,01175 \\
& Arranjo A2 & 0,07846 & 0,07957 & 0,00111 & 0,05127 & 0,07061 & 0,01934 \\
& Arranjo A3 & 0,08193 & 0,11634 & 0,03441 & 0,05216 & 0,10433 & 0,05217 \\
& Arranjo A4 & 0,09390 & 0,09649 & 0,00259 & 0,07561 & 0,08039 & 0,00478 \\
\hline
\end{tabular}


Freqüência de Recombinação

Freqüência de Recombinação
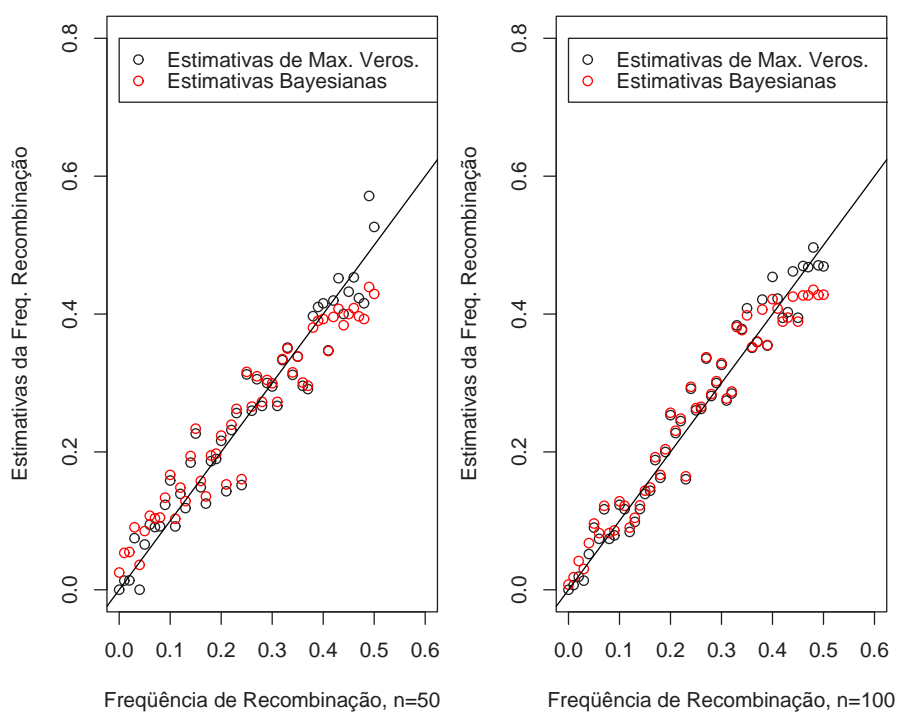

Figura 24 - Gráficos das estimativas Bayesianas e de Máxima Verossimilhança, configuração A-B1 e arranjo A1, com tamanhos amostrais n=50 e n=100, respectivamente

Tabela 17. Somas do quadrado dos resíduos para A-B1

\begin{tabular}{cccccccc}
\hline $\mathrm{n}$ & Arranjos & SQRes $_{b}$ & SQRes $_{v}$ & SQRes $_{v}-$ SQRes $_{b}$ & SQRes $_{b I_{r}}$ & SQRes $_{v I_{r}}$ & SQRes $_{v I_{r}}-$ SQRes $_{b I_{r}}$ \\
\hline \multirow{2}{*}{$n=50$} & Arranjo A1 & 0,09493 & 0,07458 & $-0,02035$ & 0,05723 & 0,06428 & 0,00705 \\
& Arranjo A2 & 0,08184 & 0,08253 & 0,00069 & 0,06092 & 0,07145 & 0,01053 \\
& Arranjo A3 & 0,13756 & 0,15422 & 0,01666 & 0,11037 & 0,14533 & 0,03496 \\
& Arranjo A4 & 0,13618 & 0,16928 & 0,03310 & 0,11336 & 0,16179 & 0,04843 \\
\multirow{5}{*}{100} & Arranjo A1 & 0,05903 & 0,04868 & $-0,01035$ & 0,04367 & 0,04655 & 0,00288 \\
& Arranjo A2 & 0,05105 & 0,04656 & $-0,00449$ & 0,03494 & 0,04264 & 0,00770 \\
& Arranjo A3 & 0,07959 & 0,07358 & $-0,00601$ & 0,06574 & 0,06711 & 0,00137 \\
& Arranjo A4 & 0,05780 & 0,08496 & 0,02716 & 0,04547 & 0,07746 & 0,03199 \\
\hline
\end{tabular}


Freqüência de Recombinação
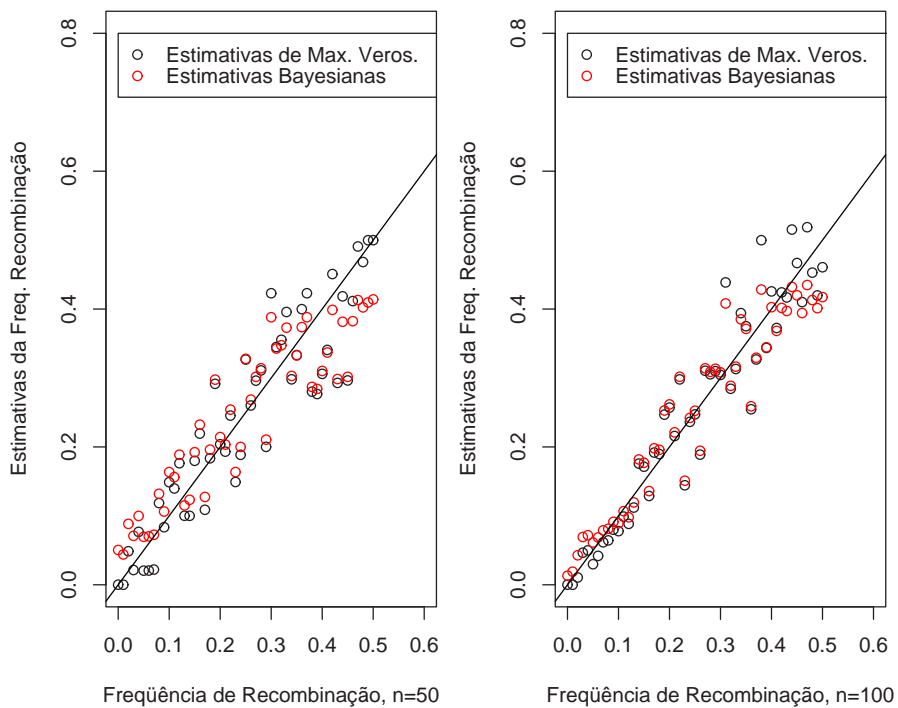

Figura 25 - Gráficos das estimativas Bayesianas e de Máxima Verossimilhança, configuração B1-B2 e arranjo A1, com tamanhos amostrais $\mathrm{n}=50$ e $\mathrm{n}=100$, respectivamente

Tabela 18. Somas do quadrado dos resíduos para B1-B2

\begin{tabular}{|c|c|c|c|c|c|c|c|}
\hline $\mathrm{n}$ & Arranjos & $S Q \operatorname{Res}_{b}$ & $S Q R e s_{v}$ & $S Q \operatorname{Res}_{v}-S Q \operatorname{Res}_{b}$ & $S Q \operatorname{Res}_{b I_{r}}$ & $S Q \operatorname{Res}_{v I_{r}}$ & $S Q \operatorname{Res}_{v I_{r}}-S Q \operatorname{Res}_{b I_{r}}$ \\
\hline \multirow[t]{4}{*}{$n=50$} & Arranjo A1 & 0,19037 & 0,17333 & $-0,01704$ & 0,14758 & 0,16798 & 0,02040 \\
\hline & Arranjo A2 & 0,21219 & 0,21720 & 0,00501 & 0,14533 & 0,17961 & 0,03428 \\
\hline & Arranjo A3 & 0,21432 & 0,31140 & 0,09708 & 0,16452 & 0,27201 & 0,10749 \\
\hline & Arranjo A4 & 0,14478 & 0,15300 & 0,00822 & 0,10314 & 0,12904 & 0,02590 \\
\hline \multirow[t]{4}{*}{$n=100$} & Arranjo A1 & 0,09537 & 0,10608 & 0,01071 & 0,06728 & 0,09344 & 0,02616 \\
\hline & Arranjo A2 & 0,07548 & 0,10102 & 0,02554 & 0,05819 & 0,09230 & 0,03420 \\
\hline & Arranjo A3 & 0,12645 & 0,16654 & 0,04009 & 0,09541 & 0,13836 & 0,04295 \\
\hline & Arranjo A4 & 0,07829 & 0,08044 & 0,00215 & 0,04350 & 0,05995 & 0,01645 \\
\hline
\end{tabular}

Como já visto, em todos os casos apresentados, com o aumento do tamanho amostral de 50 para 100, tanto as estimativas de $r$ obtidas pelo método da máxima verossimilhança como as estimativas de $r$ obtidas pelo método Bayesiano têm seus comportamentos melhorado em relação à reta identidade. Isso também é notado quando se aumenta o tamanho amostral para 200 e 500 (Anexo E). Assim, quanto mais se aumenta o tamanho amostral, maior é a precisão das estimativas da freqüência de recombinação obtidas pelos dois métodos aqui estudados, como já era 
de se esperar.

Também, para todas as combinações, a maioria das estimativas Bayesianas super-estimam os valores verdadeiros da freqüência de recombinação no intervalo $(0 ; 0,05)$. De fato, pois, através da priori dada, os valores nesse intervalo são pouco prováveis. Dessa maneira, como as estimativas usadas nas simulações dos conjuntos de dados são pequenas, as estimativas Bayesianas apresentam valores maiores. O contrário acontece no intervalo $(0,45 ; 0,5)$, já que a informação a priori relata que valores nesse intervalo são pouco prováveis. Por isso, algumas $S Q R e s_{b}$ deram maiores que $S Q R e s_{v}$. Na região do intervalo paramétrico em que a priori informa os valores mais prováveis da freqüência de recombinação, $S Q R e s_{b I_{r}}<S Q R e s_{v I_{r}}$ para todas as combinações aqui abordadas. Em resumo, com exceção do intervalo $(0,45 ; 0,5)$, em todas as combinações, a maioria das estimativas Bayesianas da freqüência de recombinação apresentam valores maiores que as estimativas de máxima verossimilhança.

Respectivamente, os testes LRT e Fator de Bayes foram usados para obter quais das estimativas de máxima verossimilhança e Bayesiana eram significativas. Para todos as configurações e arranjos abordados, todos os valores não significativos das estimativas de máxima verossimilhança também foram não significativos para as estimativas Bayesianas (Anexo F). O inverso não ocorreu. De fato, mesmo usando testes distintos para encontrar tais valores significativos, através dos gráficos mostrados nesta seção, é de se esperar que dêem mais estimativas de máxima verossimilhança significativas dos que as estimativas Bayesianas. Isso se deve ao fato de que, como notado, a maioria das estimativas Bayesianas apresentam valores maiores que as estimativas de máxima verossimilhança. Deve ser ressaltado que, para aqueles valores das estimativas (no intervalo $(0,45 ; 0,5)$ ) em que isso não ocorre, tais valores deram praticamente todos não significativos, para qualquer um dos métodos de estimação aqui usados.

Os intervalos de confiança e de credibilidade para a freqüência de recombinação foram obtidos para as estimativas de máxima verossimilhança e Bayesiana da freqüência de recombinação, respectivamente. Juntamente com os ver- 
dadeiros valores de $r$ e suas respectivas estimativas obtidas pelos dois métodos, alguns desses intervalos encontram-se no Anexo G. Em alguns dos intervalos de confiança para as estimativas de $r$ obtidas através do método da máxima verossimilhança, existem valores não plausíveis em relação ao intervalo paramétrico considerado. O mesmo não ocorre aos intervalos de credibilidade. Entretanto, esses dois tipos de intervalos não podem ser comparados já que apresentam interpretações distintas.

Para as configurações B3-C ( $A 2$ e $A 3)$, B3-B3 ( $A 2$ e $A 3)$ e C-C ( $A 2$ e $A 3)$ não foi possível calcular alguns dos intervalos de confiança obtidos para as estimativas de $r$ determinadas pelo método de máxima verossimilhança (Anexo G). De fato pois, como tais intervalos foram obtidos através do método de aproximação de Fisher, para algumas das estimativas não significativas e para estimativas aproximadamente nulas (com aproximação de quatro casas decimais), a raíz do denominador usado na aproximação de Fisher resultou em valores negativos.

De acordo com a informação a priori, diferentes distribuições a priori podem ser formuladas. Por exemplo: pode-se atribuir uma distribuição a priori em que a informação relata a ligação entre os locos e, também, uma pequena distância entre tais locos, ou seja, a informação é dada através de um mapa já construído em que os locos ligados estavam bem próximos entre si, sendo a distância entre eles praticamente nula, como as estimativas da freqüência de recombinação $(r)$ obtidas pelo método de máxima verossimilhança para a combinação dos marcadores C-C considerando os arranjos $A 2, A 3$ e $A 4$. Com a distribuição a priori aqui estudada, as estimativas Bayesianas de $r$ super-estimam os verdadeiros valores da freqüência de recombinação, principalmente, quando considera-se a combinação dos marcadores C-C e arranjos $A 2, A 3$ e $A 4$. A Figura 26 representa um exemplo de uma distribuição a priori que pode ser usada para esse tipo de informação. De fato, as estimativas Bayesianas de $r$ não super-estimam tanto os verdadeiros valores de $r$ com a nova distribuição a priori como as estimativas Bayesinas obtidas através da distribuição a priori aqui estudada (Anexo $\mathrm{H}$ ). 


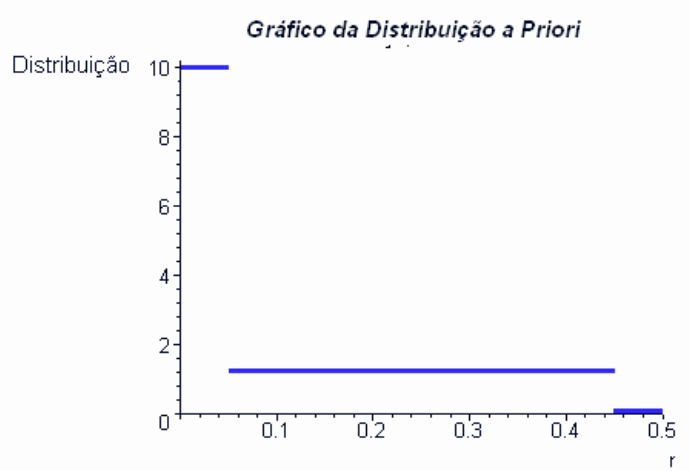

Figura 26 - Gráfico da distribuição priori com uma priori informativa

Um outro exemplo de distribuição a priori é considerar a informação de que não há ligação entre os locos que estão sendo estudados. Um exemplo de distribuição a priori informativa nesse caso é dado na Figura 27.

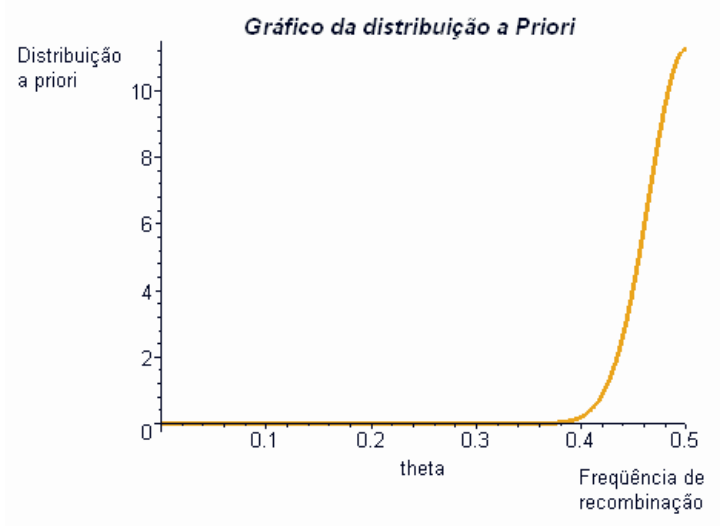

Figura 27 - Gráfico da distribuição a priori 
Para o casos em que nada se sabe a respeito dos locos que serão estudados, a distribuição a priori deve ser não informativa, isto é, todos os valores do intervalo paramétrico são equiprováveis, como mostra o gráfico da Figura 28.

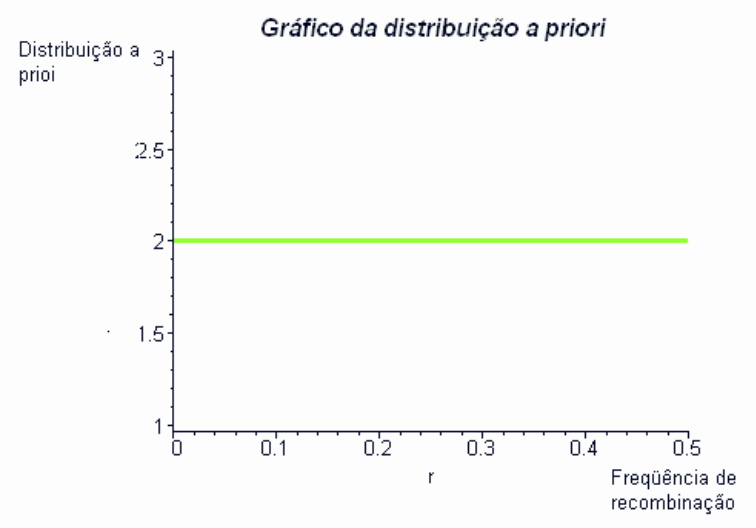

Figura 28 - Gráfico da distribuição a priori não informativa

Assim, cabe ao pesquisador e ao estatístico construir uma distribuição a priori com base em informações de mapas que já foram construídos.

\subsection{Fases de Ligação}

A fase de ligação define a configuração dos alelos de um par de locos heterozigóticos sobre os cromossomos homólogos em um único genitor. O conhecimento da fase de ligação é necessário para detectar os eventos recombinantes. Geralmente, em análise de ligação envolvendo espécies de polinização aberta em que não é possível a obtenção de linhagens endogâmicas, a fase de ligação entre os marcadores são desconhecidas a priori.

Como já citado, se a fase de ligação não pode ser determinada, então, o processo para se obtê-la é aplicar as estimativas para todas as possíveis fases de ligação e, consequentemente, deduzir a atual fase. Tal método varia para diferentes configurações. A fase de ligação mais provável entre dois marcadores $M^{1}$ e $M^{2}$ ligados pode ser estimada através dos cálculos das probabilidades a posteriori, eq. 11 (ver 
3.2), para os quatro diferentes arranjos $A_{w}^{2}, w=1,2,3$ e 4 . O arranjo correspondente a maior probabilidade a posteriori representa a fase de ligação mais provável.

Se a fase de ligação de um par de locos não pode ser (completamente) determinada baseada nesse método, a opção é determinar as fases indiretamente através de combinações com locos vizinhos com um tipo de segregação mais informativo.

Primeiramente, considera-se as configurações em que somente um dos genitores é heterozigótico para ambos os locos (configurações D1-D1, B3-D1, A-D1, C-D1, B1-D1, B2-D1), isto é, configurações em que pelo menos um dos marcadores é D1 (ou D2). Para tais configurações, com relação as estimativas da freqüência de recombinação obtidas pelo método da máxima verossimilhança, sempre $\widehat{r}_{r e p_{-}}=$ $1-\widehat{r}_{\text {ass_ }}$, com $\widehat{r}_{\text {rep_ }}$ sendo a estimativa da freqüência de recombinação considerando a fase repulsão para o primeiro genitor (arranjos $A_{3}$ e $A_{4}$ ) e $\widehat{r}_{\text {ass_- }}$ a estimativa de $r$ considerando a fase associação para o primeiro genitor (arranjos $A_{1}$ e $A_{2}$ ).

Para esses tipos de configurações, considerando os conjuntos de dados simulados para os arranjos $A_{1}$ ou $A_{2}$ e as estimativas de máxima verossimilhança, as maiores probabilidades a posteriori são dadas para os arranjos $A_{1}$ e $A_{2}$, para alguns dos conjuntos de dados simulados e $A_{1}, A_{2}, A_{3}$ e $A_{4}$ para os outros conjuntos. No entanto, os arranjos $A_{3}$ e $A_{4}$ são descartados como arranjos prováveis já que apresentam estimativas da freqüência de recombinação maiores que 0,5. O contrário também acontece quando os dados são simulados para os arranjos $A_{3}$ e $A_{4}$.

Considerando-se as estimativas da freqüência de recombinação obtidas pelo método Bayesiano, as probabilidades a posteriori calculadas são maiores para os arranjos $A_{1}$ e $A_{2}$, quando os dados são simulados a partir dos arranjos $A 1$ e $A 2$. Tais probabilidades são maiores para os arranjos $A_{3}$ e $A_{4}$. Quando os dados são gerados a partir dos arranjos $A_{3}$ e $A_{4}$.

As Tabelas 19 e 20 mostram alguns dos verdadeiros valores de $r\left(r_{\text {verd }}\right)$ usados na simulação dos conjuntos de dados, as estimativas Bayesianas e de máxima verossimilhança de $r$ e as probabilidades a posteriori para cada uma das estimativas 
considerando os quatro possíveis arranjos, em que a configuração é D1-D1. Nas Tabelas 19 e 20 os verdadeiros arranjos considerados são $A 1$ e $A 4$, respectivamente.

Tabela 19. Freqüências de recombinação verdadeiras com suas respectivas estimativas Bayesianas e de máxima verossimilhança de $r$; probabilidades a posteriori Posteriori-Bay e Posteriori-Vero usando as estimativas Bayesianas e de máxima verossimilhança, respectivamente, para os quatro tipos de arranjos, sendo $A 1$ o verdadeiro arranjo e $n=50$ para a configuração D1-D1

\begin{tabular}{ccccccc}
\hline & Tipos de arranjos & $r_{\text {ver }}=0,22$ & $r_{\text {ver }}=0,23$ & $r_{\text {ver }}=0,24$ & $r_{\text {ver }=0,25}$ & $r_{\text {ver }}=0,26$ \\
\hline \multirow{2}{*}{ Est. Bay } & $A 1$ & 0,2871 & 0,2497 & 0,2871 & 0,3049 & 0,2497 \\
& $A 2$ & 0,2871 & 0,2497 & 0,2871 & 0,3049 & 0,2497 \\
& $A 3$ & 0,4512 & 0,4576 & 0,4512 & 0,4481 & 0,4576 \\
\multirow{3}{*}{ Est. Vero } & $A 4$ & 0,4512 & 0,4576 & 0,4512 & 0,4481 & 0,4576 \\
& $A 1$ & 0,2798 & 0,2402 & 0,2798 & 0,2998 & 0,2401 \\
& $A 2$ & 0,2799 & 0,2402 & 0,2798 & 0,2998 & 0,2401 \\
Posteriori-Bay & $A 3$ & 0,7201 & 0,7598 & 0,7202 & 0,7002 & 0,7000 \\
& $A 4$ & 0,7201 & 0,7598 & 0,7202 & 0,7002 & 0,7000 \\
& $A 1$ & 0,4997 & 0,5000 & 0,4996 & 0,4992 & 0,5000 \\
& $A 2$ & 0,4997 & 0,5000 & 0,4996 & 0,4992 & 0,5000 \\
Posteriori-Vero & $A 3$ & 0,0003 & 0,0000 & 0,0003 & 0,0008 & 0,0000 \\
& $A 4$ & 0,0003 & 0,0000 & 0,0003 & 0,0008 & 0,0000 \\
& $A 1$ & 0,2500 & 0,2500 & 0,2500 & 0,2500 & 0,3050 \\
& $A 2$ & 0,2500 & 0,2500 & 0,2500 & 0,2500 & 0,3050 \\
& $A 3$ & 0,2500 & 0,2500 & 0,2500 & 0,2500 & 0,1950 \\
& $A 4$ & 0,2500 & 0,2500 & 0,2500 & 0,2500 & 0,1950 \\
\hline
\end{tabular}

Nota-se, que diferente das estimativas de $r$ obtidas pelo método da máxima verossimilhança considerando os quatro tipos de arranjos, as estimativas Bayesianas não ultrapassam 0,5 em nenhuma situação. Sendo $A_{1}$ ou $A_{2}$ o verdadeiro arranjo, as estimativas Bayesianas para os arranjos $A_{3}$ e $A_{4}$ estão próximos de 0,5 , mas não ultrapassam tal valor. O recíproco também acontece, como mostra a Tabela 20. 
Tabela 20. Freqüências de recombinação verdadeiras com suas respectivas estimativas Bayesianas e de máxima verossimilhança de $r$; probabilidades a posteriori Posteriori-Bay e Posteriori-Vero usando as estimativas Bayesianas e de máxima verossimilhança, respectivamente, para os quatro tipos de arranjos, sendo $A 4$ o verdadeiro arranjo e $\mathrm{n}=50$ para a configuração D1-D1

\begin{tabular}{ccccccc}
\hline & Tipos de arranjos & $r_{\text {ver }}=0,22$ & $r_{\text {ver }}=0,23$ & $r_{\text {ver }}=0,24$ & $r_{\text {ver }}=0,25$ & $r_{\text {ver }}=0,26$ \\
\hline Est. Bay & $A 1$ & 0,4607 & 0,4638 & 0,4638 & 0,4512 & 0,4481 \\
& $A 2$ & 0,4607 & 0,4638 & 0,4638 & 0,4512 & 0,4481 \\
$A 3$ & 0,2307 & 0,2115 & 0,2115 & 0,2871 & 0,3049 \\
\multirow{3}{*}{ Est. Vero } & $A 4$ & 0,2307 & 0,2115 & 0,2115 & 0,2871 & 0,3049 \\
& $A 1$ & 0,7802 & 0,7998 & 0,7999 & 0,7202 & 0,7002 \\
& $A 2$ & 0,7802 & 0,7998 & 0,7999 & 0,7202 & 0,7002 \\
Posteriori-Bay & $A 3$ & 0,2198 & 0,2002 & 0,2001 & 0,2798 & 0,2998 \\
& $A 4$ & 0,2198 & 0,2002 & 0,2001 & 0,2798 & 0,2998 \\
& $A 1$ & 0,0000 & 0,0000 & 0,0000 & 0,0003 & 0,0008 \\
Posteriori-Vero & $A 2$ & 0,0000 & 0,0000 & 0,0000 & 0,0003 & 0,0008 \\
& $A 3$ & 0,5000 & 0,5000 & 0,5000 & 0,4997 & 0,4992 \\
& $A 4$ & 0,5000 & 0,5000 & 0,5000 & 0,4997 & 0,4992 \\
& $A 1$ & 0,2500 & 0,2500 & 0,2500 & 0,2500 & 0,2500 \\
& $A 2$ & 0,2500 & 0,2500 & 0,2500 & 0,2500 & 0,2500 \\
& $A 3$ & 0,2500 & 0,2500 & 0,2500 & 0,2500 & 0,2500 \\
& $A 4$ & 0,2500 & 0,2500 & 0,2500 & 0,2500 & 0,2500 \\
\hline
\end{tabular}

A situação em que ambos os locos tem um tipo de segregação simétrico corresponde às configurações B3-B3, B3-C e C-C. Aqui, as estimativas de $r$ para os arranjos $A 2$ (marcadores ligados em associação no primeiro genitor e em repulsão no segundo genitor) e $A 3$ (marcadores ligados em repulsão no primeiro genitor e em associação no segundo genitor) são idênticas, já que, de acordo com as Figuras 29, 30 e 31, o primeiro genitor do arranjo $A 2$ corresponde ao segundo genitor do arranjo $A 3$ e o primeiro genitor deste último arranjo corresponde ao segundo genitor do $A 2$. Por isso, a escolha entre $A 2$ ou $A 3$ não pode ser resolvida. Dessa maneira, se o verdadeiro arranjo for $A 2$ ou $A 3$, então, para qualquer um dos métodos de estimação da freqüência de recombinação utilizados, a dúvida entre as fases $A 2$ e $A 3$ não pode ser esclarecida. 


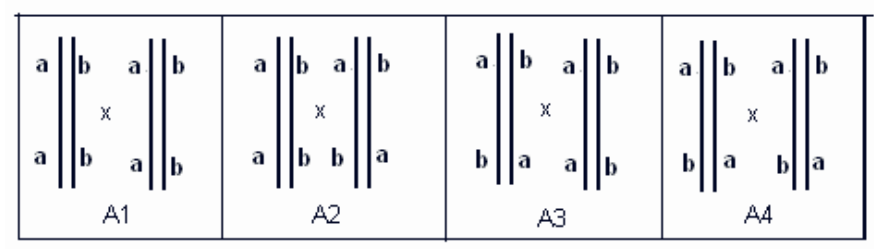

Figura 29 - Possíveis arranjos para o cruzamento $B 3 \times B 3$

\begin{tabular}{|c|c|c|c|}
\hline 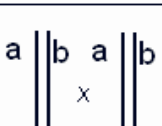 & $\mathrm{a}\left\|\mathrm{br}^{\mathrm{a}} \mathrm{x}^{\mathrm{a}}\right\|^{\mathrm{b}}$ & ${ }^{a} \| \begin{array}{cc}b & a \\
x & b\end{array}{ }^{b}$ & $a|| \begin{array}{ll}b & a \\
& x\end{array}$ \\
\hline a $\|_{A_{A_{1}}}$ a $\|_{0}$ & $a\left\|_{\mathrm{A}_{2}} \circ\right\|^{a}$ & $\circ \|_{A_{3}} \mid a$ & $\stackrel{\circ \| a}{\circ A_{A_{4}}}$ \\
\hline
\end{tabular}

Figura 30 - Possíveis arranjos para o cruzamento $B 3 \times C$

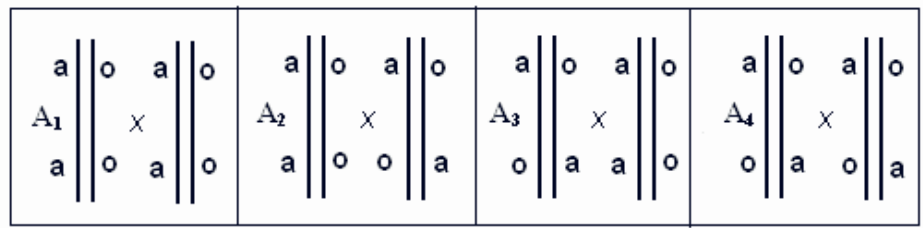

Figura 31 - Possíveis arranjos para o cruzamento $C \times C$

Além disso, para o caso clássico, $\widehat{r}_{A 1}=1-\widehat{r}_{A 4}$, em que $\widehat{r}_{A 1}$ é a estimativa para o arranjo $A 1$ (marcadores ligados em associação nos dois genitores) e $\widehat{r}_{A 4}$ é a estimativa de $r$ para o arranjo $A 4$ (marcadores ligados em repulsão nos dois genitores).

Se a fase é $A 1$ ou $A 4$ para as configurações B3-B3 e B3-C, as estimativas de $r$ obtidas pelo método de máxima verossimilhança em relação aos outros dois arranjos são bem próximas de 0,5. Nestes casos, as maiores probabilidades $a$ posteriori são dadas aos arranjos $A 1$ e $A 4$, simultâneamente, já que ambos os arran- 
jos apresentam a mesma probabilidade. Sendo $A 1$ o verdadeiro arranjo, a estimativa de $r$ para o arranjo $A 4$ é maior que 0,5 , assim como, será maior para o arranjo $A 1$ quando o verdadeiro arranjo for $A 4$. No caso Bayesiano, se o verdadeiro arranjo for A1 (ou A4), então, de imediato, as maiores probabilidades a posteriori correspondem apenas ao arranjo $A 1$ (ou $A 4$ ). A Tabela 21 mostra algumas das estimativas da freqüência de recombinação obtidas pelos dois métodos, juntamente com as probabilidades a posteriori, quando os valores de $r$ usados na simulação dos conjuntos de dados são $0,22,0,23,0,24,0,25$ e 0,26, arranjo $A 1$ e n=100, para a configuração B3-B3.

Tabela 21. Freqüências de recombinação verdadeiras com suas respectivas estimativas Bayesianas e de máxima verossimilhança de $r$; probabilidades a posteriori Posteriori-Bay e Posteriori-Vero usando as estimativas Bayesianas e de máxima verossimilhança, respectivamente, para os quatro tipos de arranjos, sendo $A 1$ o verdadeiro arranjo e $n=100$ para a configuração B3-B3

\begin{tabular}{ccccccc}
\hline & Tipos de arranjos & $r_{\text {ver }}=0,22$ & $r_{\text {ver }}=0,23$ & $r_{\text {ver }}=0,24$ & $r_{\text {ver }}=0,25$ & $r_{\text {ver }}=0,26$ \\
\hline \multirow{2}{*}{ Est. Bay } & $A 1$ & 0,2254 & 0,2880 & 0,1727 & 0,2566 & 0,2480 \\
& $A 2$ & 0,4198 & 0,4141 & 0,4278 & 0,4084 & 0,4141 \\
& $A 3$ & 0,4198 & 0,4141 & 0,4278 & 0,4084 & 0,4141 \\
\multirow{3}{*}{ Est. Vero } & $A 4$ & 0,4880 & 0,4733 & 0,4927 & 0,4917 & 0,4884 \\
& $A 1$ & 0,2200 & 0,2815 & 0,1679 & 0,2525 & 0,2431 \\
& $A 2$ & 0,5000 & 0,5000 & 0,5000 & 0,5000 & 0,5000 \\
Posteriori-Bay & $A 3$ & 0,5000 & 0,5000 & 0,5000 & 0,5000 & 0,5000 \\
& $A 4$ & 0,7800 & 0,7184 & 0,8320 & 0,7471 & 0,7569 \\
& $A 1$ & 1,0000 & 1,0000 & 1,0000 & 1,0000 & 1,0000 \\
Posteriori-Vero & $A 2$ & 0,000 & 0,000 & 0,000 & 0,000 & 0,000 \\
& $A 3$ & 0,000 & 0,000 & 0,000 & 0,000 & 0,000 \\
& $A 4$ & 0,000 & 0,000 & 0,000 & 0,000 & 0,000 \\
& $A 1$ & 0,5000 & 0,5000 & 0,5000 & 0,5000 & 0,5000 \\
& $A 2$ & 0,0000 & 0,0000 & 0,0000 & 0,0000 & 0,0000 \\
& $A 3$ & 0,0000 & 0,0000 & 0,0000 & 0,0000 & 0,0000 \\
& $A 4$ & 0,5000 & 0,5000 & 0,5000 & 0,5000 & 0,5000 \\
\hline
\end{tabular}

Na Tabela 22, as estimativas de $r$ e as probabilidades a posteriori para a configuração B3-B3 (n=100) também são apresentadas, mas considerando agora o arranjo $A 2$ usado na simulação dos conjuntos de dados. Como já mencionado, a escolha entre os arranjos $A 2$ e $A 3$ não pode ser resolvida. Nota-se através da Tabela 
22 que, de imediato, tanto as probabilidades a posteriori usando as estimativas Bayesianas de $r$ como as probabilidades a posteriori usando as estimativas de máxima verossimilhança são maiores para $A 2$ e $A 3$, simultâneamente. Dessa maneira, embora não haja necessidade de verificar qual a fase de ligação mais provável através dos valores estimados de $r$, é interessante notar que, na maioria dos casos, as estimativas da freqüência de recombinação obtidas pelos dois métodos aqui abordados são bem próximas de 0,5 para os arranjos $A 1$ e $A 4$.

Tabela 22. Freqüências de recombinação verdadeiras com suas respectivas estimativas Bayesianas e de máxima verossimilhança de $r$; probabilidades a posteriori Posteriori-Bay e Posteriori-Vero usando as estimativas Bayesianas e de máxima verossimilhança, respectivamente, para os quatro tipos de arranjos, sendo $A 2$ o verdadeiro arranjo e $\mathrm{n}=100$ para a configuração B3-B3

\begin{tabular}{ccccccc}
\hline & Tipos de arranjos & $r_{\text {ver }}=0,22$ & $r_{\text {ver }}=0,23$ & $r_{\text {ver }}=0,24$ & $r_{\text {ver }}=0,25$ & $r_{\text {ver }}=0,26$ \\
\hline \multirow{2}{*}{ Est. Bay } & $A 1$ & 0,4314 & 0,4203 & 0,4337 & 0,4317 & 0,4319 \\
& $A 2$ & 0,2535 & 0,2425 & 0,3216 & 0,2880 & 0,3217 \\
\multirow{3}{*}{ Est. Vero } & $A 3$ & 0,2535 & 0,2425 & 0,3216 & 0,2880 & 0,3217 \\
& $A 4$ & 0,4314 & 0,4483 & 0,4231 & 0,4361 & 0,4268 \\
& $A 1$ & 0,49989 & 0,45480 & 0,52062 & 0,49225 & 0,50986 \\
\multirow{3}{*}{ Posteriori-Bay } & $A 3$ & 0,23520 & 0,22627 & 0,29965 & 0,26569 & 0,29971 \\
& $A 4$ & 0,23520 & 0,22627 & 0,29965 & 0,26569 & 0,29971 \\
& $A 1$ & 0,50011 & 0,54520 & 0,47938 & 0,50775 & 0,49014 \\
& $A 2$ & 0,0034 & 0,0068 & 0,0323 & 0,0180 & 0,0389 \\
Posteriori-Vero & 0,4965 & 0,4962 & 0,4460 & 0,4848 & 0,4510 \\
& $A 3$ & 0,4965 & 0,4962 & 0,4460 & 0,48484 & 0,4510 \\
& $A 4$ & 0,0034 & 0,0008 & 0,0757 & 0,0123 & 0,0591 \\
& $A 1$ & 0,0092 & 0,0088 & 0,1155 & 0,0407 & 0,1100 \\
& $A 2$ & 0,4908 & 0,4912 & 0,3845 & 0,4593 & 0,3900 \\
& $A 3$ & 0,4908 & 0,4912 & 0,3845 & 0,4593 & 0,3900 \\
& $A 4$ & 0,0092 & 0,0088 & 0,1155 & 0,0407 & 0,1100 \\
\hline
\end{tabular}

Para a configuração C-C a situação é ainda mais complicada, pois, além de ser do tipo simétrico, ambos os locos têm um alelo nulo em ambos os genitores, o que gera uma maior dúvida em relação à estimação da fase de ligação. Se nesse cruzamento o arranjo verdadeiro for $A_{1}$ (marcadores ligados em associação nos dois genitores), para as estimativas de $r$ obtidas pelo método clássico, as probabilidades a posteriori serão maiores para os arranjos $A_{1}$ e $A_{4}$ (marcadores ligados em repulsão 
nos dois genitores). A fase $A_{1}$ é a escolhida pois as estimativas correspondentes a fase $A_{4}$ são maiores que 0,5. Para as estimativas de $r$ obtidas pelo método Bayesiano, a maior probabilidade a posteriori é dada para $A_{1}$ quando $A_{1}$ é o verdadeiro arranjo. Algumas das probabilidades a posteriori determinadas através das estimativas de máxima verossimilhança e Bayesiana de $r$ para os quatro arranjos, bem como tais estimativas, se encontram na Tabela 23.

Tabela 23. Freqüências de recombinação verdadeiras com suas respectivas estimativas Bayesianas e de máxima verossimilhança de $r$; probabilidades a posteriori Posteriori-Bay e Posteriori-Vero usando as estimativas Bayesianas e de máxima verossimilhança, respectivamente, para os quatro tipos de arranjos, sendo $A 1$ o verdadeiro arranjo e $\mathrm{n}=100$ para a configuração C-C

\begin{tabular}{ccccccc}
\hline & Tipos de arranjos & $r_{\text {ver }}=0,22$ & $r_{\text {ver }}=0,23$ & $r_{\text {ver }}=0,24$ & $r_{\text {ver }}=0,25$ & $r_{\text {ver }}=0,26$ \\
\hline \multirow{2}{*}{ Est. Bay } & $A 1$ & 0.3186 & 0.2731 & 0.2868 & 0.2819 & 0.2731 \\
& $A 2$ & 0.3824 & 0.3919 & 0.3865 & 0.3987 & 0.3919 \\
& $A 3$ & 0.3824 & 0.3919 & 0.3865 & 0.3987 & 0.3919 \\
Est. Vero & $A 4$ & 0.4415 & 0.4520 & 0.4453 & 0.4628 & 0.4520 \\
& $A 1$ & 0.3120 & 0.2638 & 0.2768 & 0.2748 & 0.2637 \\
\multirow{3}{*}{ Posteriori-Bay } & $A 2$ & 0.5000 & 0.5000 & 0.5000 & 0.5000 & 0.5000 \\
& $A 3$ & 0.5000 & 0.5000 & 0.5000 & 0.5000 & 0.5000 \\
& $A 4$ & 0.6880 & 0.7362 & 0.7232 & 0.7252 & 0.7363 \\
Posteriori-Vero & $A 2$ & 0.9687 & 0.9981 & 0.9931 & 0.9992 & 0.9981 \\
& $A 2$ & 0.0145 & 0.0009 & 0.0031 & 0.0004 & 0.0009 \\
& $A 3$ & 0.0145 & 0.0009 & 0.0031 & 0.0004 & 0.0009 \\
& $A 1$ & 0.0023 & 0.0001 & 0.0005 & 0,0001 & 0.0001 \\
& $A 2$ & 0.4879 & 0.4992 & 0.4930 & 0.4997 & 0.4992 \\
& $A 3$ & 0.01210 & 0.0008 & 0.0027 & 0.0003 & 0.0008 \\
& $A 4$ & 0.01210 & 0.0008 & 0.0027 & 0.0003 & 0.0008 \\
\hline
\end{tabular}

É importante notar que, considerando $A 1$ como o verdadeiro arranjo, as estimativas máxima verossimilhança de $r$ para os arranjos $A 2$ e $A 3$ são bem próximas de 0,5 e, assim, provavelmente, implicariam em não ligação entre os locos que estão sendo considerados. Se, entretanto, as fases são $A 2, A 3$ ou $A 4$, então, todas, exceto as estimativas de $A 1$, serão legítimas, isto é, menores que 0,5.

Se a fase de ligação verdadeira for $A_{4}$, usando as estimativas de $r$ clássicas, as probabilidades a posteriori para os quatro arranjos serão bem próximas 
entre si e, apenas as estimativas de $r$ para o arranjo $A 1$ ultrapassam o valor de 0,5, como mostra a Tabela 24. Em relação as estimativas Bayesianas, algumas das maiores probabilidades a posteriori deram para o arranjo $A_{4}$, enquanto outras deram para os arranjos $A_{2}$ e $A_{3}$ como, também, é mostrado na Tabela 24.

Tabela 24. Freqüências de recombinação verdadeiras com suas respectivas estimativas Bayesianas e de máxima verossimilhança de $r$; probabilidades a posteriori Posteriori-Bay e Posteriori-Vero usando as estimativas Bayesianas e de máxima verossimilhança, respectivamente, para os quatro tipos de arranjos, sendo $A 4$ o verdadeiro arranjo e $\mathrm{n}=100$ para a configuração C-C

\begin{tabular}{cccccccc}
\hline & Tipos de arranjos & $r_{\text {ver }}=0,22$ & $r_{\text {ver }}=0,23$ & $r_{\text {ver }}=0,24$ & $r_{\text {ver }=0,25}$ & $r_{\text {ver }}=0,26$ & $r_{\text {ver }}=0,37$ \\
\hline \multirow{2}{*}{ Est. Bay } & $A 1$ & 0,4452 & 0,4508 & 0,4388 & 0,4372 & 0,4517 & 0,4139 \\
& $A 2$ & 0,1748 & 0,1043 & 0,1185 & 0,1246 & 0,0862 & 0,3019 \\
& $A 3$ & 0,1748 & 0,1043 & 0,1185 & 0,1246 & 0,0862 & 0,3019 \\
\multirow{3}{*}{ Est. Vero } & $A 4$ & 0,3223 & 0,2026 & 0,1659 & 0,1707 & 0,1380 & 0,3882 \\
& $A 1$ & 0,6723 & 0,8140 & 0,9719 & 0,9720 & 0,9798 & 0,5259 \\
& $A 2$ & 0,1226 & 0,0362 & 0,0015 & 0,0014 & 0,0008 & 0,3369 \\
\multirow{3}{*}{ Posteriori-Bay } & $A 3$ & 0,1226 & 0,0362 & 0,0015 & 0,0014 & 0,0008 & 0,3369 \\
& $A 4$ & 0,3277 & 0,1860 & 0,0281 & 0,0280 & 0,0201 & 0,4741 \\
& $A 1$ & 0.0026 & 0.0001 & 0.0006 & 0.0009 & 0,0000 & 0,1298 \\
Posteriori-Vero & $A 2$ & 0.3040 & 0.2334 & 0.1761 & 0.1828 & 0.1355 & 0,3303 \\
& $A 3$ & 0.3040 & 0.2334 & 0.1761 & 0.1828 & 0.1355 & 0,3303 \\
& $A 4$ & 0.3894 & 0.5330 & 0.6473 & 0.6335 & 0.7290 & 0,2096 \\
& $A 1$ & 0.2500 & 0.2500 & 0.2511 & 0.2509 & 0.2511 & 0,2500 \\
& $A 2$ & 0.2500 & 0.2500 & 0.2489 & 0.2491 & 0.2489 & 0,2500 \\
& $A 3$ & 0.2500 & 0.2500 & 0.2489 & 0.2491 & 0.2489 & 0,2500 \\
& $A 4$ & 0.2500 & 0.2500 & 0.2511 & 0.2509 & 0.2511 & 0,2500 \\
\hline
\end{tabular}

Se o verdadeiro arranjo for $A_{2}$ ou $A_{3}$, fica ainda mais difícil de estimar a fase. Neste caso, as maiores probabilidades a posteriori usando as estimativas de máxima verossimilhança da freqüência de recombinação podem ser dadas aos arranjos $A 1, A 2, A 3$ e $A 4$, simultâneamente. Destes três arranjos, apenas o arranjo $A 1$ é descartado por apresentar estimativas de $r$ maiores que 0,5. Outras vezes, a maior probabilidade a posteriori é dada aos arranjos $A 1$ e $A 4$, em que $A 1$ é descartado por apresentar a estimativa de $r$ maior que 0,5, levando, assim, a uma conclusão errada da fase de ligação. Usando as estimativas de $r$ Bayesianas, as maiores probabilidades a posteriori são dadas aos arranjos $A 2$ e $A 3$, simultâneamente, ou apenas ao arranjo 
A4. As estimativas de $r$ e as probabilidades a posteriori para os quatro tipos de arranjos são mostradas na Tabela 25 em que o verdadeiro arranjo é $A 2$.

Tabela 25. Freqüências de recombinação verdadeiras com suas respectivas estimativas Bayesianas e de máxima verossimilhança de $r$; probabilidades a posteriori Posteriori-Bay e Posteriori-Vero usando as estimativas Bayesianas e de máxima verossimilhança, respectivamente, para os quatro tipos de arranjos, sendo $A 2$ o verdadeiro arranjo e $\mathrm{n}=100$ para a configuração C-C

\begin{tabular}{ccccccc}
\hline & Tipos de arranjos & $r_{\text {ver }}=0,22$ & $r_{\text {ver }}=0,23$ & $r_{\text {ver }}=0,24$ & $r_{\text {ver }=0,25}$ & $r_{\text {ver }}=0,26$ \\
\hline \multirow{2}{*}{ Est. Bay } & $A 1$ & 0,4262 & 0,4390 & 0,4236 & 0,4170 & 0,4392 \\
& $A 2$ & 0,2480 & 0,1636 & 0,2749 & 0,3297 & 0,2041 \\
& $A 3$ & 0,2480 & 0,1636 & 0,2749 & 0,3297 & 0,2041 \\
\multirow{3}{*}{ Est. Vero } & $A 4$ & 0,3540 & 0,2876 & 0,3749 & 0,4111 & 0,3392 \\
& $A 1$ & 0,6048 & 0,7089 & 0,5713 & 0,5003 & 0,6471 \\
& $A 2$ & 0,1944 & 0,0939 & 0,2414 & 0,4425 & 0,1462 \\
Posteriori-Bay & $A 3$ & 0,1944 & 0,0939 & 0,2414 & 0,4425 & 0,1462 \\
& $A 4$ & 0,3952 & 0,2911 & 0,4287 & 0,4997 & 0,3529 \\
& $A 1$ & 0,0375 & 0,0033 & 0,0610 & 0,1679 & 0,0075 \\
Posteriori-Vero & $A 2$ & 0,3220 & 0,2890 & 0,3311 & 0,3336 & 0,3083 \\
& $A 3$ & 0,3220 & 0,2890 & 0,3311 & 0,3336 & 0,3083 \\
& $A 4$ & 0,3185 & 0,4187 & 0,2767 & 0,1650 & 0,3759 \\
& $A 1$ & 0,2500 & 0,2500 & 0,2500 & 0,2501 & 0,2500 \\
& $A 2$ & 0,2500 & 0,2500 & 0,2500 & 0,2499 & 0,2500 \\
& $A 3$ & 0,2500 & 0,2500 & 0,2500 & 0,2499 & 0,2500 \\
& $A 4$ & 0,2500 & 0,2500 & 0,2500 & 0,2501 & 0,2500 \\
\hline
\end{tabular}

Para a configuração C-C somente a combinação $A 1$ pode ser distingüida das outras três. Por isso, outros marcadores ligados com um tipo de segregação mais informativo são requeridos para resolver a combinação da fase de ligação.

Na sequência, é examinada a situação em que a segregação não é simétrica e que ambos os locos têm um alelo nulo em um mesmo genitor (configurações $\mathrm{B} 1(a b \times a o)-\mathrm{C}(a o \times a o)$ e B1-B1), Figuras 32 e 33, respectivamente. 


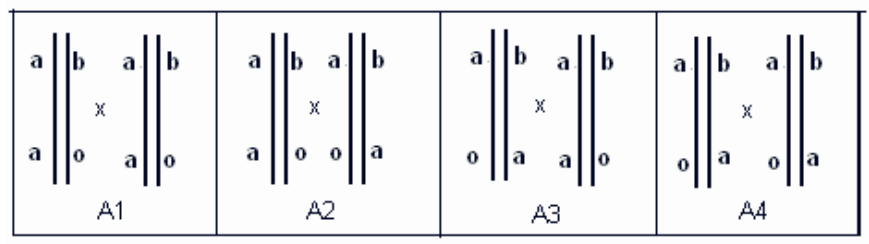

Figura 32 - Possíveis arranjos para o cruzamento B1-C

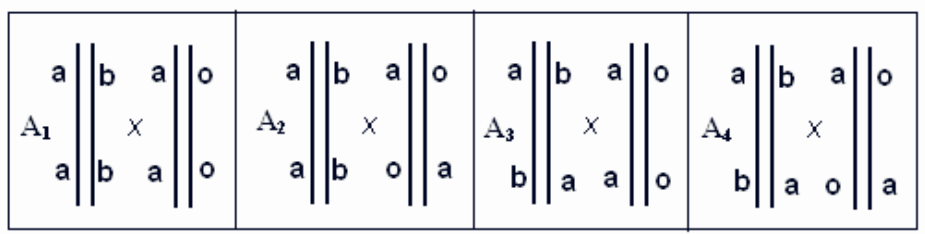

Figura 33 - Possíveis arranjos para o cruzamento B1-B1

Neste caso, sempre $\widehat{r}_{A 1}=1-\widehat{r}_{A 4}$ e $\widehat{r}_{A 2}=1-\widehat{r}_{A 3}$, considerando as estimativas de máxima verossimilhança, em que $\widehat{r}_{A i}$ é a estimativa de $r$ para o arranjo $A i$.

Se os locos estão em associação no primeiro genitor (arranjo $A 1$ ou $A 2)$, então, as estimativas da freqüência de recombinação obtidas pelo método da máxima verossimilhança para a fase correta apresentam o menor valor. Se $A 1$ é o verdadeiro arranjo, então, $A 2$ tem suas estimativas de $r$ aproximadamente iguais à 0,5 e, sendo $A 2$ o verdadeiro arranjo, $A 1$ tem suas estimativas aproximadamente iguais à 0,5 . Se, entretanto, os locos estão em repulsão para o primeiro genitor $(A 3$ ou $A 4$ ), então, para $A 3$ e $A 4$ as estimativas são menores que 0,5 e, portanto, as outras duas estimativas são maiores que 0,5. Contudo, as combinações $A 1$ e $A 2$ podem ser distingüidas uma da outra e de $A 3$ e $A 4$, respectivamente. As simulações das fases $A 3$ e $A 4$ para as configurações B1-C e B1-B1 apresentam em mais dos $95 \%$ dos casos significativos a correta combinação da fase que foi estimada, mesmo assim, seria prudente verificar a fase de ligação com locos vizinhos. Este comportamento 
particular é causado por uma típica característica do tipo de segregação $a b \times a o$. Para o primeiro genitor, a contribuição haplóide para algum fenótipo na progênie é sempre perfeitamente clara: $a$ ou $b$. Para o segundo genitor, isto depende do alelo contribuído pelo primeiro genitor: se é $b$, então, é claro, mas se é $a$, então, não pode ser resolvido se o segundo genitor contribuíu com o alelo $a$ ou $o$.

Considerando B1-C e B1-B1, através das estimativas de máxima verossimilhança, as probabilidades a posteriori foram obtidas. Quando o verdadeiro arranjo é $A 1$ as maiores probabilidades a posteriori são dadas aos arranjos $A 1$ e $A 4$. Dessa maneira, considerando esses dois arranjos, é necessário verificar qual deles apresenta a estimativa de $r$ menor que 0,5 , que neste caso, como já citado, são as estimativas correspondente ao arranjo $A 1$. Sendo $A 4$ o verdadeiro arranjo, para a maioria dos conjuntos de dados simulados, as maiores probabilidades a posteriori são dadas também aos arranjos $A 1$ e $A 4$, sendo que as estimativas de $r$ para $A 4$ apresentam valores menores que 0,5. Através das estimativas Bayesianas de $r$, as maiores probabilidades a posteriori são dadas ao arranjo usado na simulação dos conjuntos de dados. Na Tabela 26 se encontram algumas das probabilidades a posteriori usando as estimativas de $r$ considerando os dois métodos de estimação e as quatro possíveis fases de ligação, bem como, tais estimativas, para a configuração B1-C em que os dados foram simulados considerando o arranjo $A 1$. 
Tabela 26. Freqüências de recombinação verdadeiras com suas respectivas estimativas Bayesianas e de máxima verossimilhança de $r$; probabilidades a posteriori Posteriori-Bay e Posteriori-Vero usando as estimativas Bayesianas e de máxima verossimilhança, respectivamente, para os quatro tipos de arranjos, sendo $A 1$ o verdadeiro arranjo e $\mathrm{n}=100$ para a configuração B1-C

\begin{tabular}{ccccccc}
\hline & Tipos de arranjos & $r_{\text {ver }}=0,22$ & $r_{\text {ver }}=0,23$ & $r_{\text {ver }}=0,24$ & $r_{\text {ver }}=0,25$ & $r_{\text {ver }}=0,26$ \\
\hline \multirow{2}{*}{ Est. Bay } & $A 1$ & 0,1806 & 0,3180 & 0,1960 & 0,2926 & 0,2849 \\
& $A 2$ & 0,4110 & 0,4329 & 0,3880 & 0,4110 & 0,4125 \\
& $A 3$ & 0,4241 & 0,4027 & 0,4375 & 0,4232 & 0,4266 \\
\multirow{3}{*}{ Est. Vero } & $A 4$ & 0,4748 & 0,4451 & 0,4813 & 0,4542 & 0,4675 \\
& $A 1$ & 0,1709 & 0,3117 & 0,1879 & 0,2844 & 0,2784 \\
& $A 2$ & 0,4675 & 0,5514 & 0,4088 & 0,4694 & 0,4680 \\
Posteriori-Bay & $A 3$ & 0,5325 & 0,4486 & 0,5912 & 0,5306 & 0,5320 \\
& $A 4$ & 0,8291 & 0,6883 & 0,8121 & 0,7156 & 0,7216 \\
& $A 1$ & 1,0000 & 0,9719 & 1,0000 & 0,9966 & 0,9994 \\
Posteriori-Vero & $A 2$ & 0,0000 & 0,0041 & 0,0000 & 0,0022 & 0,0004 \\
& $A 3$ & 0,0000 & 0,0220 & 0,0000 & 0,0009 & 0,0001 \\
& $A 4$ & 0,0000 & 0,0019 & 0,0000 & 0,0003 & 0,0000 \\
& $A 1$ & 0,5000 & 0,4856 & 0,5000 & 0,4983 & 0,4997 \\
& $A 2$ & 0,0000 & 0,0144 & 0,0000 & 0,0017 & 0,0003 \\
& $A 3$ & 0,0000 & 0,0144 & 0,0000 & 0,0017 & 0,0003 \\
& $A 4$ & 0,5000 & 0,4856 & 0,5000 & 0,4983 & 0,49973 \\
\hline
\end{tabular}

Se o verdadeiro arranjo é $A 2$ ou $A 3$, as maiores probabilidades a posteriori considerando as estimativas de máxima verossimilhança são dadas aos arranjos $A 2$ e $A 3$. A escolha entre estes dois tipos de arranjos se dá através das estimativas da freqüência de recombinação determinada, lembrando que $\widehat{r}_{A 2}=1-\widehat{r}_{A 3}$. Usando o método Bayesiano, de imediato, a partir da probabilidade a posteriori estima-se qual é a fase mais provável. Deve ser ressaltado que, embora as estimativas de Bayes não ultrapassem o valor de 0,5 , sendo $A 2$ o verdadeiro arranjo, as estimativas de $r$ correspondente ao $A 3$ se encontram no intervalo $(0,4 ; 0,5)$ e vice-versa. Algumas das probabilidades a posteriori para cada arranjo, usando as estimativas obtidas pelos dois métodos, se encontram na Tabela 27 juntamente com tais estimativas considerando a configuração B1-C e o arranjo $A 2$. 
Tabela 27. Freqüências de recombinação verdadeiras com suas respectivas estimativas Bayesianas e de máxima verossimilhança de $r$; probabilidades a posteriori Posteriori-Bay e Posteriori-Vero usando as estimativas Bayesianas e de máxima verossimilhança, respectivamente, para os quatro tipos de arranjos, sendo $A 2$ o verdadeiro arranjo e $\mathrm{n}=100$ para a configuração B1-C

\begin{tabular}{ccccccc}
\hline & Tipos de arranjos & $r_{\text {ver }}=0,22$ & $r_{\text {ver }}=0,23$ & $r_{\text {ver }}=0,24$ & $r_{\text {ver }}=0,25$ & $r_{\text {ver }}=0,26$ \\
\hline \multirow{2}{*}{ Est. Bay } & $A 1$ & 0,3939 & 0,3835 & 0,4022 & 0,4165 & 0,4082 \\
& $A 2$ & 0,2216 & 0,3099 & 0,2032 & 0,2540 & 0,3262 \\
& $A 3$ & 0,4684 & 0,4484 & 0,4679 & 0,4662 & 0,4411 \\
\multirow{3}{*}{ Est. Vero } & $A 4$ & 0,4277 & 0,4306 & 0,4306 & 0,4202 & 0,4183 \\
& $A 1$ & 0,4287 & 0,4070 & 0,4402 & 0,4864 & 0,4712 \\
& $A 2$ & 0,2120 & 0,3028 & 0,1932 & 0,2455 & 0,3212 \\
Posteriori-Bay & $A 3$ & 0,7880 & 0,6972 & 0,8068 & 0,7545 & 0,6788 \\
& $A 4$ & 0,5713 & 0,5930 & 0,5598 & 0,5136 & 0,5288 \\
& $A 1$ & 0,0000 & 0,0255 & 0,0000 & 0,0000 & 0,0251 \\
Posteriori-Vero & $A 2$ & 1,0000 & 0,9718 & 1,0000 & 1,0000 & 0,9599 \\
& $A 3$ & 0,0000 & 0,0010 & 0,0000 & 0,0000 & 0,0036 \\
& $A 4$ & 0,0000 & 0,0018 & 0,0000 & 0,0000 & 0,0113 \\
& $A 1$ & 0,0000 & 0,0135 & 0,0000 & 0,0000 & 0,0194 \\
& $A 2$ & 0,5000 & 0,4865 & 0,5000 & 0,5000 & 0,4806 \\
& $A 3$ & 0,5000 & 0,4865 & 0,5000 & 0,5000 & 0,4806 \\
& $A 4$ & 0,0000 & 0,0135 & 0,0000 & 0,0000 & 0,0194 \\
\hline
\end{tabular}

As configurações restantes (A-B3, B1-B3, A-C, A-B1 e B1-B2) apresentam informação suficiente para resolver qual a combinação da fase de ligação mais provável. Para as estimativas de $r$ obtidas pelo método da máxima verossimilhança, sempre $\widehat{r}_{A 1}=1-\widehat{r}_{A 4}$ e $\widehat{r}_{A 2}=1-\widehat{r}_{A 3}$, conduzindo, portanto, as duas legítimas estimativas, isto é, dos 4 arranjos apenas dois deles apresentam as estimativas de $r$ menores que 0,5. Para esses tipos de configurações, sendo $A 1$ ou $A 4$ o verdadeiro arranjo, as maiores probabilidades a posteriori são dadas a estes dois arranjos, simultâneamente. As maiores probabilidades a posteriori são dadas aos arranjos $A 2 \mathrm{e}$ $A 3$, simultâneamente, quando um deles for o verdadeiro arranjo. Como a estimativa com a fase correta tem sempre praticamente o menor valor, dos dois arranjos que apresentam as maiores probabilidades, o arranjo estimado é o que apresenta a estimativa de $r$ menor que 0,5. Considerando as estimativas Bayesianas de $r$, as maiores probabilidades a posteriori foram dadas à apenas um único tipo de arranjo. 
Como não foi possível determinar as estimativas da freqüência de recombinação através do método da máxima verossimilhança para a configuração A-A, também, não foi possível estimar a fase de ligação para esse tipo de configuração.

Para A-B3, B1-B3, A-C, A-B1 e B1-B2, tanto usando as estimativas da freqüência de recombinação obtidas pelo método da máxima verossimilhança como as obtidas pelo método Bayesiano, as estimativas da fase de ligação correspondem aos verdadeiros arranjos usados na simulação dos conjuntos de dados, como mostram as Tabelas 28 e 29 em que consideram a configuração A-B3 para os arranjos $A 1$ e $A 2$, respectivamente.

Tabela 28. Freqüências de recombinação verdadeiras com suas respectivas estimativas Bayesianas e de máxima verossimilhança de $r$; probabilidades a posteriori Posteriori-Bay e Posteriori-Vero usando as estimativas Bayesianas e de máxima verossimilhança, respectivamente, para os quatro tipos de arranjos, sendo $A 1$ o verdadeiro arranjo e $\mathrm{n}=100$ para a configuração A-B3

\begin{tabular}{ccccccc}
\hline & Tipos de arranjos & $r_{\text {ver }}=0,22$ & $r_{\text {ver }}=0,23$ & $r_{\text {ver }}=0,24$ & $r_{\text {ver }}=0,25$ & $r_{\text {ver }}=0,26$ \\
\hline \multirow{2}{*}{ Est. Bay } & $A 1$ & 0,2350 & 0,1783 & 0,3052 & 0,2051 & 0,2099 \\
& $A 2$ & 0,4314 & 0,4361 & 0,4390 & 0,4487 & 0,4378 \\
& $A 3$ & 0,4314 & 0,4361 & 0,4248 & 0,4212 & 0,4287 \\
\multirow{3}{*}{ Est. Vero } & $A 4$ & 0,4845 & 0,4927 & 0,4744 & 0,4902 & 0,4908 \\
& $A 1$ & 0,2293 & 0,1736 & 0,2993 & 0,2001 & 0,2049 \\
& $A 2$ & 0,4999 & 0,4999 & 0,5257 & 0,5439 & 0,5162 \\
Posteriori-Bay & $A 3$ & 0,5001 & 0,5001 & 0,4743 & 0,4561 & 0,4838 \\
& $A 4$ & 0,7707 & 0,8264 & 0,7007 & 0,7999 & 0,7951 \\
& $A 1$ & 1,0000 & 1,0000 & 0,9997 & 1,0000 & 1,0000 \\
& $A 2$ & 0,0000 & 0,0000 & 0,0001 & 0,0000 & 0,0000 \\
Posteriori-Vero & $A 3$ & 0,0000 & 0,0000 & 0,0002 & 0,0000 & 0,0000 \\
& $A 4$ & 0,0000 & 0,0000 & 0,0000 & 0,0000 & 0,0000 \\
& $A 1$ & 0,5000 & 0,5000 & 0,4998 & 0,5000 & 0,5000 \\
& $A 2$ & 0,0000 & 0,0000 & 0,0002 & 0,0000 & 0,0000 \\
& $A 3$ & 0,0000 & 0,0000 & 0,0002 & 0,0000 & 0,0000 \\
& $A 4$ & 0,5000 & 0,5000 & 0,4998 & 0,5000 & 0,5000 \\
\hline
\end{tabular}


Tabela 29. Freqüências de recombinação verdadeiras com suas respectivas estimativas Bayesianas e de máxima verossimilhança de $r$; probabilidades a posteriori Posteriori-Bay e Posteriori-Vero usando as estimativas Bayesianas e de máxima verossimilhança, respectivamente, para os quatro tipos de arranjos, sendo $A 2$ o verdadeiro arranjo e $\mathrm{n}=100$ para a configuração A-B3

\begin{tabular}{ccccccc}
\hline & Tipos de arranjos & $r_{\text {ver }}=0,22$ & $r_{\text {ver }}=0,23$ & $r_{\text {ver }}=0,24$ & $r_{\text {ver }}=0,25$ & $r_{\text {ver }}=0,26$ \\
\hline \multirow{2}{*}{ Est. Bay } & $A 1$ & 0,3939 & 0,3835 & 0,4022 & 0,4165 & 0,4082 \\
& $A 2$ & 0,2216 & 0,3099 & 0,2032 & 0,2540 & 0,3262 \\
& $A 3$ & 0,4684 & 0,4484 & 0,4679 & 0,4662 & 0,4411 \\
\multirow{3}{*}{ Est. Vero } & $A 4$ & 0,4277 & 0,4306 & 0,4306 & 0,4202 & 0,4183 \\
& $A 1$ & 0,4287 & 0,4070 & 0,4402 & 0,4864 & 0,4712 \\
& $A 2$ & 0,2120 & 0,3028 & 0,1932 & 0,2455 & 0,3212 \\
Posteriori-Bay & $A 3$ & 0,7880 & 0,6972 & 0,8068 & 0,7545 & 0,6788 \\
& $A 4$ & 0,5713 & 0,5930 & 0,5598 & 0,5136 & 0,5288 \\
& $A 1$ & 0,0000 & 0,0255 & 0,0000 & 0,0000 & 0,0251 \\
Posteriori-Vero & $A 2$ & 1,0000 & 0,9718 & 1,0000 & 1,0000 & 0,9599 \\
& $A 3$ & 0,0000 & 0,0010 & 0,0000 & 0,0000 & 0,0036 \\
& $A 4$ & 0,0000 & 0,0018 & 0,0000 & 0,0000 & 0,0113 \\
& $A 1$ & 0,0000 & 0,0135 & 0,0000 & 0,0000 & 0,0194 \\
& $A 2$ & 0,5000 & 0,4865 & 0,5000 & 0,5000 & 0,4806 \\
& $A 3$ & 0,5000 & 0,4865 & 0,5000 & 0,5000 & 0,4806 \\
& $A 4$ & 0,0000 & 0,0135 & 0,0000 & 0,0000 & 0,0194 \\
\hline
\end{tabular}

Através dos resultados aqui obtidos, nota-se que a estimação da fase de ligação não apresenta conclusões distintas quando se usa um ou outro método de estimação para a freqüência de recombinação. Entretanto, usando as estimativas Bayesianas da freqüência de recombinação, quando for possível estimar a fase de ligação, através da probabilidade a posteriori, de imediato, se tem qual é a fase estimada.

Como mostra Wu et al. (2002), a probabilidade a posteriori para várias combinações de arranjos diferem rapidamente quando uma análise conjunta é conduzida. Por tanto, a análise conjunta tem melhor poder para caracterizar a fase de ligação do que a análise que considera dois marcadores de cada vez. A maior vantagem nessa análise é que, considerando dois marcadores pouco informativos, a fase de ligação entre eles pode ser esclarecida se a fase de ligação multi-locos incluí marcadores completamente informativos. Entretanto, cálculos mais complexos 
devem ser realizados para se fazer tal análise.

\subsection{Considerações Finais}

Na região em que a priori apresenta uma maior probabilidade para a freqüência de recombinação, $(0,05 ; 0,45)$, as estimativas Bayesianas de $r$ apresentaram menor soma de quadrado do resíduo (SQRes) que as estimativas de máxima verossimilhança, para toda configuração considerando qualquer tipo de arranjo, como mostra a Figura 34. O eixo das abcissas apresenta, em ordem crescente, as seguintes configurações: D1-D1 (1), B3-D1(2), A-D1(3), C-D1(4), B1-D1(5), B1-D2(6), B3B3(7), A-B3(8), C-B3(9), B1-B3(10), A-C(11), A-B1(12), C-C(13), B1-C(14), B1B1(15) e B1-B2(16). Como visto nas Tabelas 3, 4, 6, 7, 8, 9, 10, 11, 12, 13, 14, 15, 16, 17 e 18, as maiores diferenças entre as somas de quadrado dos resíduos para as estimativas de máxima verossimilhança e Bayesiana são dadas aos conjuntos de dados simulados a partir dos arranjos $A 2, A 3$ e $A 4$, quando a configuração considerada era pouco informativa, como também pode ser notado graficamente através da Figura 34. Para as demais configurações, a diferença entre as somas de quadrado não diferem muito entre si. Dessa maneira, considerando o intervalo $(0,05 ; 0,45)$, as estimativas Bayesianas são mais precisas que as estimativas de máxima verossimilhança, principalmente quando o tipo de segregação da configuração considerada é pouco informativo. 

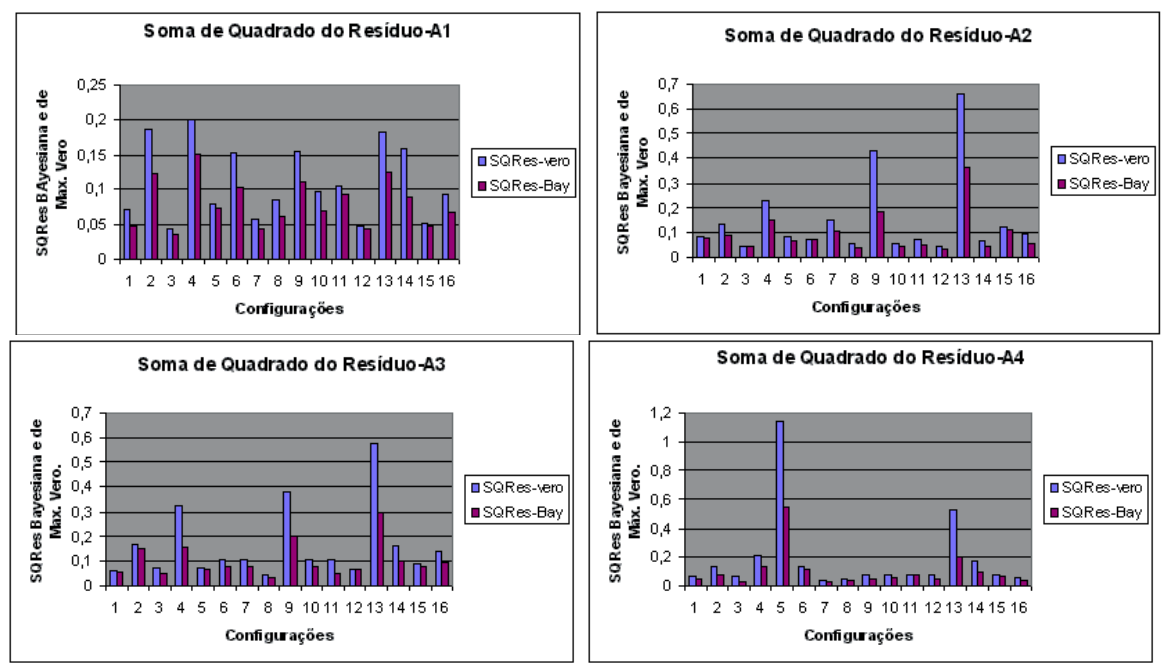

Figura 34 - Gráficos das somas de quadrado dos resíduos para as estimativas de $r$ usando os conjuntos de dados simulados a partir dos arranjos $A 1, A 2$, $A 3$ e $A 4$, respectivamente, com tamanho amostral $\mathrm{n}=100$

Considerando o intervalo paramétrico, para alguns casos as somas de quadrado dos resíduos obtidas para as estimativas Bayesianas $\left(S Q R e s_{b}\right)$ são maiores que as somas de quadrado dos resíduos obtidas para as estimativas de máxima verossimilhança $\left(S Q R e s_{v}\right)$, já que tal intervalo contém valores de $r$ em que a priori considera pouco prováveis. Entretanto, ainda considerando todo o intervalo paramétrico, para a maioria dos casos $S Q R e s_{b}<S Q R e s_{v}$. Os gráficos das somas de quadrado dos resíduos para as estimativas consideranto todo o intervalo paramétrico são apresentados na Figura 35. Como na Figura 34, a abcissa de cada um dos gráficos apresentados na Figura 35 considera em ordem crescente as seguintes configurações: D1-D1 (1), B3-D1(2), A-D1(3), C-D1(4), B1-D1(5), B1-D2(6), B3-B3(7), A-B3(8), C-B3(9), B1-B3(10), A-C(11), A-B1(12), C-C(13), B1-C(14), B1-B1(15) e B1-B2(16). 

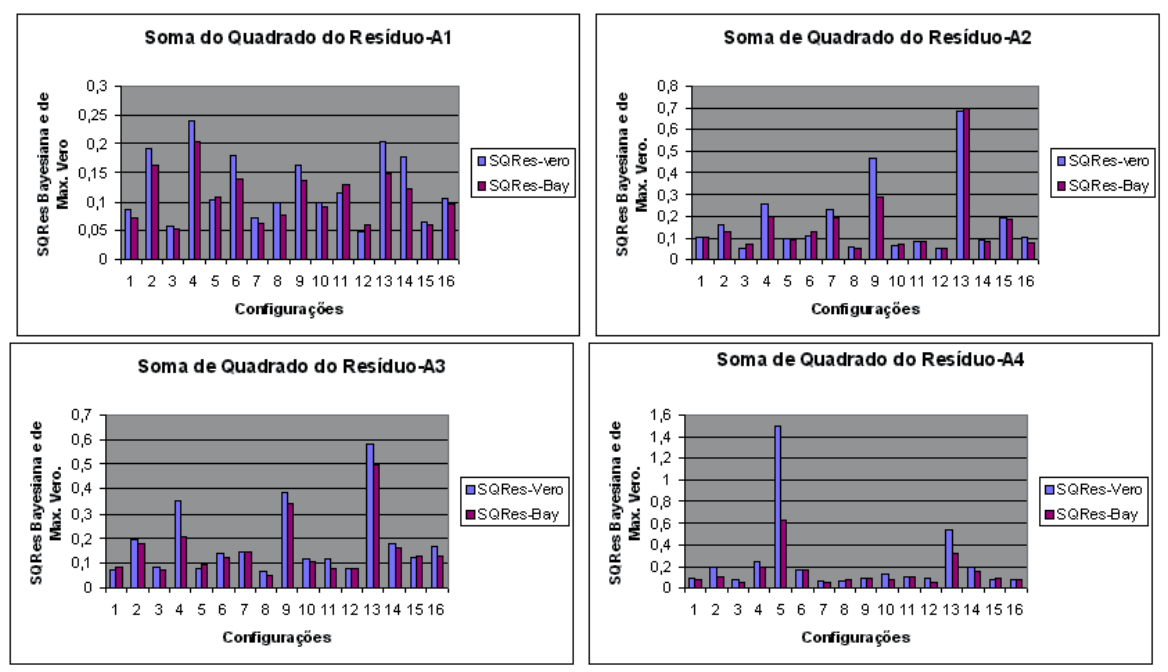

Figura 35 - Gráficos das somas de quadrado dos resíduos para as estimativas de $r$ usando os conjuntos de dados simulados a partir dos arranjos $A 1, A 2$, $A 3$ e $A 4$, respectivamente, com tamanho amostral $\mathrm{n}=100$

A distribuição a priori aqui usada informa que, a partir de um suposto mapa já construído na literatura em que os locos apresentam o mesmo tipo de segregação aos locos a serem estudados, os marcadores considerados estão ligados. Contudo, outras distribuições a priori podem ser atribuídas para estimar a freqüência de recombinação dependendo de qual é a informação que se tem a priori.

Além disso, com base no trabalho de Maliepaard et al. (1997), a maioria das estimativas de máxima verossimilhança sub-estimam os valores verdadeiros de $r$ na região $(0 ; 0,05)$, principalmente quando a segregação considerada é pouco informativa. Nesses casos, as estimativas da freqüência de recombinação obtidas pelo método da máxima verossimilhança são nulas considerando uma aproximação de 5 casas decimais. Dessa maneira, a distância entre os locos considerados seria aproximadamente nula, o que é absurdo já que está sendo considerado dois locos distintos. Dependendo da informação acrescentada na distribuição a priori, problemas como esse podem ser resolvidos. Assim, cabe ao pesquisador e ao estatístico construir uma distribuição a priori que represente adequadamente a informação que se tem $a$ 
priori.

Quanto as estimativas das fases de ligação, os dois métodos levam à mesma conclusão: para marcadores mais informativos, a estimação da fase de ligação é correta; para marcadores poucos informativos, é necessário estimar a fase de ligação entre os dois marcadores com um outro marcador ligado à esses que seja mais informativo. 


\section{CONCLUSÕES}

Com base nos resultados obtidos, pode-se concluir que:

i ) A estimação da fase de ligação não apresenta conclusões distintas quando se usa um ou outro método de estimação para a freqüência de recombinação;

ii ) em geral, as estimativas Bayesianas da freqüência de recombinação apresentam menor SQRes que as estimativas de máxima verossimilhança, principalmente, quando se considera o intervalo em que a distribuição a priori relata os valores mais prováveis para a freqüência de recombinação;

iii ) as estimativas obtidas pelo método Bayesiano apresentaram um bom comportamento em relação à estimação da freqüência de recombinação. Como visto, o método Bayesiano tem uma teoria diferente do método clássico de encarar o problema. Aqui, resultados já obtidos através de outros estudos podem ser incorporados num novo estudo de ligação genética. Assim, tal método apresenta a vantagem de poder incorporar a informação do pesquisador, o que se for corretamente empregado na distribuição a priori, implicará em resultados mais precisos quanto à estimação da freqüência de recombinação. 
ANEXOS 
ANEXO A - Programa R para simulação dos conjuntos de dados

\section{\#\#\#\#\#\#\#\#\#\#\#\#\#\#\#\#\#\#\#\#\#\#\#\#\#\#\#\#\#\#\#\#\#\#\#\#\#\#\#\#\#\#\#\#\#\#\#\#\#\#\#\#\#\#\#\#\#\#\#\#\#}

\# Simulando os dados de um cruzamento do tipo B1 e B1 (arranjo A1)

para $r$ \# variando de 0 a 0.5

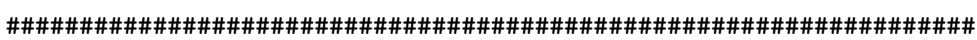

\# Tamanho da amostra $\mathrm{N}=\mathrm{n}$ para cada valor de $\mathrm{r}$. Entrar com o valor de $n$.

\# Para cada tipo de cruzamento e arranjo é necessário entrar com a

\# classe fenotípica correspondente (representada pelo vetor $\mathrm{x}$ ).

\# $\mathrm{x}$ : vetor que tem como elementos as possiveis classes

\#fenotípicas.

\# p: vetor de probabilidades das classes fenotipicas

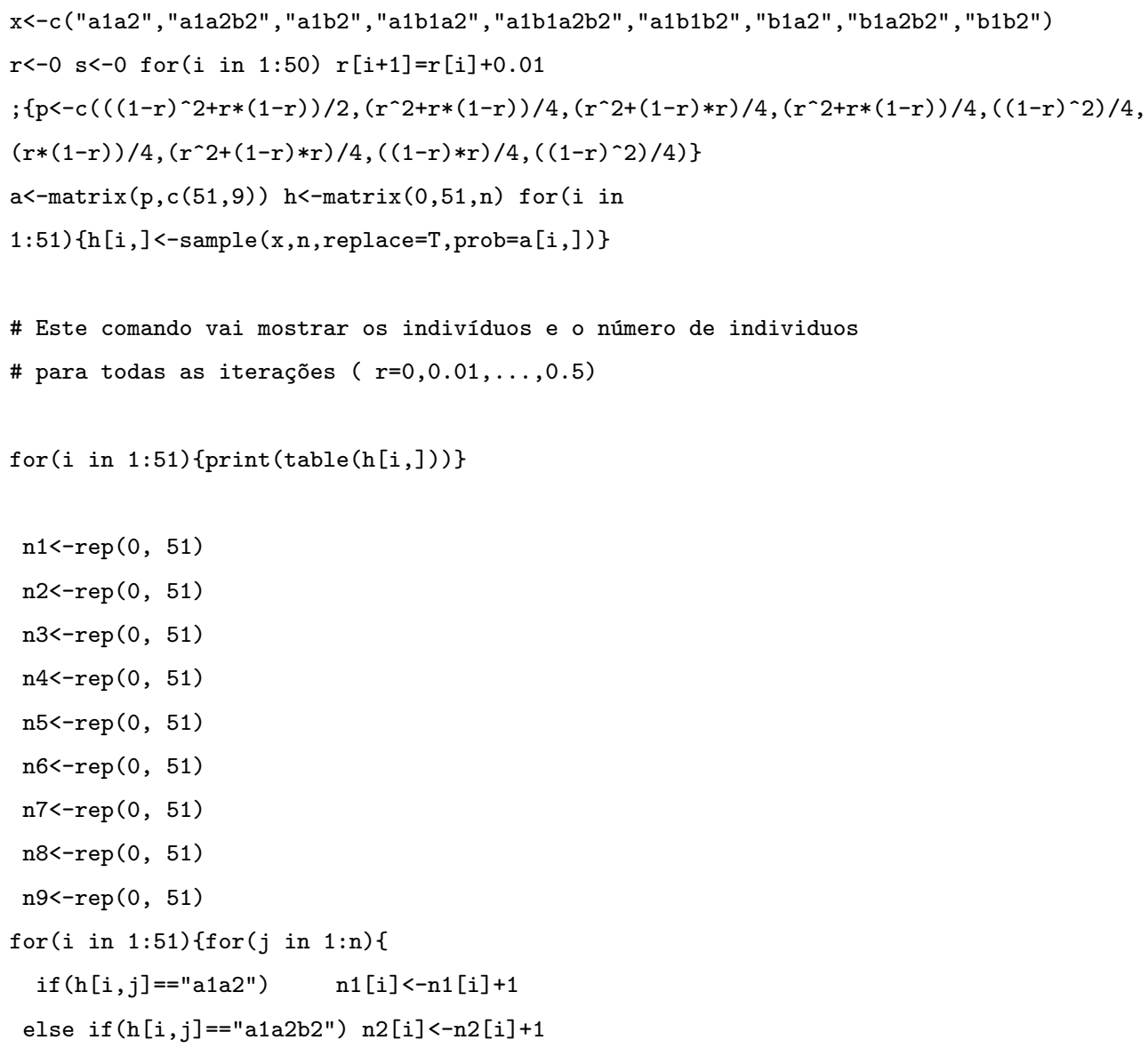


else if $(h[i, j]==" a 1 b 2 ") n 3[i]<-n 3[i]+1$

else if $(h[i, j]==" a 1 b 1 a 2 ") \quad n 4[i]<-n 4[i]+1$

else if $(h[i, j]==" a 1 b 1 a 2 b 2 ") \quad n 5[i]<-n 5[i]+1$

else if $(h[i, j]==" a 1 b 1 b 2 ") n 6[i]<-n 6[i]+1$

else if $(h[i, j]==" b 1 a 2 ") \quad n 7[i]<-n 7[i]+1$

else if $(h[i, j]==" b 1 a 2 b 2 ") \quad n 8[i]<-n 8[i]+1$

else if $(h[i, j]==" b 1 b 2 ") n 9[i]<-n 9[i]+1$

\} \} 
ANEXO B - Programa R para a estimação das freqüências de recombinação (usando os métodos de máxima verossimilhança e Bayesiano), intervalo de confiança clássico, intervalo de credibilidade, cálculo das SQRes, teste LRT e Fator de Bayes

A continuação dos programas do Anexo A seguem neste Anexo.

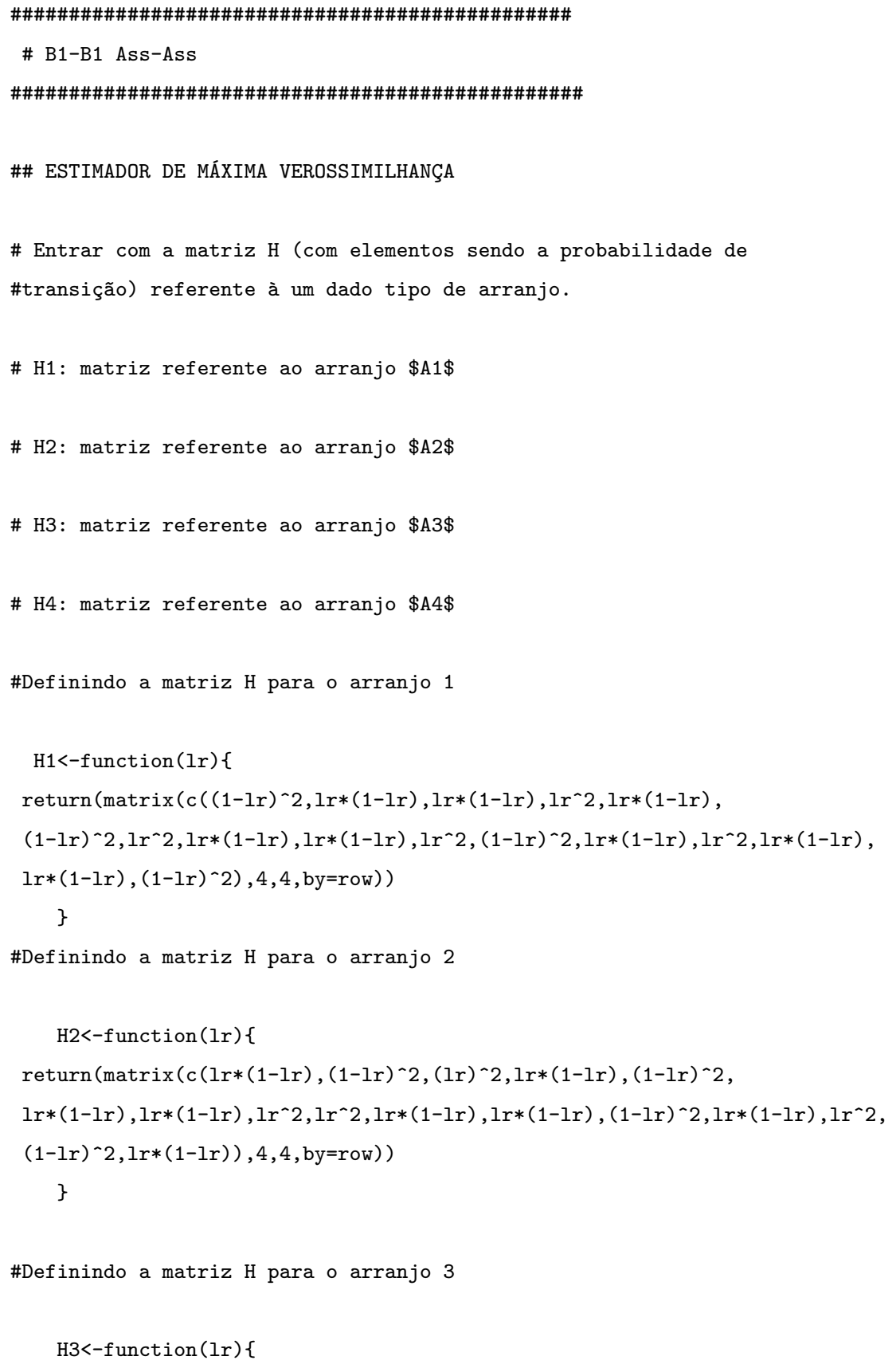


\# Entrar com o valor de $\mathrm{n}$.

$\mathrm{N}<-\mathrm{n}$

for (i in 1:51) \{

$\mathrm{m}<-\operatorname{matrix}(\mathrm{c}(\mathrm{n} 1[i], \mathrm{n} 2[i], \mathrm{n} 3[\mathrm{i}], \mathrm{n} 4[\mathrm{i}], \mathrm{n} 5[i], \mathrm{n} 6[\mathrm{i}], \mathrm{n} 7[\mathrm{i}], \mathrm{n} 8[\mathrm{i}], \mathrm{n} 9[\mathrm{i}]), 3,3, \mathrm{by}=\mathrm{row})$

while $(\operatorname{abs}(r[i]-c f)>0.0001)\{r[i]<-c f$

$c<-0$

for (i1 in $1: 3)\{$

for (i2 in $1: 3)\{$

$\mathrm{c}<-1 /(2 * \mathrm{~N}) * \mathrm{~m}[\mathrm{i} 1, \mathrm{i} 2] *(\mathrm{ma}[\mathrm{i} 1] \% * \%,(((\mathrm{IpB} 1 \mathrm{t} \% * \% \mathrm{D} 1 \mathrm{H}(\mathrm{r}[\mathrm{i}])) \% * \%$

$t(\operatorname{IpB} 1 \mathrm{t})) \% * \% \operatorname{ma}[, i 2])) /((\operatorname{ma}[i 1] \% * \%,((\operatorname{IpB} 1 \mathrm{t} \% * \% \mathrm{H} 1(\mathrm{r}[\mathrm{i}])) \% * \% t(\operatorname{IpB} 1 \mathrm{t}))) \% * \% \operatorname{ma}[, i 2])+\mathrm{c}$ $c f<-c$

\}

confinf [i]<-r[i] -1.96*(1/(-(kC(r[i], n1 [i] , n2 [i] , n3 [i] , n4 [i] ,

$\mathrm{n} 5[\mathrm{i}], \mathrm{n} 6[\mathrm{i}], \mathrm{n} 7[\mathrm{i}], \mathrm{n} 8[\mathrm{i}], \mathrm{n} 9[\mathrm{i}])) * \mathrm{~N}))^{\wedge}(1 / 2)$

conf sup $[i]<-r[i]+1.96 *(1 /(-(\mathrm{kC}(\mathrm{r}[\mathrm{i}], \mathrm{n} 1[\mathrm{i}], \mathrm{n} 2[\mathrm{i}], \mathrm{n} 3[\mathrm{i}], \mathrm{n} 4[\mathrm{i}]$,

$\mathrm{n} 5[\mathrm{i}], \mathrm{n} 6[\mathrm{i}], \mathrm{n} 7[\mathrm{i}], \mathrm{n} 8[\mathrm{i}], \mathrm{n} 9[\mathrm{i}])) * \mathrm{~N})) \wedge(1 / 2)$

\}\}\}

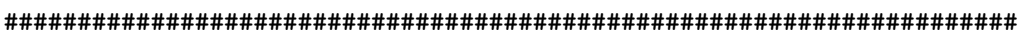

$\#$

ESTIMADOR BAYESIANO com PRIORI INFORMATIVA e HPD \#

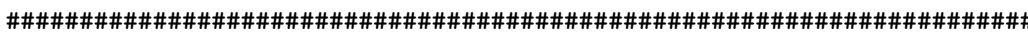

\# Função de verossimilhança calculada no Maple (ver Anexo C)

referente à um dado tipo de cruzamento

veroB1<-function $(\operatorname{lr}, 11,12,13,14,15,16,17,18,19)\{$

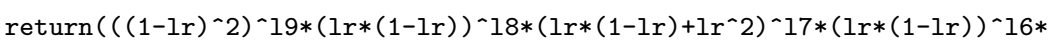

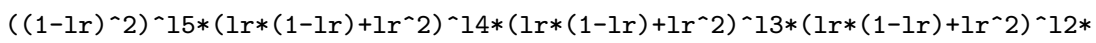

$(2 *(1-l r) \wedge 2+2 * \ln *(1-\ln )) \wedge 11)$

\}

\# Priori informativa

priori<-function(lr) $\{$ if $(l r<0.05)\{0.1 *(l r) /(l r)\}$ else

$\{$ if $(\operatorname{lr}<0.45)\{2.5 *(\operatorname{lr}) /(\operatorname{lr})\}$ else $\{0.1\}\}\}$ 
\# Posteriori proporcional.

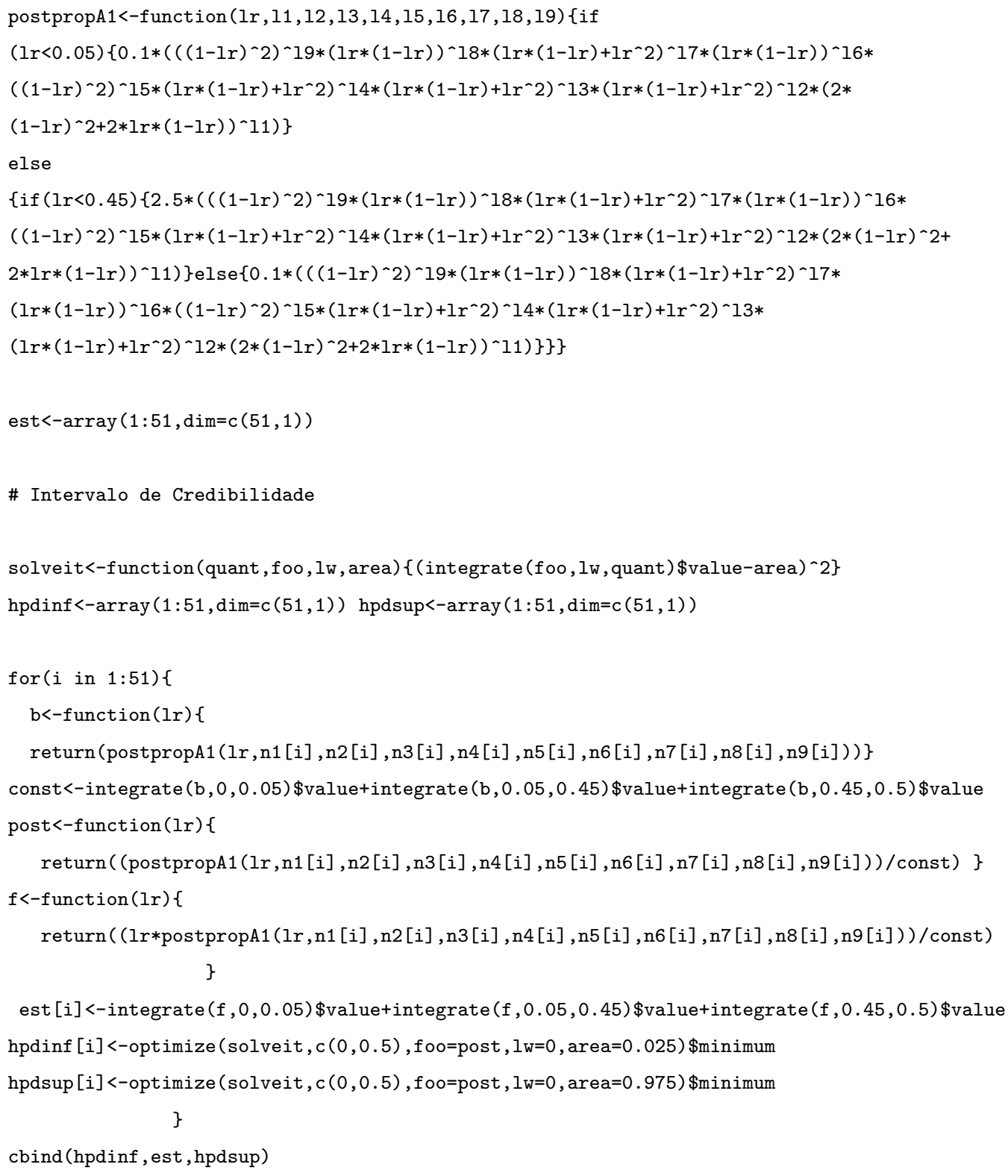




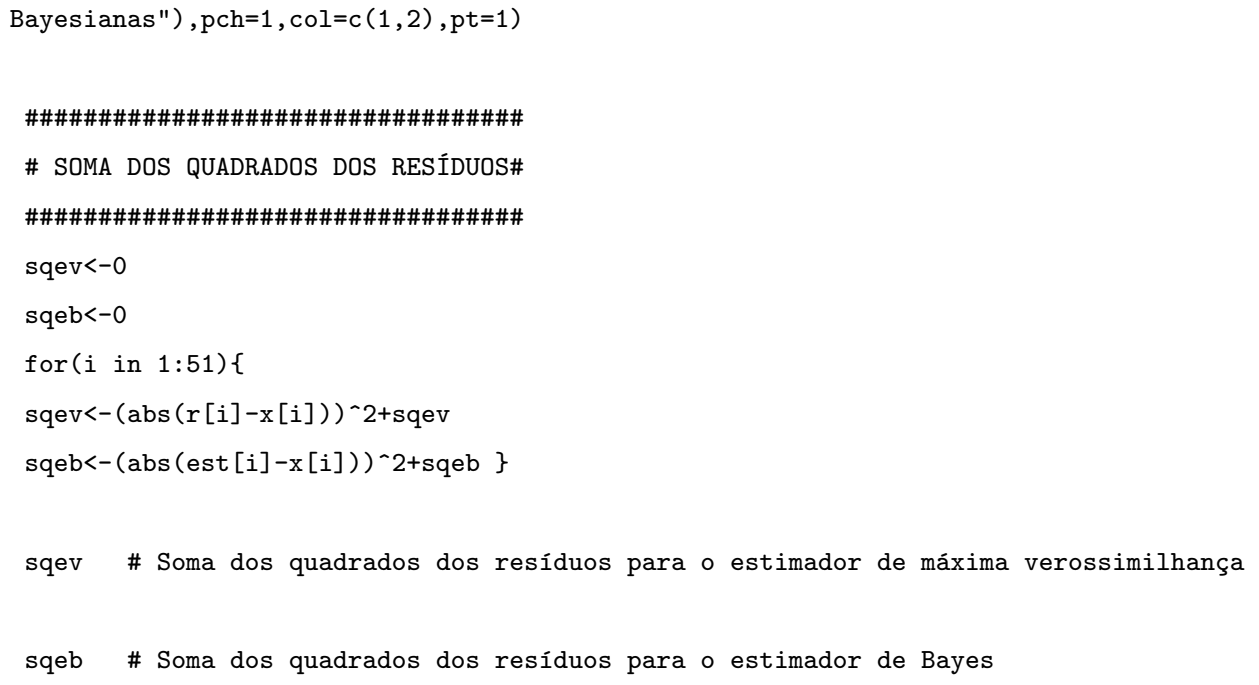




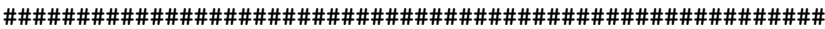

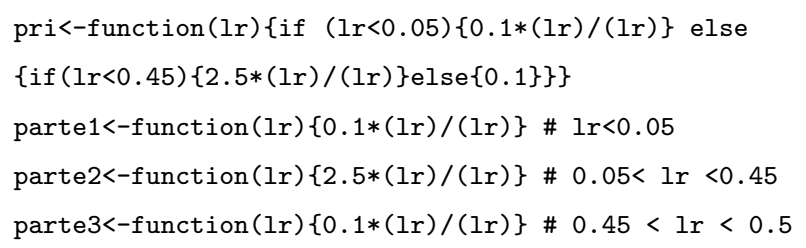

\} 
ANEXO C - Verossimilhanças calculadas no Maple 6

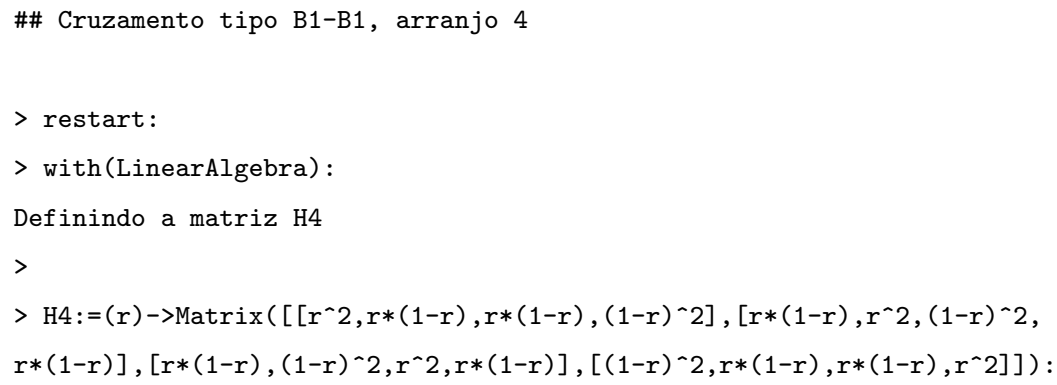

\#\# Cruzamento tipo B3-C, arranjo 4 


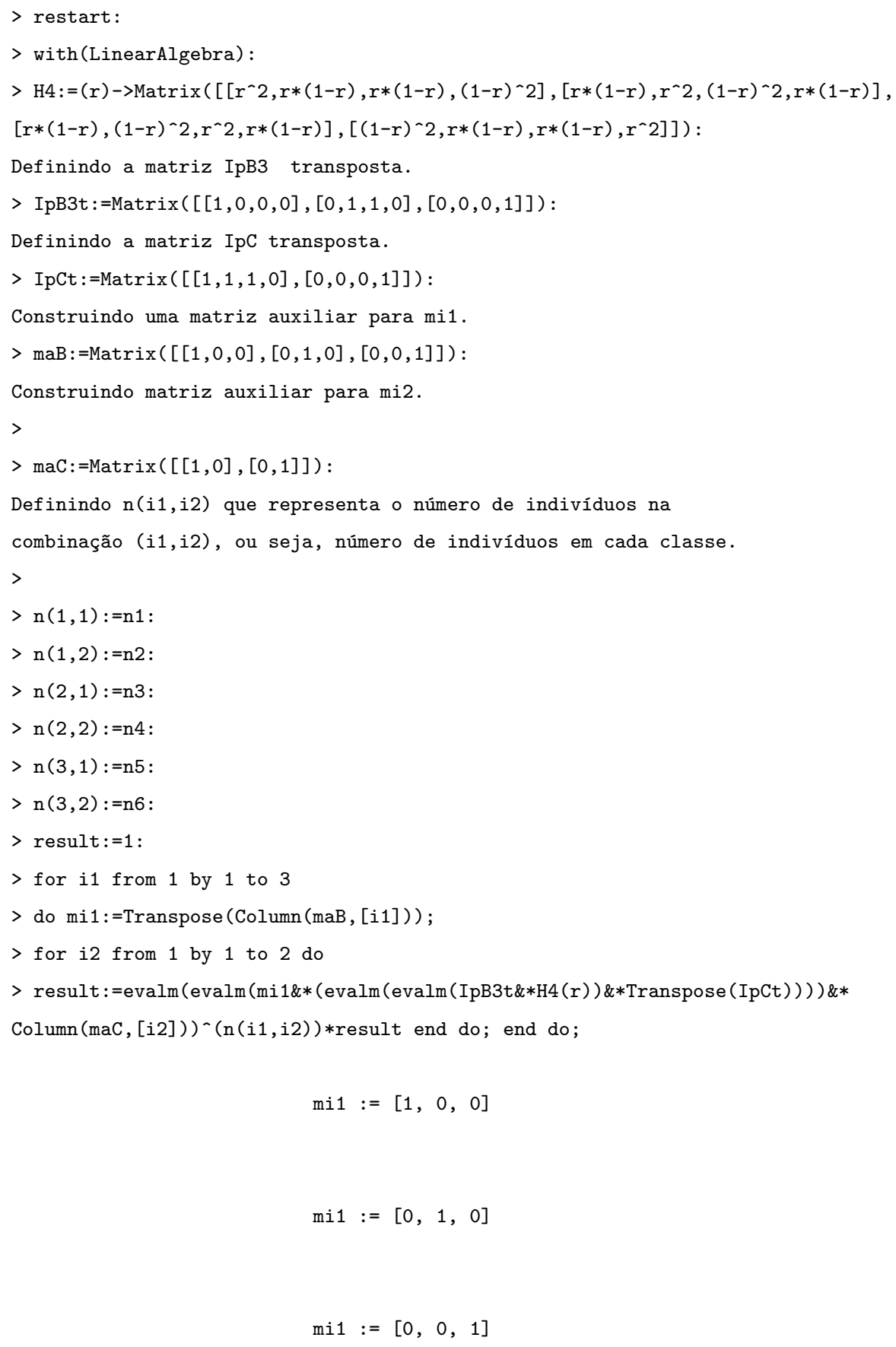


ANEXO D - Programa no R da estimação das fases de ligação

\# Cruzamento B1-B1; $\mathrm{n}=50$

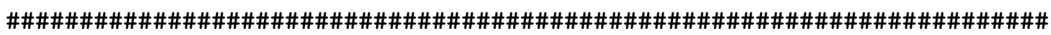

\#Programa para calcular as estimativas de Bayes. Cruzamento dos

\#tipos B1 e B1. \#

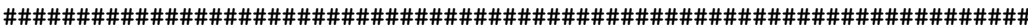

\# Para cada tipo de cruzamento, entrar com os valores que foram

\#gerados no Anexo A

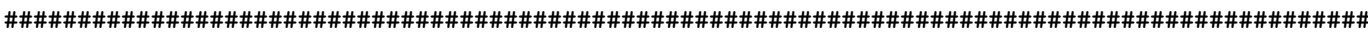

\# ENTRAR COM oS VALORES DE n1, n2, .., n9 (NÚMERO DE INDivíduOS

EM CADA CLASSE FENOTÍPICA) \#

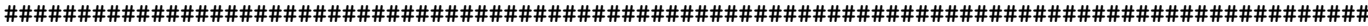

\# n: tamanho amostral

dados<-read.table("dadosB1B1aa_n.txt", head=T) \# Tem que

especificar o diretorio $\mathrm{C}: \backslash g s \backslash$ Meus documentos $\backslash j u l i n h o \backslash$ Conjunto de

Dados attach(dados)

$\mathrm{n} 1<-\operatorname{dados}[, 1]$

$\mathrm{n} 2<-$ dados $[, 2]$

n3<-dados $[, 3]$

n $4<-$ dados $[, 4]$

n5<-dados $[, 5]$

n6<-dados $[, 6]$

$\mathrm{n} 7<-$ dados $[, 7]$

n8<-dados $[, 8]$

n $9<-$ dados $[, 9]$

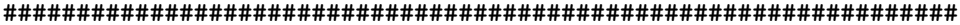

Arranjo 1 - Ass-Ass

\#

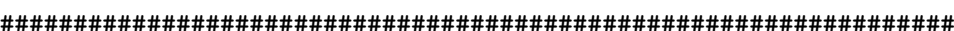

\# ESTimativas de MÁxima VERossimilhanÇa

\# verossimilhança para o arranjo 1

\# ESTIMADOR DE MÁXIMA VEROSSIMILHANÇA 


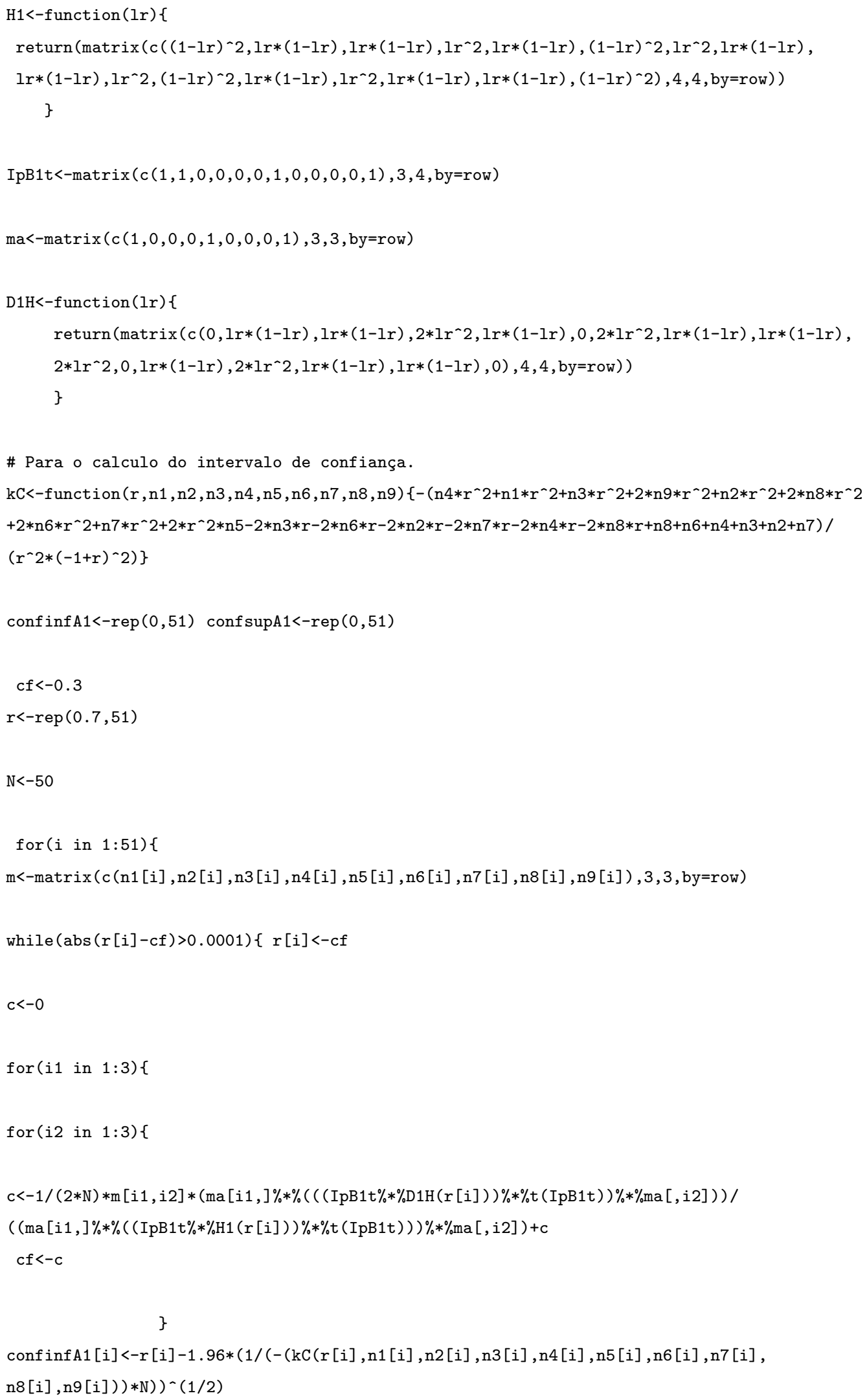


confsupA1 [i] <-r [i] +1.96*(1/(-(kC(r[i], n1 [i] , n2 [i] , n3 [i] , n4 [i] , n5 [i] , n6 [i] , n7 [i] , $\mathrm{n} 8[\mathrm{i}], \mathrm{n} 9[\mathrm{i}])) * \mathrm{~N})) \wedge(1 / 2)\}\}\}$

$r A 1<-r$

\# ESTIMADOR BAYESIANO \#

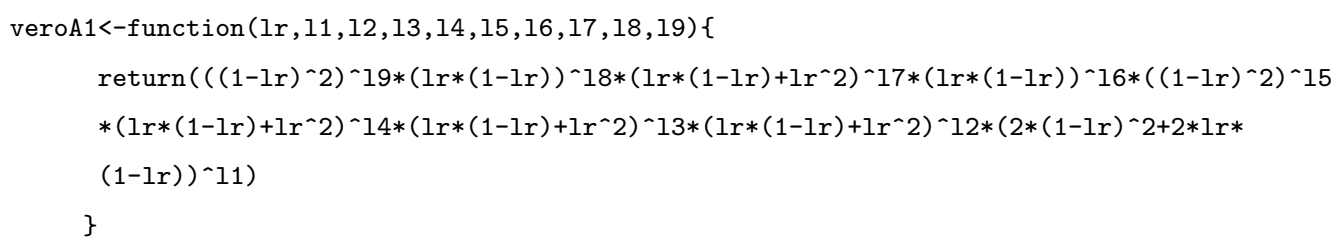


\}

est [i]<-integrate (f, 0, 0.05) \$value+integrate (f, $0.05,0.45)$ \$value+integrate $(f, 0.45,0.5)$ \$value hpdinf $[i]<-o p t i m i z e$ (solveit, $c(0,0.5)$, foo=post, $l_{w}=0$, area=0.025) \$minimum hpdsup [i]<-optimize (solveit, c $(0,0.5)$, foo=post, $1 \mathrm{w}=0$, area $=0.975)$ \$minimum \}

esta1<-est

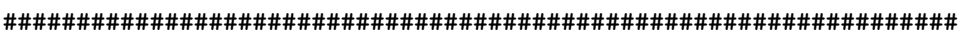

$\#$

Arranjo 2 - Ass-Rep

$\#$

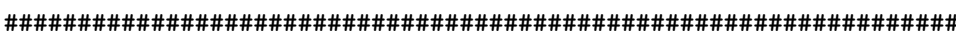

\# ESTimativaS DE MÁXIMA VEROSSIMILHANÇA

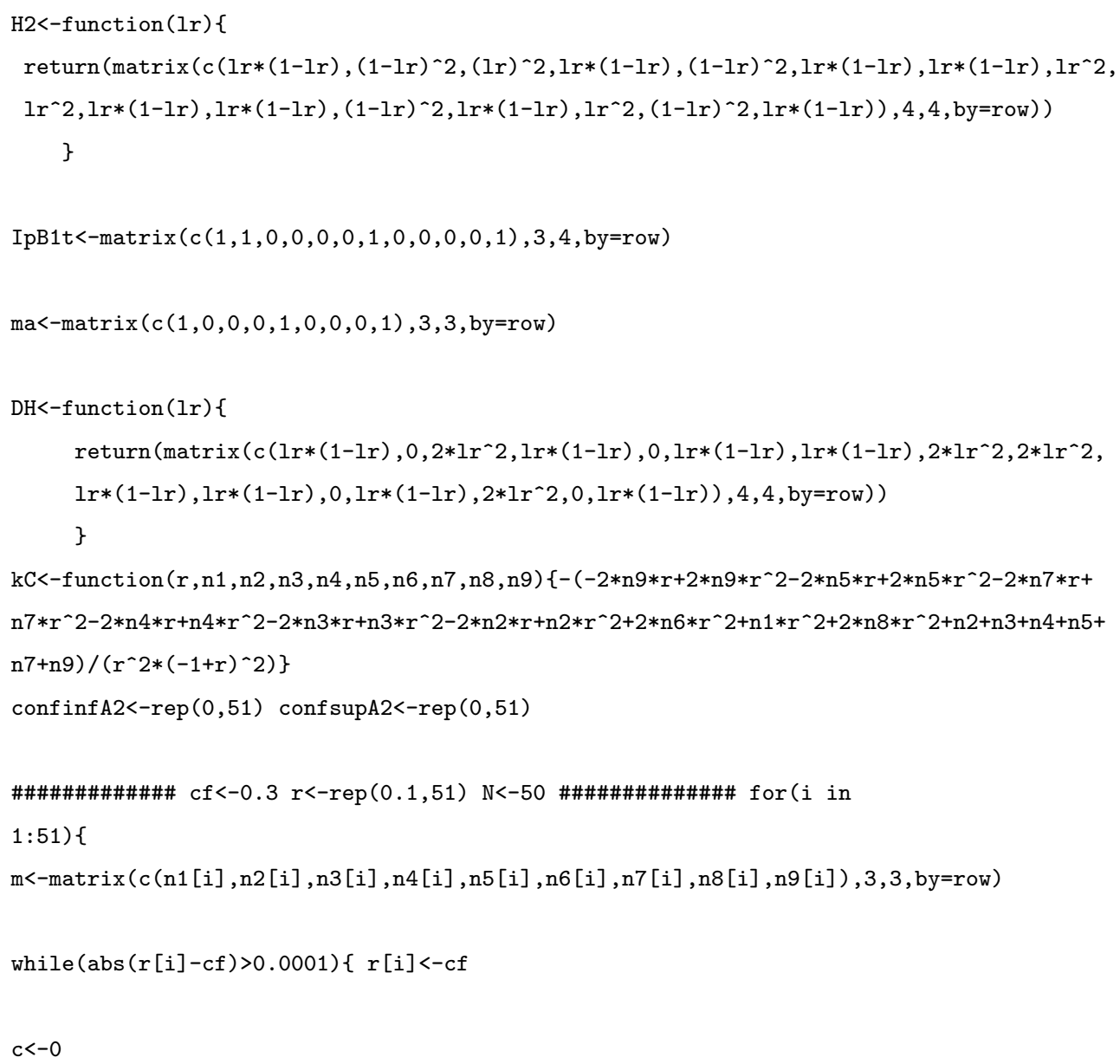




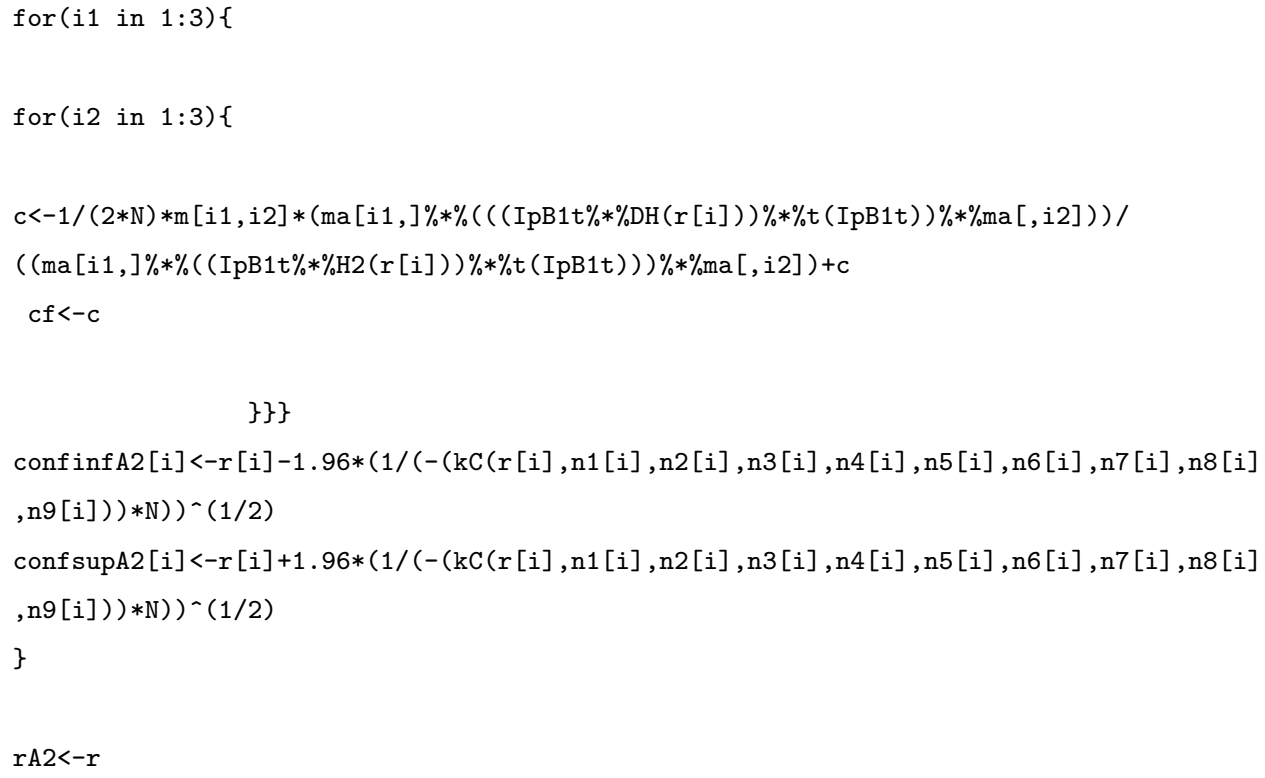


\# Para o calculo do intervalo de confiança.

$\mathrm{kC}<-$ function $(\mathrm{r}, \mathrm{n} 1, \mathrm{n} 2, \mathrm{n} 3, \mathrm{n} 4, \mathrm{n} 5, \mathrm{n} 6, \mathrm{n} 7, \mathrm{n} 8, \mathrm{n} 9)\{-(-4 * \mathrm{n} 6 * \mathrm{r}-2 * \mathrm{n} 1 * \mathrm{r}-2 * \mathrm{n} 5 * \mathrm{r}-4 * \mathrm{n} 8 * \mathrm{r}-2 * \mathrm{n} 9 * \mathrm{r}+2 *$ $\left.\mathrm{n} 8 * \mathrm{r}^{\wedge} 2+2 * \mathrm{n} 6 * \mathrm{r}^{\wedge} 2+\mathrm{n} 1 * \mathrm{r}^{\wedge} 2+\mathrm{n} 7 * \mathrm{r}^{\wedge} 2+\mathrm{n} 4 * \mathrm{r}^{\wedge} 2+\mathrm{n} 2 * \mathrm{r}^{\wedge} 2+\mathrm{n} 3 * \mathrm{r}^{\wedge} 2+2 * \mathrm{n} 5 * \mathrm{r}^{\wedge} 2+2 * \mathrm{n} 9 * \mathrm{r}^{\wedge} 2+\mathrm{n} 1+\mathrm{n} 5+2 * \mathrm{n} 6+2 * \mathrm{n} 8+\mathrm{n} 9\right) /$ $\left.\left(r^{\wedge} 2 *(-1+r)^{\wedge} 2\right)\right\}$

confinfA3<-rep $(0,51)$ confsupA3<-rep $(0,51)$

cf $<-0.3 r<-r e p(0.7,51)$

$\mathrm{N}<-50$

for ( $i$ in 1:51) \{

m<-matrix (c (n1 [i] , n2 [i] , n3 [i] , n4 [i] , n5 [i] , n6 [i] , n7 [i] , n8 [i] , n9 [i]) , 3, 3, by=row)

while $(\operatorname{abs}(r[i]-c f)>0.0001)\{r[i]<-c f$

$c<-0$

for (i1 in $1: 3)\{$

for (i2 in $1: 3)\{$

$c<-1 /(2 * \mathrm{~N}) * \mathrm{~m}[\mathrm{i} 1, \mathrm{i} 2] *(\operatorname{maB}[\mathrm{i} 1] \% * \%,(((\operatorname{IpB} 1 \mathrm{t} \% * \% \mathrm{D} 3 \mathrm{H}(\mathrm{r}[\mathrm{i}])) \% * \% \mathrm{t}(\mathrm{IpB} 1 \mathrm{t})) \% * \% \operatorname{maB}[, \mathrm{i} 2])) /$ $((\operatorname{maB}[i 1] \% * \%,((\operatorname{IpB} 1 \mathrm{t} \% * \% \mathrm{H} 3(\mathrm{r}[\mathrm{i}])) \% * \% \mathrm{t}(\mathrm{IpB} 1 \mathrm{t}))) \% * \% \operatorname{maB}[, \mathrm{i} 2])+\mathrm{c}$

$c f<-c$

\}\}\}

confinf A3 [i] <-r [i] -1.96*(1/(-(kC(r[i] ,n1 [i] ,n2 [i] ,n3[i] , n4 [i] , n5 [i] , n6 [i] , n7 [i] , $\mathrm{n} 8[\mathrm{i}], \mathrm{n} 9[\mathrm{i}])) * \mathrm{~N}))^{\wedge}(1 / 2)$

confsupA3[i]<-r [i] +1.96*(1/(-(kC(r[i] ,n1[i] , n2 [i] , n3 [i] , n4 [i] , n5 [i] , n6 [i] , n7 [i] , $\mathrm{n} 8[\mathrm{i}], \mathrm{n} 9[\mathrm{i}])) * \mathrm{~N})) \wedge(1 / 2)\}$

$r A 3<-r$

\# ESTIMADOR BAYESIANO \#

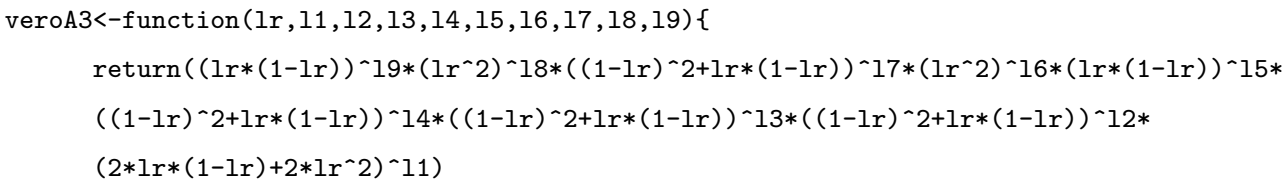




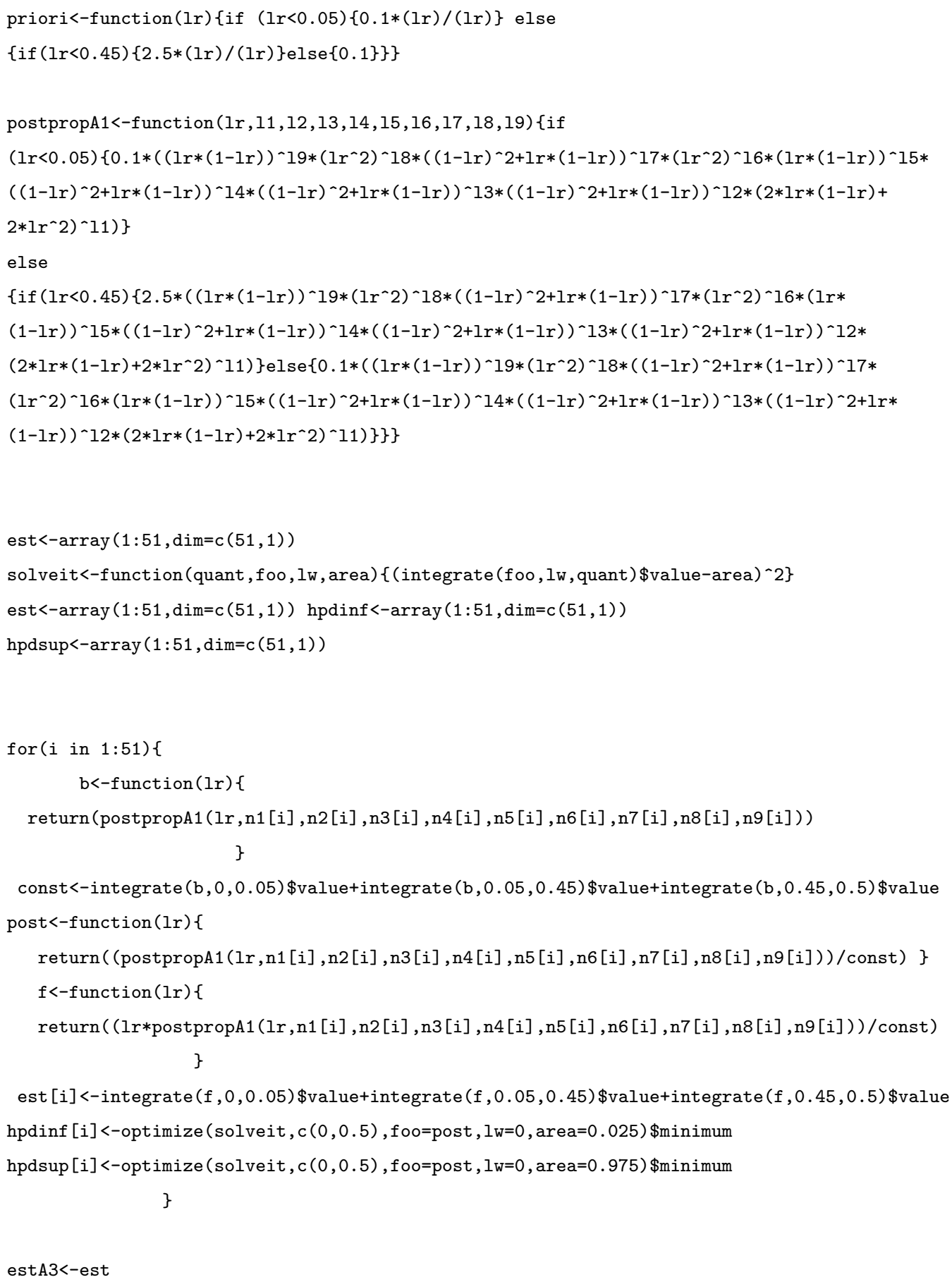


\# ESTimativas DE MÁXima VEROSSimilhanÇA \#

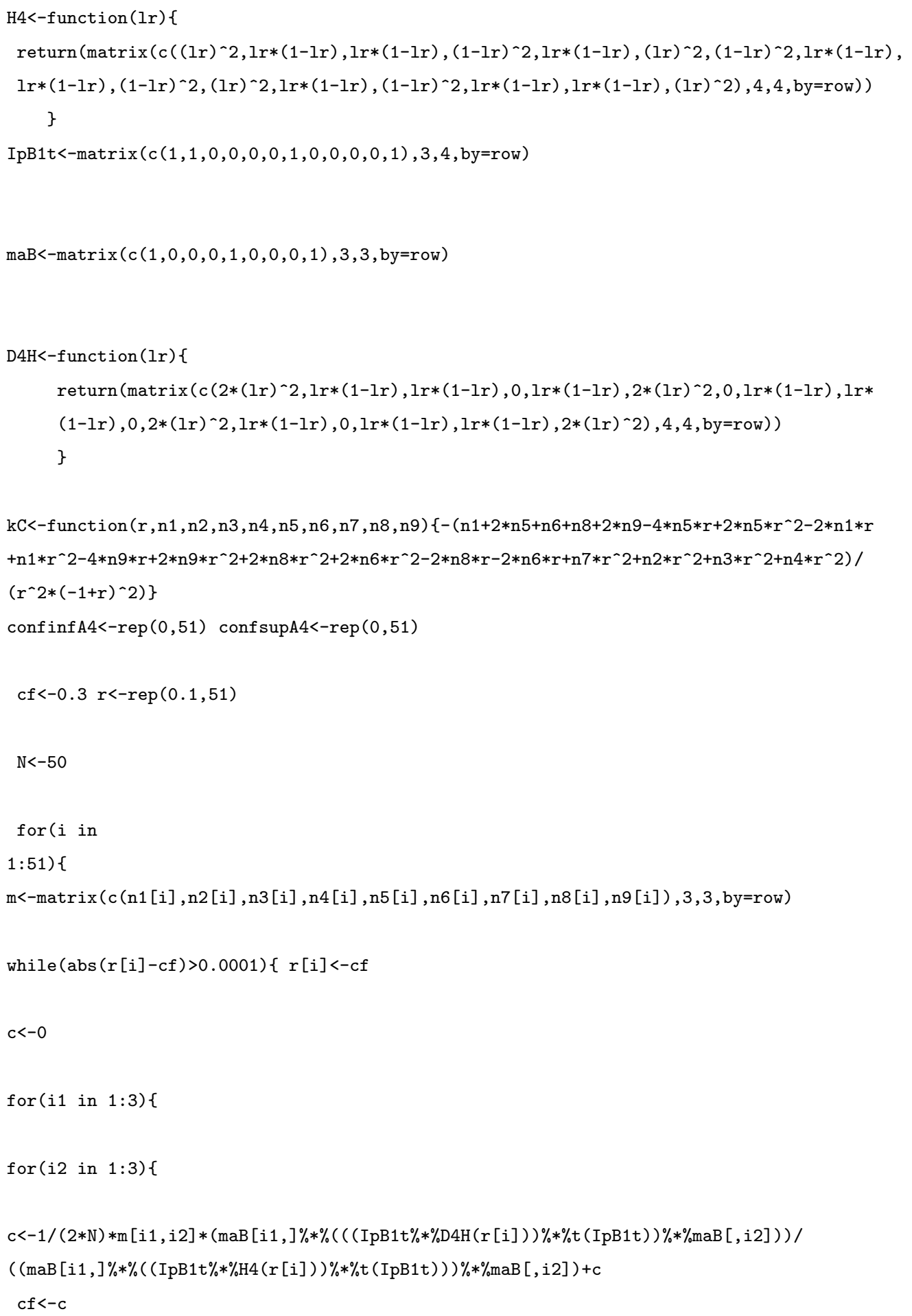


const<-integrate ( $b, 0,0.05)$ value+integrate ( $b, 0.05,0.45)$ \$value+integrate $(b, 0.45,0.5)$ \$value post<-function(lr) \{

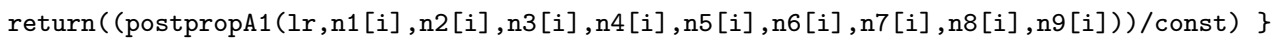

$f<-$ function(lr) \{

return ((lr*postpropA1 (lr, n1 [i] , n2 [i] , n3 [i] , n4 [i] , n5 [i] , n6 [i] , n7 [i] , n8 [i] , n9 [i] ))/const) \}

est [i]<-integrate (f, 0, 0.05) \$value+integrate ( $f, 0.05,0.45)$ \$value+integrate $(f, 0.45,0.5)$ \$value hpdinf $[i]<-o p t i m i z e$ (solveit, $c(0,0.5)$, foo=post, $1 \mathrm{w}=0$, area $=0.025)$ \$minimum

hpdsup [i]<-optimize (solveit, c $(0,0.5)$, foo=post, $1 \mathrm{w}=0$, area=0.975) \$minimum

\}

estA4<-est

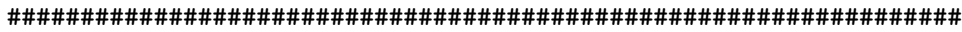

\# SAIDA I - ESTIMATIVAS DAS FREQÜÊNCIAS DE RECOMBINAÇÃO PARA \#

\# $\quad$ OS ARRANJOS A1, A2, A3 E A4 \#

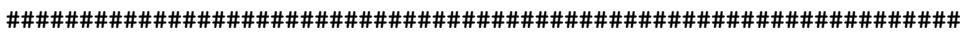

rA1

rA2

rA3

rA4

estA1

estA2

esta3

estA4

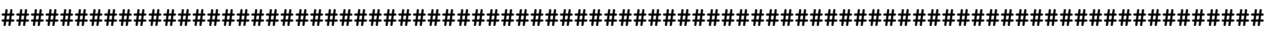

\# Programa para estimar a fase de ligação entre cruzamentos dos

\# tipos B1 e B1 \#\#\#

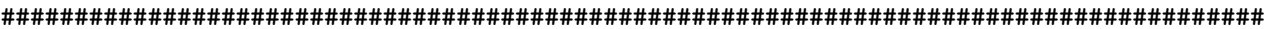

\# Definindo a distribuição de probabilidade a priori para a fase

de ligação.

priori<-1/4

constb<-rep $(0,51)$ constv<-rep $(0,51)$ fasepostA1b<-rep $(0,51)$

faseposta2b<-rep $(0,51)$ fasepostA3b<-rep $(0,51)$

fasepost $A 4 b<-r e p(0,51)$ fasepostA1v<-rep $(0,51)$

fasepost $A 2 v<-r e p(0,51)$ fasepost $A v<<-r e p(0,51)$

fasepost $A 4 v<-r e p(0,51)$ 
for (i in 1:51) \{

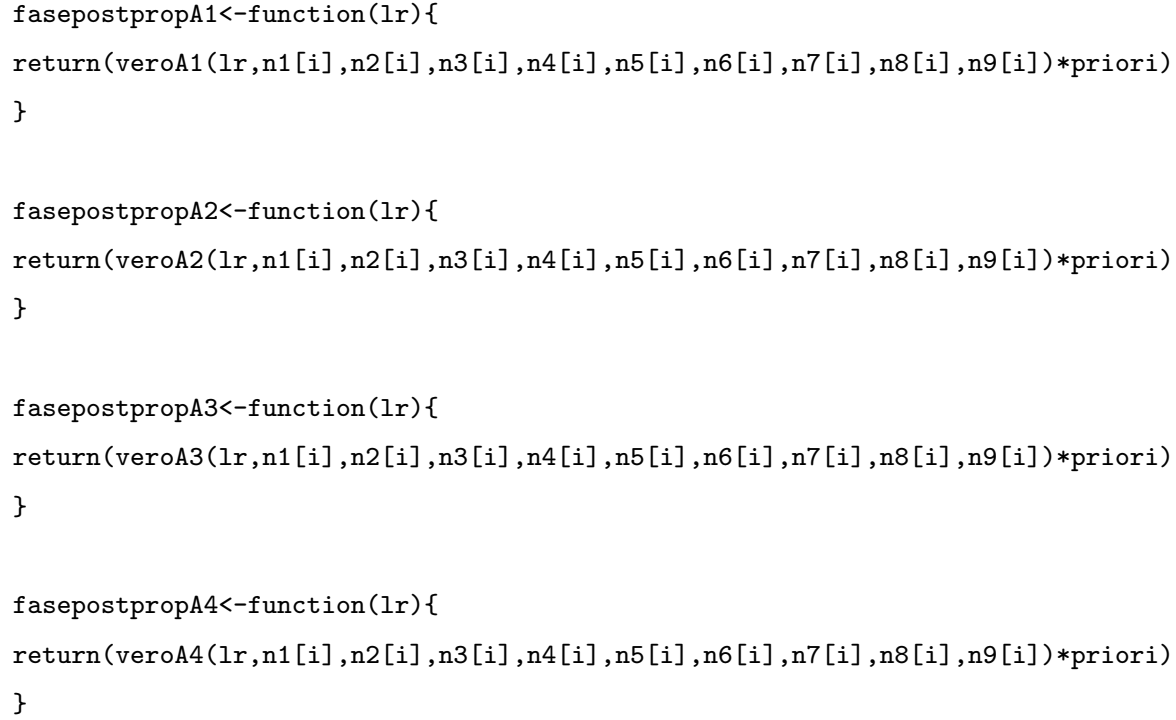


fasepostA3v[i]<-fasepostpropA3 (rA3[i])/constv[i]

fasepostA4v[i]<-fasepostpropA4(rA4[i])/constv[i] \}

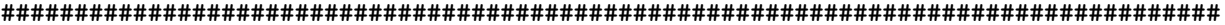

\# SAÍdA II - PROBABILIDADES A POSTERIORI DOS ARRANJOS A1, A2, A3 E

A4 APLICADA ÀS \# \#

ESTIMATIVAS DAS RESPECTIVAS

FREQÜÊNCIAS DE RECOMBINAÇÃO

$$
\text { \# }
$$

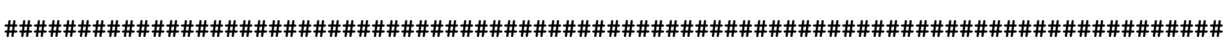

faseb<-cbind ( $f$ asepost $A 1 b$, fasepost $A 2 b, f$ asepost $A 3 b, f$ asepost $A 4 b$ )

fasev<-cbind (fasepostA1v, fasepostA2v, fasepostA3v, fasepostA4v)

$r<-c b i n d(r A 1, r A 2, r A 3, r A 4)$ est<-cbind (estA1, estA2, estA3, estA4) 
ANEXO E - Gráficos das estimativas da freqüência de recombinação obtidas pelos métodos da máxima verossimilhança e Bayesianos de tamanhos 200 e 500

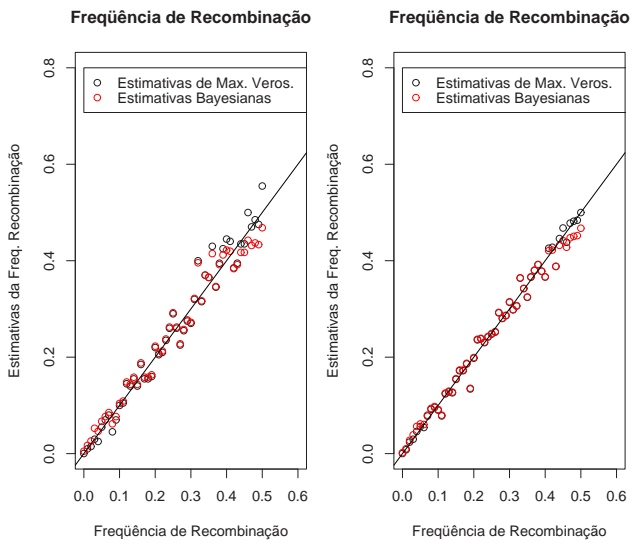

Figura 36 - Gráficos das estimativas Bayesianas e de Máxima Verossimilhança, configuração D1-D1 e arranjo A1, com n=200 e n=500, respectivamente
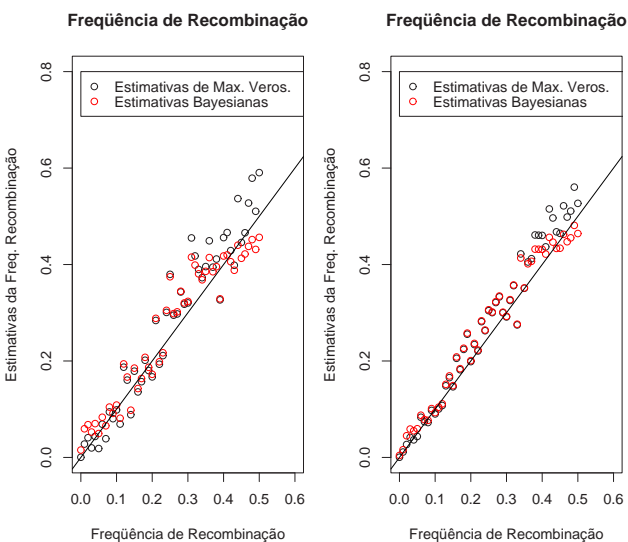

Figura 37 - Gráficos das estimativas Bayesianas e de Máxima Verossimilhança, configuração B3-D1 e arranjo A3, com n=200 e n=500, respectivamente 

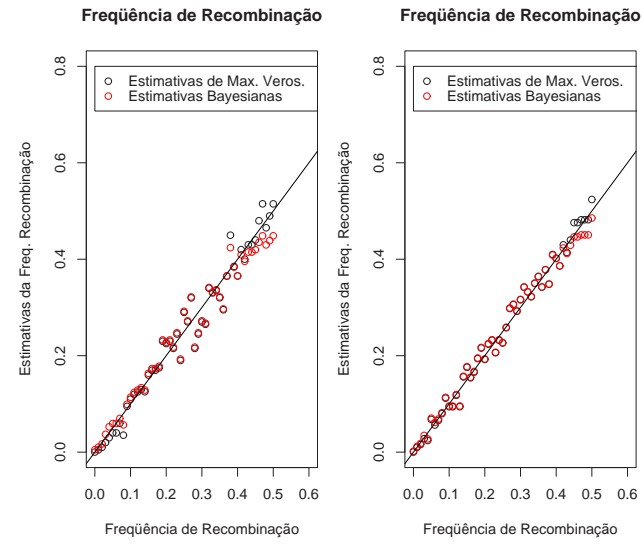

Figura 38 - Gráficos das estimativas Bayesianas e de Máxima Verossimilhança, configuração A-D1 e arranjo A1, com n=200 e n=500, respectivamente
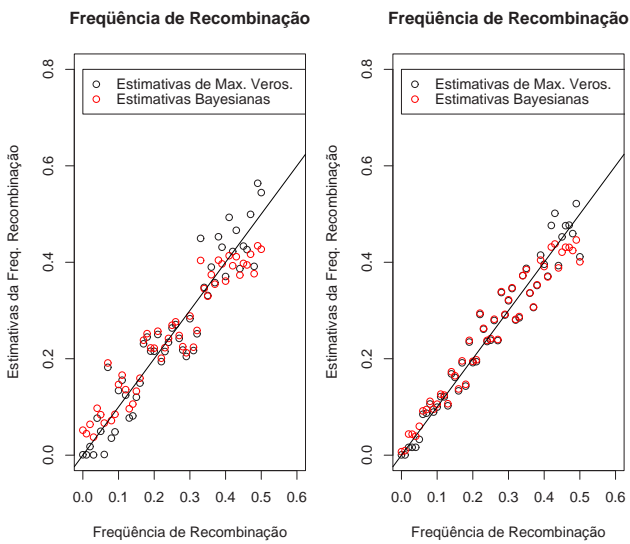

Figura 39 - Gráficos das estimativas Bayesianas e de Máxima Verossimilhança, configuração C-D1 e arranjo A3, com n=200 e n=500, respectivamente 

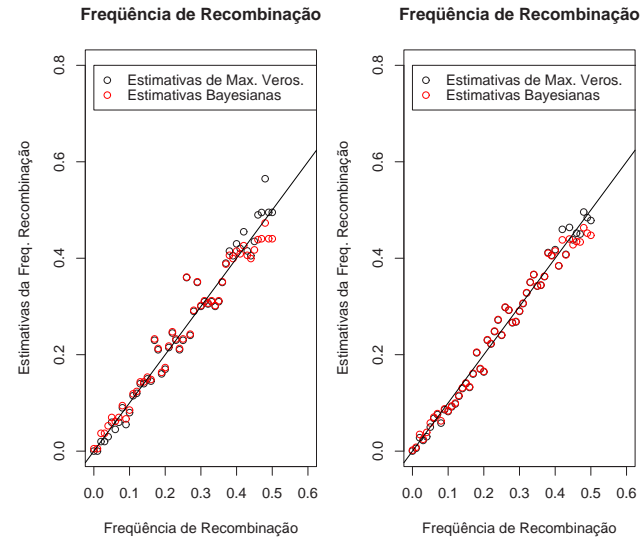

Figura 40 - Gráficos das estimativas Bayesianas e de Máxima Verossimilhança, configuração B1-D1 e arranjo A1, com n=200 e n=500, respectivamente
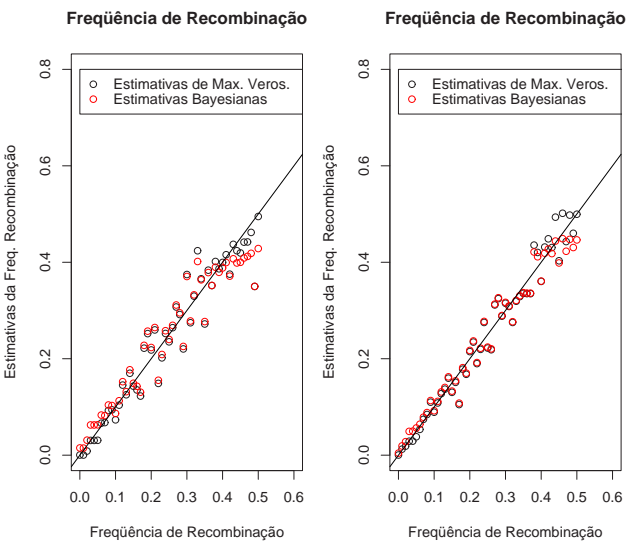

Figura 41 - Gráficos das estimativas Bayesianas e de Máxima Verossimilhança, configuração B1-D2 e arranjo A1, com n=200 e n=500, respectivamente 

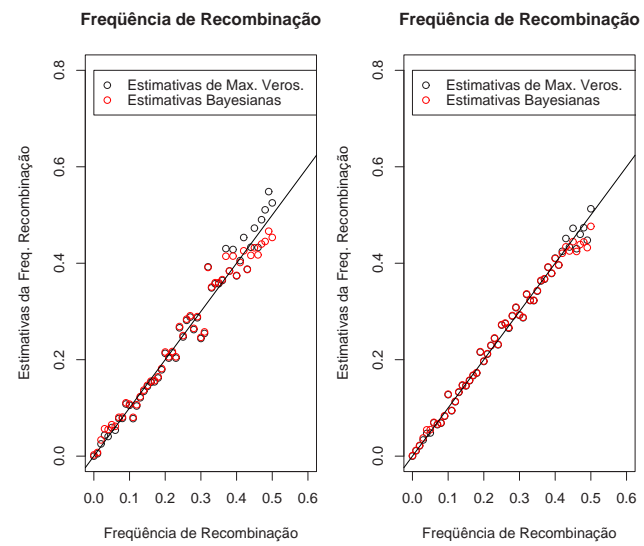

Figura 42 - Gráficos das estimativas Bayesianas e de Máxima Verossimilhança, configuração B3-B3 e arranjo A1, com n=200 e n=500, respectivamente
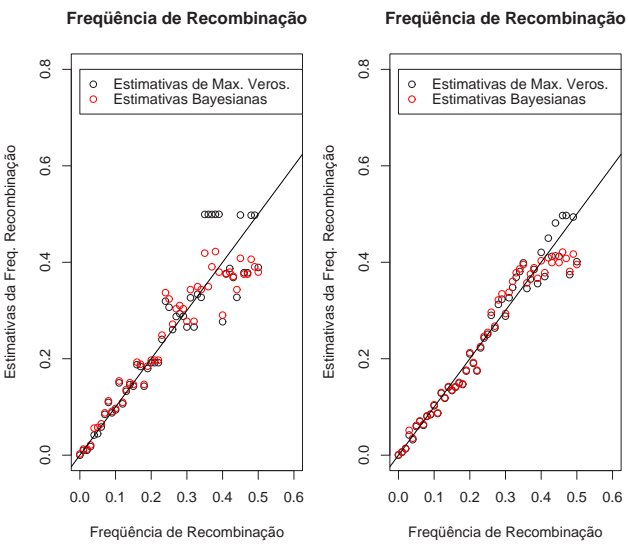

Figura 43 - Gráficos das estimativas Bayesianas e de Máxima Verossimilhança, configuração B3-B3 e arranjo A2, com n=200 e n=500, respectivamente 

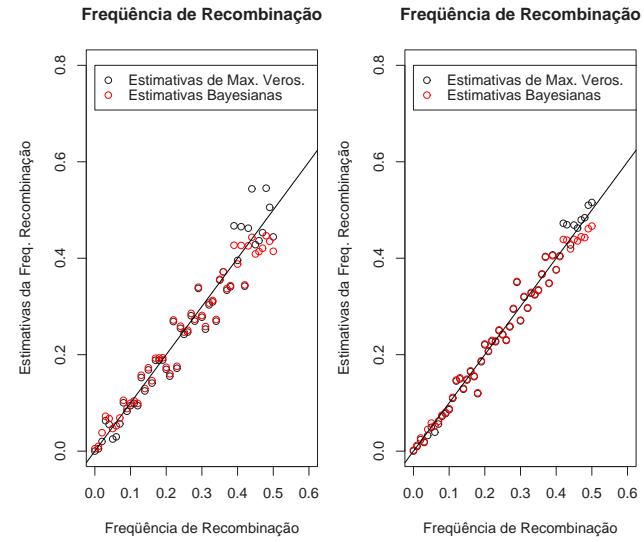

Figura 44 - Gráficos das estimativas Bayesianas e de Máxima Verossimilhança, configuração B3-C e arranjo A1, com n=200 e n=500, respectivamente
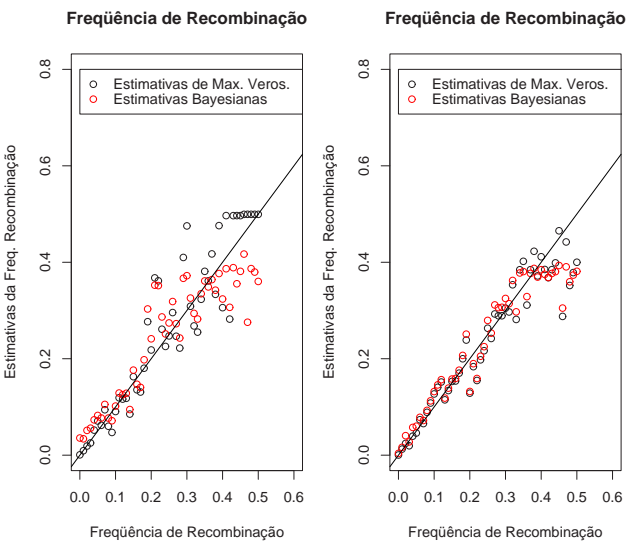

Figura 45 - Gráficos das estimativas Bayesianas e de Máxima Verossimilhança, configuração B3-C e arranjo A2, com n=200 e n=500, respectivamente 

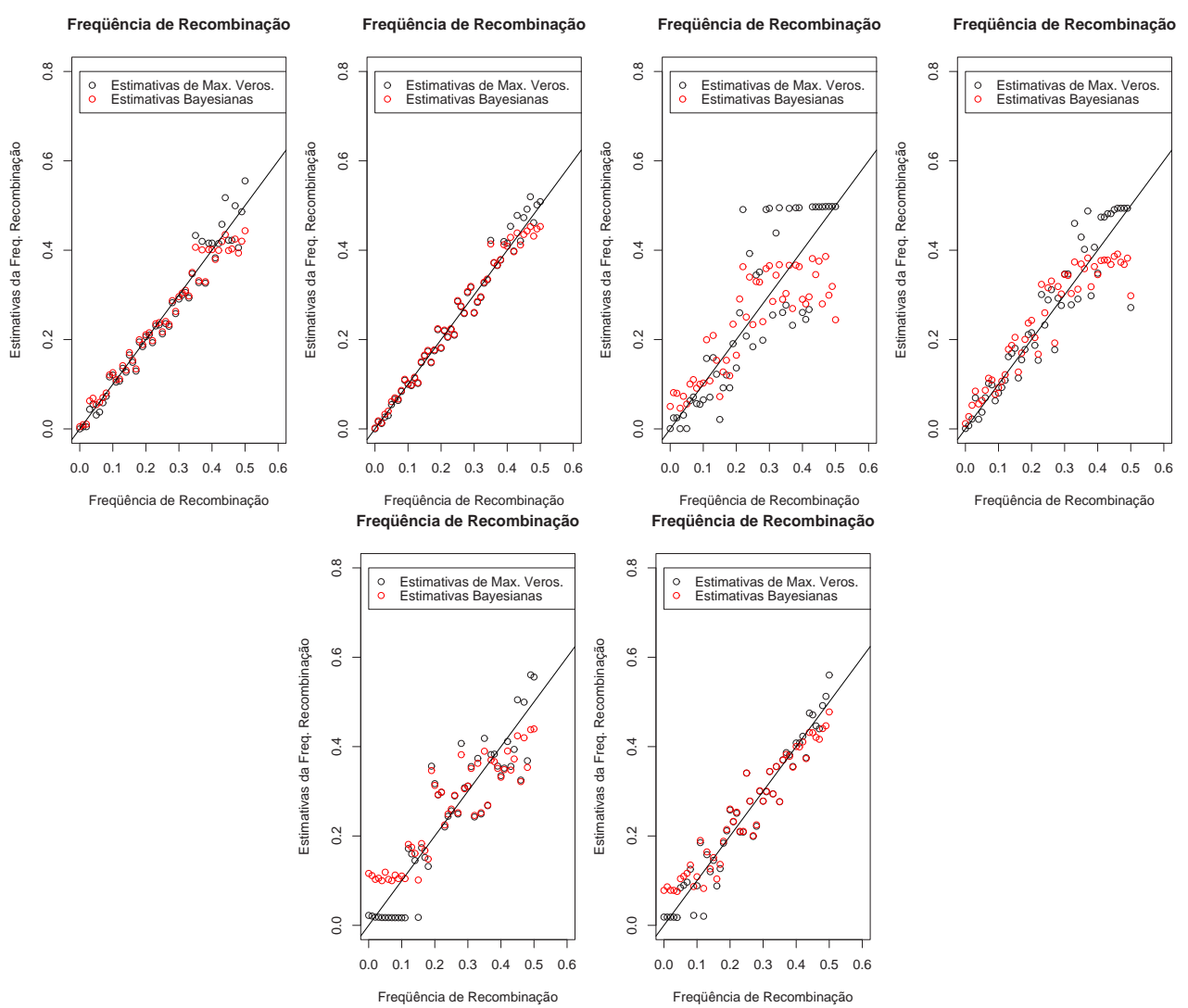

Figura 46 - Gráficos das estimativas Bayesianas e de Máxima Verossimilhança, configuração C-C considerando A1 ( $\mathrm{n}=200)$, A1 $(\mathrm{n}=500)$, A3 $(\mathrm{n}=200)$, A3 $(\mathrm{n}=500), \mathrm{A} 4(\mathrm{n}=200)$ e A4 $(\mathrm{n}=500)$, respectivamente 


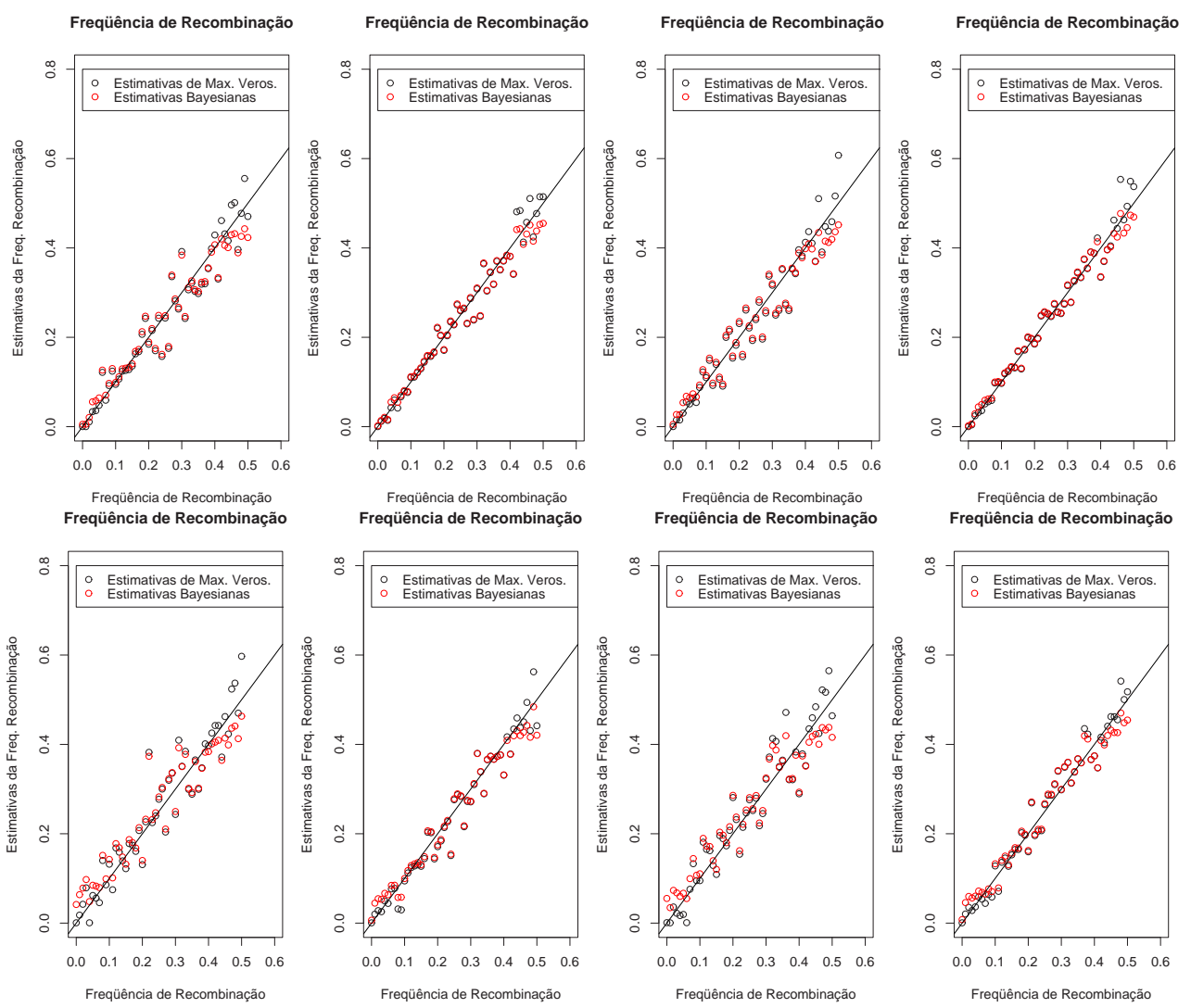

Figura 47 - Gráficos das estimativas Bayesianas e de Máxima Verossimilhança, configuração B1-C considerando A1 ( $\mathrm{n}=200), \mathrm{A} 1$ ( $\mathrm{n}=500), \mathrm{A} 2(\mathrm{n}=200), \mathrm{A} 2$ $(n=500), A 3(n=200), A 3(n=500), A 4(n=200)$ e A4 $(n=500)$, respectivamente 


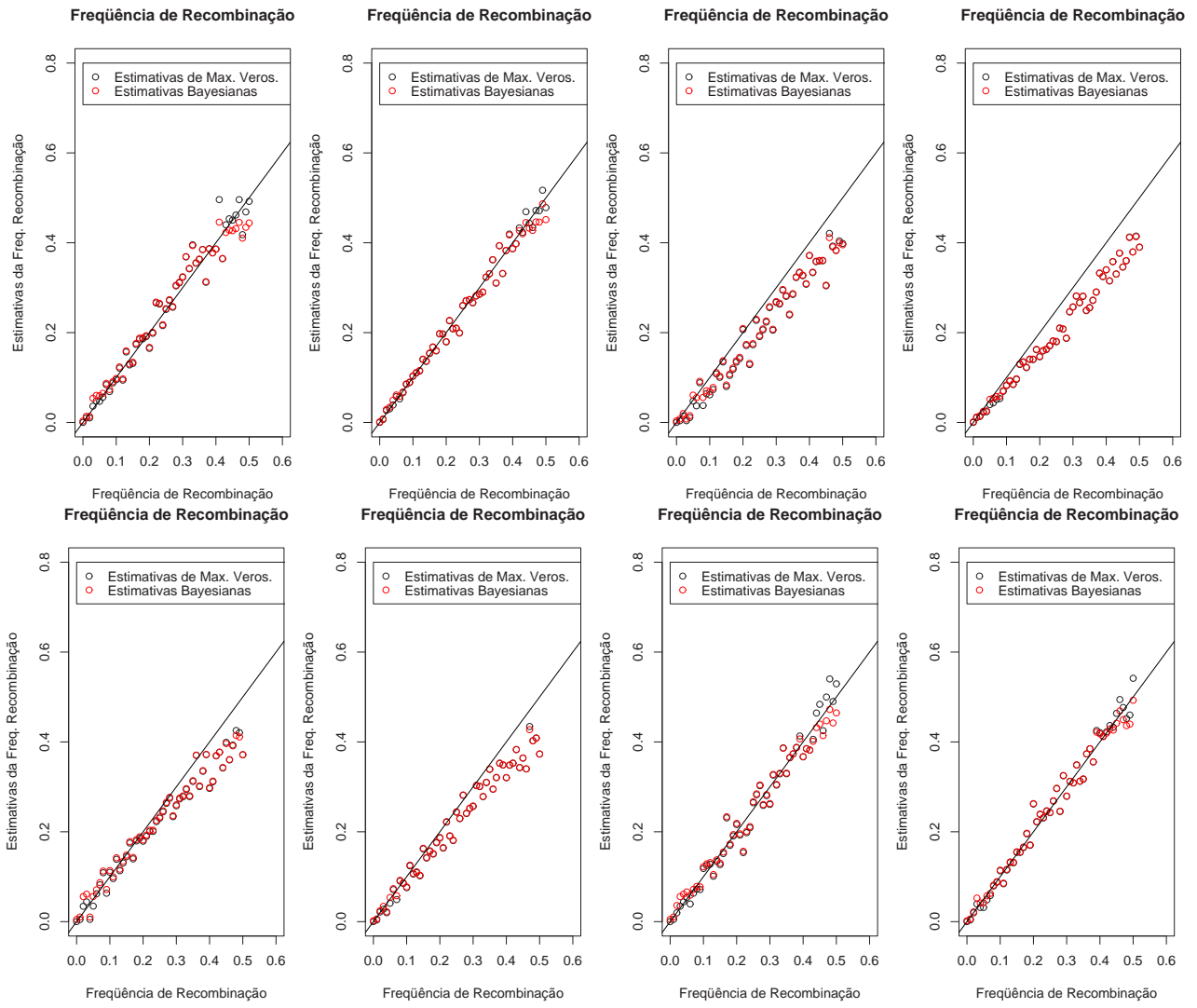

Figura 48 - Gráficos das estimativas Bayesianas e de Máxima Verossimilhança, configuração B1-B1 considerando A1 ( $\mathrm{n}=200)$, A1 ( $\mathrm{n}=500)$, A2 ( $\mathrm{n}=200)$, A2 $(n=500), A 3(n=200), A 3(n=500), A 4(n=200)$ e A4 $(n=500)$, respectivamente 

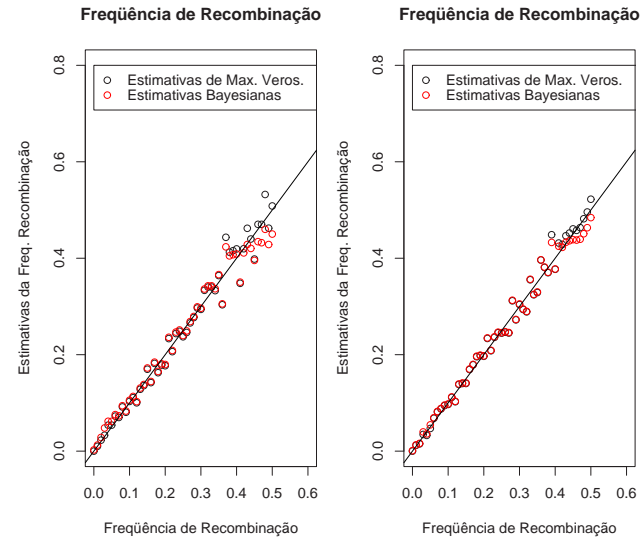

Figura 49 - Gráficos das estimativas Bayesianas e de Máxima Verossimilhança, configuração A-B3 e arranjo A1, com n=200 e n=500, respectivamente
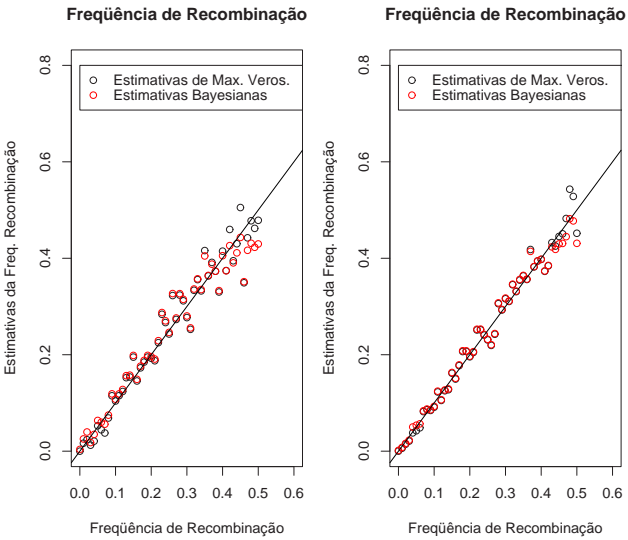

Figura 50 - Gráficos das estimativas Bayesianas e de Máxima Verossimilhança, configuração B1-B3 e arranjo A1, com n=200 e n=500, respectivamente 

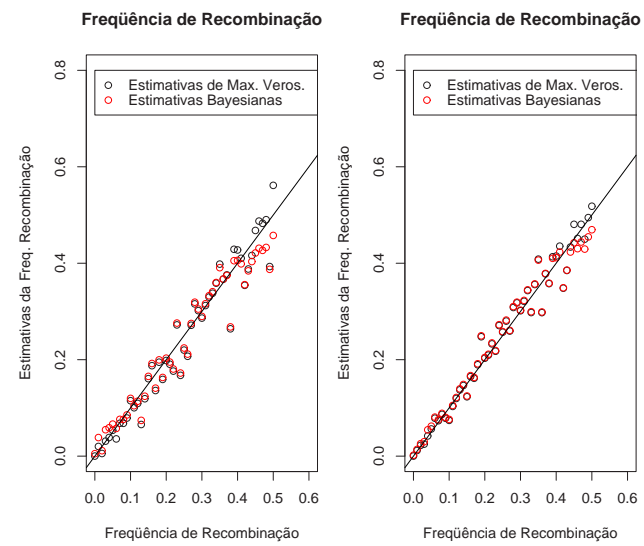

Figura 51 - Gráficos das estimativas Bayesianas e de Máxima Verossimilhança, configuração A-C e arranjo A1, com n=200 e n=500, respectivamente
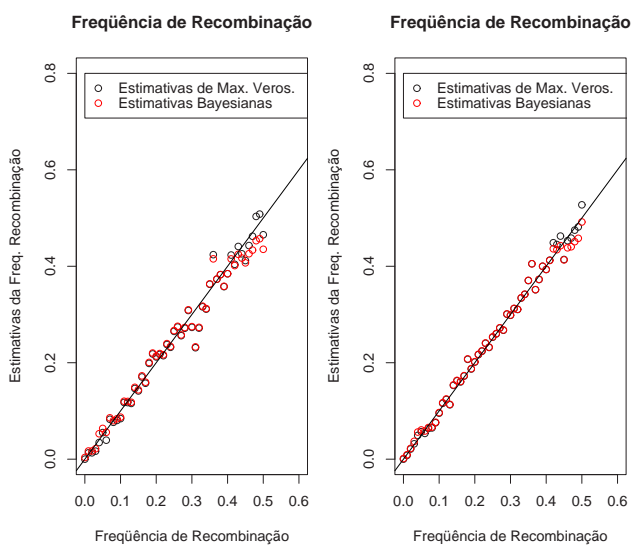

Figura 52 - Gráficos das estimativas Bayesianas e de Máxima Verossimilhança, configuração A-B1 e arranjo A1, com n=200 e n=500, respectivamente 

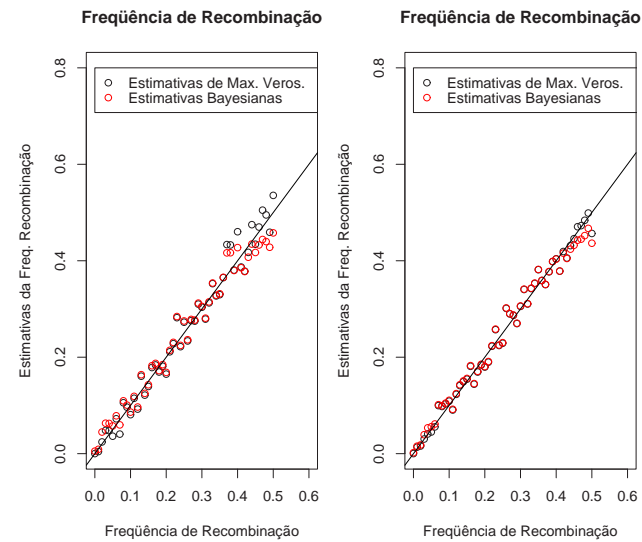

Figura 53 - Gráficos das estimativas Bayesianas e de Máxima Verossimilhança, configuração B1-B2 e arranjo A1, com n=200 e n=500, respectivamente 
ANEXO F - Gráficos das estimativas significativas da freqüência de recombinação obtidas pelos métodos da máxima verossimilhança e Bayesianos de tamanhos 50 e 100

Freqüência de Recombinação

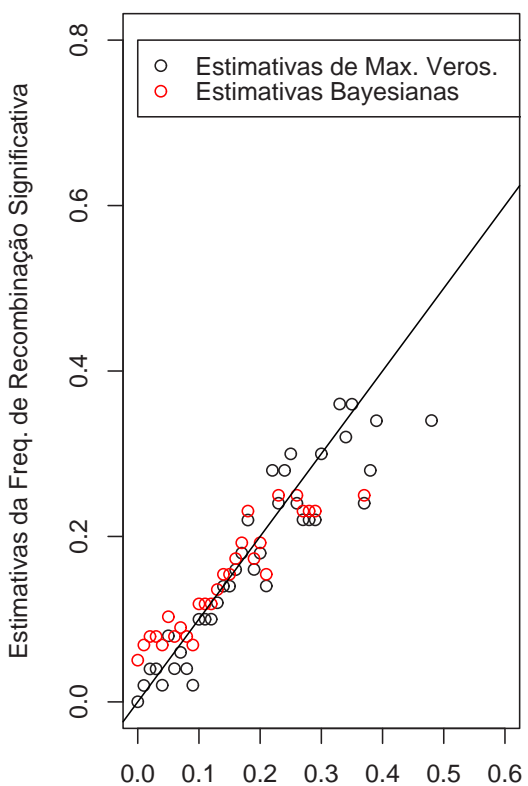

Freqüência de Recombinação, $n=50$
Freqüência de Recombinação

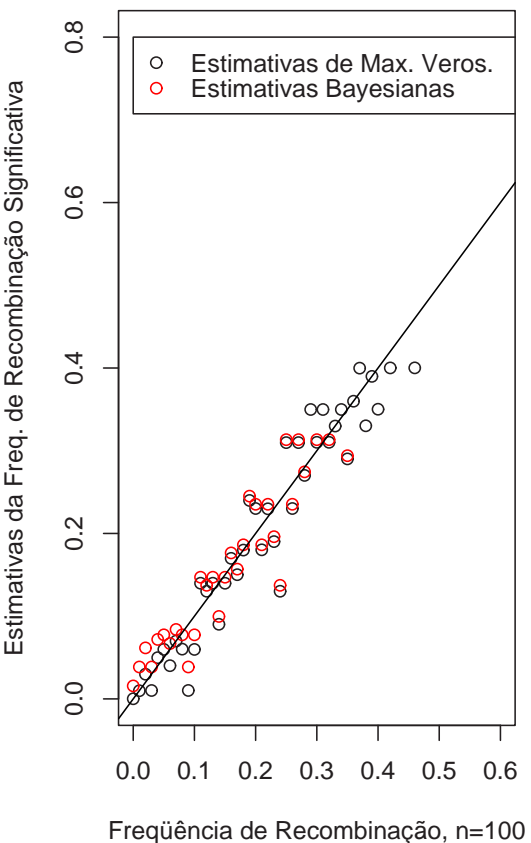

Figura 54 - Gráficos das estimativas significativas Bayesianas e de Máxima Verossimilhança, configuração D1-D1 e arranjo A1, com n=50 e n=100, respectivamente 

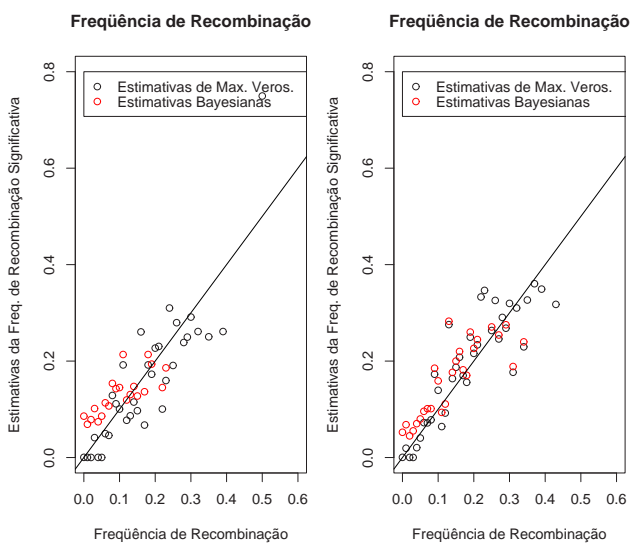

Figura 55 - Gráficos das estimativas significativas Bayesianas e de Máxima Verossimilhança, configuração B3-D1 e arranjo A3, com n=50 e n=100, respectivamente
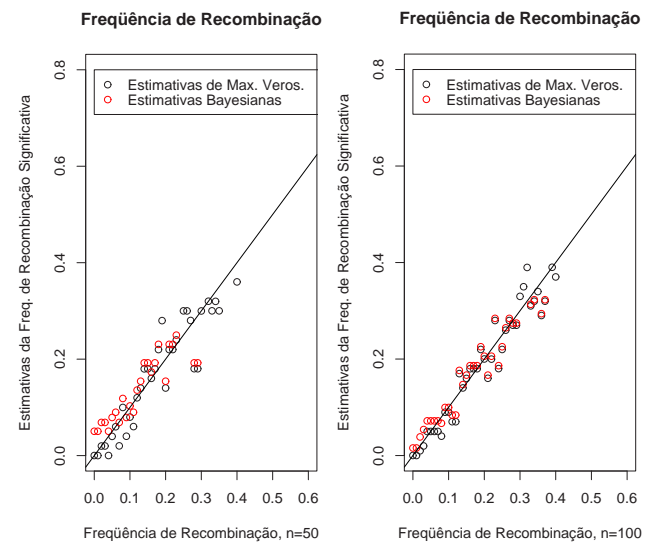

Figura 56 - Gráficos das estimativas significativas Bayesianas e de Máxima Verossimilhança, configuração A-D1 e arranjo A1, com n=50 e n=100, respectivamente 

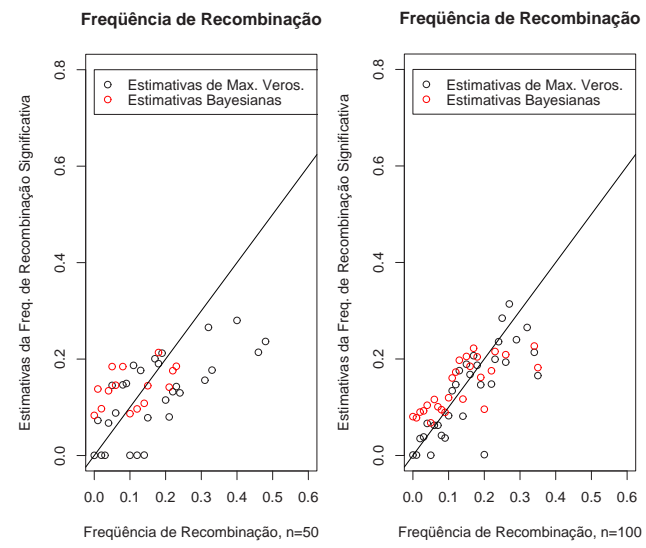

Figura 57 - Gráficos das estimativas significativas Bayesianas e de Máxima Verossimilhança, configuração C-D1 e arranjo A3, com n=50 e n=100, respectivamente
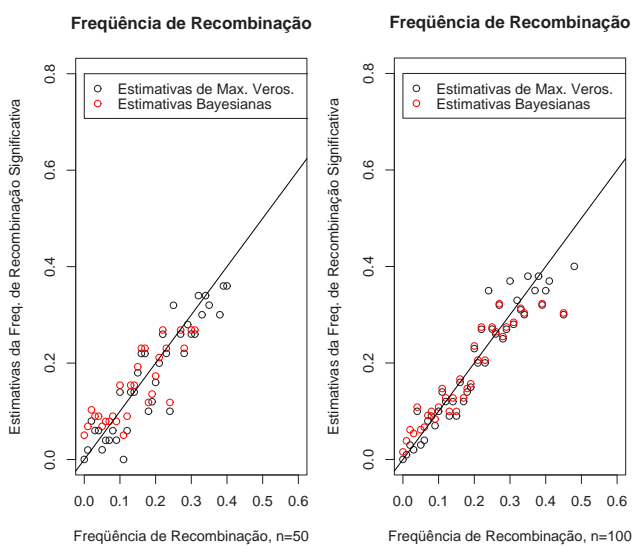

Figura 58 - Gráficos das estimativas significativas Bayesianas e de Máxima Verossimilhança, configuração B1-D1 e arranjo A1, com n=50 e n=100, respectivamente 

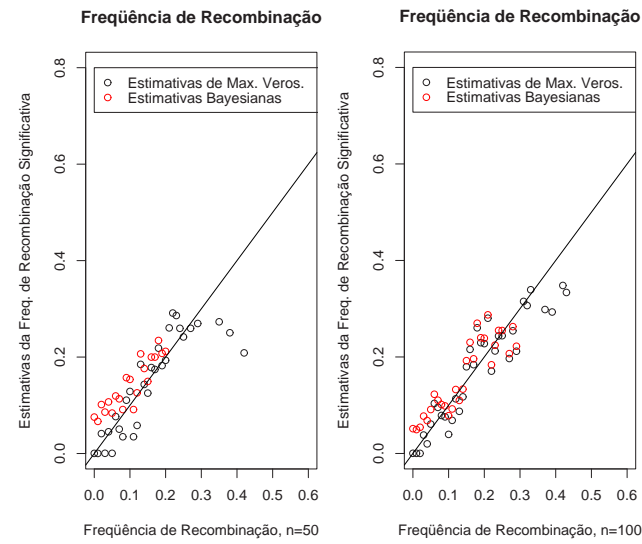

Figura 59 - Gráficos das estimativas significativas Bayesianas e de Máxima Verossimilhança, configuração B1-D2 e arranjo A1, com n=50 e n=100, respectivamente
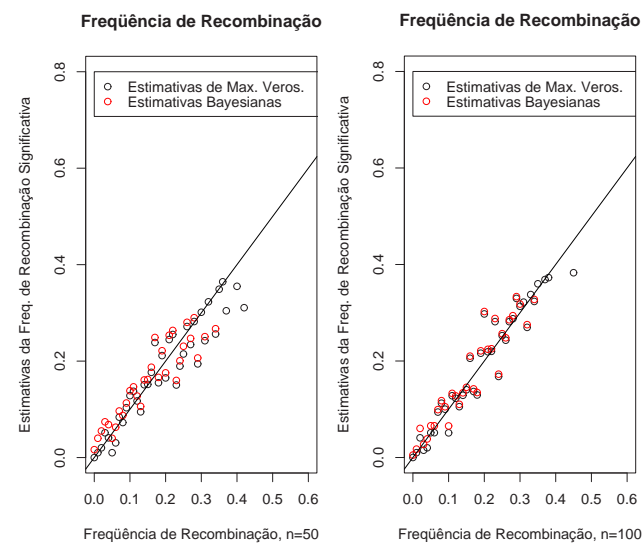

Figura 60 - Gráficos das estimativas significativas Bayesianas e de Máxima Verossimilhança, configuração B3-B3 e arranjo A1, com n=50 e n=100, respectivamente 

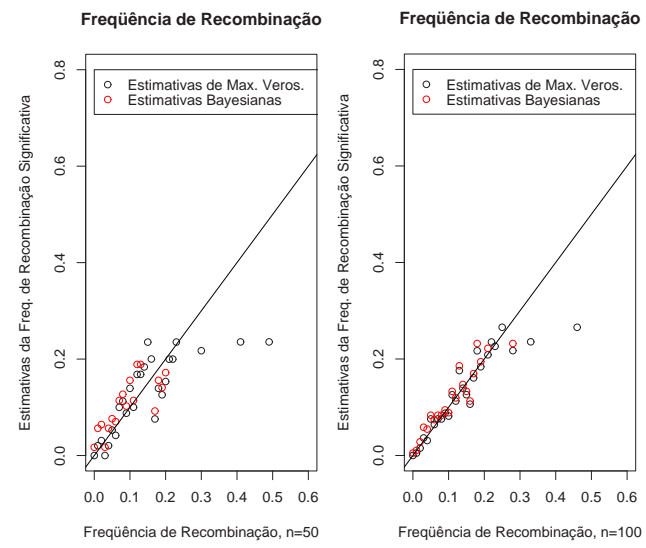

Figura 61 - Gráficos das estimativas significativas Bayesianas e de Máxima Verossimilhança, configuração B3-B3 e arranjo A2, com n=50 e n=100, respectivamente

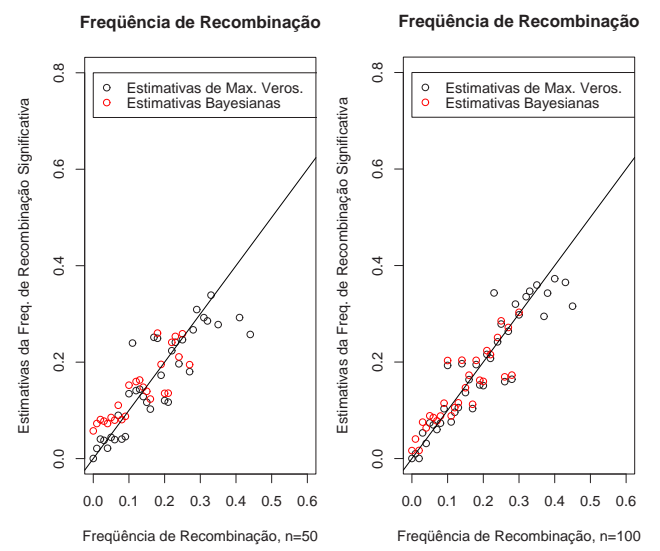

Figura 62 - Gráficos das estimativas significativas Bayesianas e de Máxima Verossimilhança, configuração B3-C e arranjo A1, com n=50 e n=100, respectivamente 
Freqüência de Recombinação

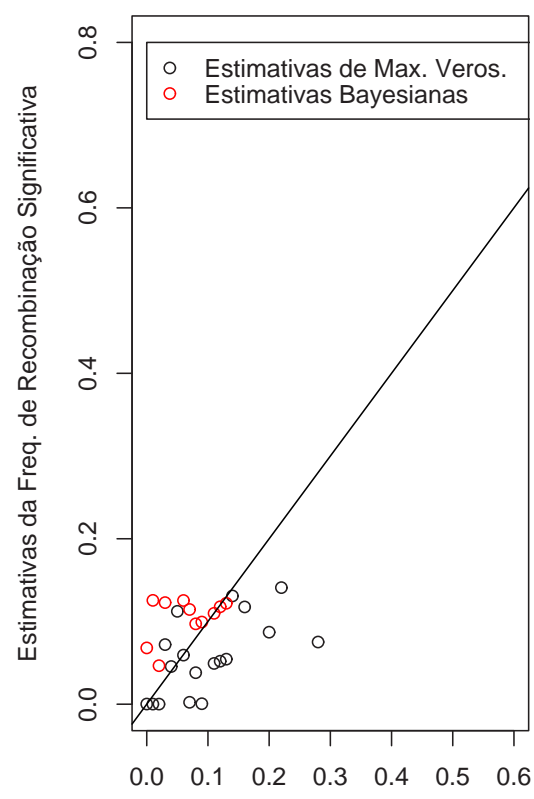

Freqüência de Recombinação, $n=50$

\section{Freqüência de Recombinação}

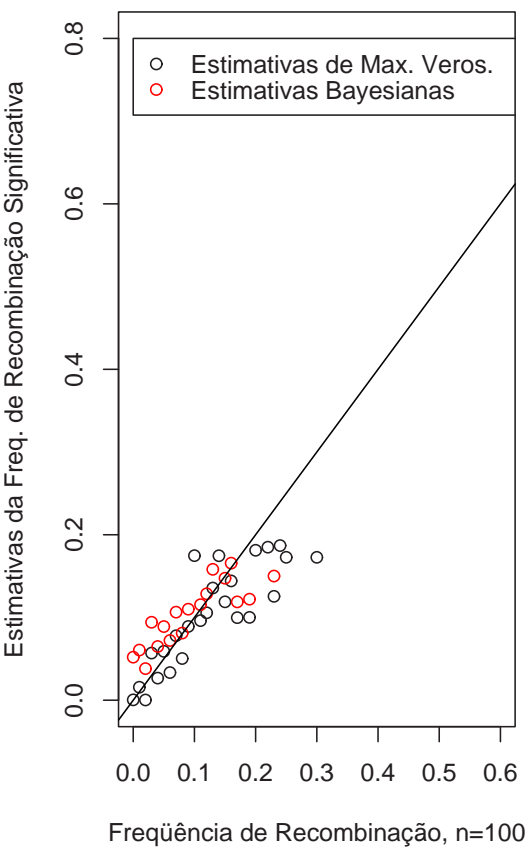

Figura 63 - Gráficos das estimativas significativas Bayesianas e de Máxima Verossimilhança, configuração B3-C e arranjo A2, com n=50 e n=100, respectivamente 

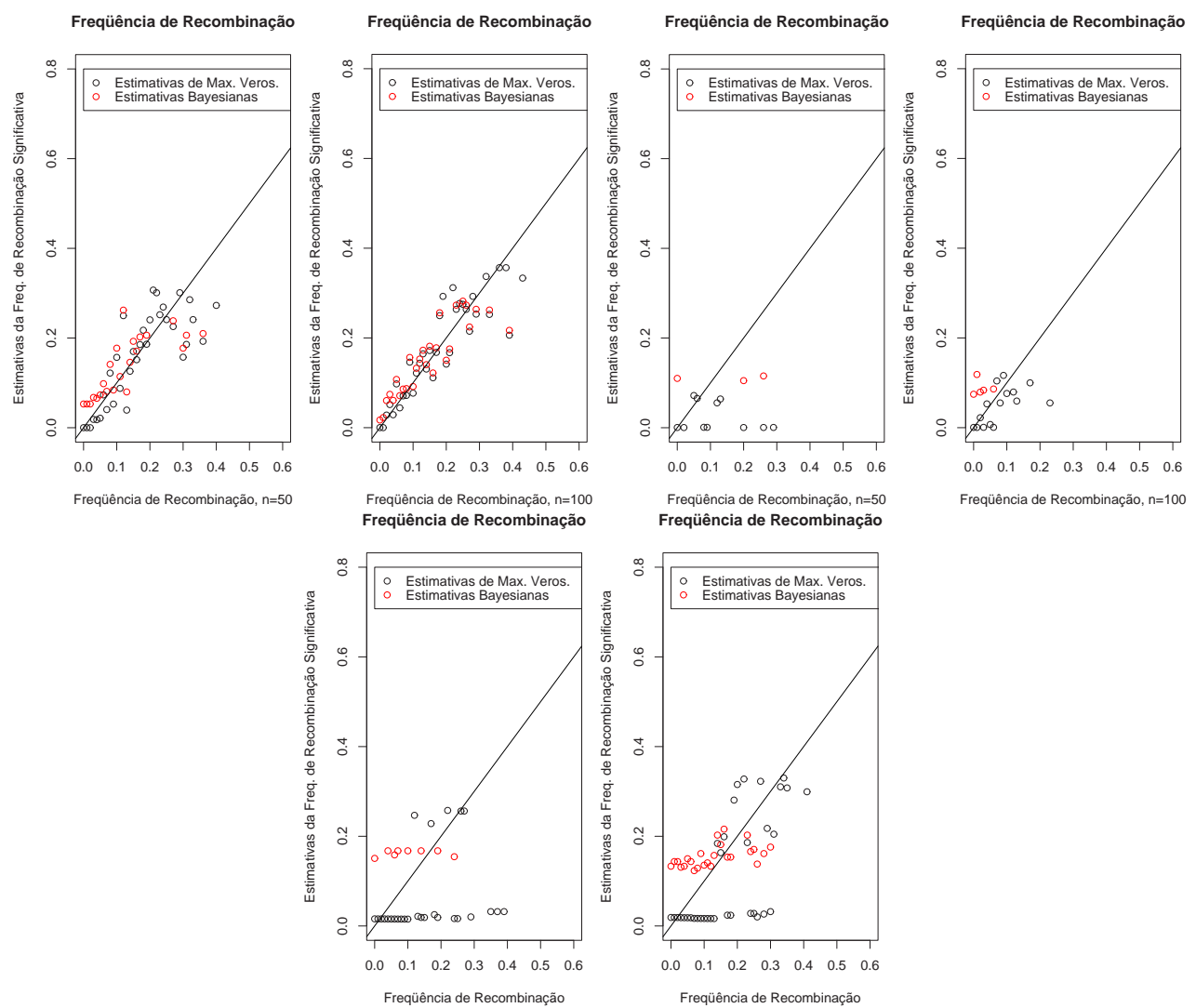

Figura 64 - Gráficos das estimativas significativas Bayesianas e de Máxima Verossimilhança, configuração C-C considerando A1 (n=50), A1 (n=100), A3 $(\mathrm{n}=50), \mathrm{A} 3(\mathrm{n}=100), \mathrm{A} 4(\mathrm{n}=50)$ e $\mathrm{A} 4(\mathrm{n}=100)$, respectivamente 


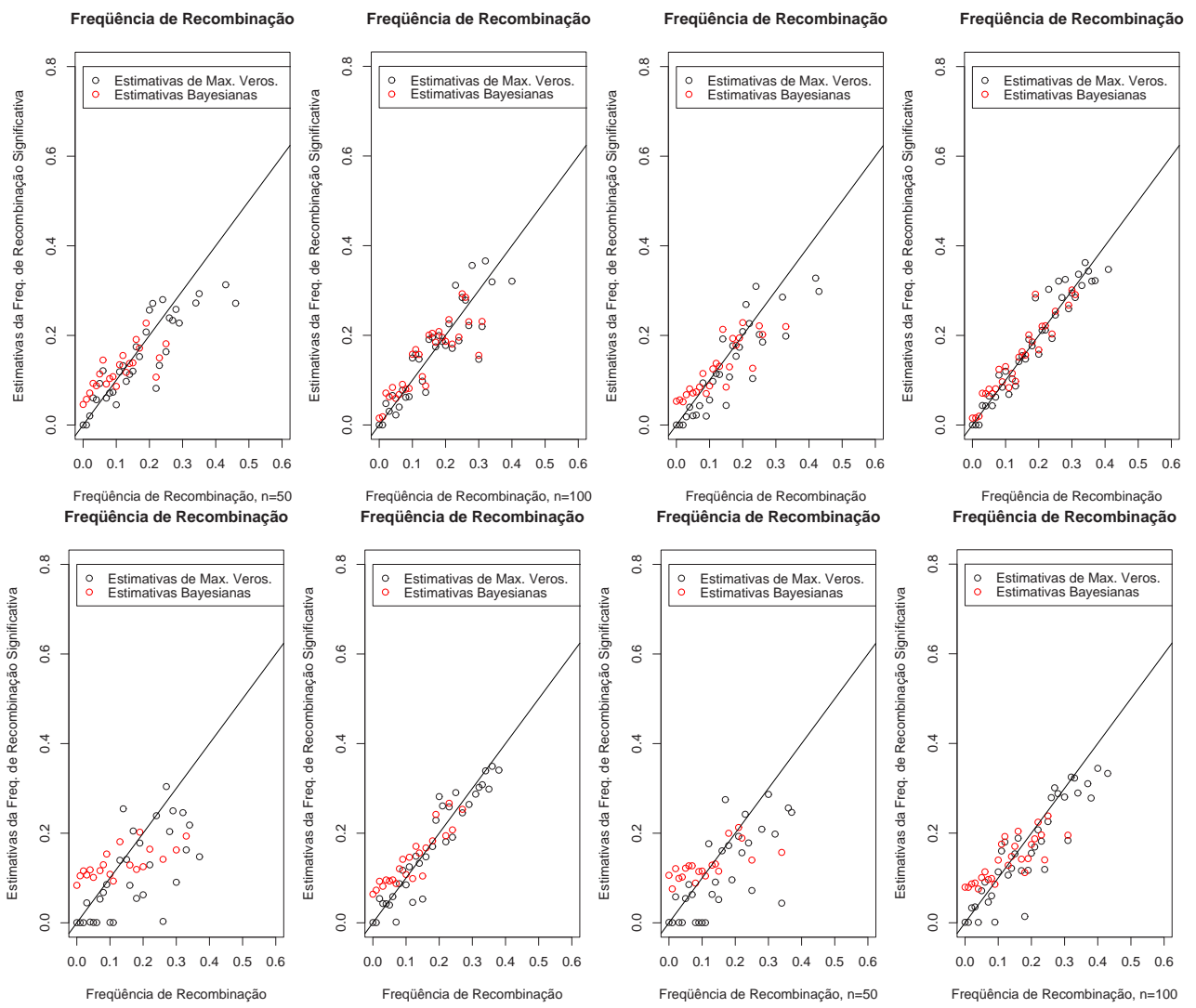

Figura 65 - Gráficos das estimativas significativas Bayesianas e de Máxima Verossimilhança, configuração B1-C considerando A1 ( $\mathrm{n}=50), \mathrm{A} 1$ ( $\mathrm{n}=100), \mathrm{A} 2$ $(\mathrm{n}=50), A 2(\mathrm{n}=100), \mathrm{A} 3(\mathrm{n}=50), \mathrm{A} 3(\mathrm{n}=100), \mathrm{A} 4(\mathrm{n}=50)$ e $\mathrm{A} 4(\mathrm{n}=100)$, respectivamente 


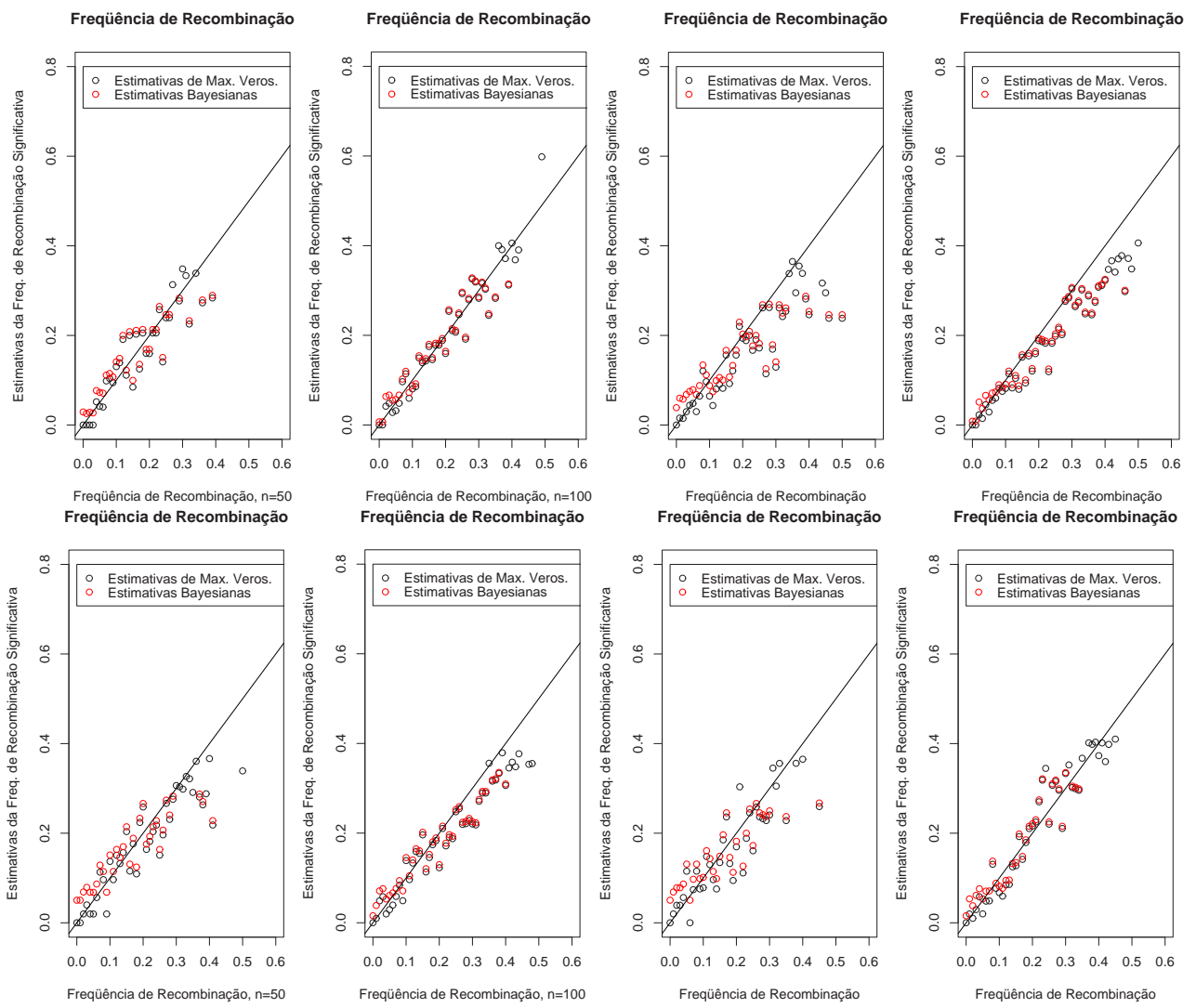

Figura 66 - Gráficos das estimativas significativas Bayesianas e de Máxima Verossimilhança, configuração B1-B1 considerando A1 ( $\mathrm{n}=50), \mathrm{A} 1$ ( $\mathrm{n}=100), \mathrm{A} 2$ $(n=50), A 2(n=100), A 3(n=50), A 3(n=100), A 4(n=50)$ e $A 4(n=100)$, respectivamente 

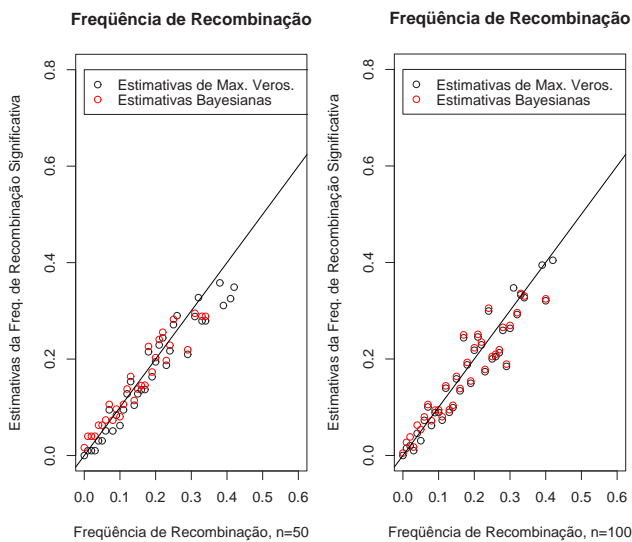

Figura 67 - Gráficos das estimativas significativas Bayesianas e de Máxima Verossimilhança, configuração A-B3 e arranjo A1, com n=50 e n=100, respectivamente
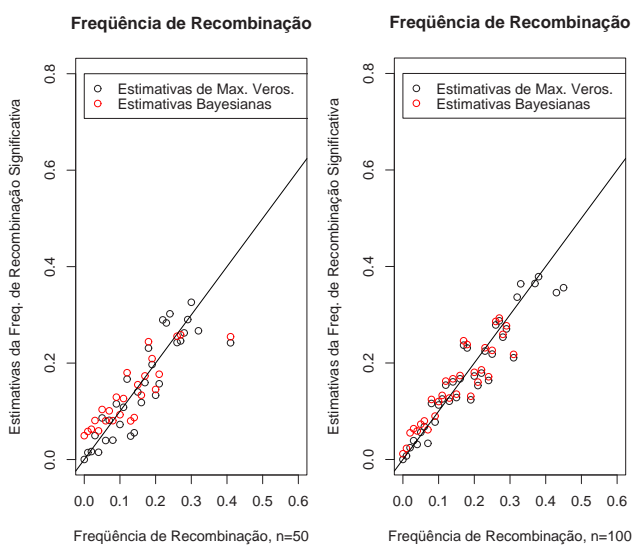

Figura 68 - Gráficos das estimativas significativas Bayesianas e de Máxima Verossimilhança, configuração B1-B3 e arranjo A1, com n=50 e n=100, respectivamente 

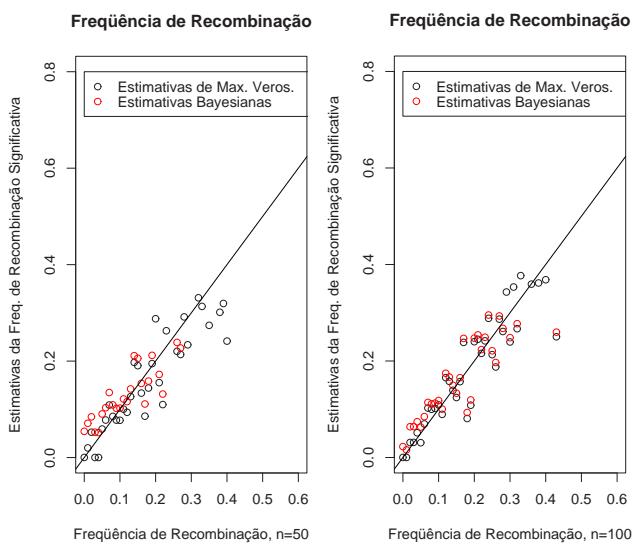

Figura 69 - Gráficos das estimativas significativas Bayesianas e de Máxima Verossimilhança, configuração A-C e arranjo A1, com n=50 e n=100, respectivamente
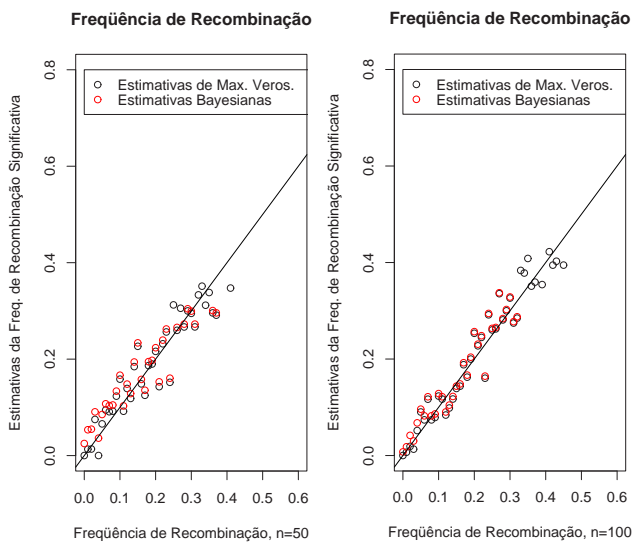

Figura 70 - Gráficos das estimativas significativas Bayesianas e de Máxima Verossimilhança, configuração A-B1 e arranjo A1, com n=50 e n=100, respectivamente 

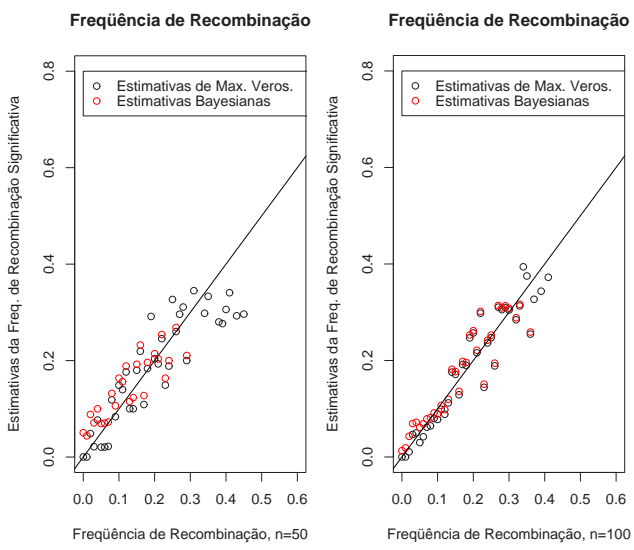

Figura 71 - Gráficos das estimativas significativas Bayesianas e de Máxima Verossimilhança, configuração B1-B2 e arranjo A1, com n=50 e n=100, respectivamente 
ANEXO G - Tabelas, considerando $\mathrm{n}=50$, com: alguns dos verdadeiros valores de $r$ usados na simulação dos conjuntos de dados; as estimativas de $r$ obtidas pelo método Bayesiano; intervalo de credibilidade para as estimativas Bayesianas; estimativas de $r$ obtidas pelo método da máxima verossimilhança; intervalos de confiança

Tabela 30. Valores verdadeiros para a freqüência de recombinação, estimativas Bayesiana para a freqüência de recombinação e Intervalos de Credibilidade para conjuntos de dados de tamanhos $\mathrm{n}=50$, cruzamento D1-D1, arranjo $A_{1}$

\begin{tabular}{ccccc}
\hline$r_{\text {verdadeiro }}$ & Est. Bay & Int. de Cred. & Est. Max. Vero. & IC \\
\hline 0,15 & 0,15423 & $(0,09996 ; 0,25899)$ & 0,13992 & $(0,12633 ; 0,15352)$ \\
0,16 & 0,17318 & $(0,09994 ; 0,28493)$ & 0,15984 & $(0,14548 ; 0,17420)$ \\
0,17 & 0,19232 & $(0,10003 ; 0,30849)$ & 0,17984 & $(0,16479 ; 0,19489)$ \\
0,18 & 0,23067 & $(0,12790 ; 0,35275)$ & 0,21984 & $(0,20361 ; 0,23607)$ \\
0,19 & 0,17318 & $(0,09994 ; 0,28493)$ & 0,16012 & $(0,14574 ; 0,17450)$ \\
0,20 & 0,19232 & $(0,10003 ; 0,30849)$ & 0,17984 & $(0,16479 ; 0,19489)$ \\
0,21 & 0,15423 & $(0,09996 ; 0,25899)$ & 0,14016 & $(0,12654 ; 0,15377)$ \\
0,22 & 0,28707 & $(0,17471 ; 0,40962)$ & 0,27986 & $(0,26227 ; 0,29746)$ \\
0,23 & 0,24973 & $(0,14324 ; 0,37354)$ & 0,24016 & $(0,22341 ; 0,25691)$ \\
0,24 & 0,28707 & $(0,17471 ; 0,40962)$ & 0,27984 & $(0,26225 ; 0,29744)$ \\
0,25 & 0,30493 & $(0,19074 ; 0,42295)$ & 0,29984 & $(0,28188 ; 0,31780)$ \\
0,44 & 0,41297 & $(0,33082 ; 0,45099)$ & 0,50016 & $(0,48056 ; 0,51976)$ \\
\hline
\end{tabular}

Tabela 31. Valores verdadeiros para a freqüência de recombinação, estimativas Bayesiana para a freqüência de recombinação e Intervalos de Credibilidade para conjuntos de dados de tamanhos $\mathrm{n}=50$, cruzamento B3-D1, arranjo $A_{1}$

\begin{tabular}{ccccc}
\hline$r_{\text {verdadeiro }}$ & Est. Bay & Int. de Cred. & Est. Max. Vero. & IC \\
\hline 0,15 & 0,12757 & $(0,09999 ; 0,19956)$ & 0,09708 & $(0,08232 ; 0,11185)$ \\
0,16 & 0,27227 & $(0,12525 ; 0,42576)$ & 0,26047 & $(0,23511 ; 0,28582)$ \\
0,17 & 0,13642 & $(0,09996 ; 0,17475)$ & 0,06732 & $(0,04931 ; 0,08534)$ \\
0,18 & 0,21360 & $(0,10000 ; 0,37267)$ & 0,19200 & $(0,17061 ; 0,21340)$ \\
0,19 & 0,19373 & $(0,09996 ; 0,34126)$ & 0,17274 & $(0,15326 ; 0,19221)$ \\
0,20 & 0,24574 & $(0,10187 ; 0,41104)$ & 0,22689 & $(0,20216 ; 0,25163)$ \\
0,21 & 0,24718 & $(0,11085 ; 0,40563)$ & 0,23043 & $(0,20755 ; 0,25331)$ \\
0,22 & 0,14511 & $(0,09999 ; 0,23131)$ & 0,10049 & $(0,08182 ; 0,11917)$ \\
0,23 & 0,18595 & $(0,09996 ; 0,33508)$ & 0,15966 & $(0,13937 ; 0,17995)$ \\
0,24 & 0,31040 & $(0,17100 ; 0,43680)$ & 0,31003 & $(0,28623 ; 0,33383)$ \\
0,25 & 0,21588 & $(0,09995 ; 0,38465)$ & 0,19089 & $(0,16710 ; 0,21469)$ \\
\hline
\end{tabular}


Tabela 32. Verdadeiros valores de $r$ usados na simulação dos conjuntos de dados, estimativas de $r$ obtidas pelo método Bayesiano, intervalo de credibilidade para as estimativas Bayesianas; estimativas de $r$ obtidas pelo método da máxima verossimilhança e intervalos de confiança considerando a configuração A-D1, arranjo $A 1, \mathrm{n}=50$

\begin{tabular}{ccccc}
\hline$r_{\text {verdadeiro }}$ & Est. Bay & Int. Credib & Est. Máx. Vero & IC \\
\hline 0,00 & 0,05047 & $(0,00139 ; 0,09996)$ & 0,00015 & $(-0,03905 ; 0,03934)$ \\
0,01 & 0,05047 & $(0,00139 ; 0,09996)$ & 0,00073 & $(-0,03912 ; 0,03927)$ \\
0,02 & 0,06880 & $(0,01546 ; 0,09995)$ & 0,01984 & $(0,01440 ; 0,02529)$ \\
0,03 & 0,06880 & $(0,01546 ; 0,09995)$ & 0,01992 & $(0,01445 ; 0,02539)$ \\
0,04 & 0,05047 & $(0,00139 ; 0,09996)$ & 0,00016 & $(-0,03904 ; 0,03935)$ \\
0,05 & 0,07906 & $(0,04051 ; 0,10004)$ & 0,03984 & $(0,03219 ; 0,04750)$ \\
0,06 & 0,08987 & $(0,06928 ; 0,10004)$ & 0,05984 & $(0,05056 ; 0,06913)$ \\
0,07 & 0,06880 & $(0,01546 ; 0,09995)$ & 0,02016 & $(0,01463 ; 0,02569)$ \\
0,08 & 0,11845 & $(0,09999 ; 0,18822)$ & 0,09984 & $(0,08810 ; 0,11159)$ \\
0,09 & 0,07906 & $(0,04051 ; 0,10004)$ & 0,04012 & $(0,03241 ; 0,04782)$ \\
0,10 & 0,10296 & $(0,09700 ; 0,14294)$ & 0,07984 & $(0,06923 ; 0,09046)$ \\
0,11 & 0,08987 & $(0,06928 ; 0,10004)$ & 0,06016 & $(0,05082 ; 0,06949)$ \\
0,12 & 0,13579 & $(0,09999 ; 0,22760)$ & 0,11988 & $(0,10716 ; 0,13261)$ \\
0,13 & 0,15423 & $(0,09996 ; 0,25899)$ & 0,13984 & $(0,12625 ; 0,15343)$ \\
0,14 & 0,19232 & $(0,10003 ; 0,30849)$ & 0,17984 & $(0,16479 ; 0,19489)$ \\
0,15 & 0,19232 & $(0,10003 ; 0,30849)$ & 0,17992 & $(0,16487 ; 0,19498)$ \\
\hline
\end{tabular}

Tabela 33. Valores verdadeiros para a freqüência de recombinação, estimativas Bayesiana para a freqüência de recombinação e Intervalos de Credibilidade para conjuntos de dados de tamanhos $\mathrm{n}=50$, cruzamento C-D1, arranjo $A_{3}$

\begin{tabular}{ccccc}
\hline$r_{\text {verdadeiro }}$ & Est. Bay & Int. de Credibilidaden & Est. Max. Vero. & IC \\
\hline 0,15 & 0,14473 & $(0,09999 ; 0,20232)$ & 0,07832 & $(0,058244116 ; 0,098397904)$ \\
0,16 & 0,29800 & $(0,13022 ; 0,43939)$ & 0,30492 & $(0,273604531 ; 0,336232291)$ \\
0,17 & 0,22456 & $(0,09996 ; 0,39566)$ & 0,20065 & $(0,17133474 ; 0,229966401)$ \\
0,18 & 0,21358 & $(0,09996 ; 0,37848)$ & 0,19050 & $(0,16751067 ; 0,213491613)$ \\
0,19 & 0,23342 & $(0,10000 ; 0,40490)$ & 0,21227 & $(0,18526088 ; 0,239271973)$ \\
0,20 & 0,17568 & $(0,09999 ; 0,28827)$ & 0,11505 & $(0,087890764 ; 0,142212673)$ \\
0,21 & 0,14172 & $(0,09999 ; 0,19640)$ & 0,08001 & $(0,059875215 ; 0,100141582)$ \\
0,22 & 0,17588 & $(0,09999 ; 0,31070)$ & 0,13236 & $(0,109069248 ; 0,155642346)$ \\
0,23 & 0,18509 & $(0,09999 ; 0,33165)$ & 0,14302 & $(0,118323167 ; 0,167715296)$ \\
0,24 & 0,18645 & $(0,09999 ; 0,31573)$ & 0,12989 & $(0,100418813 ; 0,159351439)$ \\
0,25 & 0,32603 & $(0,13403 ; 0,44595)$ & 0,40593 & $(0,363784814 ; 0,448071905)$ \\
\hline
\end{tabular}


Tabela 34. Verdadeiros valores de $r$ usados na simulação dos conjuntos de dados, estimativas de $r$ obtidas pelo método Bayesiano, intervalo de credibilidade para as estimativas Bayesianas; estimativas de $r$ obtidas pelo método da máxima verossimilhança e intervalos de confiança considerando a configuração B1D1, arranjo $A 1, \mathrm{n}=50$

\begin{tabular}{ccccc}
\hline$r_{\text {verdadeiro }}$ & Est. Bay & Int. Credib & Est. Máx. Vero & IC \\
\hline 0,00 & 0,05047 & $(0,00139 ; 0,09996)$ & 0,00015 & $(-0,03905 ; 0,03934)$ \\
0,01 & 0,06880 & $(0,01546 ; 0,09995)$ & 0,01984 & $(0,01440 ; 0,02529)$ \\
0,02 & 0,10296 & $(0,09700 ; 0,14294)$ & 0,07988 & $(0,06926 ; 0,09050)$ \\
0,03 & 0,08987 & $(0,06928 ; 0,10004)$ & 0,06016 & $(0,05082 ; 0,06949)$ \\
0,04 & 0,08987 & $(0,06928 ; 0,10004)$ & 0,06008 & $(0,05076 ; 0,06940)$ \\
0,05 & 0,06880 & $(0,01546 ; 0,09995)$ & 0,02016 & $(0,01463 ; 0,02569)$ \\
0,06 & 0,07906 & $(0,04051 ; 0,10004)$ & 0,03984 & $(0,03219 ; 0,04750)$ \\
0,07 & 0,07906 & $(0,04051 ; 0,10004)$ & 0,03992 & $(0,03225 ; 0,04759)$ \\
0,08 & 0,08987 & $(0,06928 ; 0,10004)$ & 0,05984 & $(0,05056 ; 0,06913)$ \\
0,09 & 0,07906 & $(0,04051 ; 0,10004)$ & 0,04016 & $(0,03245 ; 0,04787)$ \\
0,10 & 0,15423 & $(0,09996 ; 0,25899)$ & 0,13980 & $(0,12622 ; 0,15339)$ \\
0,11 & 0,05047 & $(0,00139 ; 0,09996)$ & 0,00014 & $(-0,03906 ; 0,03933)$ \\
0,12 & 0,08987 & $(0,06928 ; 0,10004)$ & 0,05988 & $(0,05059 ; 0,06918)$ \\
0,13 & 0,15423 & $(0,09996 ; 0,25899)$ & 0,13984 & $(0,12625 ; 0,15343)$ \\
0,14 & 0,15423 & $(0,09996 ; 0,25899)$ & 0,13992 & $(0,12633 ; 0,15352)$ \\
0,15 & 0,19232 & $(0,10003 ; 0,30849)$ & 0,17984 & $(0,16479 ; 0,19489)$ \\
\hline
\end{tabular}

Tabela 35. Verdadeiros valores de $r$ usados na simulação dos conjuntos de dados, estimativas de $r$ obtidas pelo método Bayesiano, intervalo de credibilidade para as estimativas Bayesianas; estimativas de $r$ obtidas pelo método da máxima verossimilhança e intervalos de confiança considerando a configuração B1$\mathrm{D} 2$, arranjo $A 1, \mathrm{n}=50$

\begin{tabular}{ccccc}
\hline$r_{\text {verdadeiro }}$ & Est. Bay & Int. Credib & Est. Máx. Vero & IC \\
\hline 0,00 & 0,07556 & $(0,00654 ; 0,09999)$ & 0,00030 & $(-0,05303 ; 0,05362)$ \\
0,01 & 0,06664 & $(0,00381 ; 0,09998)$ & 0,00022 & $(-0,04731 ; 0,04774)$ \\
0,02 & 0,10155 & $(0,05580 ; 0,10004)$ & 0,04128 & $(0,03007 ; 0,05248)$ \\
0,03 & 0,08585 & $(0,01117 ; 0,09999)$ & 0,00047 & $(-0,05999 ; 0,06093)$ \\
0,04 & 0,10697 & $(0,06334 ; 0,10005)$ & 0,04505 & $(0,03285 ; 0,05726)$ \\
0,05 & 0,08386 & $(0,01018 ; 0,09999)$ & 0,00040 & $(-0,05867 ; 0,05947)$ \\
0,06 & 0,11933 & $(0,09999 ; 0,16133)$ & 0,07658 & $(0,06216 ; 0,09101)$ \\
0,07 & 0,11343 & $(0,07236 ; 0,11430)$ & 0,05048 & $(0,03685 ; 0,06411)$ \\
0,08 & 0,09115 & $(0,04165 ; 0,10004)$ & 0,03474 & $(0,02528 ; 0,04420)$ \\
0,09 & 0,15727 & $(0,09999 ; 0,26362)$ & 0,11058 & $(0,09013 ; 0,13102)$ \\
0,10 & 0,15371 & $(0,09999 ; 0,26852)$ & 0,12872 & $(0,11207 ; 0,14538)$ \\
0,11 & 0,09115 & $(0,04165 ; 0,10004)$ & 0,03476 & $(0,02530 ; 0,04423)$ \\
0,12 & 0,12577 & $(0,08966 ; 0,14621)$ & 0,05824 & $(0,04257 ; 0,07391)$ \\
0,13 & 0,20659 & $(0,09995 ; 0,36215)$ & 0,18486 & $(0,16417 ; 0,20556)$ \\
0,14 & 0,17626 & $(0,09999 ; 0,31835)$ & 0,14323 & $(0,12202 ; 0,16445)$ \\
0,15 & 0,14946 & $(0,09999 ; 0,25897)$ & 0,12526 & $(0,10903 ; 0,14150)$ \\
\hline
\end{tabular}


Tabela 36. Verdadeiros valores de $r$ usados na simulação dos conjuntos de dados, estimativas de $r$ obtidas pelo método Bayesiano, intervalo de credibilidade para as estimativas Bayesianas; estimativas de $r$ obtidas pelo método da máxima verossimilhança e intervalos de confiança considerando a configuração B3B3, arranjo $A 3, \mathrm{n}=50$

\begin{tabular}{ccccc}
\hline$r_{\text {verdadeiro }}$ & Est. Bay & Int. Credib & Est. Máx. Vero & IC \\
\hline 0,00 & 0,01709 & $(0,00029 ; 0,09997)$ & 0,00000 & NA \\
0,01 & 0,05644 & $(0,01156 ; 0,09997)$ & 0,02040 & $(0,01640 ; 0,02440)$ \\
0,02 & 0,04139 & $(0,00363 ; 0,09995)$ & 0,01011 & $(0,00731 ; 0,01291)$ \\
0,03 & 0,04139 & $(0,00363 ; 0,09995)$ & 0,01010 & $(0,00730 ; 0,01290)$ \\
0,04 & 0,07014 & $(0,19999 ; 0,18068)$ & 0,04173 & $(0,03593 ; 0,04753)$ \\
0,05 & 0,07629 & $(0,20000 ; 0,20001)$ & 0,05277 & $(0,04620 ; 0,05935)$ \\
0,06 & 0,14099 & $(0,09998 ; 0,23925)$ & 0,12576 & $(0,11491 ; 0,13660)$ \\
0,07 & 0,10253 & $(0,09999 ; 0,15638)$ & 0,08776 & $(0,07904 ; 0,09648)$ \\
0,08 & 0,09228 & $(0,08884 ; 0,12629)$ & 0,07579 & $(0,06777 ; 0,08382)$ \\
0,09 & 0,11419 & $(0,09999 ; 0,18593)$ & 0,09995 & $(0,09055 ; 0,10936)$ \\
0,10 & 0,07014 & $(0,19999 ; 0,18068)$ & 0,04182 & $(0,03601 ; 0,04764)$ \\
0,11 & 0,14099 & $(0,09998 ; 0,23925)$ & 0,12575 & $(0,11491 ; 0,13659)$ \\
0,12 & 0,11419 & $(0,09999 ; 0,18593)$ & 0,10007 & $(0,09065 ; 0,10949)$ \\
0,13 & 0,10253 & $(0,09999 ; 0,15638)$ & 0,08778 & $(0,07906 ; 0,09651)$ \\
0,49 & 0,34597 & $(0,21532 ; 0,44646)$ & 0,49964 & NA \\
\hline
\end{tabular}

Tabela 37. Valores verdadeiros para a freqüência de recombinação, estimativas Bayesiana para a freqüência de recombinação e Intervalos de Credibilidade para conjuntos de dados de tamanhos $n=50$, cruzamento B3-C, arranjo $A_{1}$

\begin{tabular}{ccccc}
\hline$r_{\text {verdadeiro }}$ & Est. Bay & Int. de Credibilidaden & Est. Max. Vero. & IC \\
\hline 0,15 & 0,13954 & $(0,09999 ; 0,24071)$ & 0,11673 & $(0,10261 ; 0,13086)$ \\
0,16 & 0,12350 & $(0,09999 ; 0,20142)$ & 0,10262 & $(0,09024 ; 0,11500)$ \\
0,17 & 0,26504 & $(0,14431 ; 0,40542)$ & 0,25148 & $(0,23198 ; 0,27097)$ \\
0,18 & 0,26021 & $(0,15249 ; 0,38665)$ & 0,24948 & $(0,23249 ; 0,26647)$ \\
0,19 & 0,19533 & $(0,09999 ; 0,34402)$ & 0,17284 & $(0,15502 ; 0,19066)$ \\
0,20 & 0,13536 & $(0,09999 ; 0,22712)$ & 0,12038 & $(0,10827 ; 0,13250)$ \\
0,21 & 0,13568 & $(0,09999 ; 0,23116)$ & 0,11708 & $(0,10416 ; 0,12999)$ \\
0,22 & 0,24111 & $(0,12662 ; 0,38474)$ & 0,22371 & $(0,20532 ; 0,24210)$ \\
0,23 & 0,25340 & $(0,14231 ; 0,38513)$ & 0,24122 & $(0,22358 ; 0,25885)$ \\
0,24 & 0,21086 & $(0,11180 ; 0,33631)$ & 0,19653 & $(0,18076 ; 0,21230)$ \\
0,25 & 0,25881 & $(0,14519 ; 0,39261)$ & 0,24646 & $(0,22836 ; 0,26455)$ \\
\hline
\end{tabular}


Tabela 38. Verdadeiros valores de $r$ usados na simulação dos conjuntos de dados, estimativas de $r$ obtidas pelo método Bayesiano, intervalo de credibilidade para as estimativas Bayesianas; estimativas de $r$ obtidas pelo método da máxima verossimilhança e intervalos de confiança considerando a configuração C-C, arranjo $A 1, \mathrm{n}=50$

\begin{tabular}{ccccc}
\hline$r_{\text {verdadeiro }}$ & Est. Bay & Int. Credib & Est. Máx. Vero & IC \\
\hline 0,00 & 0,05292 & $(0,00154 ; 0,09995)$ & 0,00013 & $(-0,07014 ; 0,07041)$ \\
0,01 & 0,05292 & $(0,00154 ; 0,09995)$ & 0,00007 & $(-0,07021 ; 0,07034)$ \\
0,02 & 0,05292 & $(0,00154 ; 0,09995)$ & 0,00003 & $(-0,07024 ; 0,07031)$ \\
0,03 & 0,06756 & $(0,01383 ; 0,09998)$ & 0,01857 & $(0,01344 ; 0,02369)$ \\
0,04 & 0,06563 & $(0,01241 ; 0,09997)$ & 0,01792 & $(0,01298 ; 0,02287)$ \\
0,05 & 0,07309 & $(0,01847 ; 0,09995)$ & 0,02123 & $(0,01536 ; 0,02710)$ \\
0,06 & 0,09819 & $(0,08841 ; 0,12827)$ & 0,07320 & $(0,06324 ; 0,08317)$ \\
0,07 & 0,08114 & $(0,04195 ; 0,10004)$ & 0,04043 & $(0,03256 ; 0,04830)$ \\
0,08 & 0,14124 & $(0,09999 ; 0,24321)$ & 0,12186 & $(0,10839 ; 0,13532)$ \\
0,09 & 0,08405 & $(0,05803 ; 0,10004)$ & 0,05270 & $(0,04439 ; 0,06102)$ \\
0,10 & 0,17737 & $(0,09999 ; 0,31043)$ & 0,15690 & $(0,14080 ; 0,17299)$ \\
0,11 & 0,11413 & $(0,09999 ; 0,17133)$ & 0,08778 & $(0,07575 ; 0,09981)$ \\
0,12 & 0,26223 & $(0,14958 ; 0,39498)$ & 0,24989 & $(0,23200 ; 0,26777)$ \\
0,13 & 0,07979 & $(0,03997 ; 0,10004)$ & 0,03929 & $(0,03165 ; 0,04693)$ \\
0,14 & 0,14591 & $(0,09999 ; 0,25356)$ & 0,12593 & $(0,11199 ; 0,13987)$ \\
0,15 & 0,19270 & $(0,09998 ; 0,33974)$ & 0,16997 & $(0,15238 ; 0,18756)$ \\
0,16 & 0,17079 & $(0,09999 ; 0,29768)$ & 0,15163 & $(0,13613 ; 0,16713)$ \\
0,17 & 0,20240 & $(0,10002 ; 0,33527)$ & 0,18543 & $(0,16895 ; 0,20191)$ \\
0,18 & 0,23729 & $(0,11631 ; 0,39045)$ & 0,21742 & $(0,19775 ; 0,23709)$ \\
0,19 & 0,20626 & $(0,10003 ; 0,35226)$ & 0,18623 & $(0,16837 ; 0,20408)$ \\
0,20 & 0,25815 & $(0,13263 ; 0,40826)$ & 0,24054 & $(0,22001 ; 0,26107)$ \\
\hline
\end{tabular}

Tabela 39. Verdadeiros valores de $r$ usados na simulação dos conjuntos de dados, estimativas de $r$ obtidas pelo método Bayesiano, intervalo de credibilidade para as estimativas Bayesianas; estimativas de $r$ obtidas pelo método da máxima verossimilhança e intervalos de confiança considerando a configuração C-C, arranjo $A 2, \mathrm{n}=50$

\begin{tabular}{ccccc}
\hline$r_{\text {verdadeiro }}$ & Est. Bay & Int. Credib & Est. Máx. Vero & IC \\
\hline 0,00 & 0,04735 & $(0,00114 ; 0,09998)$ & 0,00016 & $(-0,05528 ; 0,05561)$ \\
0,01 & 0,04677 & $(0,00111 ; 0,09999)$ & 0,00007 & $(-0,04550 ; 0,04564)$ \\
0,02 & 0,05364 & $(0,00162 ; 0,09997)$ & 0,00003 & $(-0,05235 ; 0,05242)$ \\
0,03 & 0,08972 & $(0,05658 ; 0,10004)$ & 0,04892 & $(0,03953 ; 0,05832)$ \\
0,04 & 0,09829 & $(0,08089 ; 0,11769)$ & 0,06619 & $(0,05578 ; 0,07661)$ \\
0,05 & 0,10786 & $(0,09999 ; 0,15472)$ & 0,08223 & $(0,07105 ; 0,09341)$ \\
0,06 & 0,07498 & $(0,02057 ; 0,09997)$ & 0,02293 & $(0,01661 ; 0,02925)$ \\
0,07 & 0,09457 & $(0,08275 ; 0,11809)$ & 0,06942 & $(0,05996 ; 0,07888)$ \\
0,08 & 0,14846 & $(0,09997 ; 0,25215)$ & 0,13245 & $(0,11864 ; 0,14625)$ \\
0,09 & 0,12411 & $(0,09999 ; 0,20340)$ & 0,10161 & $(0,08914 ; 0,11408)$ \\
0,10 & 0,10208 & $(0,09429 ; 0,13912)$ & 0,07741 & $(0,06691 ; 0,08792)$ \\
0,11 & 0,15107 & $(0,10000 ; 0,26310)$ & 0,13141 & $(0,11706 ; 0,14576)$ \\
0,12 & 0,10336 & $(0,08891 ; 0,13207)$ & 0,07166 & $(0,06044 ; 0,08288)$ \\
0,13 & 0,11433 & $(0,09999 ; 0,17217)$ & 0,08803 & $(0,07604 ; 0,10001)$ \\
0,14 & 0,11103 & $(0,09999 ; 0,16289)$ & 0,08475 & $(0,07314 ; 0,09635)$ \\
0,15 & 0,13680 & $(0,09999 ; 0,23436)$ & 0,11717 & $(0,10415 ; 0,13019)$ \\
\hline
\end{tabular}


Tabela 40. Verdadeiros valores de $r$ usados na simulação dos conjuntos de dados, estimativas de $r$ obtidas pelo método Bayesiano, intervalo de credibilidade para as estimativas Bayesianas; estimativas de $r$ obtidas pelo método da máxima verossimilhança e intervalos de confiança considerando a configuração B1-C, arranjo $A 1, \mathrm{n}=50$

\begin{tabular}{ccccc}
\hline$r_{\text {verdadeiro }}$ & Est. Bay & Int. Credib & Est. Máx. Vero & IC \\
\hline 0,00 & 0,04593 & $(0,00106 ; 0,09998)$ & 0,00011 & $(-0,04742 ; 0,04764)$ \\
0,01 & 0,05736 & $(0,00202 ; 0,09997)$ & 0,00005 & $(-0,06396 ; 0,06406)$ \\
0,02 & 0,07142 & $(0,01691 ; 0,09995)$ & 0,02029 & $(0,01468 ; 0,02590)$ \\
0,03 & 0,09301 & $(0,07199 ; 0,10233)$ & 0,06058 & $(0,05097 ; 0,07019)$ \\
0,04 & 0,08767 & $(0,06423 ; 0,10004)$ & 0,05649 & $(0,04760 ; 0,06538)$ \\
0,05 & 0,11394 & $(0,09999 ; 0,17709)$ & 0,09281 & $(0,08150 ; 0,10412)$ \\
0,06 & 0,14500 & $(0,09999 ; 0,25338)$ & 0,12111 & $(0,10641 ; 0,13582)$ \\
0,07 & 0,09162 & $(0,07043 ; 0,10001)$ & 0,06020 & $(0,05071 ; 0,06969)$ \\
0,08 & 0,10360 & $(0,08911 ; 0,13252)$ & 0,07131 & $(0,06010 ; 0,08252)$ \\
0,09 & 0,10799 & $(0,09385 ; 0,14255)$ & 0,07330 & $(0,06161 ; 0,08500)$ \\
0,10 & 0,08624 & $(0,05014 ; 0,10004)$ & 0,04522 & $(0,03644 ; 0,05399)$ \\
0,11 & 0,13457 & $(0,09999 ; 0,22641)$ & 0,11886 & $(0,10677 ; 0,13095)$ \\
0,12 & 0,15515 & $(0,09999 ; 0,27590)$ & 0,13250 & $(0,11760 ; 0,14741)$ \\
0,13 & 0,11751 & $(0,09999 ; 0,18621)$ & 0,09746 & $(0,08573 ; 0,10919)$ \\
0,14 & 0,13744 & $(0,09999 ; 0,23675)$ & 0,11298 & $(0,09907 ; 0,12690)$ \\
0,15 & 0,13874 & $(0,09999 ; 0,23714)$ & 0,12009 & $(0,10691 ; 0,13328)$ \\
\hline
\end{tabular}

Tabela 41. Valores verdadeiros para a freqüência de recombinação, estimativas Bayesiana para a freqüência de recombinação e Intervalos de Credibilidade para conjuntos de dados de tamanhos $\mathrm{n}=50$, cruzamento B1-B1, arranjo $A_{1}$

\begin{tabular}{ccccc}
\hline$r_{\text {verdadeiro }}$ & Est. Bay & Int. de Credibilidaden & Est. Max. Vero. & IC \\
\hline 0,15 & 0,09973 & $(0,09956 ; 0,14457)$ & 0,08458 & $(0,07542 ; 0,09373)$ \\
0,16 & 0,21127 & $(0,12517 ; 0,31272)$ & 0,20279 & $(0,18938 ; 0,21621)$ \\
0,17 & 0,13543 & $(0,09997 ; 0,21857)$ & 0,12513 & $(0,11432 ; 0,13595)$ \\
0,18 & 0,21333 & $(0,12895 ; 0,31217)$ & 0,20536 & $(0,19226 ; 0,21847)$ \\
0,19 & 0,16884 & $(0,10004 ; 0,25948)$ & 0,16004 & $(0,14831 ; 0,17178)$ \\
0,20 & 0,16903 & $(0,10006 ; 0,26365)$ & 0,15948 & $(0,14726 ; 0,17170)$ \\
0,21 & 0,21333 & $(0,12895 ; 0,31217)$ & 0,20541 & $(0,19231 ; 0,21852)$ \\
0,22 & 0,21333 & $(0,12895 ; 0,31217)$ & 0,20546 & $(0,19235 ; 0,21857)$ \\
0,23 & 0,26456 & $(0,16763 ; 0,37416)$ & 0,25750 & $(0,24258 ; 0,27241)$ \\
0,24 & 0,15077 & $(0,09996 ; 0,23992)$ & 0,14091 & $(0,12947 ; 0,15236)$ \\
0,25 & 0,24655 & $(0,15537 ; 0,35076)$ & 0,23938 & $(0,22534 ; 0,25341)$ \\
\hline
\end{tabular}


Tabela 42. Verdadeiros valores de $r$ usados na simulação dos conjuntos de dados, estimativas de $r$ obtidas pelo método Bayesiano, intervalo de credibilidade para as estimativas Bayesianas; estimativas de $r$ obtidas pelo método da máxima verossimilhança e intervalos de confiança considerando a configuração A-B3, arranjo $A 1, \mathrm{n}=50$

\begin{tabular}{ccccc}
\hline$r_{\text {verdadeiro }}$ & Est. Bay & Int. Credib & Est. Máx. Vero & IC \\
\hline 0,00 & 0,01639 & $(0,00028 ; 0,09995)$ & 0,00001 & $(-0,04000 ; 0,04002)$ \\
0,01 & 0,03987 & $(0,00350 ; 0,09998)$ & 0,01000 & $(0,00724 ; 0,01276)$ \\
0,02 & 0,03998 & $(0,00351 ; 0,09998)$ & 0,01005 & $(0,00727 ; 0,01283)$ \\
0,03 & 0,03998 & $(0,00351 ; 0,09998)$ & 0,01005 & $(0,00727 ; 0,01283)$ \\
0,04 & 0,06289 & $(0,02262 ; 0,09999)$ & 0,03046 & $(0,02562 ; 0,03530)$ \\
0,05 & 0,06284 & $(0,02257 ; 0,09998)$ & 0,03047 & $(0,02563 ; 0,03531)$ \\
0,06 & 0,07369 & $(0,19997 ; 0,20001)$ & 0,05118 & $(0,04492 ; 0,05745)$ \\
0,07 & 0,10606 & $(0,09999 ; 0,16477)$ & 0,09473 & $(0,08613 ; 0,10333)$ \\
0,08 & 0,07322 & $(0,19994 ; 0,20001)$ & 0,05102 & $(0,04479 ; 0,05724)$ \\
0,09 & 0,09626 & $(0,09743 ; 0,14029)$ & 0,08361 & $(0,07555 ; 0,09167)$ \\
0,10 & 0,08051 & $(0,19999 ; 0,20001)$ & 0,06220 & $(0,05524 ; 0,06916)$ \\
0,11 & 0,10606 & $(0,09999 ; 0,16477)$ & 0,09474 & $(0,08613 ; 0,10334)$ \\
0,12 & 0,13790 & $(0,09999 ; 0,21885)$ & 0,12794 & $(0,11796 ; 0,13793)$ \\
0,13 & 0,16396 & $(0,10000 ; 0,25545)$ & 0,15330 & $(0,14215 ; 0,16446)$ \\
0,14 & 0,11421 & $(0,09999 ; 0,18071)$ & 0,10433 & $(0,09544 ; 0,11322)$ \\
0,15 & 0,13790 & $(0,09999 ; 0,21885)$ & 0,12796 & $(0,11797 ; 0,13795)$ \\
\hline
\end{tabular}

Tabela 43. Verdadeiros valores de $r$ usados na simulação dos conjuntos de dados, estimativas de $r$ obtidas pelo método Bayesiano, intervalo de credibilidade para as estimativas Bayesianas; estimativas de $r$ obtidas pelo método da máxima verossimilhança e intervalos de confiança considerando a configuração B1B3, arranjo $A 1, \mathrm{n}=50$

\begin{tabular}{ccccc}
\hline$r_{\text {verdadeiro }}$ & Est. Bay & Int. Credib & Est. Máx. Vero & IC \\
\hline 0,00 & 0,04949 & $(0,00133 ; 0,10000)$ & 0,00013 & $(-0,04607 ; 0,04632)$ \\
0,01 & 0,05818 & $(0,00802 ; 0,09997)$ & 0,01444 & $(0,01045 ; 0,01842)$ \\
0,02 & 0,06283 & $(0,01069 ; 0,09996)$ & 0,01657 & $(0,01201 ; 0,02113)$ \\
0,03 & 0,08093 & $(0,05313 ; 0,10004)$ & 0,04966 & $(0,04186 ; 0,05747)$ \\
0,04 & 0,05939 & $(0,00860 ; 0,09994)$ & 0,01508 & $(0,01092 ; 0,01924)$ \\
0,05 & 0,10377 & $(0,09999 ; 0,15452)$ & 0,08621 & $(0,07660 ; 0,09582)$ \\
0,06 & 0,08039 & $(0,04049 ; 0,10004)$ & 0,03947 & $(0,03179 ; 0,04715)$ \\
0,07 & 0,10100 & $(0,09766 ; 0,14324)$ & 0,08127 & $(0,07147 ; 0,09107)$ \\
0,08 & 0,08062 & $(0,04128 ; 0,10004)$ & 0,04016 & $(0,03237 ; 0,04795)$ \\
0,09 & 0,12932 & $(0,09999 ; 0,21454)$ & 0,11544 & $(0,10443 ; 0,12645)$ \\
0,10 & 0,09296 & $(0,08537 ; 0,12087)$ & 0,07272 & $(0,06388 ; 0,08157)$ \\
0,11 & 0,12650 & $(0,09999 ; 0,21054)$ & 0,10838 & $(0,09645 ; 0,12032)$ \\
0,12 & 0,18007 & $(0,10001 ; 0,28953)$ & 0,16679 & $(0,15337 ; 0,18020)$ \\
0,13 & 0,08010 & $(0,05124 ; 0,10004)$ & 0,04861 & $(0,04094 ; 0,05628)$ \\
0,14 & 0,08705 & $(0,06311 ; 0,10004)$ & 0,05551 & $(0,04678 ; 0,06425)$ \\
0,15 & 0,15521 & $(0,10000 ; 0,26172)$ & 0,14007 & $(0,12690 ; 0,15324)$ \\
\hline
\end{tabular}


Tabela 44. Verdadeiros valores de $r$ usados na simulação dos conjuntos de dados, estimativas de $r$ obtidas pelo método Bayesiano, intervalo de credibilidade para as estimativas Bayesianas; estimativas de $r$ obtidas pelo método da máxima verossimilhança e intervalos de confiança considerando a configuração A-C, arranjo $A 1, \mathrm{n}=50$

\begin{tabular}{ccccc}
\hline$r_{\text {verdadeiro }}$ & Est. Bay & Int. Credib & Est. Máx. Vero & IC \\
\hline 0,00 & 0,05434 & $(0,00167 ; 0,09994)$ & 0,00020 & $(-0,06913 ; 0,06953)$ \\
0,01 & 0,07108 & $(0,01642 ; 0,09996)$ & 0,01994 & $(0,01442 ; 0,02546)$ \\
0,02 & 0,08449 & $(0,05843 ; 0,10004)$ & 0,05261 & $(0,04429 ; 0,06093)$ \\
0,03 & 0,05254 & $(0,00153 ; 0,09998)$ & 0,00013 & $(-0,04966 ; 0,04992)$ \\
0,04 & 0,05178 & $(0,00146 ; 0,09998)$ & 0,00007 & $(-0,05232 ; 0,05245)$ \\
0,05 & 0,09038 & $(0,06887 ; 0,10004)$ & 0,05915 & $(0,04987 ; 0,06843)$ \\
0,06 & 0,10333 & $(0,09572 ; 0,14217)$ & 0,07778 & $(0,06718 ; 0,08838)$ \\
0,07 & 0,13475 & $(0,09999 ; 0,23144)$ & 0,10886 & $(0,09527 ; 0,12244)$ \\
0,08 & 0,10920 & $(0,09999 ; 0,15925)$ & 0,08535 & $(0,07393 ; 0,09676)$ \\
0,09 & 0,10206 & $(0,09445 ; 0,13930)$ & 0,07761 & $(0,06712 ; 0,08811)$ \\
0,10 & 0,10243 & $(0,09447 ; 0,13973)$ & 0,07723 & $(0,06671 ; 0,08776)$ \\
0,11 & 0,12146 & $(0,09999 ; 0,19633)$ & 0,10035 & $(0,08823 ; 0,11247)$ \\
0,12 & 0,11599 & $(0,09999 ; 0,18237)$ & 0,09383 & $(0,08227 ; 0,10540)$ \\
0,13 & 0,14225 & $(0,09996 ; 0,24121)$ & 0,12631 & $(0,11357 ; 0,13904)$ \\
0,14 & 0,21120 & $(0,11273 ; 0,33478)$ & 0,19730 & $(0,18165 ; 0,21295)$ \\
0,15 & 0,20568 & $(0,10559 ; 0,33369)$ & 0,19049 & $(0,17449 ; 0,20650)$ \\
\hline
\end{tabular}

Tabela 45. Verdadeiros valores de $r$ usados na simulação dos conjuntos de dados, estimativas de $r$ obtidas pelo método Bayesiano, intervalo de credibilidade para as estimativas Bayesianas; estimativas de $r$ obtidas pelo método da máxima verossimilhança e intervalos de confiança considerando a configuração A-B1, arranjo $A 1, \mathrm{n}=50$

\begin{tabular}{ccccc}
\hline$r_{\text {verdadeiro }}$ & Est. Bay & Int. Credib & Est. Máx. Vero & IC \\
\hline 0,00 & 0,02506 & $(0,00041 ; 0,09996)$ & 0,00007 & $(-0,03072 ; 0,03087)$ \\
0,01 & 0,05359 & $(0,00641 ; 0,09997)$ & 0,01328 & $(0,00962 ; 0,01694)$ \\
0,02 & 0,05475 & $(0,00681 ; 0,09996)$ & 0,01360 & $(0,00985 ; 0,01734)$ \\
0,03 & 0,09068 & $(0,08653 ; 0,12070)$ & 0,07490 & $(0,06675 ; 0,08305)$ \\
0,04 & 0,03617 & $(0,00067 ; 0,09996)$ & 0,00012 & $(-0,03400 ; 0,03423)$ \\
0,05 & 0,08523 & $(0,07427 ; 0,10070)$ & 0,06574 & $(0,05786 ; 0,07361)$ \\
0,06 & 0,10737 & $(0,09999 ; 0,16544)$ & 0,09446 & $(0,08504 ; 0,10388)$ \\
0,07 & 0,10369 & $(0,09999 ; 0,15675)$ & 0,09095 & $(0,08187 ; 0,10004)$ \\
0,08 & 0,10488 & $(0,09999 ; 0,15958)$ & 0,09204 & $(0,08285 ; 0,10123)$ \\
0,09 & 0,13365 & $(0,09999 ; 0,21549)$ & 0,12324 & $(0,11258 ; 0,13391)$ \\
0,10 & 0,16667 & $(0,10002 ; 0,25290)$ & 0,15850 & $(0,14732 ; 0,16968)$ \\
0,11 & 0,10297 & $(0,09999 ; 0,15617)$ & 0,09197 & $(0,08338 ; 0,10056)$ \\
0,12 & 0,14821 & $(0,09999 ; 0,23225)$ & 0,13915 & $(0,12836 ; 0,14994)$ \\
0,13 & 0,12861 & $(0,09999 ; 0,20668)$ & 0,11849 & $(0,10821 ; 0,12877)$ \\
0,14 & 0,19403 & $(0,10927 ; 0,29604)$ & 0,18449 & $(0,17116 ; 0,19783)$ \\
0,15 & 0,23376 & $(0,14683 ; 0,33378)$ & 0,22663 & $(0,21323 ; 0,24002)$ \\
\hline
\end{tabular}


Tabela 46. Verdadeiros valores de $r$ usados na simulação dos conjuntos de dados, estimativas de $r$ obtidas pelo método Bayesiano, intervalo de credibilidade para as estimativas Bayesianas; estimativas de $r$ obtidas pelo método da máxima verossimilhança e intervalos de confiança considerando a configuração B1B2, arranjo $A 1, \mathrm{n}=50$

\begin{tabular}{ccccc}
\hline$r_{\text {verdadeiro }}$ & Est. Bay & Int. Credib & Est. Máx. Vero & IC \\
\hline 0,00 & 0,05047 & $(0,00139 ; 0,09996)$ & 0,00015 & $(-0,03905 ; 0,03934)$ \\
0,01 & 0,04401 & $(0,00098 ; 0,09996)$ & 0,00007 & $(-0,03664 ; 0,03678)$ \\
0,02 & 0,08840 & $(0,05547 ; 0,10004)$ & 0,04863 & $(0,03934 ; 0,05793)$ \\
0,03 & 0,07099 & $(0,01752 ; 0,09994)$ & 0,02145 & $(0,01557 ; 0,02733)$ \\
0,04 & 0,09993 & $(0,09252 ; 0,13471)$ & 0,07677 & $(0,06654 ; 0,08699)$ \\
0,05 & 0,06951 & $(0,01612 ; 0,10000)$ & 0,02054 & $(0,01491 ; 0,02617)$ \\
0,06 & 0,07024 & $(0,01679 ; 0,09994)$ & 0,02065 & $(0,01498 ; 0,02631)$ \\
0,07 & 0,07256 & $(0,01909 ; 0,09996)$ & 0,02209 & $(0,01603 ; 0,02814)$ \\
0,08 & 0,13199 & $(0,09999 ; 0,21792)$ & 0,11857 & $(0,10690 ; 0,13023)$ \\
0,09 & 0,10627 & $(0,09998 ; 0,15188)$ & 0,08352 & $(0,07244 ; 0,09460)$ \\
0,10 & 0,16355 & $(0,09996 ; 0,27506)$ & 0,14882 & $(0,13444 ; 0,16321)$ \\
0,11 & 0,15619 & $(0,09997 ; 0,26739)$ & 0,13972 & $(0,12505 ; 0,15438)$ \\
0,12 & 0,18870 & $(0,10002 ; 0,30301)$ & 0,17635 & $(0,16156 ; 0,19114)$ \\
0,13 & 0,11517 & $(0,09999 ; 0,18242)$ & 0,10013 & $(0,08938 ; 0,11087)$ \\
0,14 & 0,12327 & $(0,09999 ; 0,19621)$ & 0,10005 & $(0,08690 ; 0,11320)$ \\
0,15 & 0,19232 & $(0,10003 ; 0,30849)$ & 0,17984 & $(0,16479 ; 0,19489)$ \\
\hline
\end{tabular}


ANEXO H - Gráficos das distribuições a priori e das estimativas Bayesianas da freqüência de recombinação considerando o caso C-C, arranjo $A 4$ e n=50
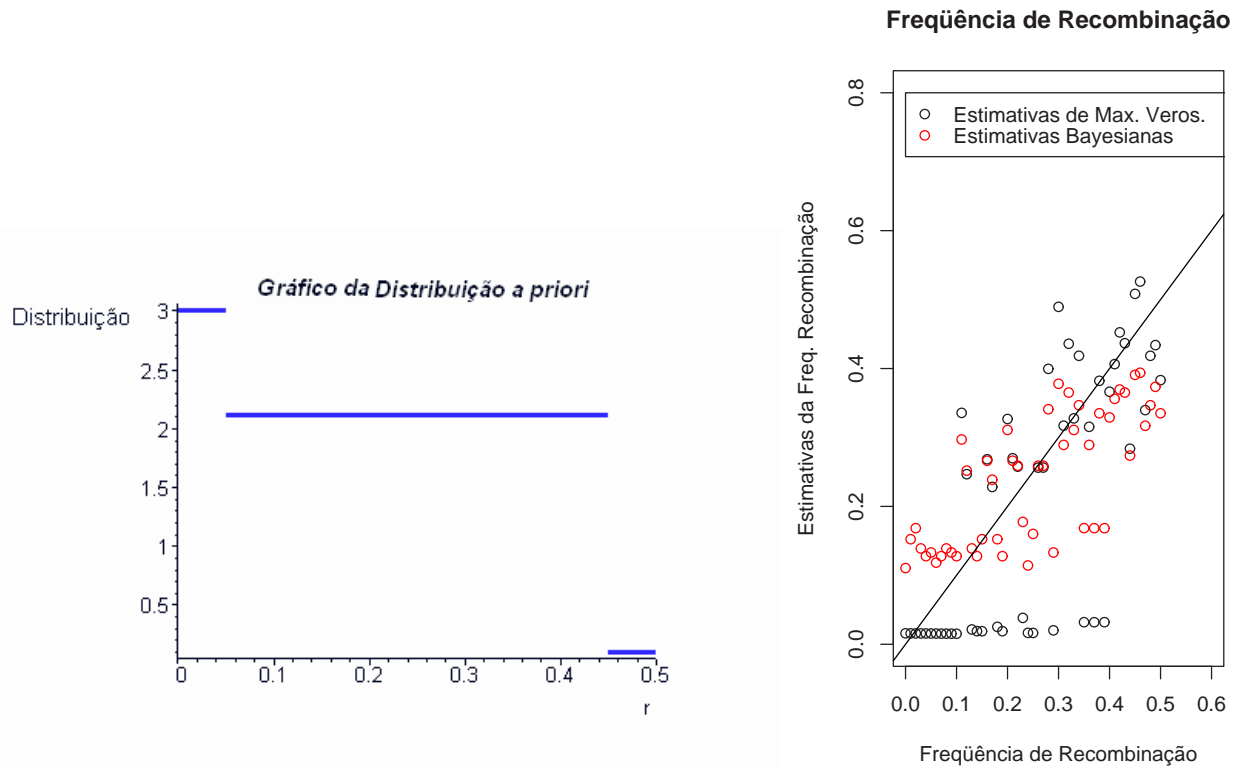

Figura 72 - Gráficos da distribuição priori e das estimativas da freqüência de recombinação 
Freqüência de Recombinação

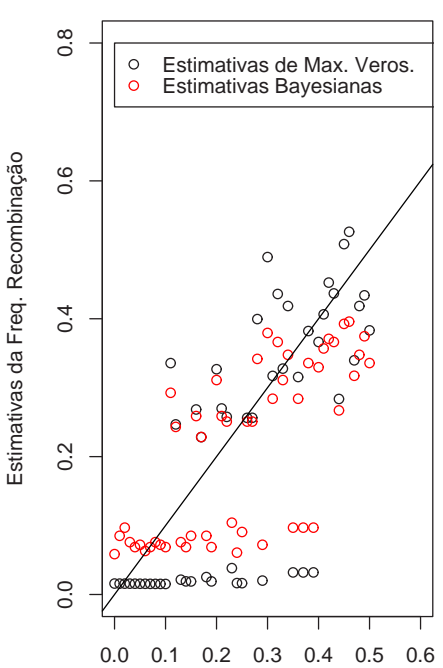

Freqüência de Recombinação

Figura 73 - Gráficos da distribuição priori e das estimativas da freqüência de recombinação
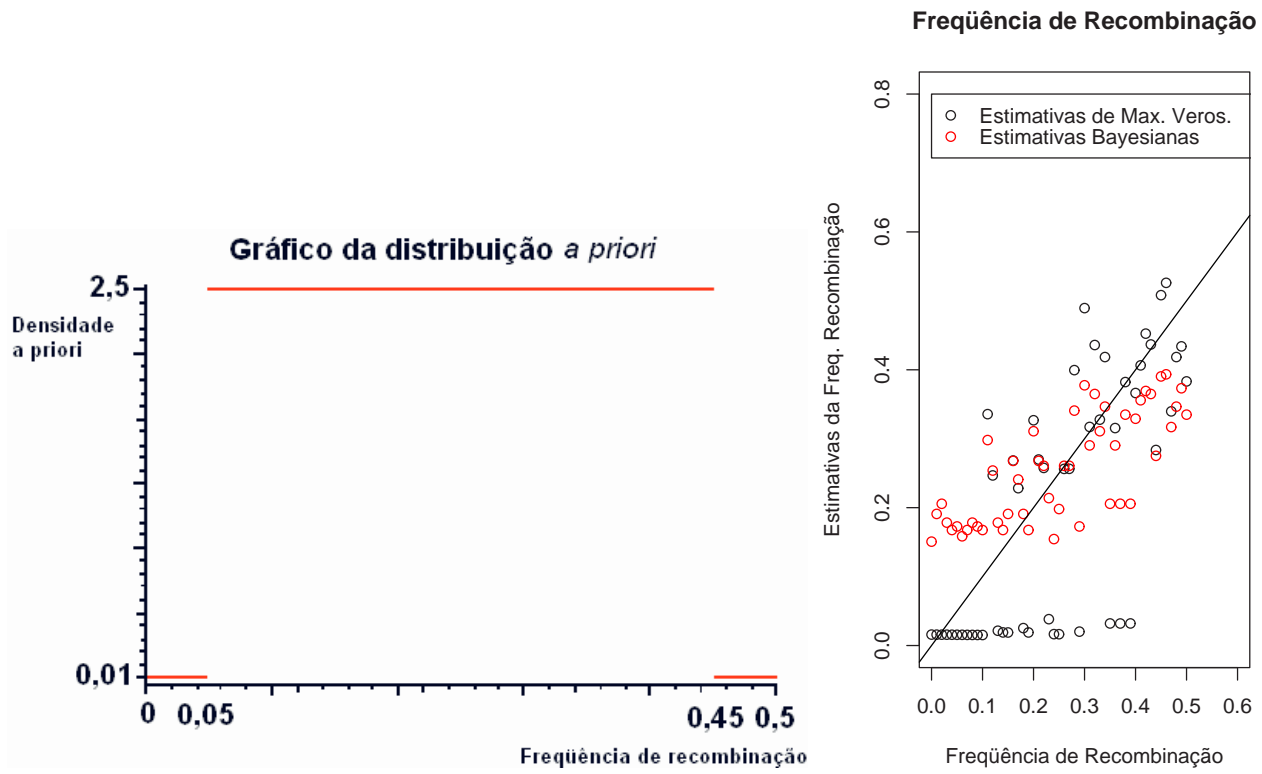

Figura 74 - Gráficos da distribuição priori e das estimativas da freqüência de recombinação 
Freqüência de Recombinação

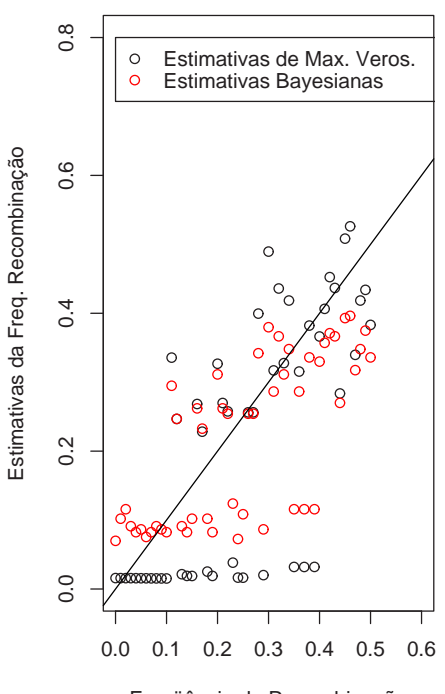

Freqüência de Recombinação

Figura 75 - Gráficos da distribuição priori e das estimativas da freqüência de recombinação 


\section{REFERÊNCIAS BIBLIOGRÁFICAS}

BOX, G.E.P.; TIAO, G.C. Bayesian inference in statistical analysis. New York: Wiley, 1992. 588p.

CRISTOFAnI, M. Mapas de ligação de Citrus sunki Hort. ex. Tan. e Poncirus trifoliata (L.) Raf. cv. Rubidoux e localização do gene de resistência ao vírus da tristeza. Piracicaba, 1997. 140 p. Tese (Doutorado) - Escola Superior de Agricultura "Luiz de Queiroz", Universidade de São Paulo

GELMAN, A.; CARLIN, J.B.; STERN, H.S.; RUBIN, D.B. Bayesian Data Analysis. 2. ed. London: Chapman and Hall, 2003. 668p.

GRIFFITHS, A.J.F.; MILlER, J.H.; SUZUKI, D.T.; LEWONTIN, R.C.; GELBART,W.M. Introdução à genética. 7.ed. Rio de Janeiro: Guanabara Koogan, 2002. 794p.

JEFFREYS, H. Theory of probability. 3.ed. Oxford: Clarendon Press, 1961. 447p.

KALBFLEISCH, J.G. Probability and statistics inference. 2.ed. New York: Springer - Velarg, 1985. 2v, 343p.

LANGE, K.S. Statistics for biology and health: mathematical and statistical methods for genetic analysis. New York: Springer, 1997. 265p.

LEANDRO, R.A. Introdução à estatística bayesiana. Piracicaba: Escola Superior de Agricultura "Luiz de Queiroz", Departamento de Ciências Exatas, 2001. 51p. 
LEE, P.M. Bayesian statistics: an introduction. 2.ed. London: Euston Road, 1997. $338 \mathrm{p}$.

LIU, B.H. Statistical genomics: linkage, mapping and QTL analysis. Boca Ranton: CRC Press, 1998. 611p.

MALIEPAARD, C.; JASEN, J.; VAN, O. Linkage analysis in a full-sib family of an outbreeding plant species: overview and consequences for aplications. Genetics Research, v.70, p.237-250, 1997.

NORDHEIM,E.V.; O'MALLEY,D.M.; GURIES,R.P. Estimation of recombination frequency in genetic linkage studies. Theoretical and Applied Genetics, v 66, p. 313-321, 1983.

PASTINA, M.M. Construção de um mapa genético para cana-de-açúcar com marcador RFLP usando os programas computacionais MAPMAKER/EXP E JOINMAP simultaneamente. Piracicaba, 2002. 13 p. Trabalho (Iniciação Científica) Escola Superior de Agricultura "Luiz de Queiroz", Universidade de São Paulo.

R DEVELOPMENT CORE TEAM. R: a language and environment for statistical computing. 3-900051-00-3, URL http://www.R-project.org.

SMITH, A.F.M. Bayesian methods in Reliability. In SANDER, P.; BADEUX, R. Topics in safety, reliability and quality. London: Kleiwer Academic Publishers (ed)., 1991, p.34-79.

WU, R.; MA,C.-X.; PAINTER, I.; ZENG,Z.-B. Simultaneous maximum likelihood estimation of linkage and linkage phases in outcrossing species. Theoretical Population Biology, v.61, p.349-363, 2002. 